0

- 9

408 र० 109

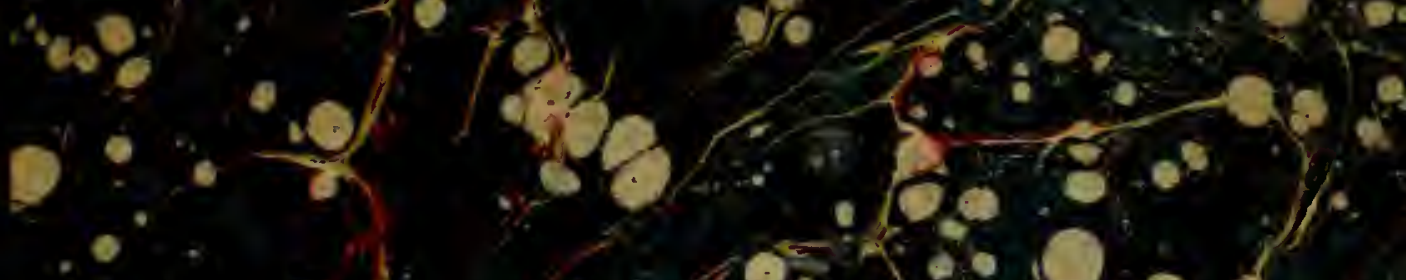

$100.40:$

$0.0 \%$ - $90.0 . \% .00$

n.

$$
\text { a }
$$

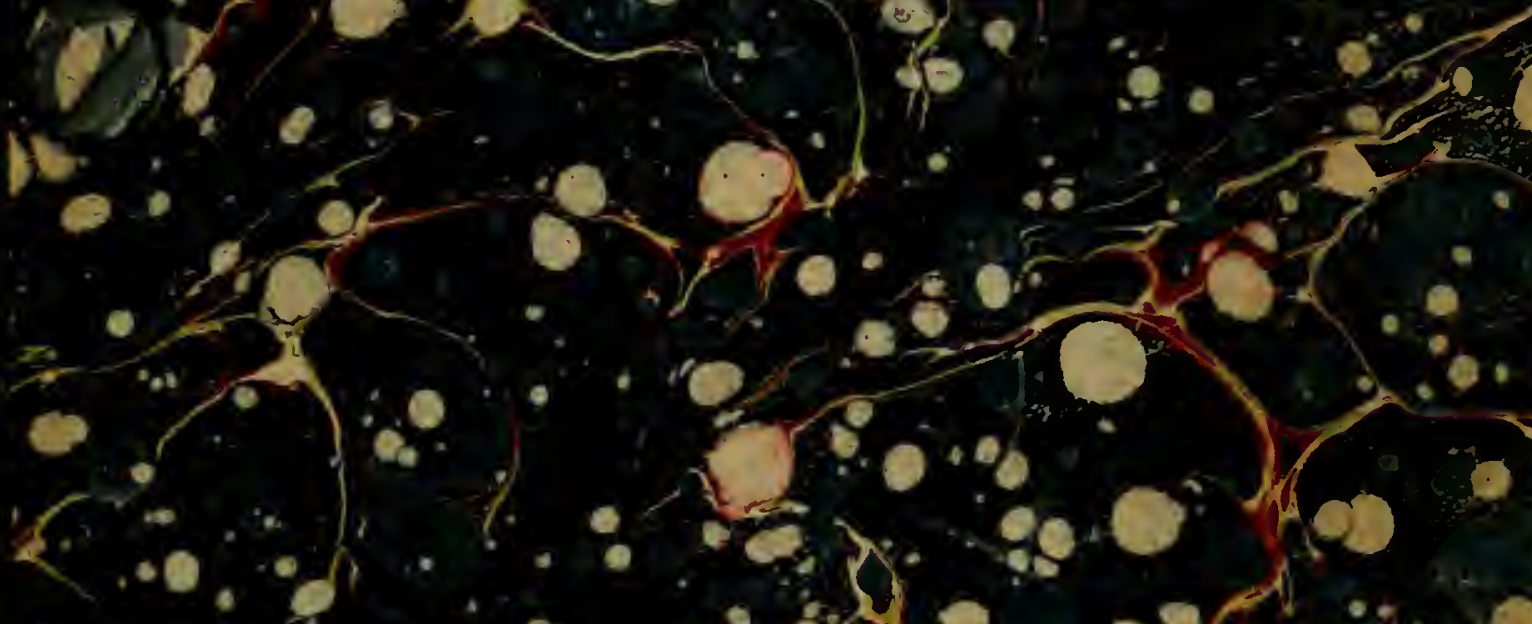

s.

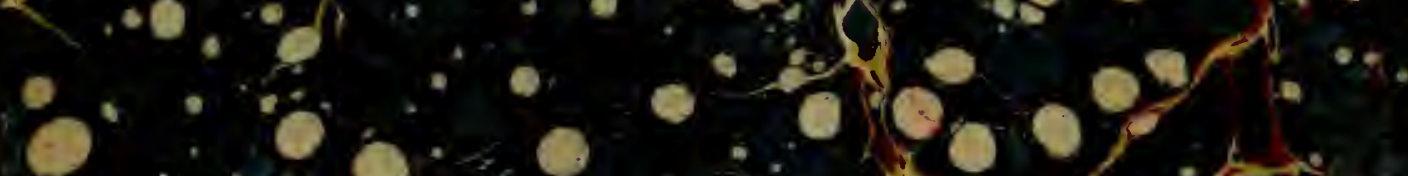

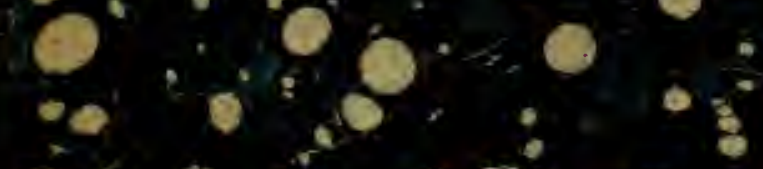

Pon

$10 \div 0$

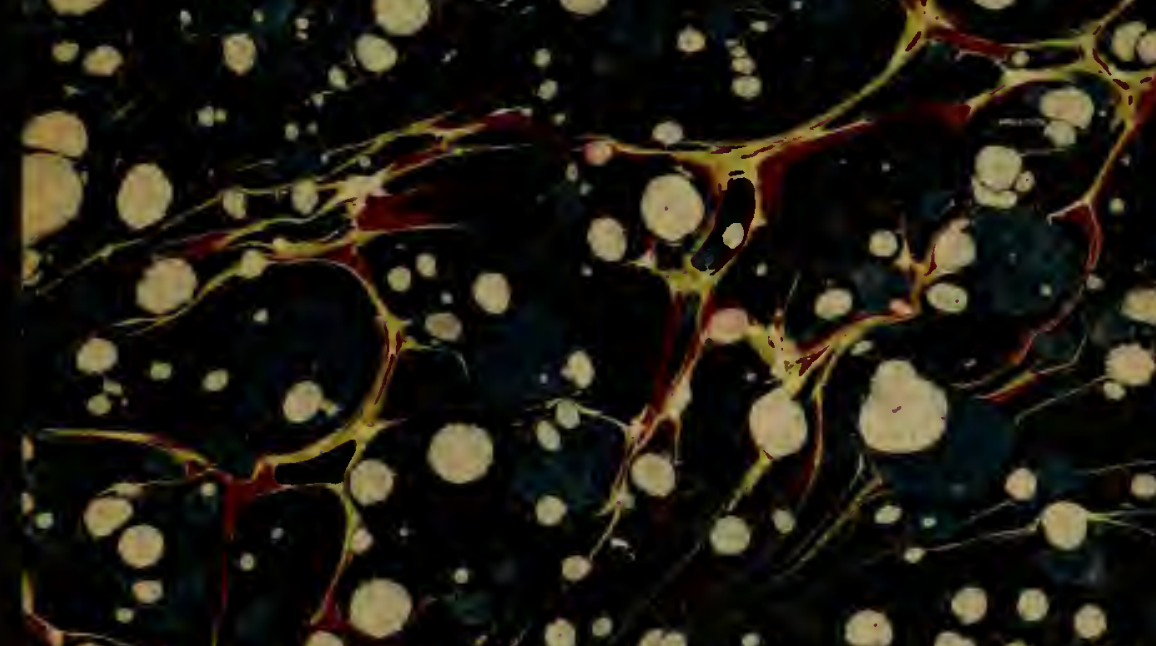

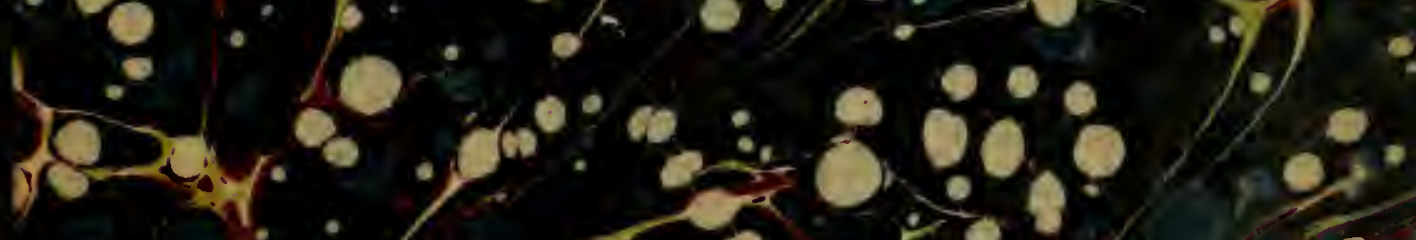

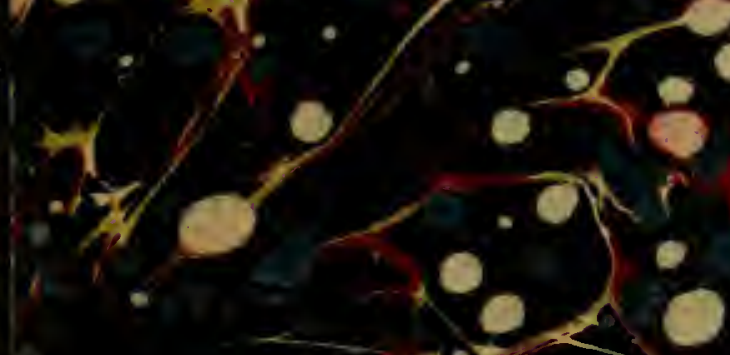

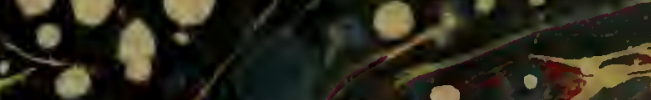
- $17 / 2=00 \cdot 0$

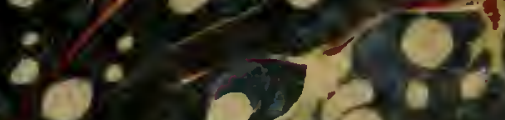




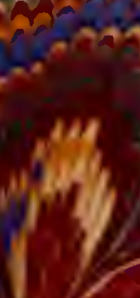

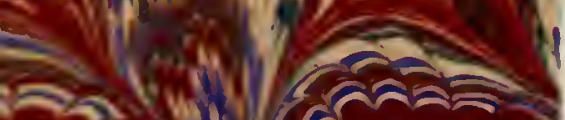 Sa

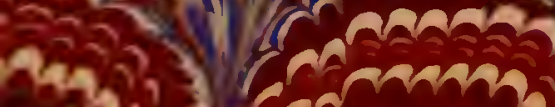

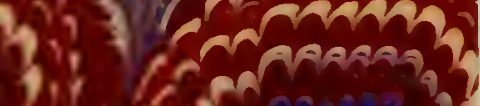 1)itres ming

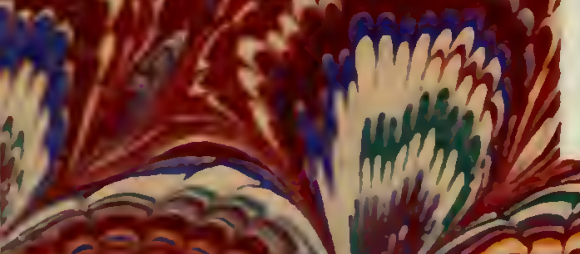

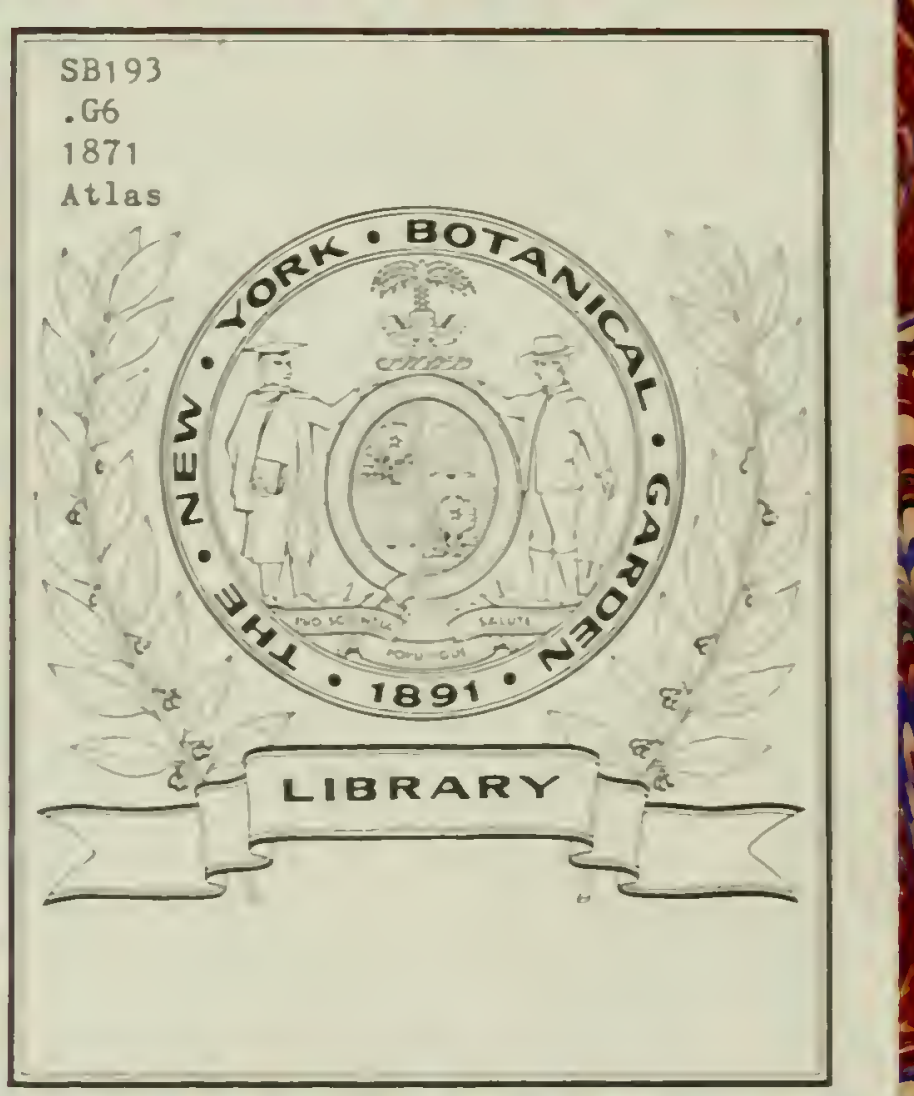

Cกิลลวิ 4.1) जर्ति किकि? min $x$,

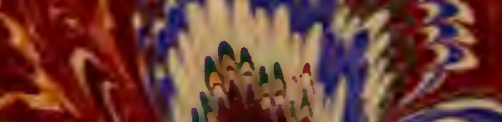

ii) $10=2$

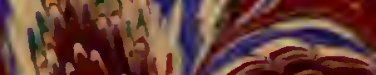

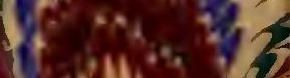

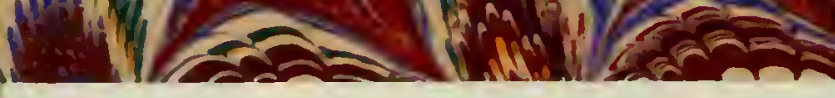

.

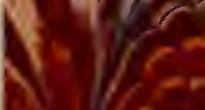

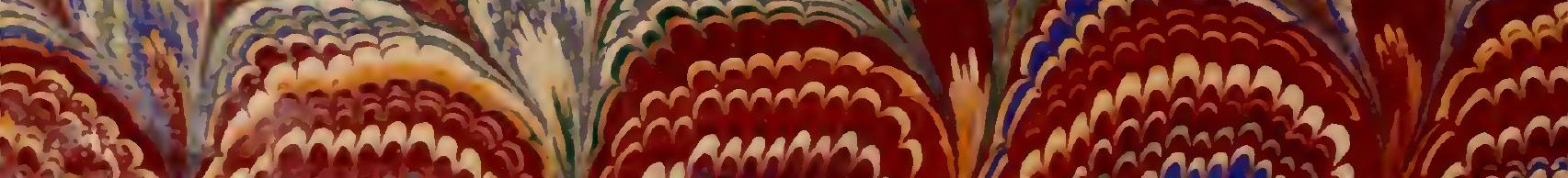

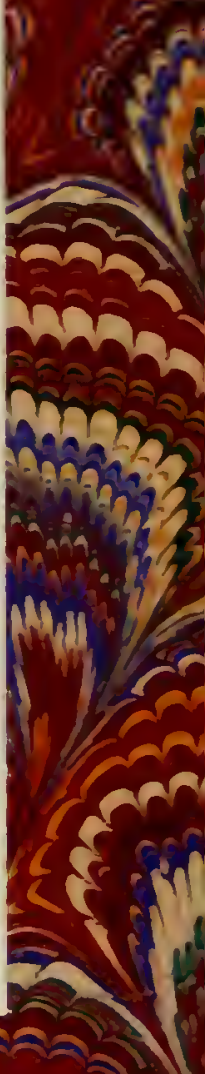



JOUTELLE

\section{ICONOGRAPHIE}

FOURRAGÉRE 



\section{NOUVELLE}

\section{ICONOGRIPIIIE FOURRAGERE}

HISTOIRE BOTANIQLE, ECOYOVIOLE ET AGRICOLE

DES PLANTES FOURRAGÈRES

ET TIE-

PLAITES NUISIBLES QUI SE RENCONTRENT DANS LES PRAIRIES ET LES PATLRAGES

AVEC PLANCHES GRAVEes SUR CUIVRE ET COLORIĖes

$P A R$ MI

\section{J. GOURDON}

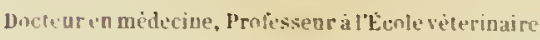
de Toulouse.

\section{P. NAUDIN}

Victcrinaire en ler an lye rëgiment dartilleric a cheval, chevalier de la Legion d'Honneur.

\section{A TLAS}

\section{PARIS}

P. ASSELIN, SUGcesseur de BÉCHET JeUne et LABÉ

LIBRAIRE DE L.A F.ACLLTE DE MÉDECINE.

ET DE LA SOCIÉTÉ CEXTRALE DE MÉDECINE VÉTÉRIAIRL

Place de l'Ecole-de-Mridecune 



\title{
TABLE ALPHABETIQUE
}

\author{
DES
}

\section{PLANTES REPRESENTEES IANS LATLIS}

\begin{tabular}{|c|c|c|c|c|c|}
\hline YOMS DES PLASTES & xis & Pages & YOYS DES PLANTES & $x^{n+m}$ & $\operatorname{lag}^{2}$ \\
\hline & 73 & 399 & Canche flexueuse... & 114 & 595 \\
\hline Aconit napel............ & 5 & 11 & Canche grazonnante........ & 114 & 795 \\
\hline Agrostide des chiens..... & 113 & 798 & Canche précuce. $\ldots . . .$. & 114 & 795 \\
\hline Agrostide commune... . . & 113 & 798 & Cardamine des press........ & 13 & 29 \\
\hline rostide jouet du vent.... & 113 & 798 & Carline sans tice $\ldots \ldots \ldots \ldots$. & 71 & 364 \\
\hline Agrostide stolonifëre....... & 113 & 798 & Carotte fourragere........ & 60) & 254 \\
\hline Aigremoine.............. & 34 & 215 & Ceutaurèe jacée........... & 70 & $35 \pi$ \\
\hline trope......... & 23 & 57 & Chardon étoilé.......... & 70 & 337 \\
\hline mille commune... & 56 & 218 & morroīdal. . & 69 & 34 \\
\hline piste des Canaries.... & 118 & 808 & on Marie....... & 69 & 344 \\
\hline Alpiste roseau......... & 118 & 800 & ine majeure..... & 9 & \\
\hline atille..... & 4 & 10 & e saurage.... & $\overline{7 i}$ & 419 \\
\hline tine & 53 & 209 & Chier & 121 & 820 \\
\hline thỵllide vulnéraire & 26 & 70 & rande). & 66 & 311 \\
\hline ise commune.. . & 73 & 400 & rcée parisienne...... . . . & 57 & 2294 \\
\hline & 111 & 789 & d'automne .... ... & 96 & 7201 \\
\hline follette. & 111 & 790 & Consoude à feuilles rudes.... & 83 & 517 \\
\hline 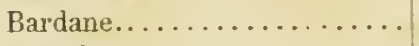 & it & 366 & ot................. & 8 & 15 \\
\hline & 85 & 571 & rrèe......... & 39 & 145 \\
\hline mmune...... & 52 & 207 & maritime ....... & 14 & $2 \pi$ \\
\hline Berce brancursine....... & 62 & 284 & Cynosure à crète....... & 112 & 797 \\
\hline rle à larges feuilles. . & 65 & 298 & e dorée........... & 112 & 797 \\
\hline & 122 & 820 & uné......... & 105 & 785 \\
\hline -à-pastenr. & 15 & 31 & uine..... & 116 & 802 \\
\hline Brize à gros épillets... . & 108 & 787 & igitale pourprée.... & 87 & .285 \\
\hline Brize tremblante...... & 108 & 787 & Doucette............. & 68 & 331 \\
\hline ador & 103 & 782 & & 94 & 687 \\
\hline ome des hois........ & $10^{2} 2$ & 782 & Eveil-matin. & 94 & 685 \\
\hline Brome fragile... ...... & 102 & 782 & Fenouil officinal ..... & 63 & 293 \\
\hline rome mou ......... & 102 & 782 & Fétuque dure........ & 101 & 781 \\
\hline Buyle & 89 & 615 & Fétuque faus brome.. & 101 & 781 \\
\hline Buyrane rampante ou Arrête & & & Fètuque ovine . ...... & 101 & 781 \\
\hline & 25 & 69 & Fétuque queue de rat... & 101 & 781 \\
\hline Caille-lait jaune........... & 67 & 324 & Fëve des marars..... & 40 & \\
\hline
\end{tabular}

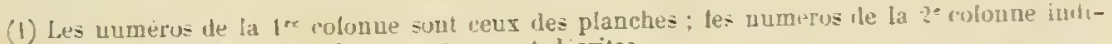
yurnt tes pages du texte wi les plantes a trunvent decrites. 
UVY IIS HLATES

Pit 1 r $^{*}$

Fil jermdule.

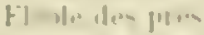

Flum, ond ranle.

Futus re male.

Fronems junat irme

Fresnental.

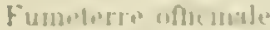

Galera nu line des Chover.

Gaude.

renit à balaı.

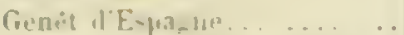

Ci.monum a fruille- mollles .

Ci:rasiuna à foulle de cirué .

G. ranıum colombin.........

Gesore ulturea . ..........

liese das prio..... ......

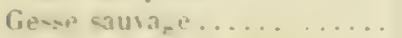

fipo... sans loulles.........

Gience Iuluereluse

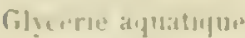

ilscerre fluttante.

IJ.-

1) ellebore noir.

IJ,uline lamense

11 a biale-

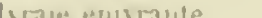

livale visate.

hi. I. $1 \%$ it crite.

late lo" des cluens.

Ladilie de. rivazos

lawhe fans - auclent

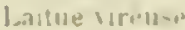

lasusu pr blatı.

lonthlle (penture)

l.entille Frullier

Limare tiorreatre

Linatiresto

Lotwer cormones.

Lizun hans.

L.121411 j71114.

Lapin]

Luserso. antusio.

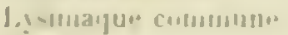

Mais.

Matrunatu I I ander.

Wr.]lum affucmin]

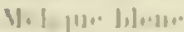

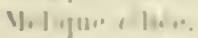

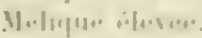

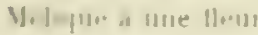

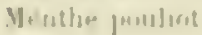

\begin{tabular}{|c|c|c|c|}
\hline$\cdots$ & 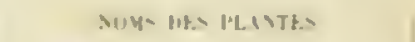 & 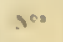 & H... \\
\hline$x$ & $\$ 111 \cdot 1,1$ a 10. & $|1| x \mid$ & $i(k)$ \\
\hline 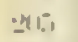 & Mula d.. IIun;ren. & 117 & Win; \\
\hline wri & Youn un de-chasups. & 81 & Six \\
\hline जit & Montarile dea chanup.. i. & 13 & $=1$ \\
\hline सil & Savet rultu: . . . . & 12 & 20 \\
\hline$\therefore \geq 1$ & 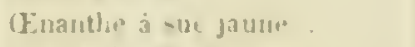 & lisi & 299 \\
\hline 705 & Irfe di deux ranz-.. . & 1211 & 813 \\
\hline 17 & 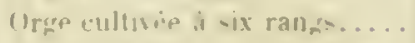 & 12911 & 812 \\
\hline 120 & 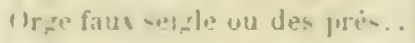 & $1: 21$ & XII \\
\hline 33 & Irge queur de courss.... & 1211 & 811 \\
\hline $6 \overline{5}$ & Mriran rulrave . . . . . & Se & 61. \\
\hline 57 & 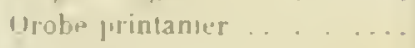 & is & 121 \\
\hline Ai & Itpin acre. . . . . . & 50 & 240 \\
\hline 47 & raalde a-eolle.. . . ... & 2.2 & 31 \\
\hline 位 & Panai-culturi............ & (i) & 279 \\
\hline 181 & Paurc ciljullaıre . $\quad \ldots$ & 115 & 802 \\
\hline 12.2 & Panic pured de con. . ... & 115 & enा \\
\hline $1 \times 2$ & Pa-palo - & 116 & 813 \\
\hline 181 & Pat-\{0. r fos peinturiers... . & 15 & 31 \\
\hline $1 \times 1$ & Paturin anmu & $10 \%$ & $7 \times 7$ \\
\hline Jivi & Paturin lublueus. ....... & 107 & 787 \\
\hline 7बi; & Paturan connum . . . . . & $111 \%$ & TAT \\
\hline 32 & Paturun Erasori-. . . . . & I118 & ixi \\
\hline 12 & Paturan it grams ipillets & 1fle & TRT \\
\hline 795 & Paturu de pris..... & 107 & 787 \\
\hline 12 & l'envi.. de champ... .. & 18 & $3 i$ \\
\hline 816 & Pirol daloumell... . . . & ij & $1: 2$ \\
\hline 817 & $P\left[x^{4}\right]-d$ in-eau $\ldots . .$. & $3 n$ & l㧒 \\
\hline 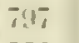 & Piuprenullo. . . . . . & 5ii & 211 \\
\hline$\pi n$ & Pisenlit.. . . . . & is & 4:3; \\
\hline 73 & 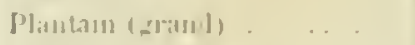 & :3 & $1 i^{2} 23$ \\
\hline$\because \because:$ & Plantanu lancroulo.. ... . & 42 & live \\
\hline fil & 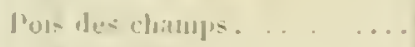 & 49 & IMi \\
\hline (i): & Poin clushere $\quad \ldots$ & in) & $2(x)$ \\
\hline 17t; & 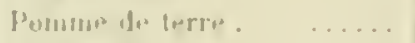 & 84 & 327 \\
\hline $1 \% 6$ & l'umar ipsneus. .... & 8; & $5 i 2$ \\
\hline (ix) & 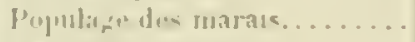 & 4 & 10 \\
\hline Ffit; & Jeterstille rampante..... & 53 & $24 n$ \\
\hline $1+2$ & J'edr. $\ldots \ldots \ldots \ldots$ & 125 & $8 \hat{3}$ \\
\hline 71 & liawnelle... . & 11 & 2(1) \\
\hline i: & 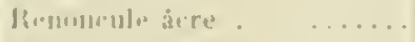 & 2 & 6 \\
\hline JRS & J6rnoncule llawame $\ldots$. & 2 & 6 \\
\hline 111 & 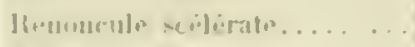 & 1 & 5 \\
\hline $4: 7$ & 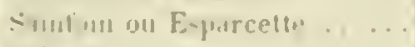 & $3 x$ & $1: x 3$ \\
\hline$x: 111$ & silicarre... . . . & 24 & 220 \\
\hline$\{1:\}$ & Sal-111-des juas. & Ni & SIN \\
\hline J11; & Sanzmentlos officumale. . & Ni & 218 \\
\hline & 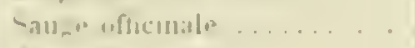 & mi & (i) \\
\hline $7 \times 4$ & 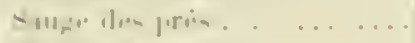 & (x) & bil: \\
\hline & 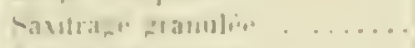 & $5 ?$ & $2 \omega ;$ \\
\hline & 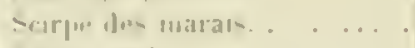 & $9 k$ & 767 \\
\hline & - & 9.8 & itis \\
\hline
\end{tabular}


TABLE ILPIIAETIUTE DFE PLAXTES REPRLSENTEES DANS L ITLAS.

YOMS DES H.AYTES

Seigle cultive

Stneçon jacobée.

Senecon vulgaire

Sherar de des champs......

Silène enflé

Sauchet brun

Souchet jaune.............

Souchet lony .. ........

spergule des champs.

Stellaire movenne..... . .

Stipe penné. ...........

Thym serpollet........... 91

Trelle des champs......... 32

Trëfle fraisier... ....... . 30

Trètle incarnat......

\begin{tabular}{r|}
$10 *$ \\
123 \\
75 \\
75 \\
116 \\
67 \\
20 \\
97 \\
97 \\
97 \\
19 \\
20 \\
109 \\
91 \\
32 \\
30 \\
30
\end{tabular}

\begin{tabular}{|c|} 
Panfes \\
823 \\
407 \\
406 \\
815 \\
324 \\
39 \\
765 \\
765 \\
764 \\
36 \\
39 \\
799 \\
613 \\
99 \\
99 \\
91
\end{tabular}

SIMS DES PLANTES

Trélle des près.... . . . .

Trétle rampant. ...... 31

Topinamhour . . . . . $\quad$ i을

Trifonelle ou Fenurrer... . $34 \quad 105$

\begin{tabular}{lll|l|l} 
Triodie conchés. . . . . . . & 112 & 789
\end{tabular}

Tussilage.............. $76 \quad 413$

Valériane phu. ... ....... $68 \quad 331$

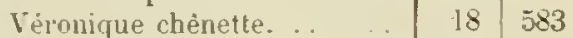

Vesce craque.......... 41.160

Vesce cultirèe......... 42.164

Vesce à une tleur........ $41 \quad 160$

Vesce des haies. . . .... $43 \quad 473$

Vipérine ............ $82 \quad 511$

Vulpin des chanps ....... 119,810

Vulpin renouille . . . . . . 119

Vulpin des pros. . . . . . 1190810 


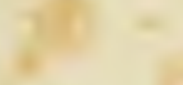

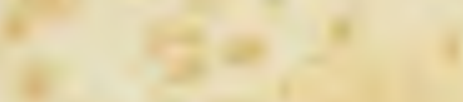

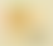

\section{(2)}

(2)

. 


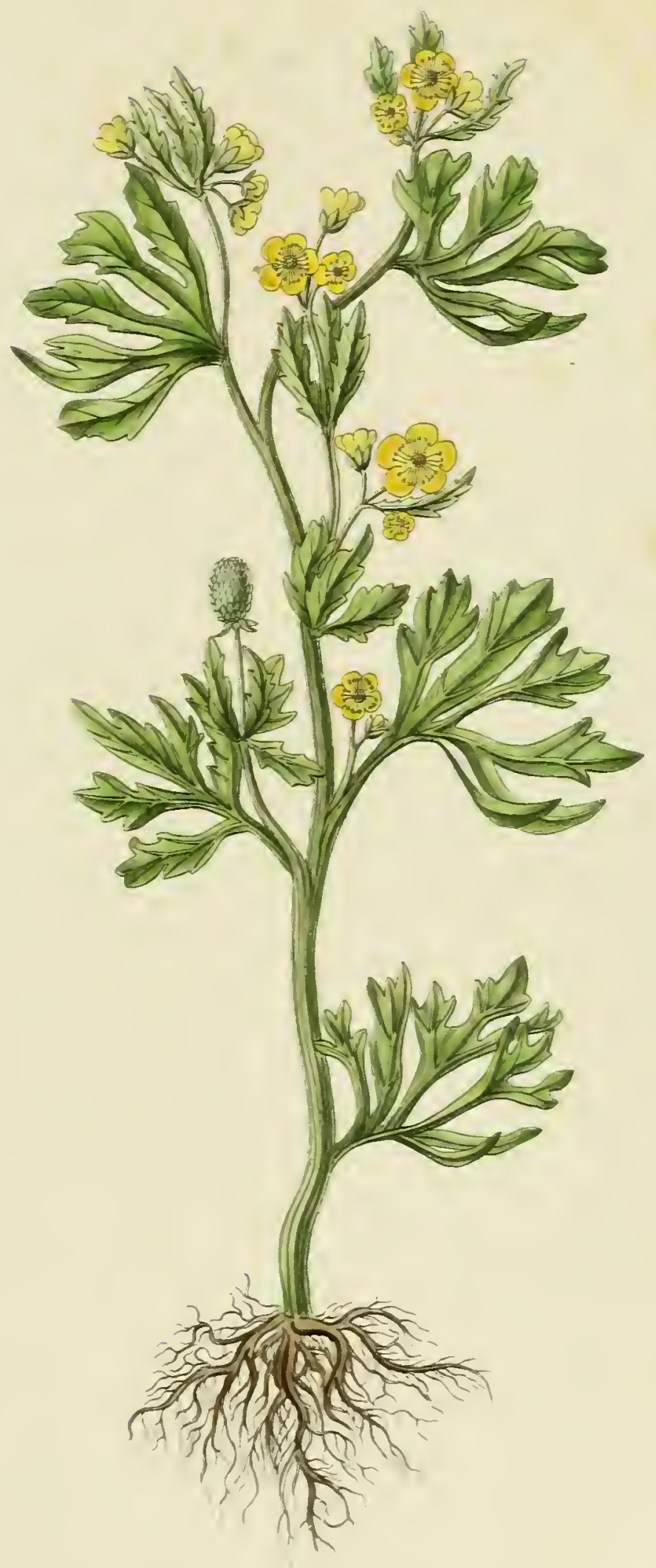

RESUNCLLE SCELERITE 



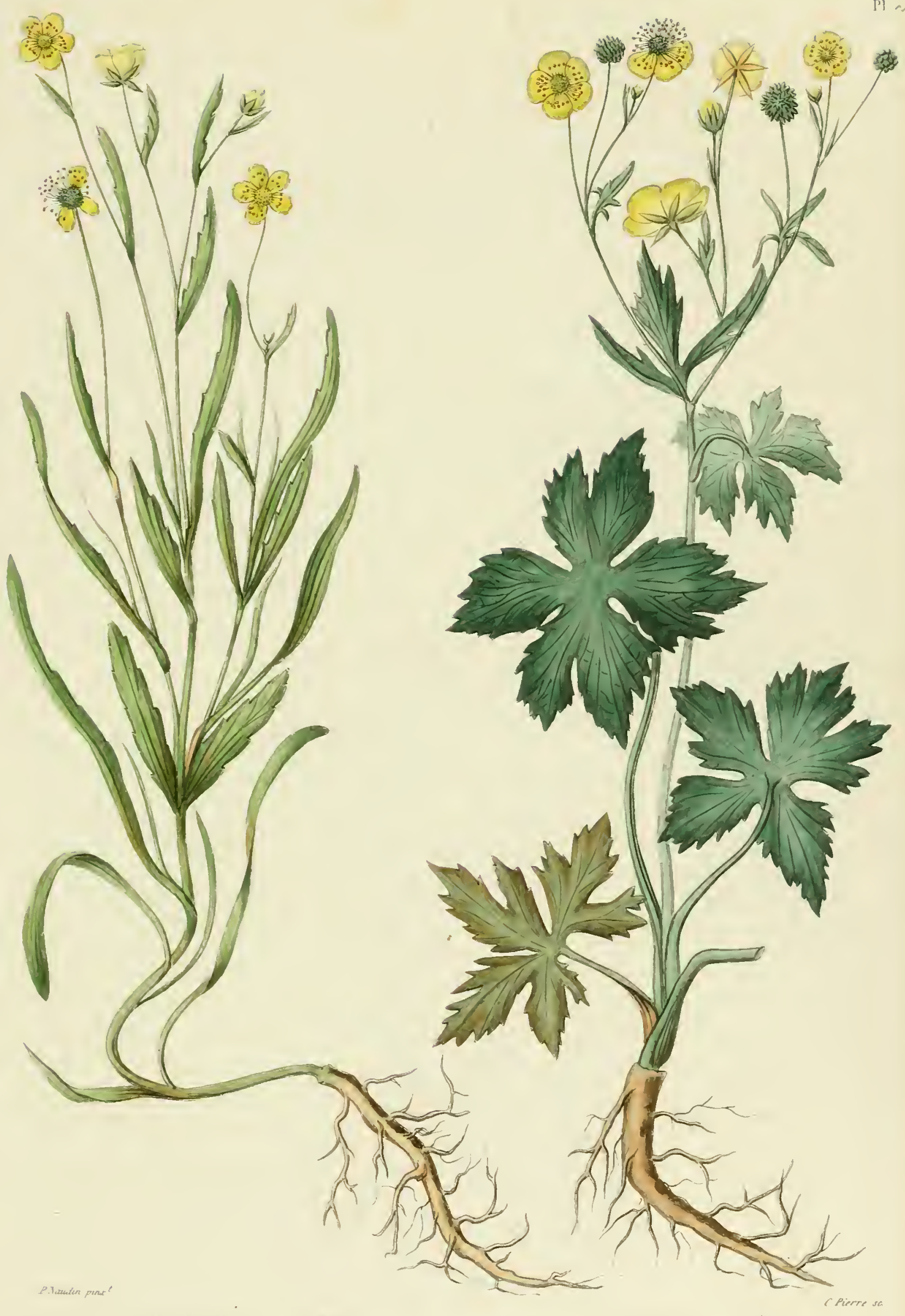





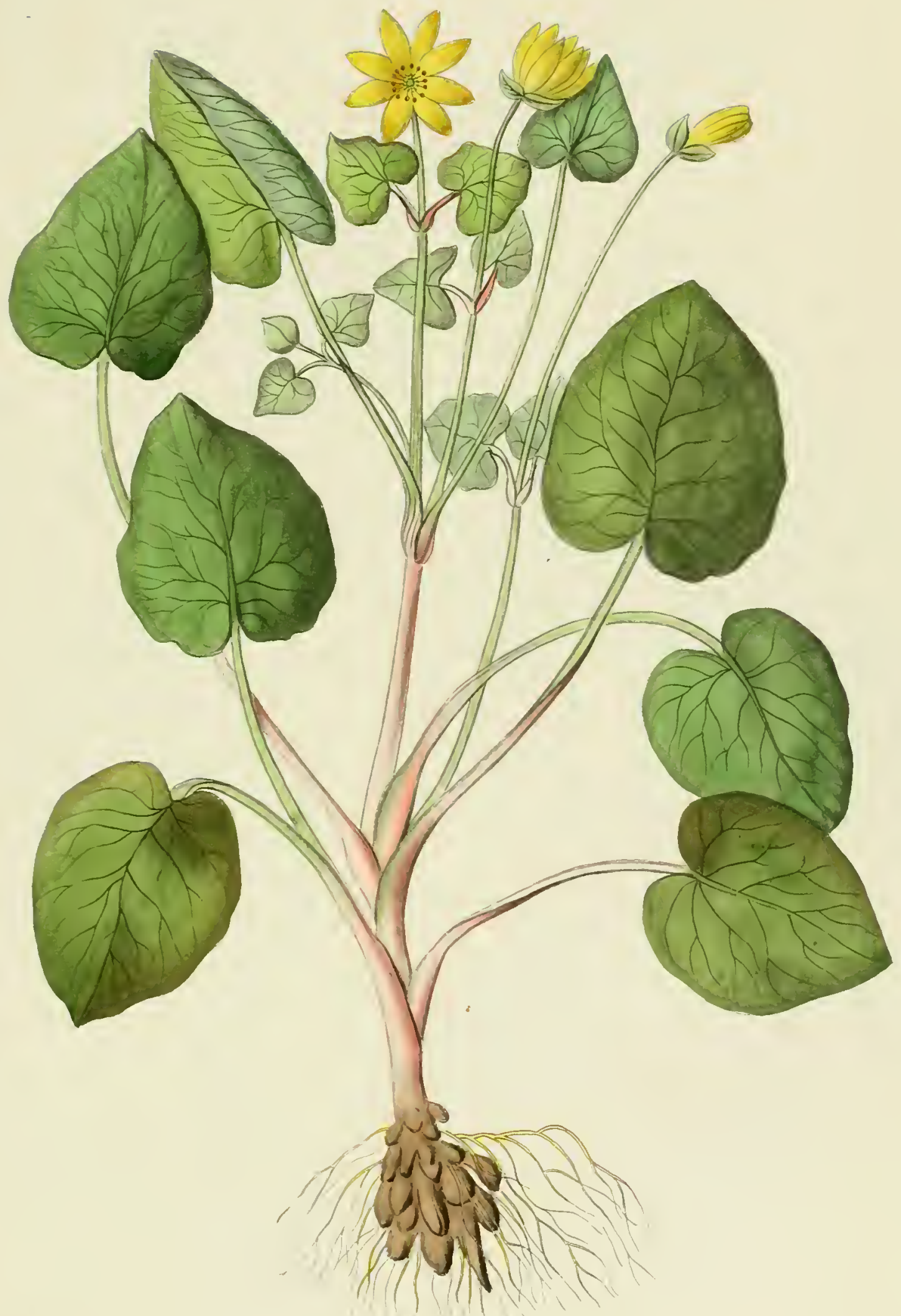




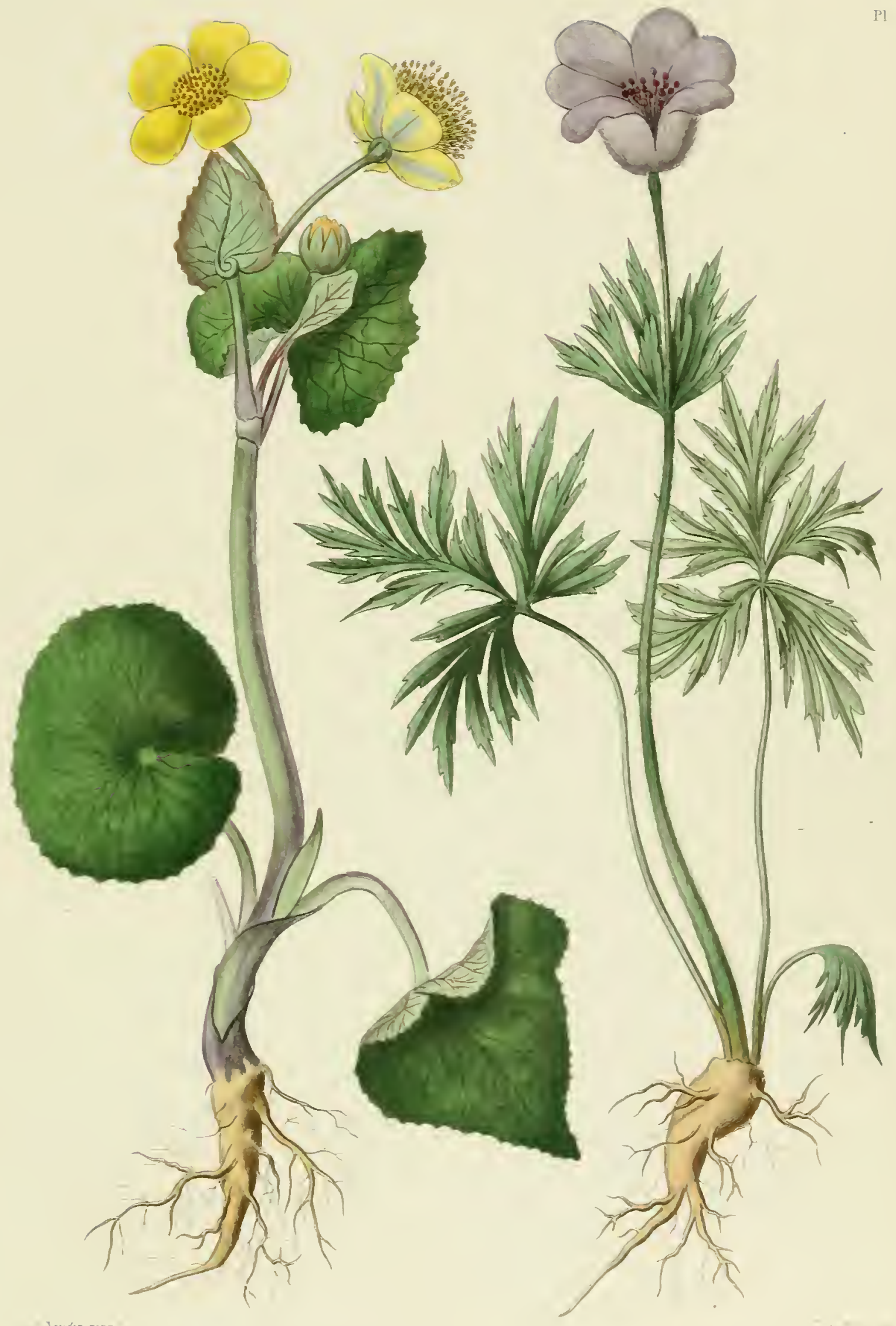





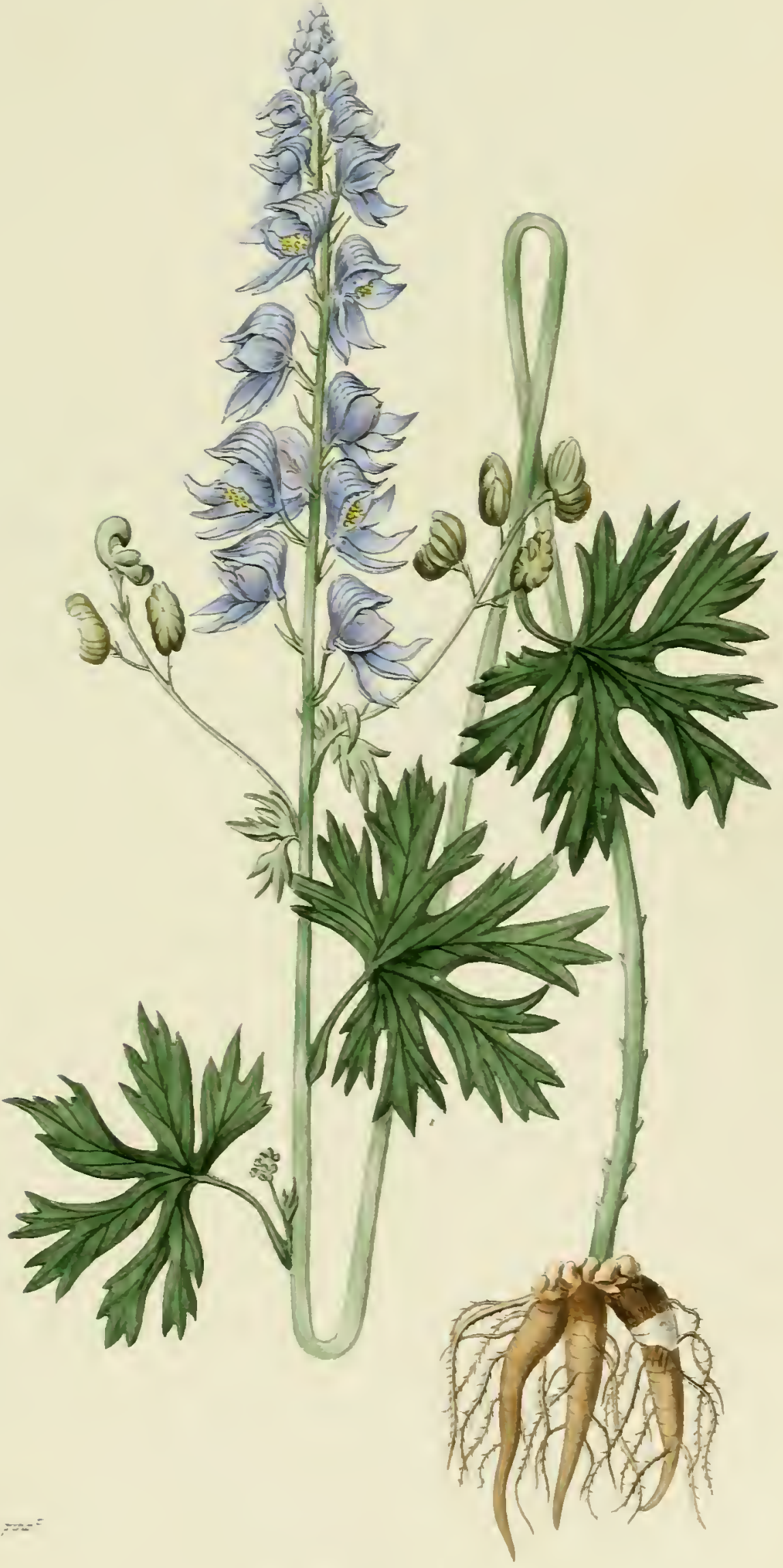





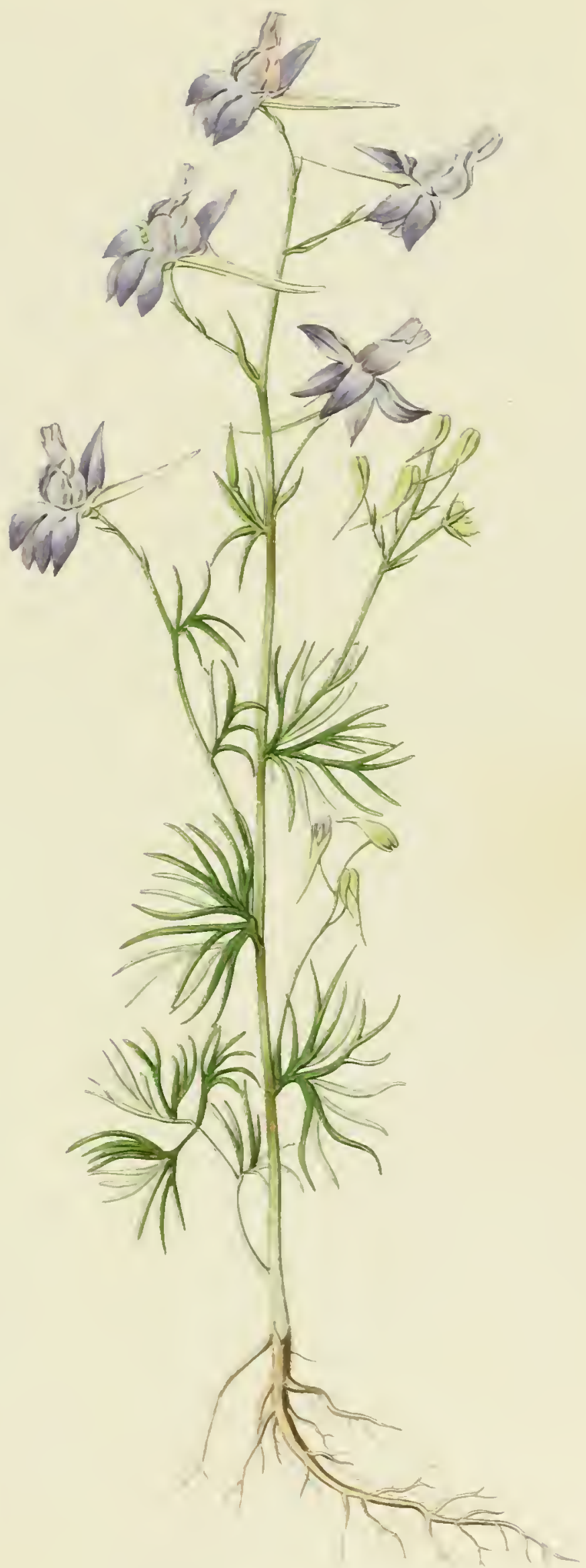

['IE.T) D' H.OLETTE. 



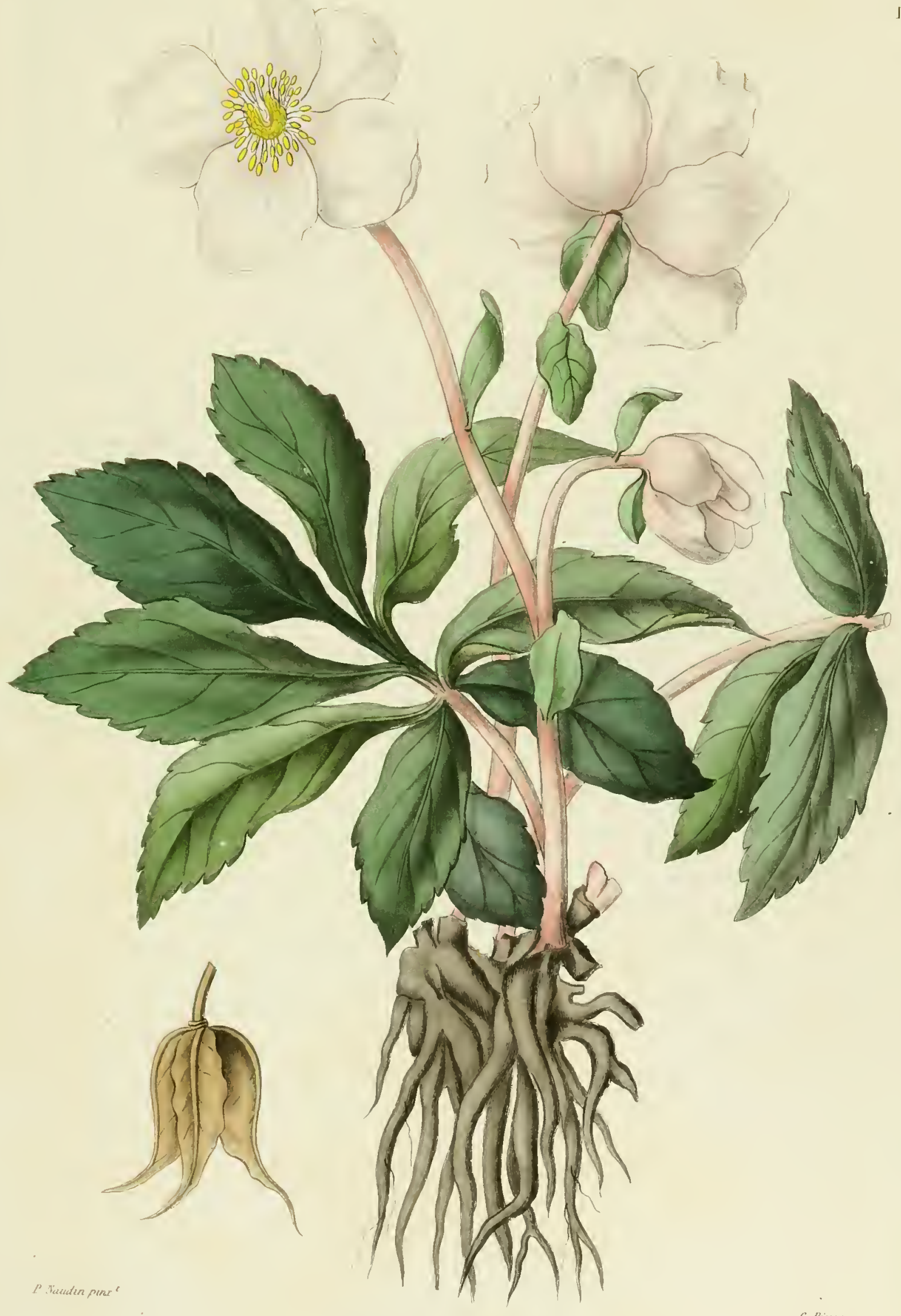

HELLEBBORE TOHR. 



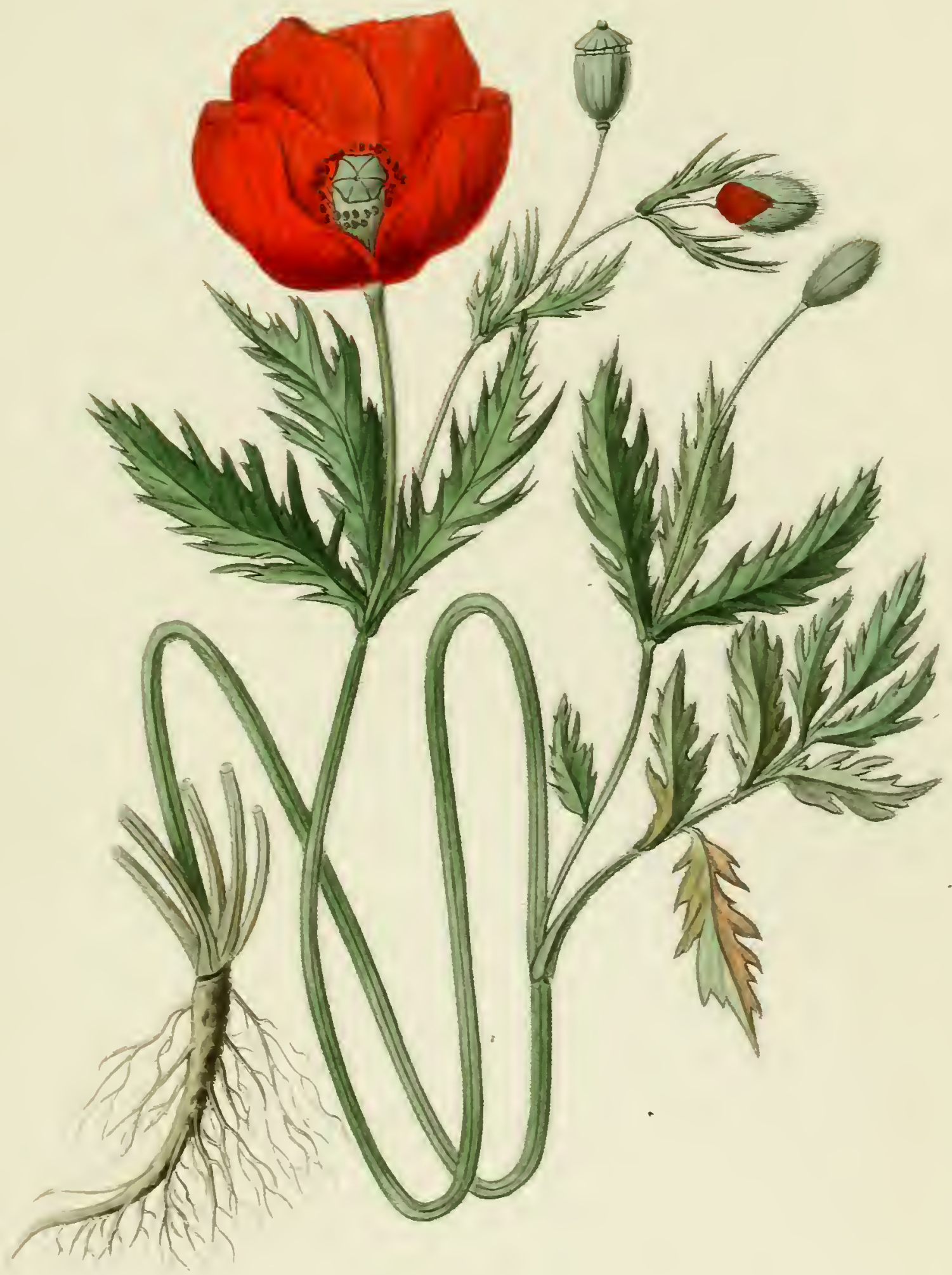





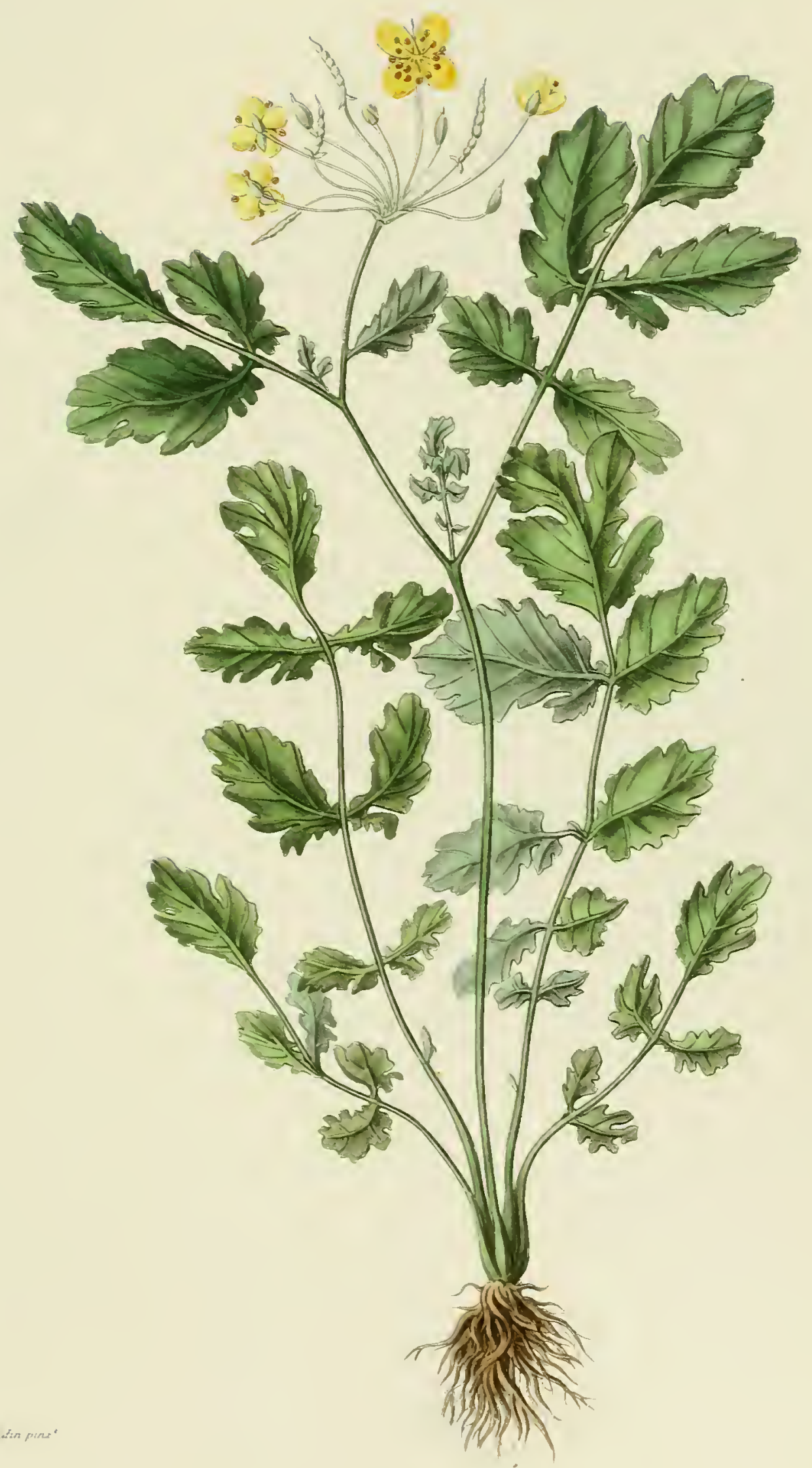

II 



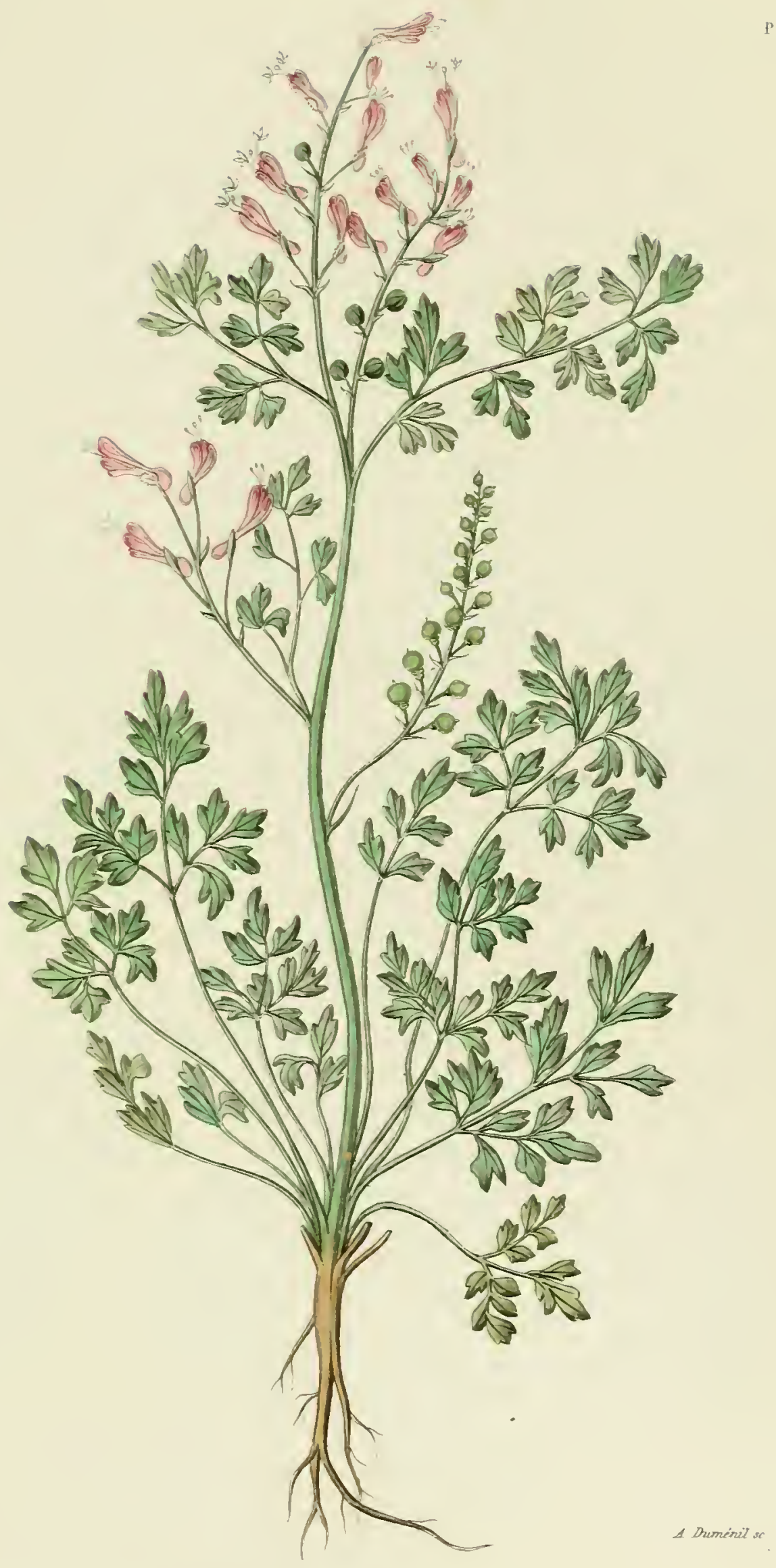

FL METERRE OFFICINALE 



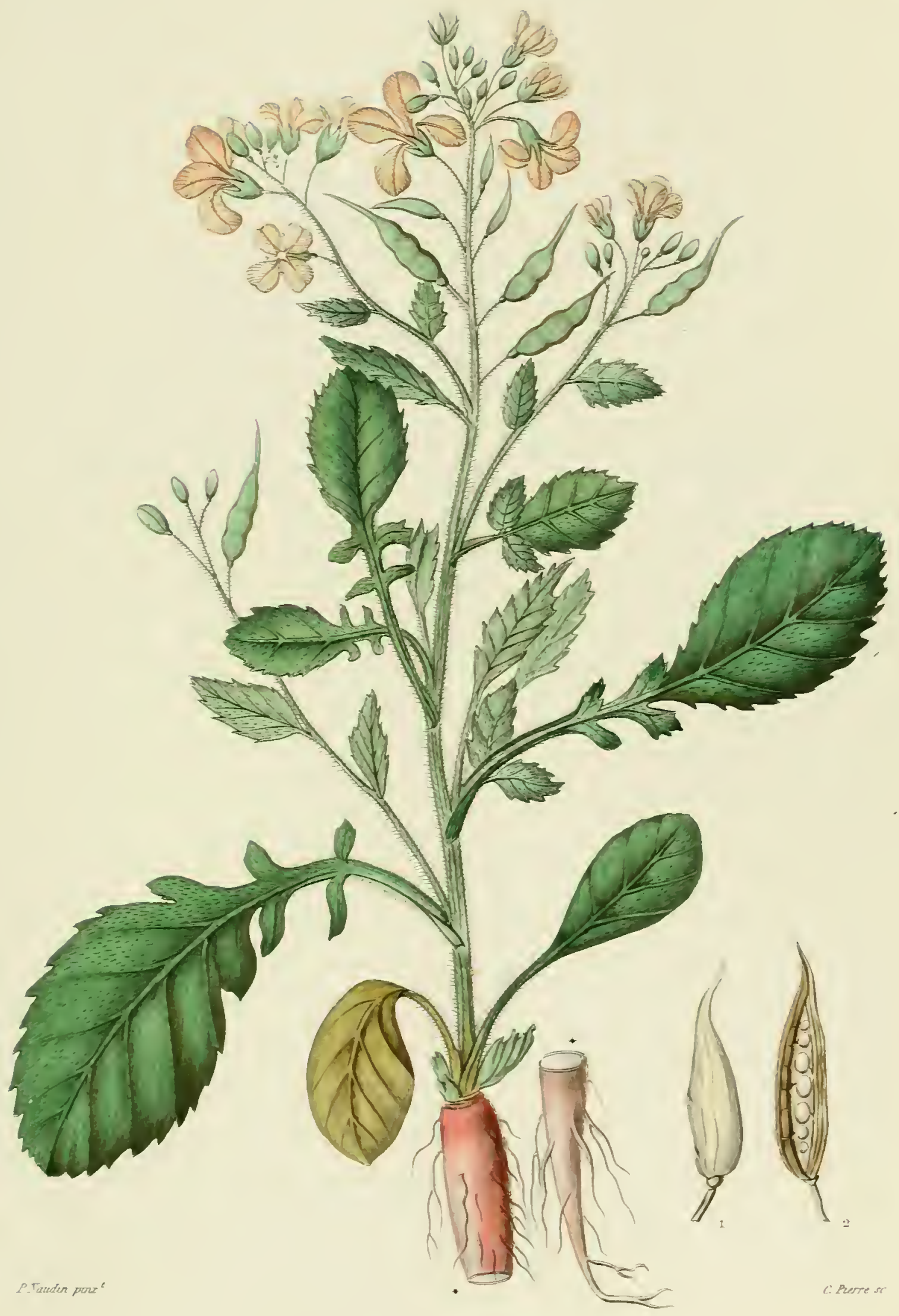

R.IVEXEII.E. 



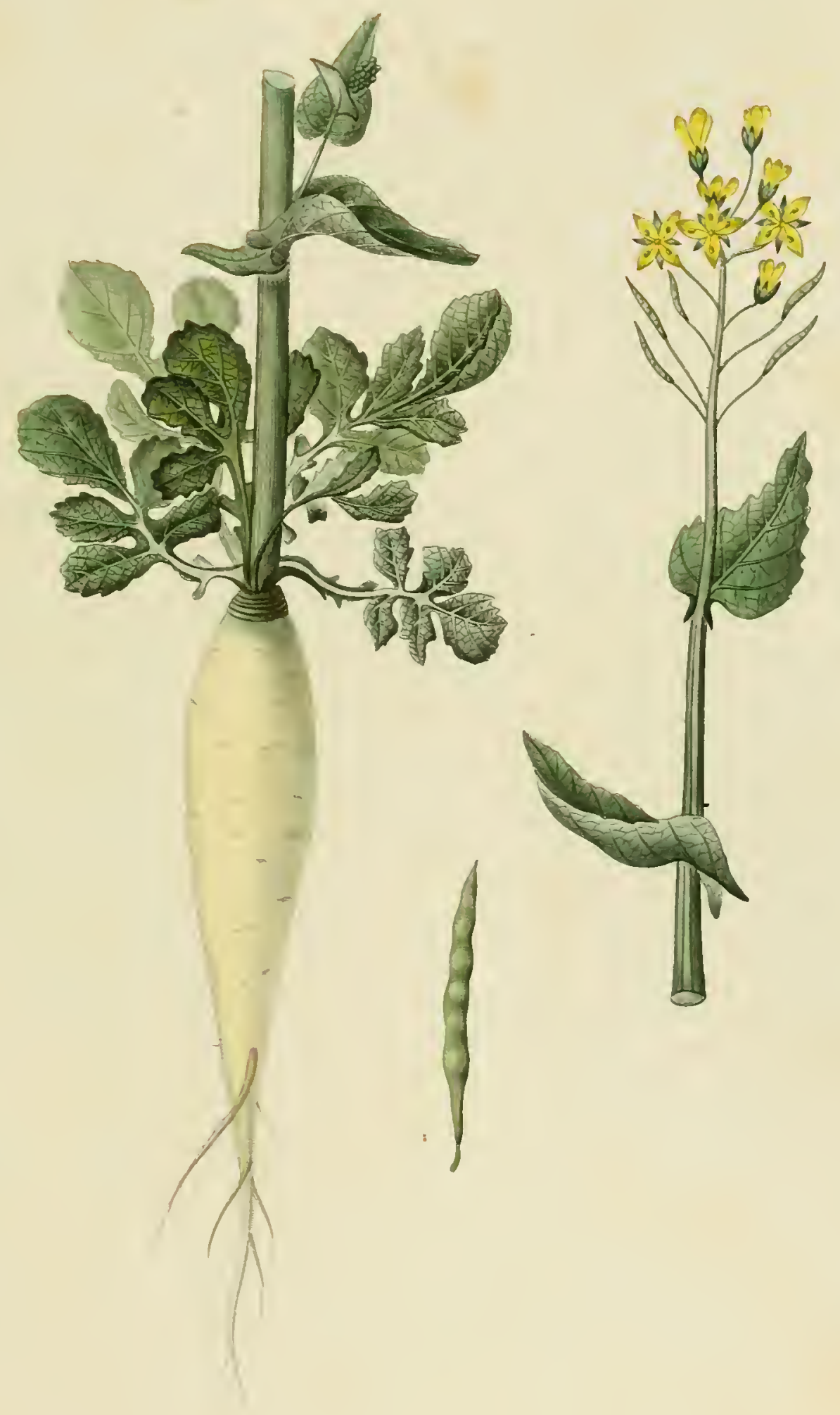




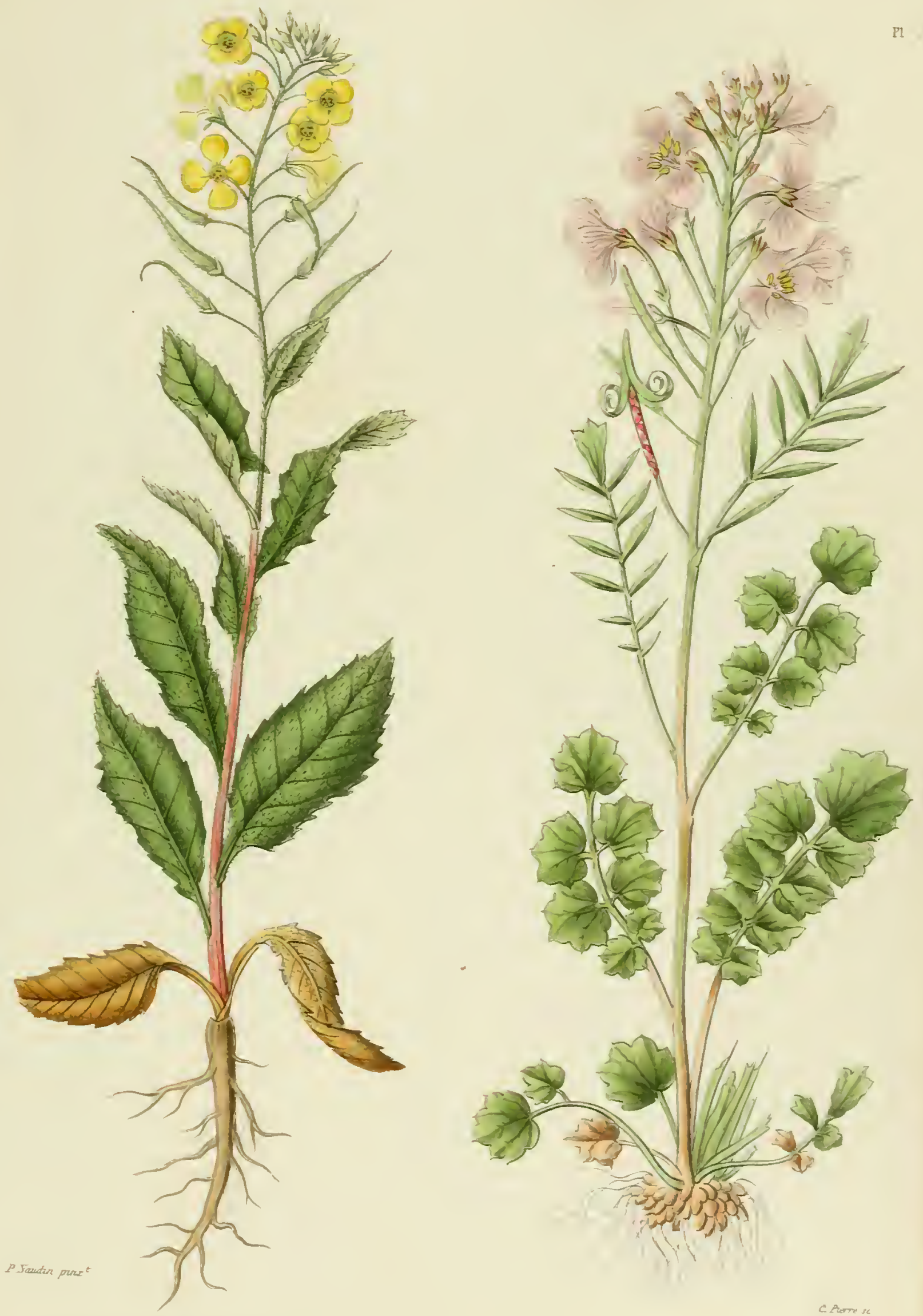

IOLTARDE DES CHLUPS 



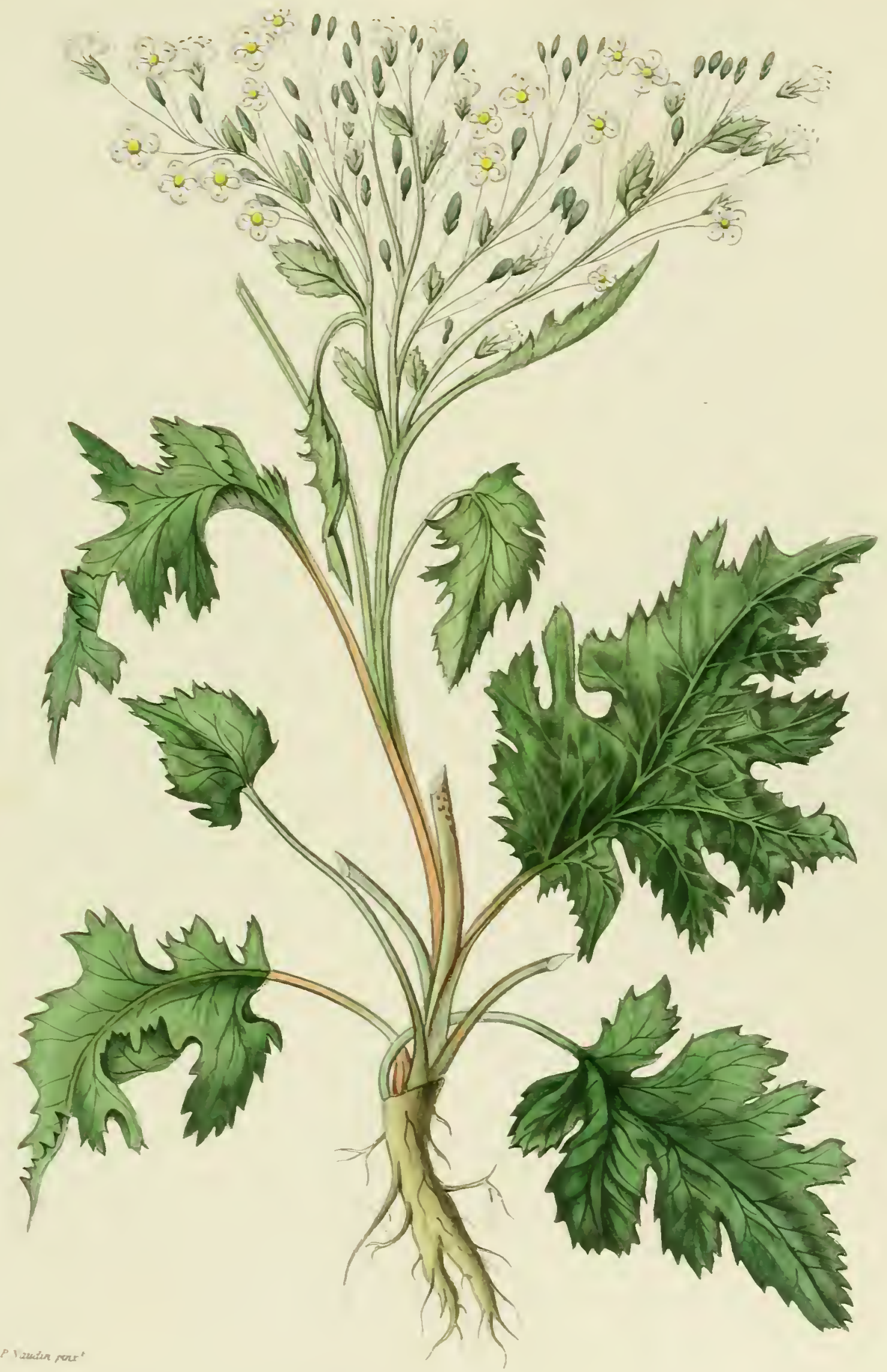

('RAMHE MARITIIE 



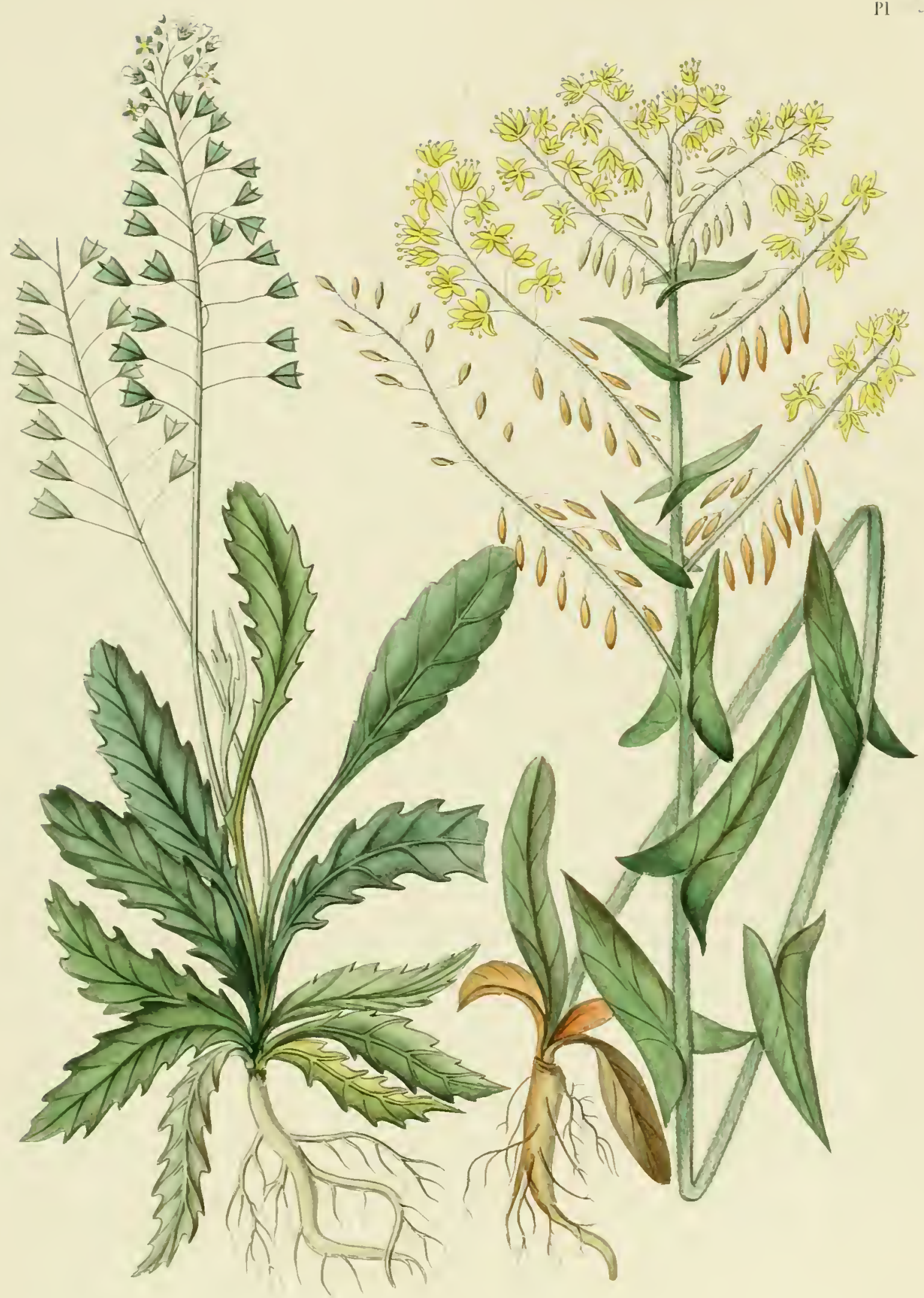





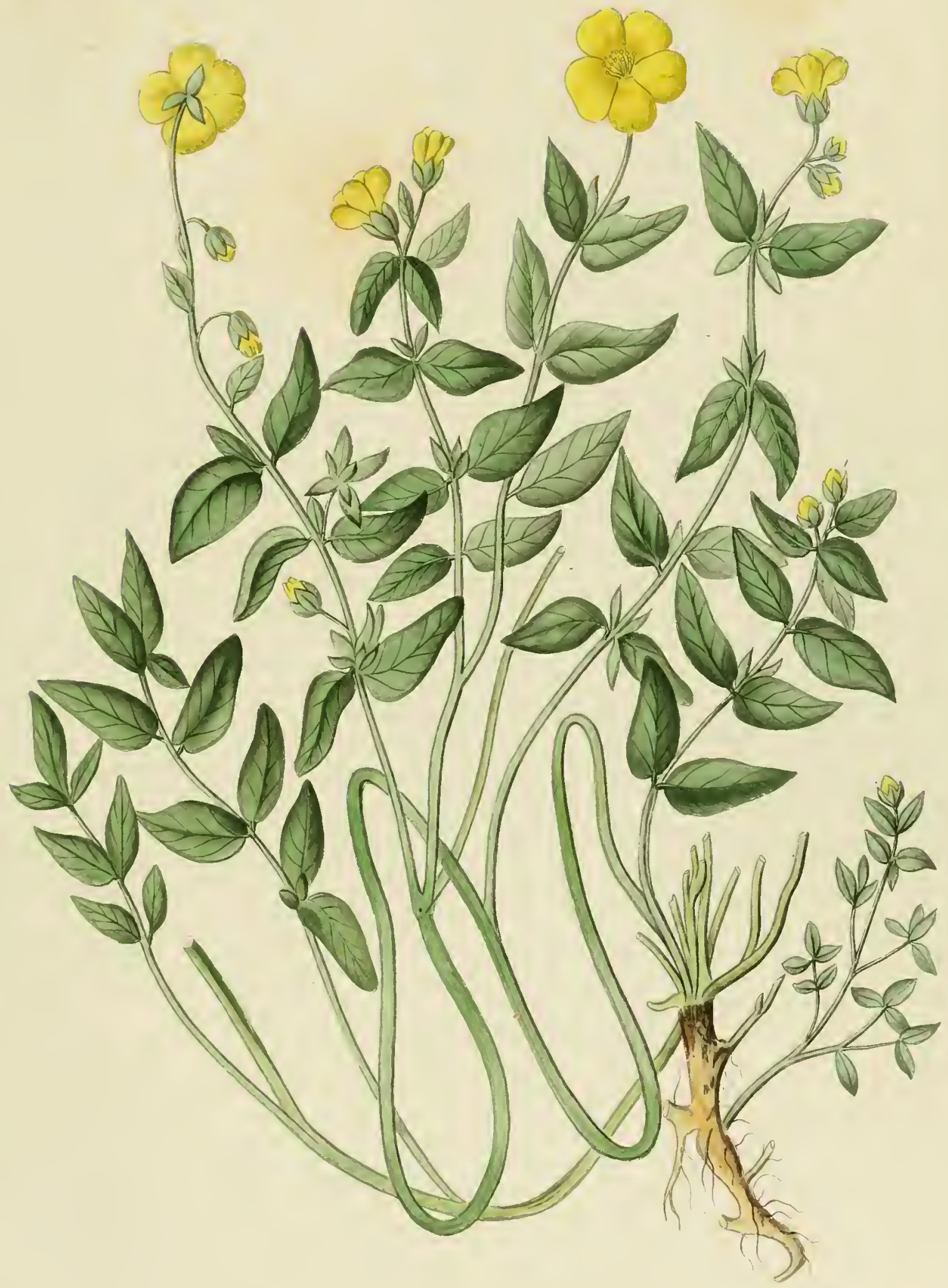

HELIANTHEME (OUNIX. 



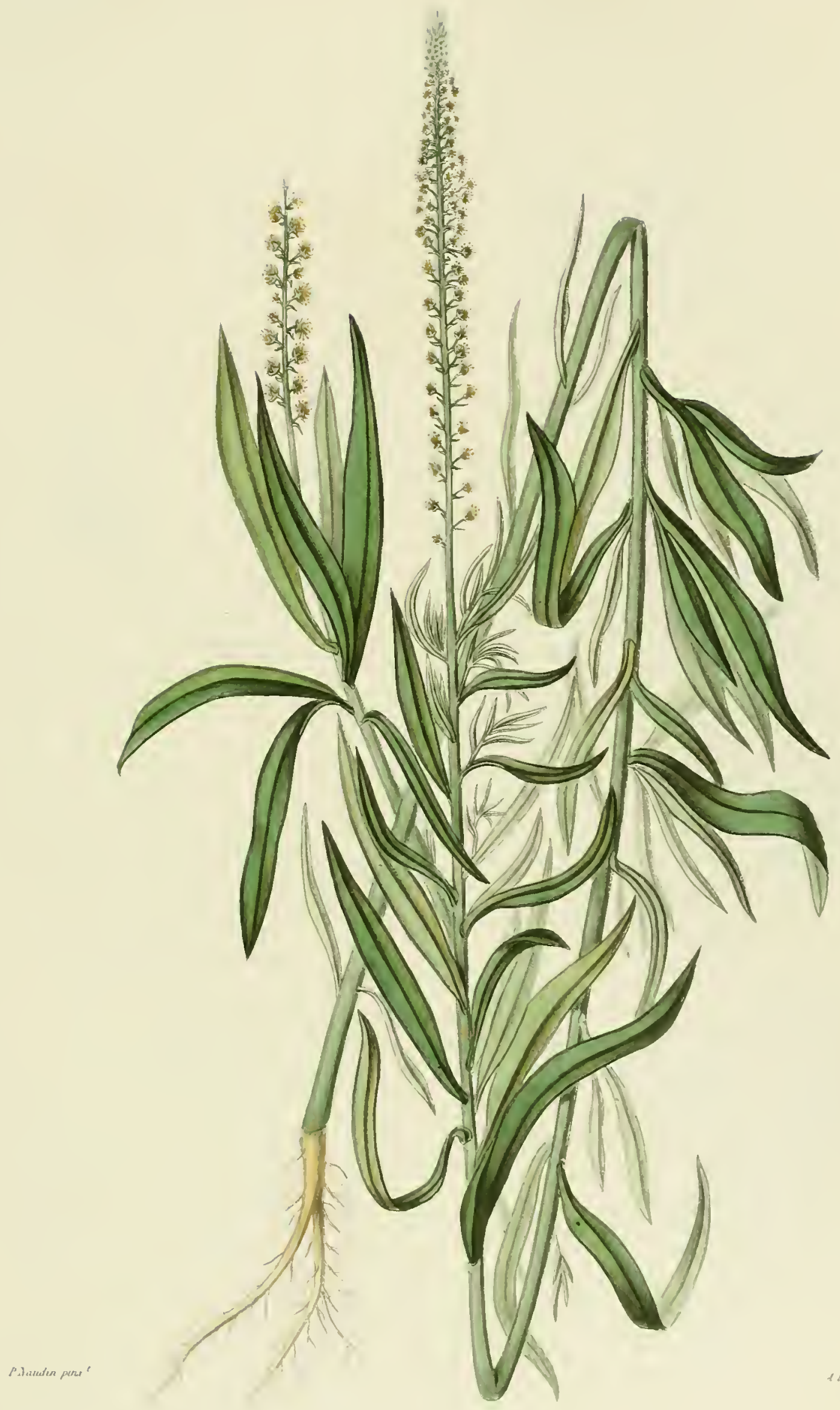





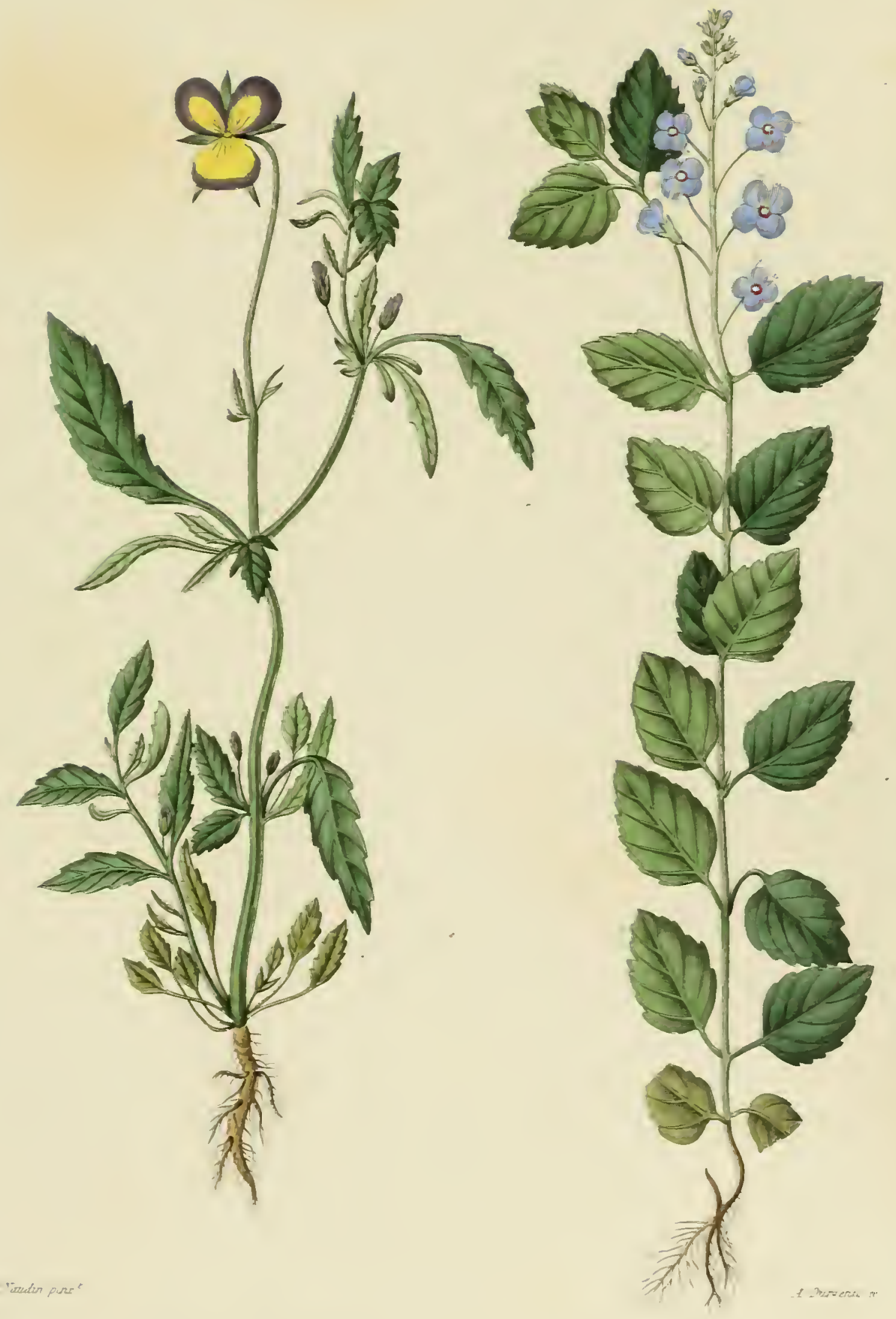





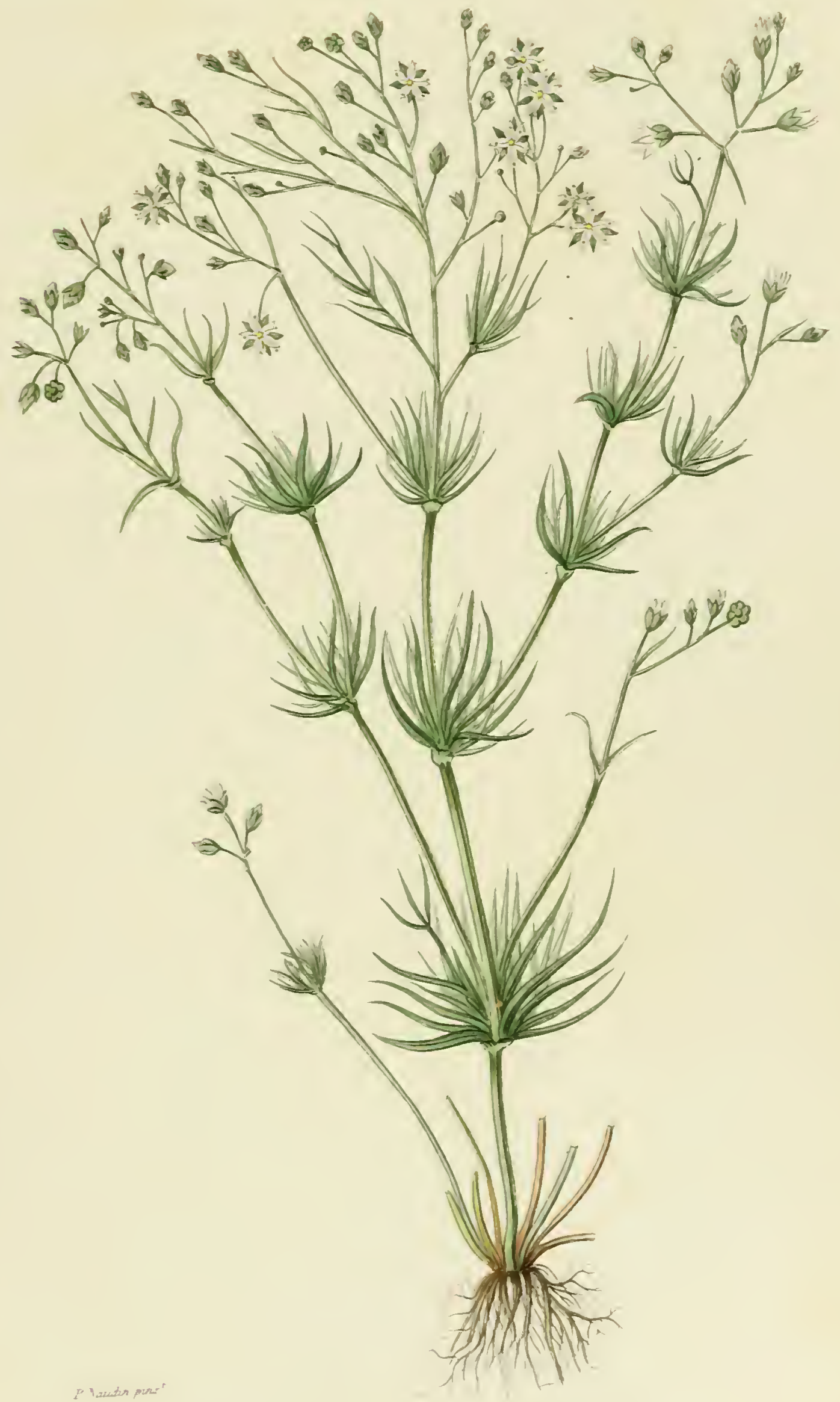





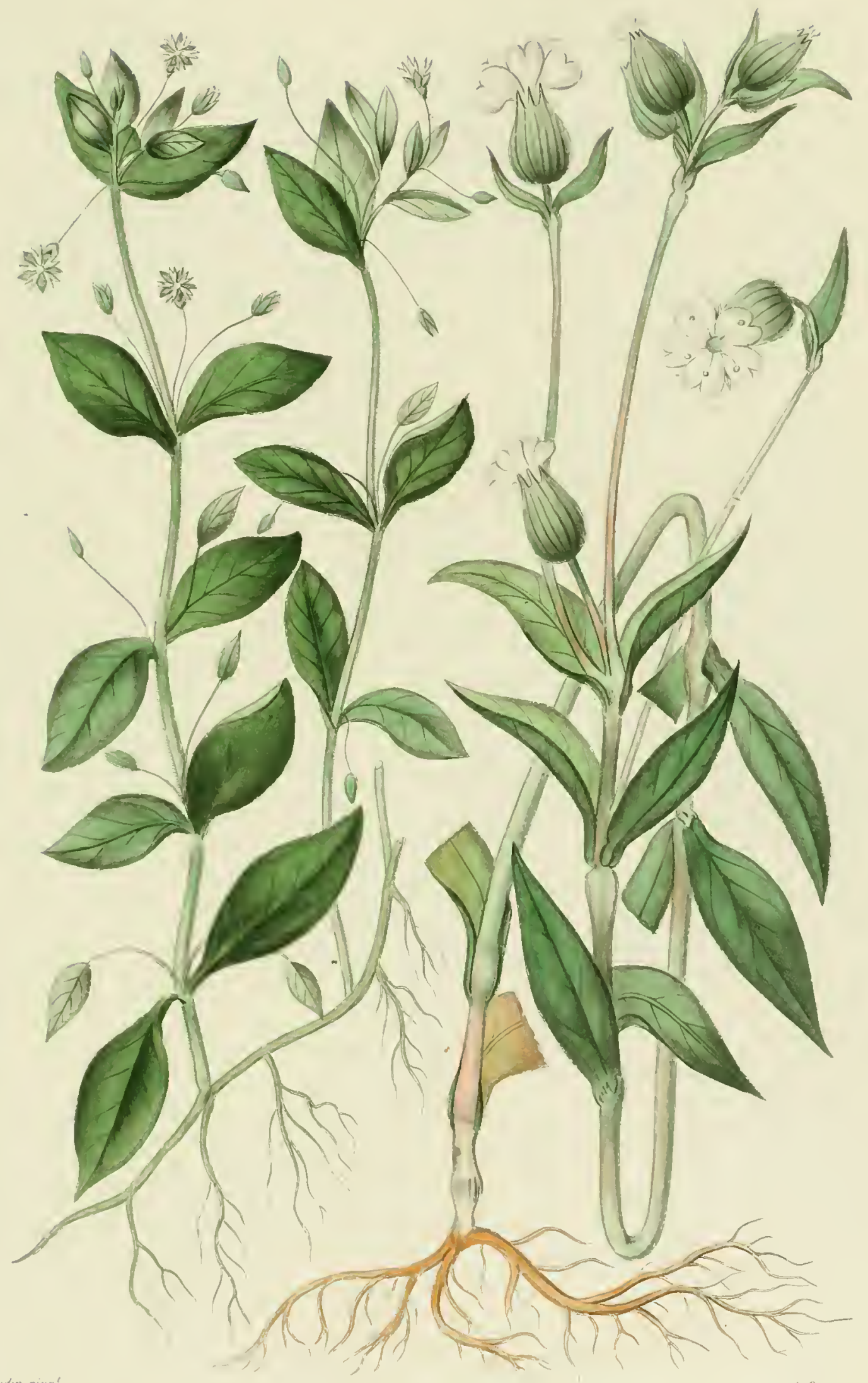

STELLUIRE, U(1) GENE

SILINE ENFLE. 



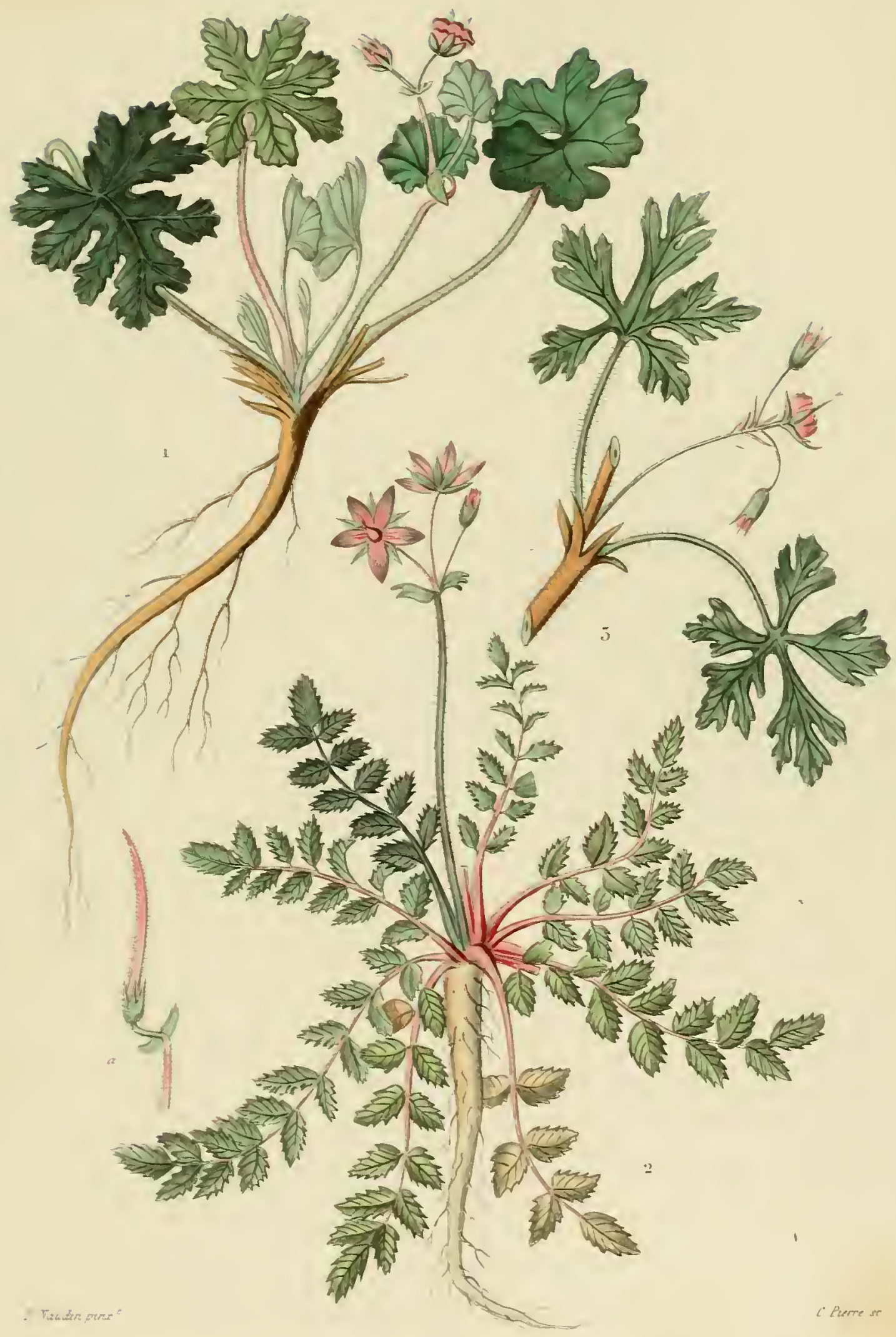

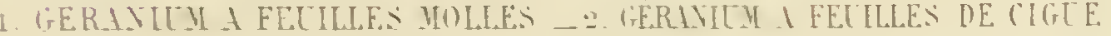





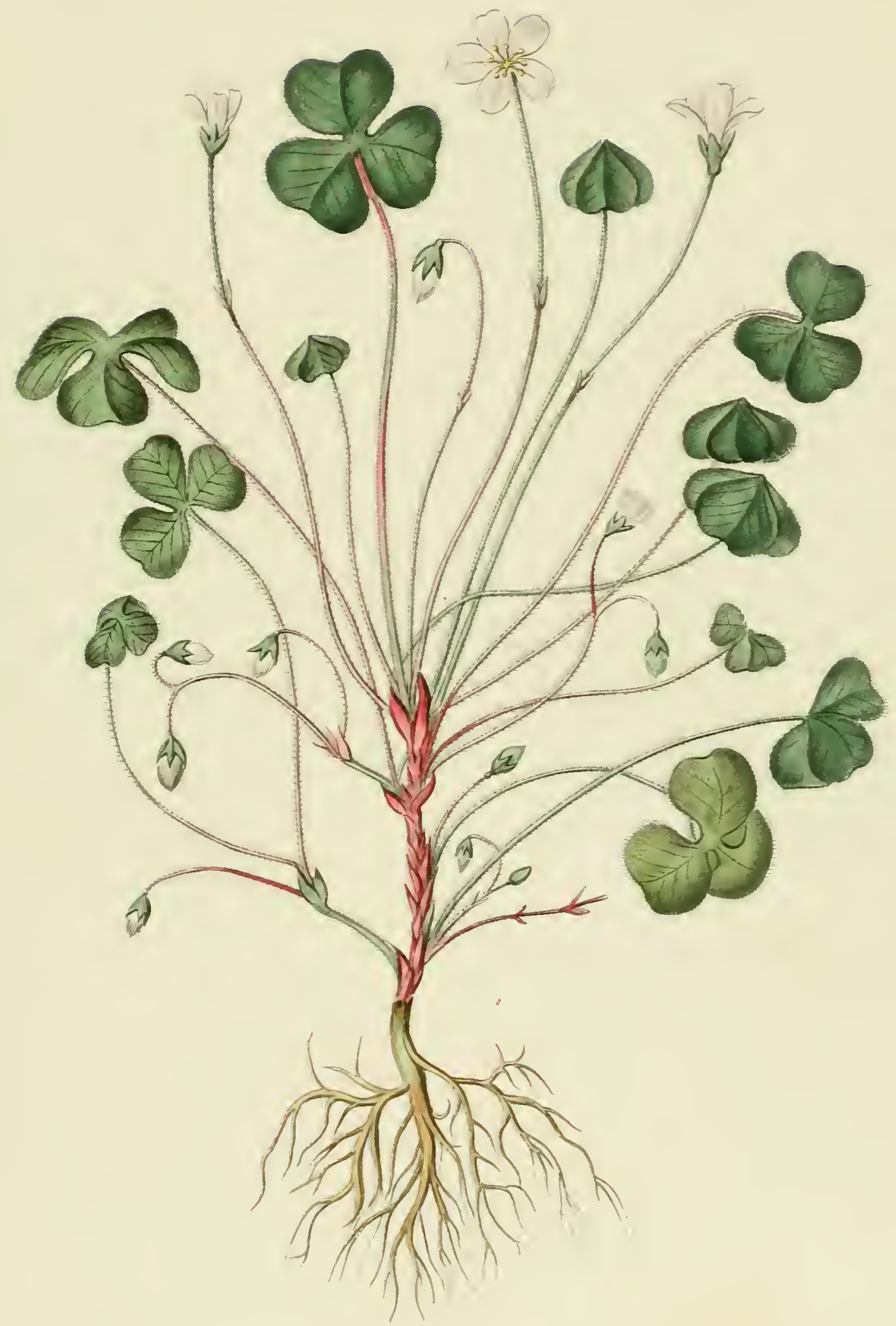





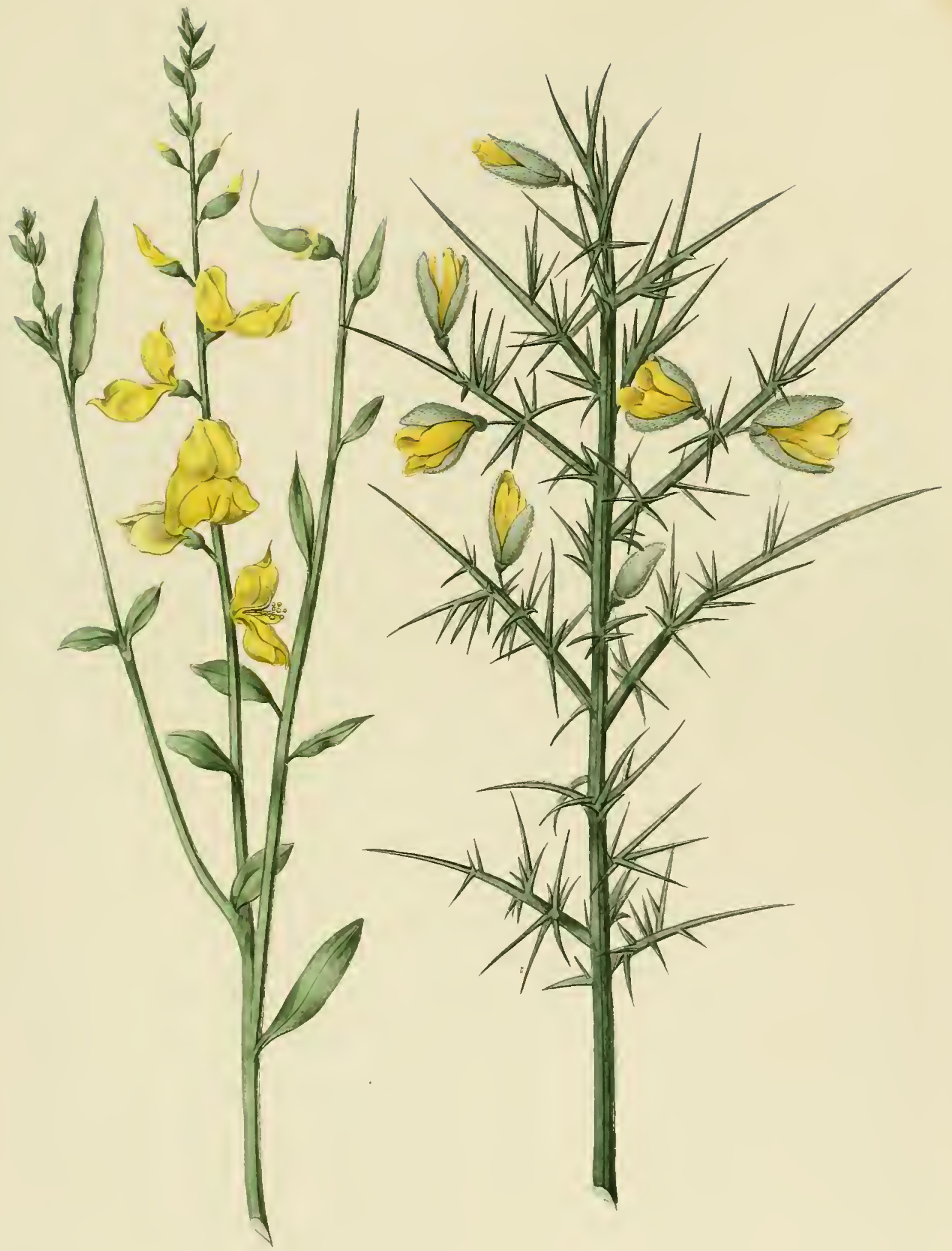





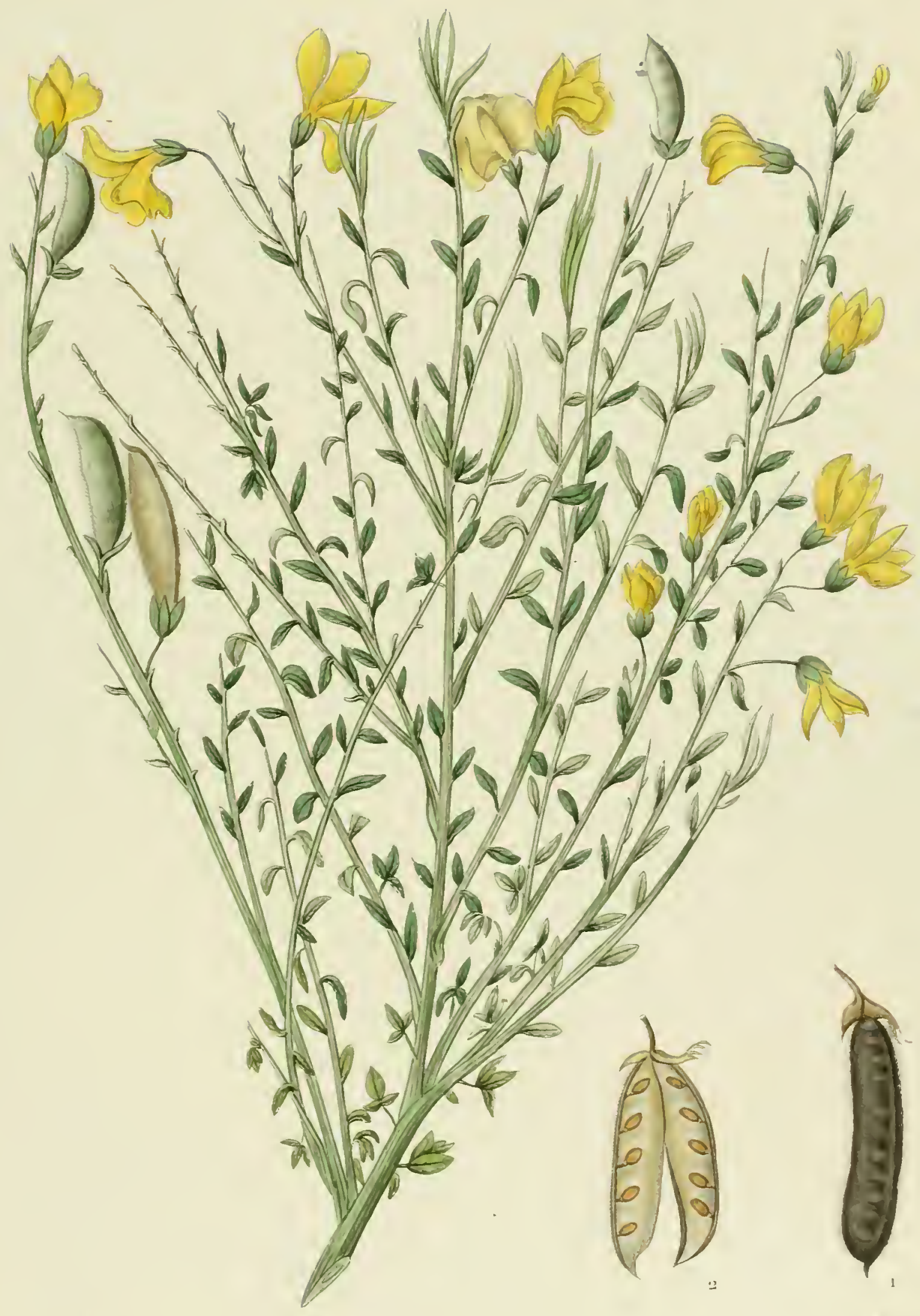





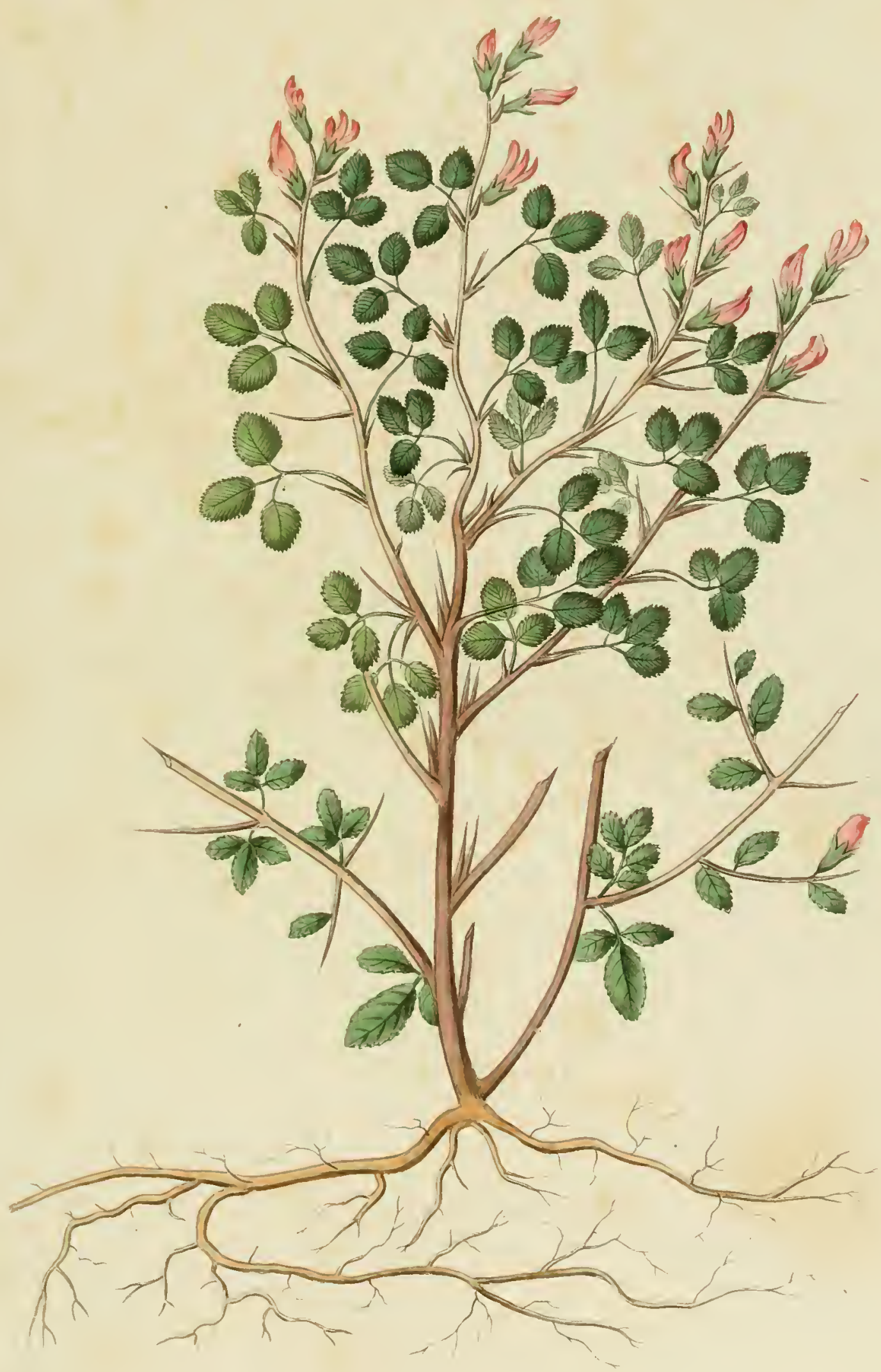




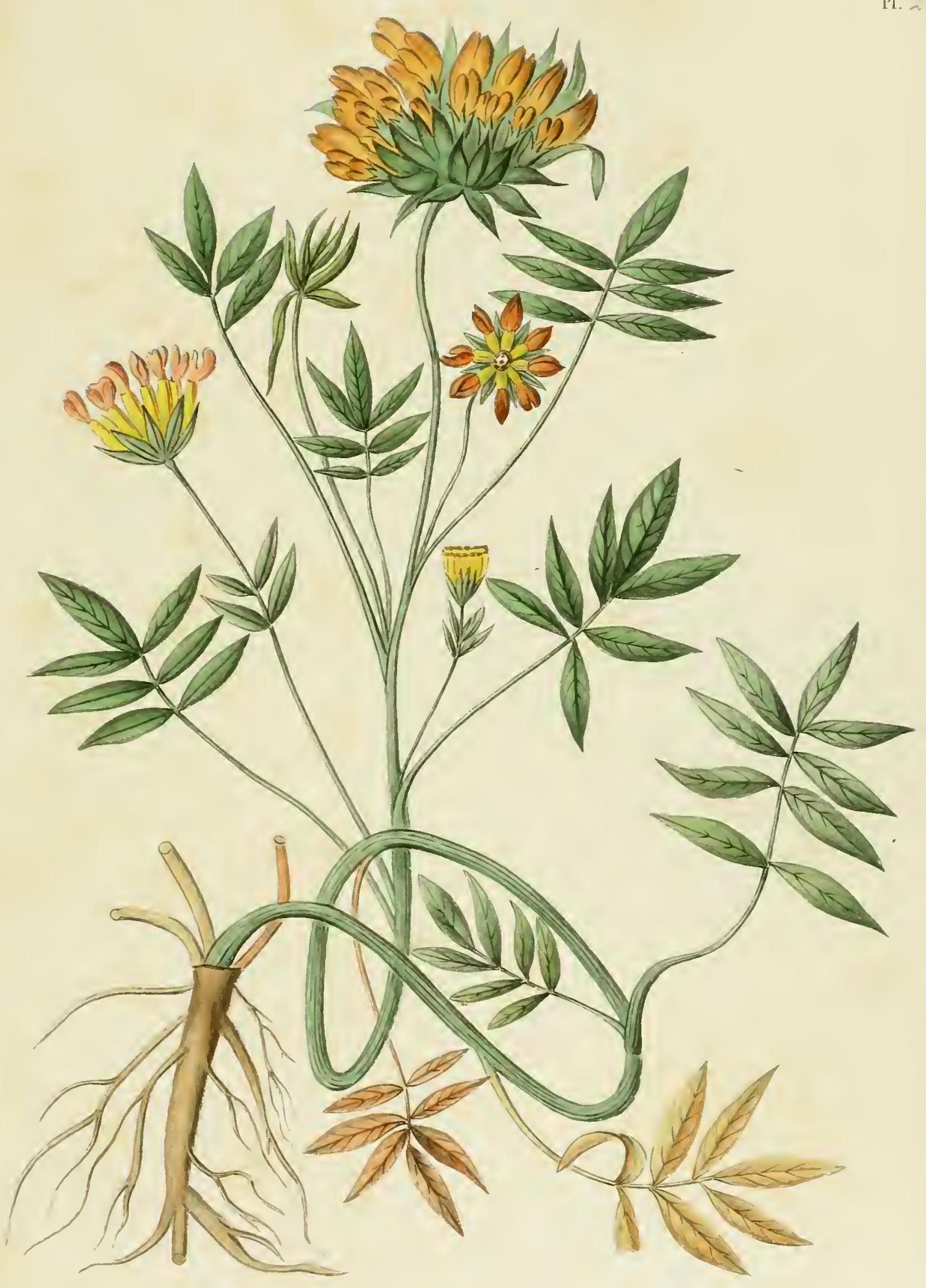





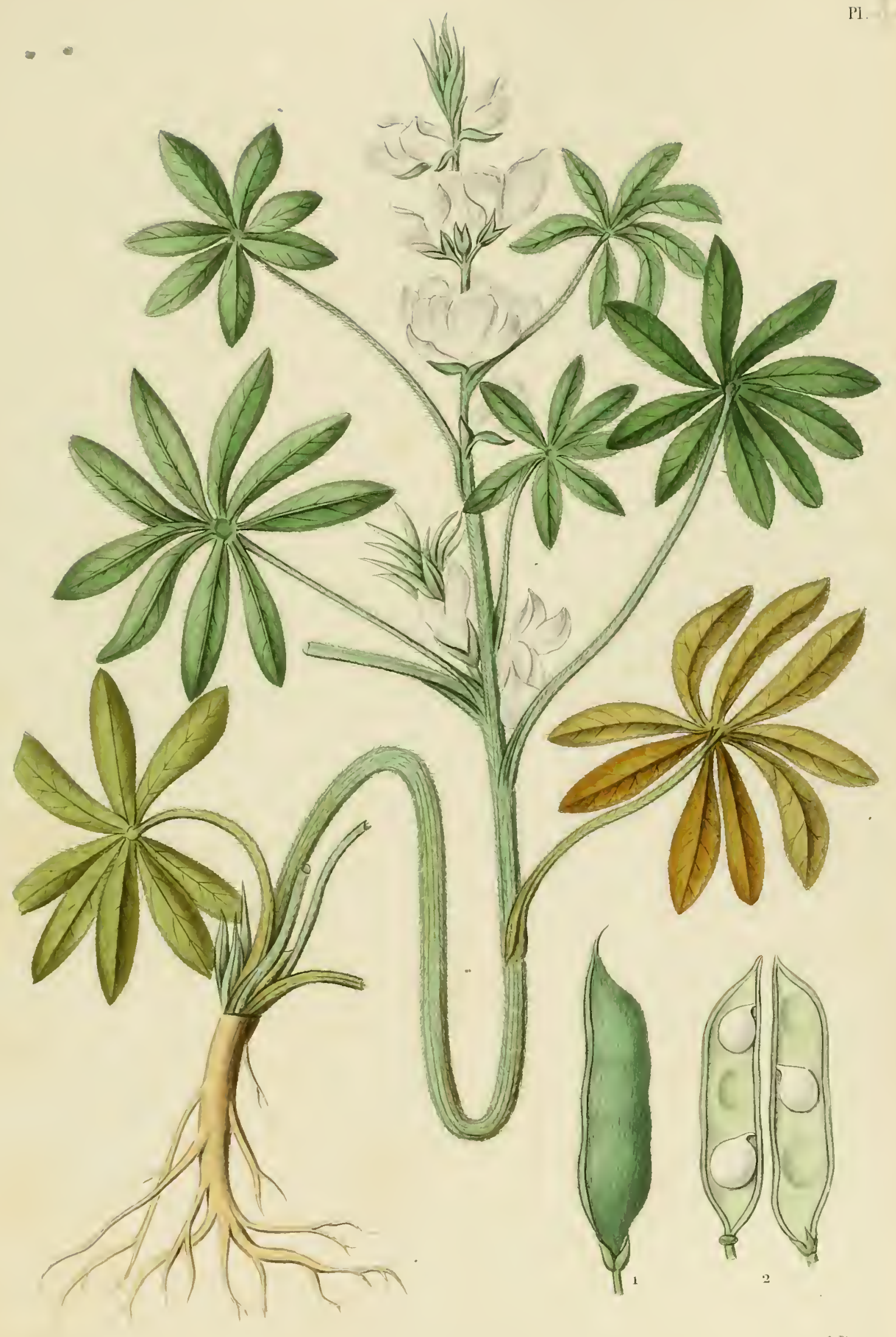





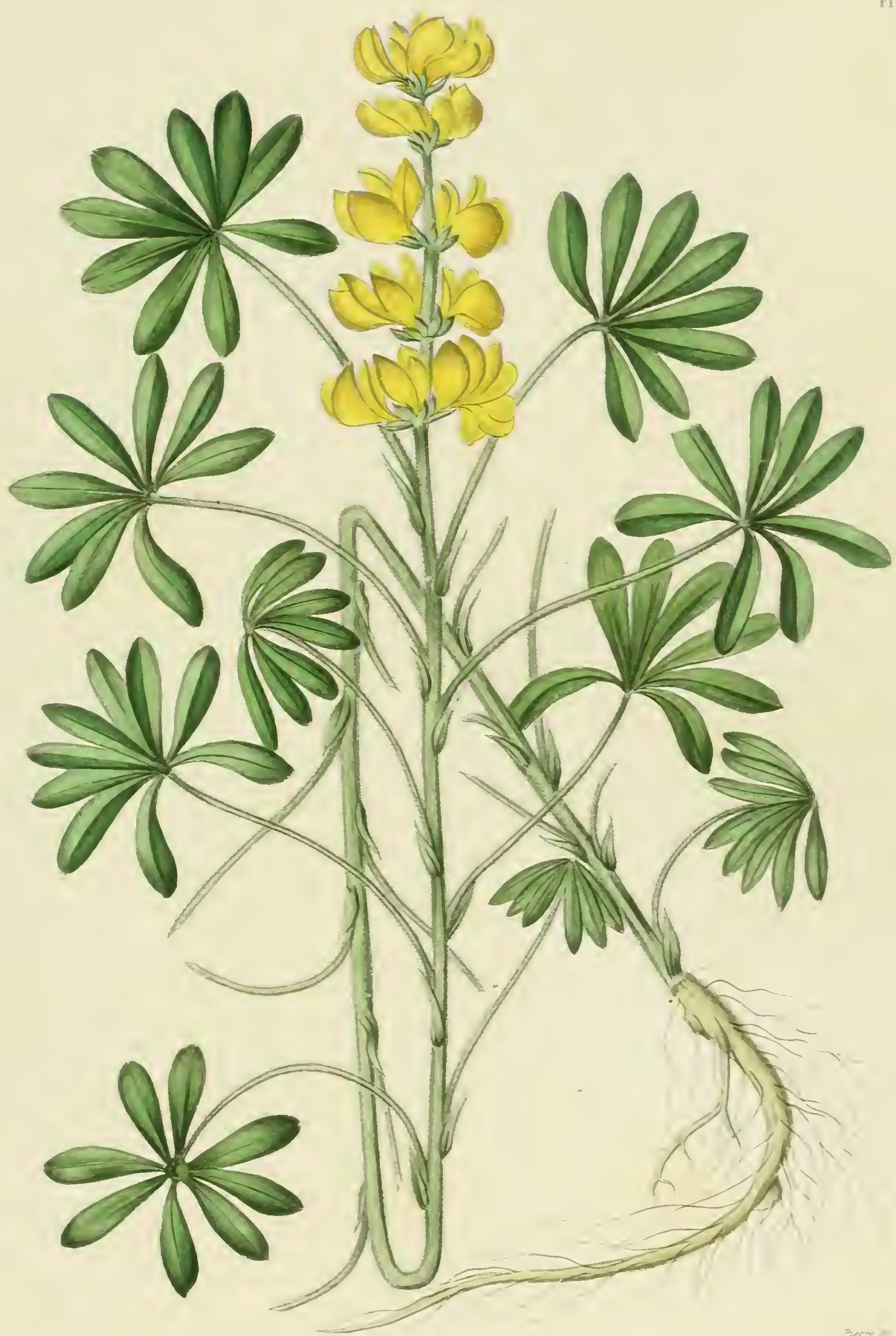

LEPIS JAUYE 



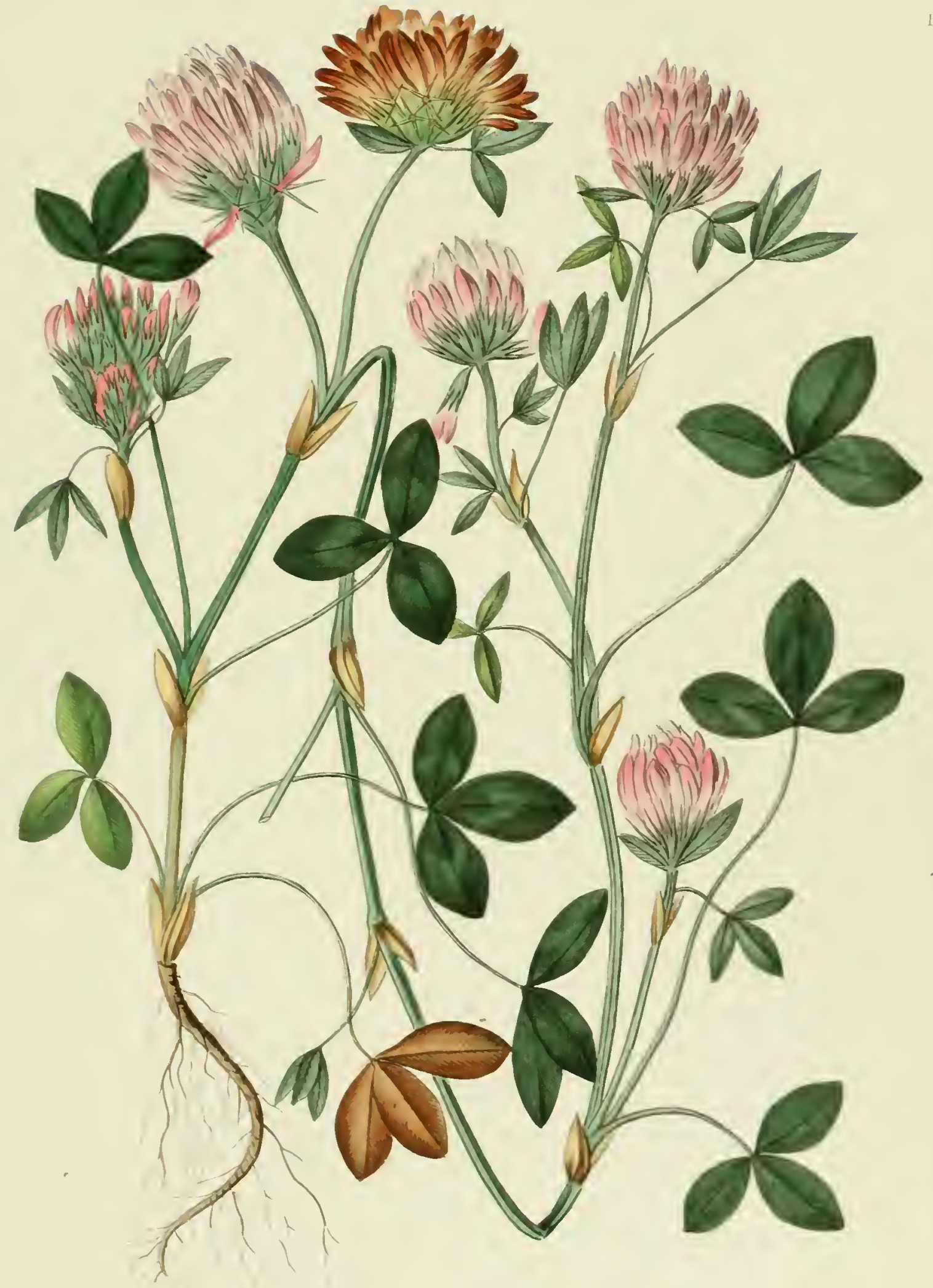

TREFIE DES RRE 



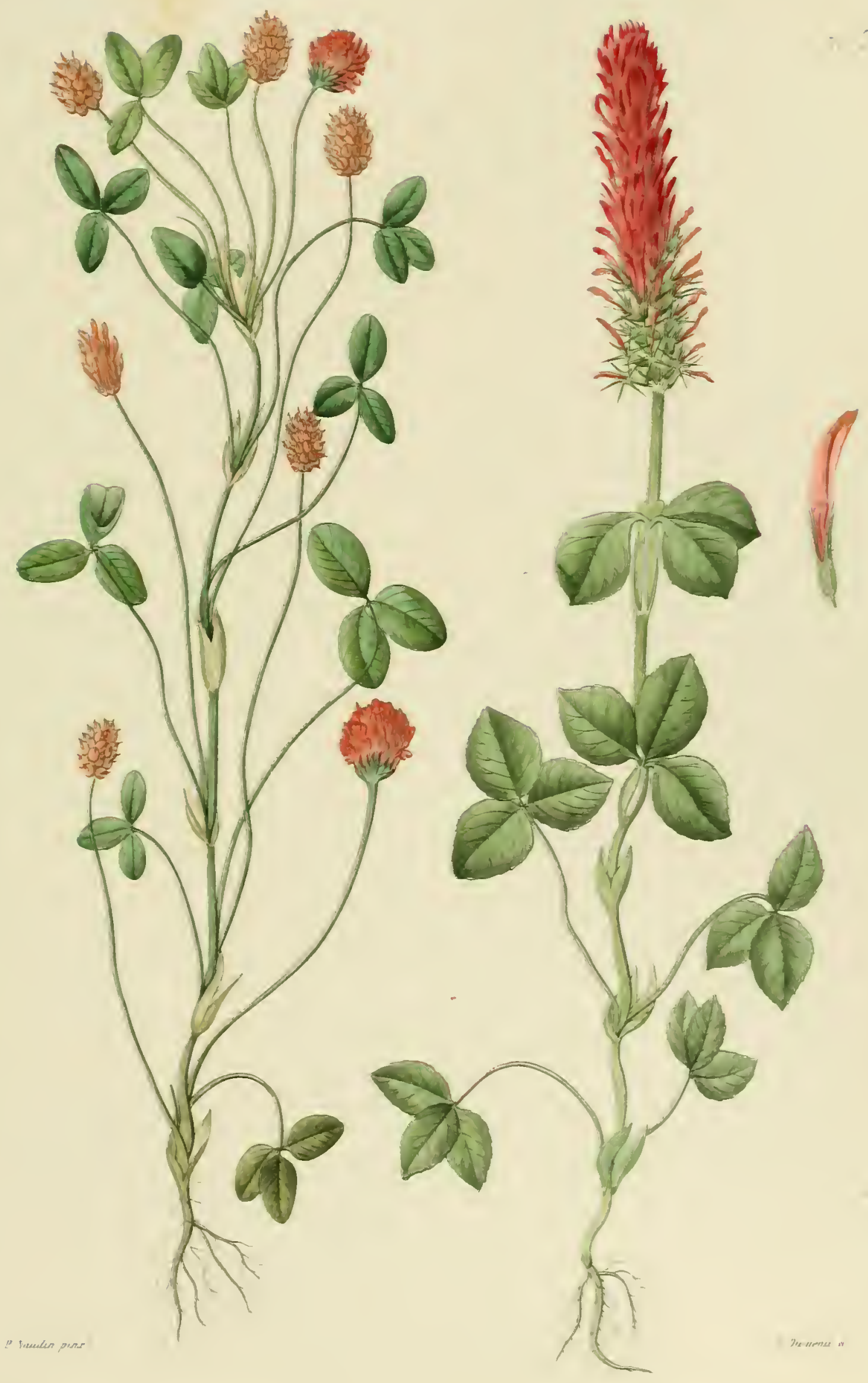





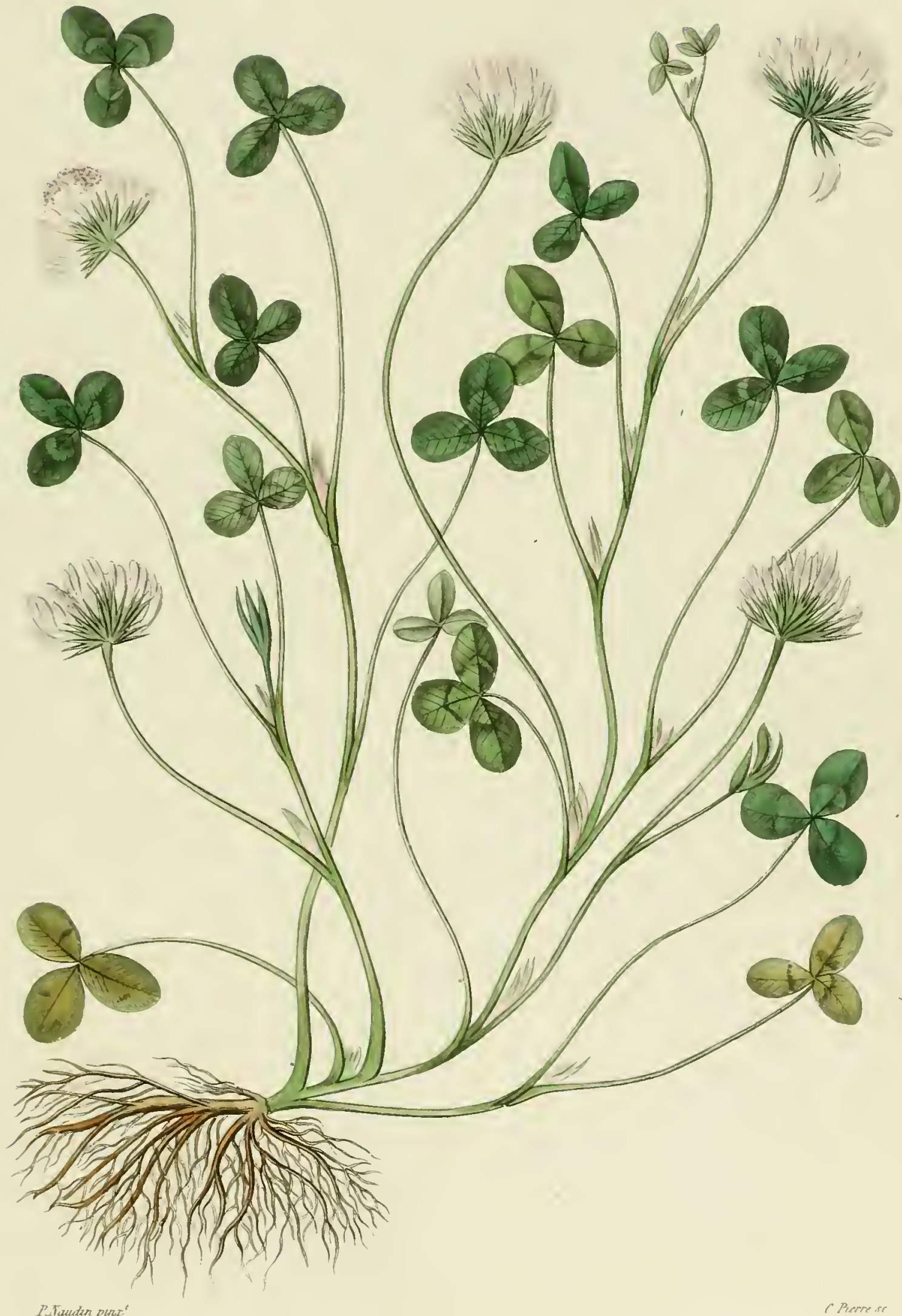





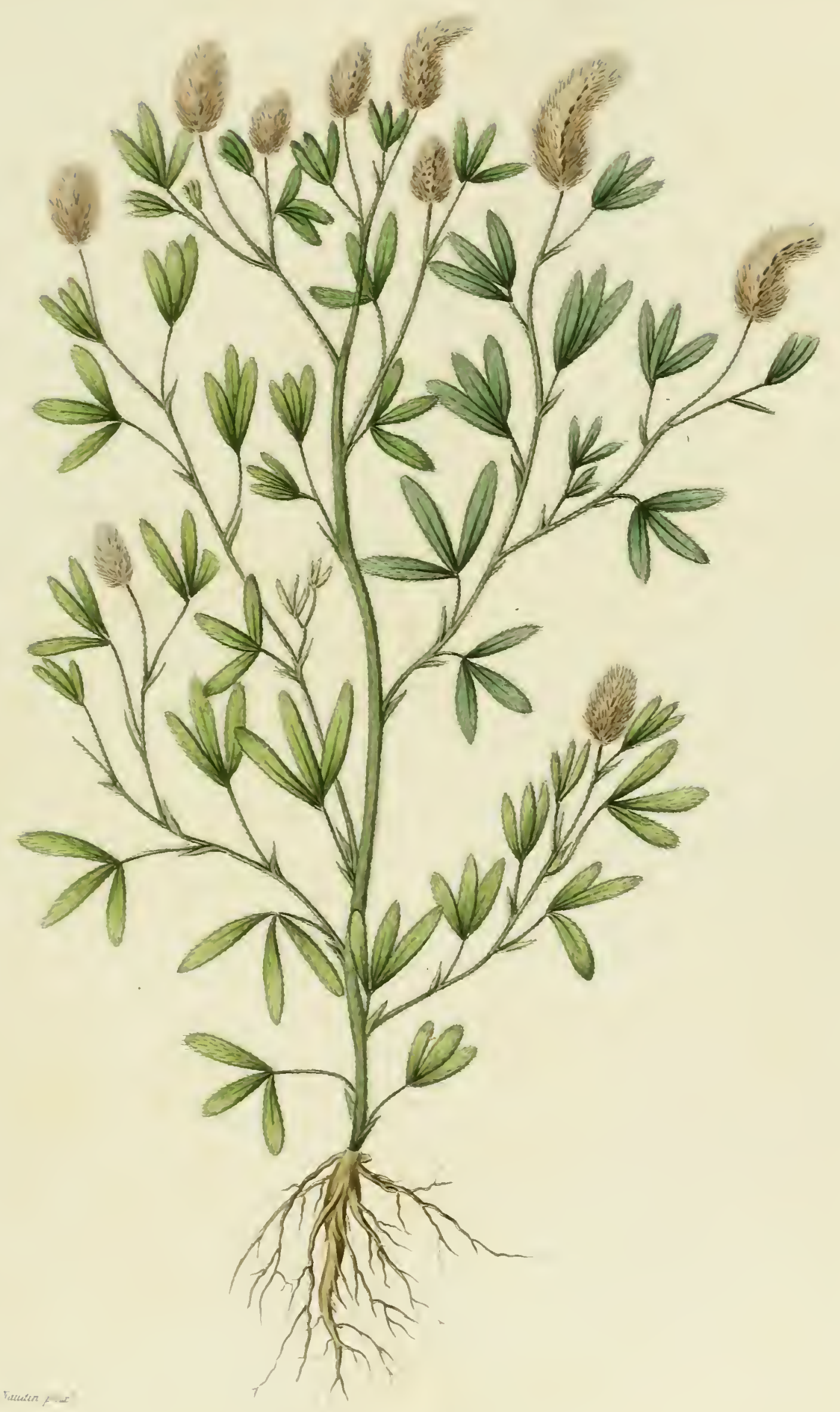





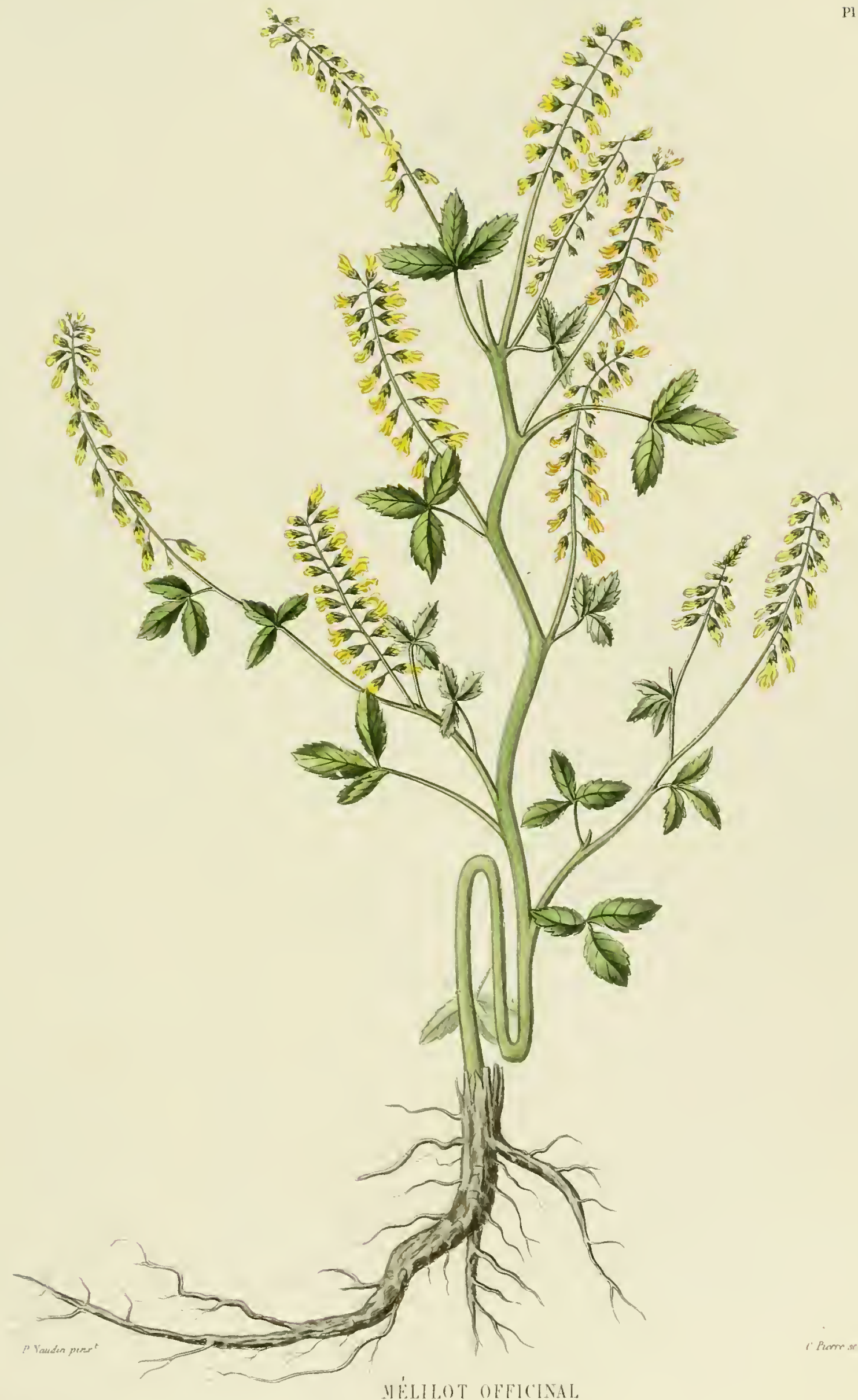





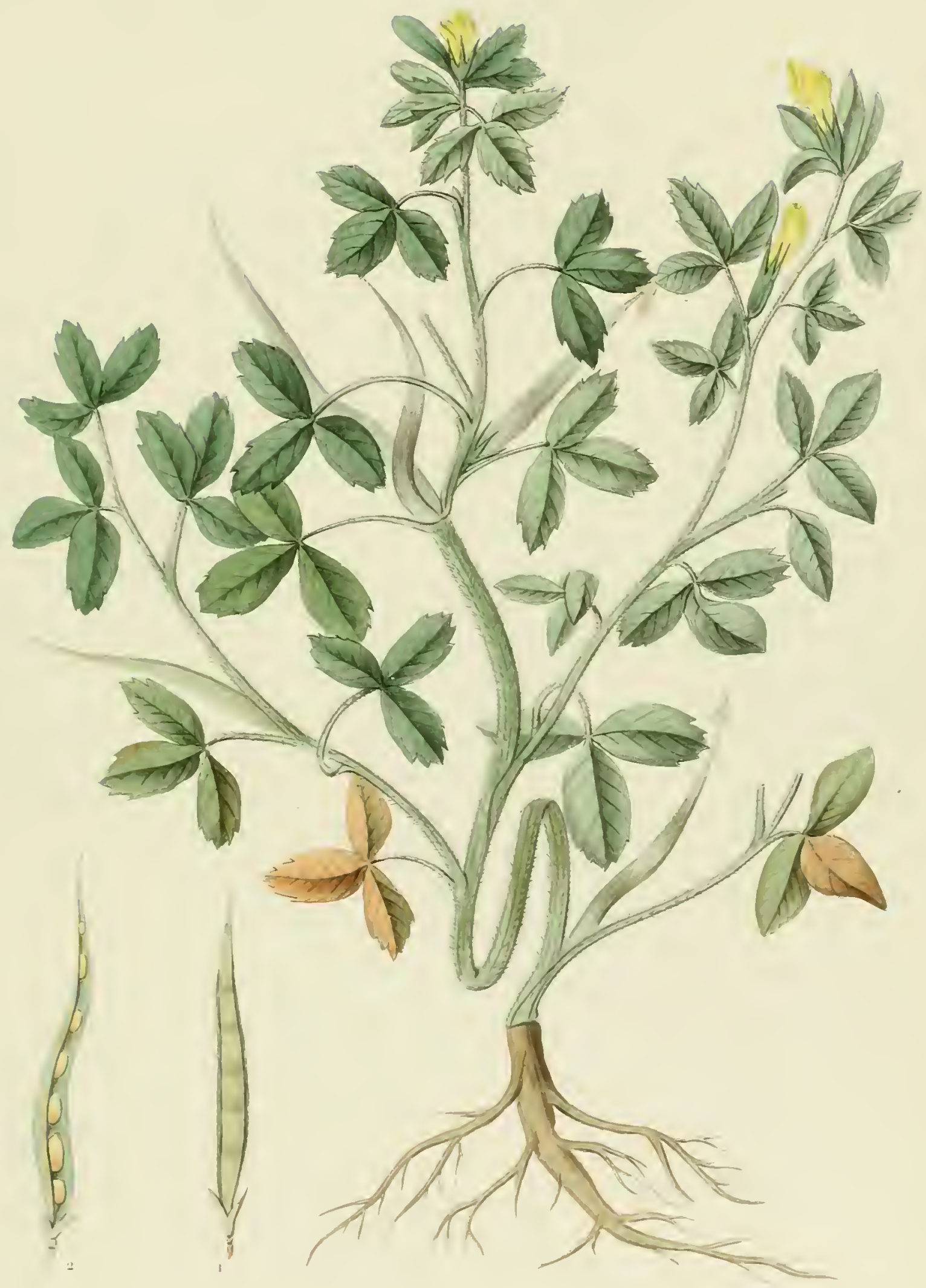





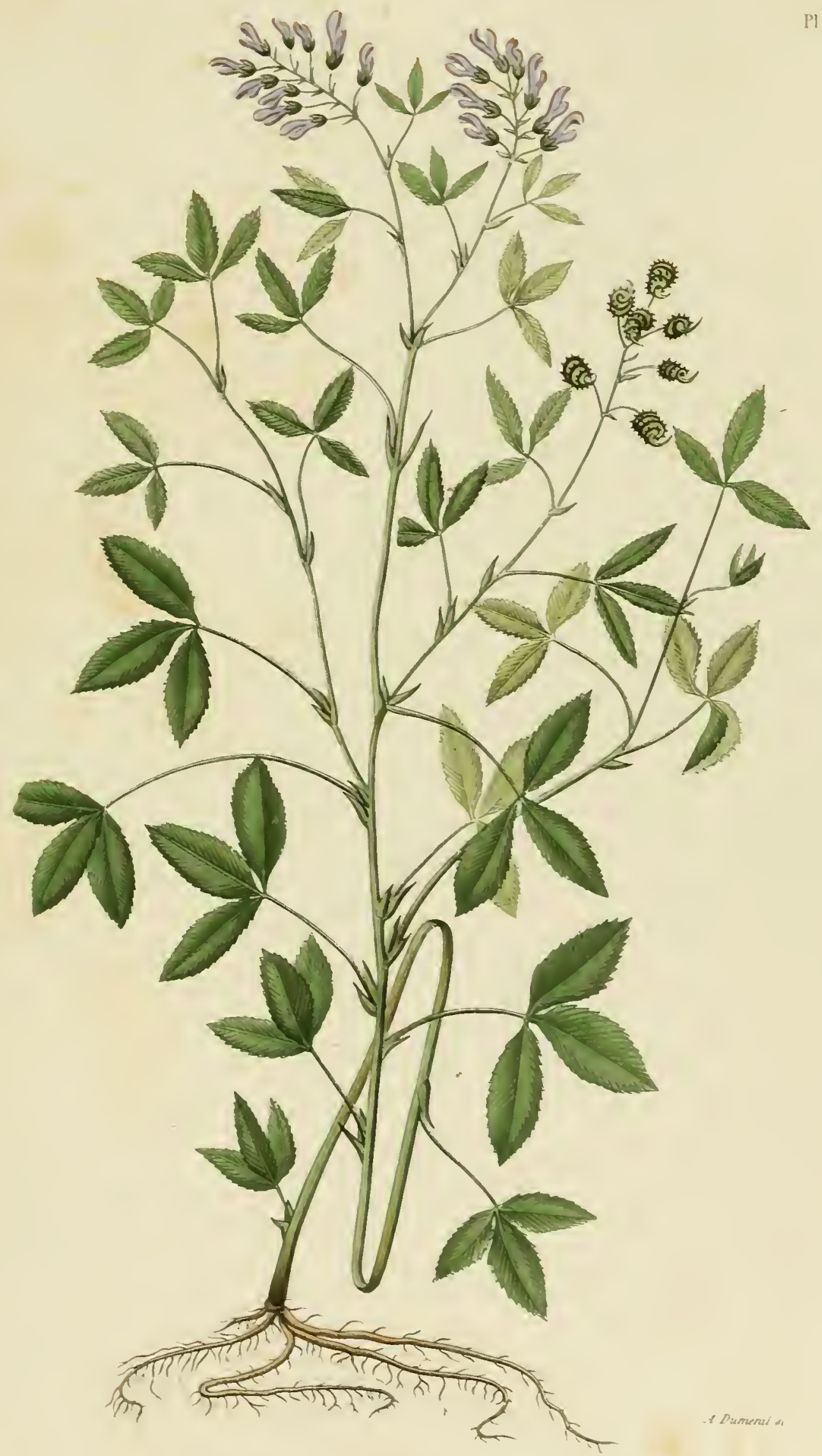

I.TZERYE CLITIVEE. 



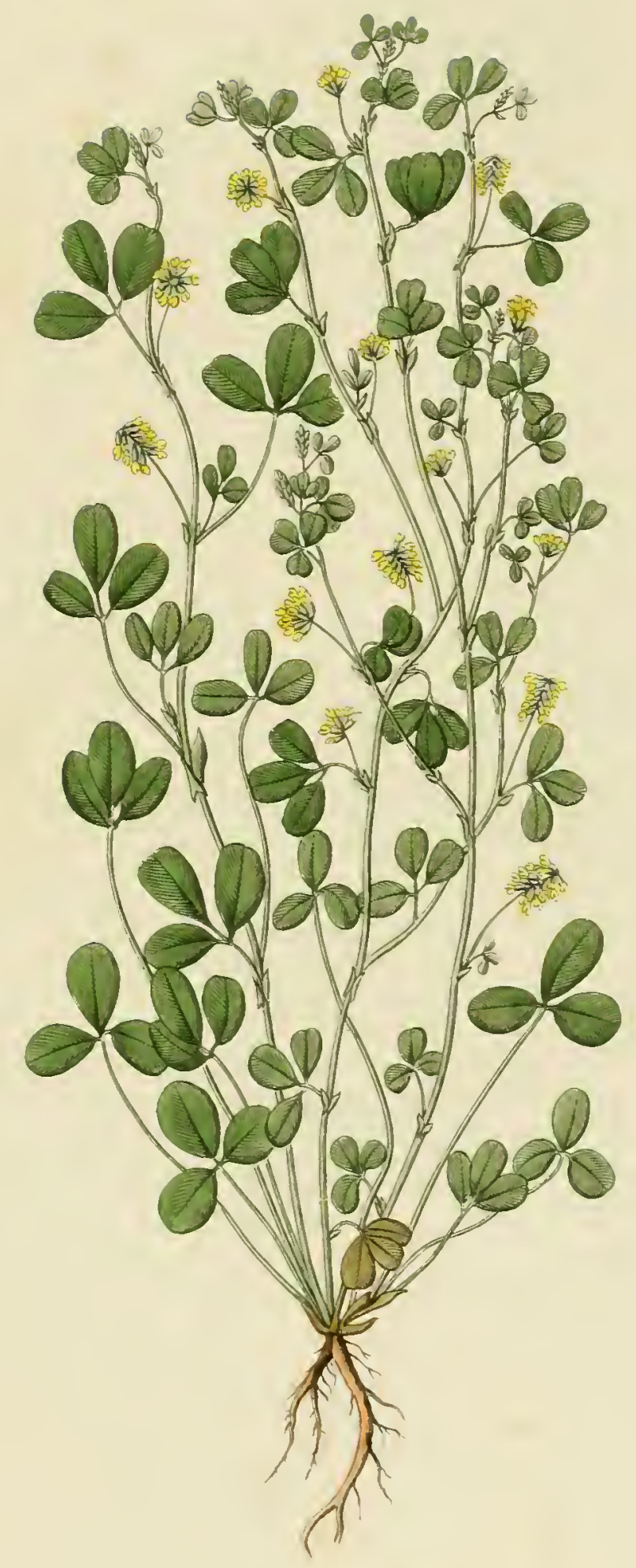

L.TPLINF OU MINETTE MOREF. 



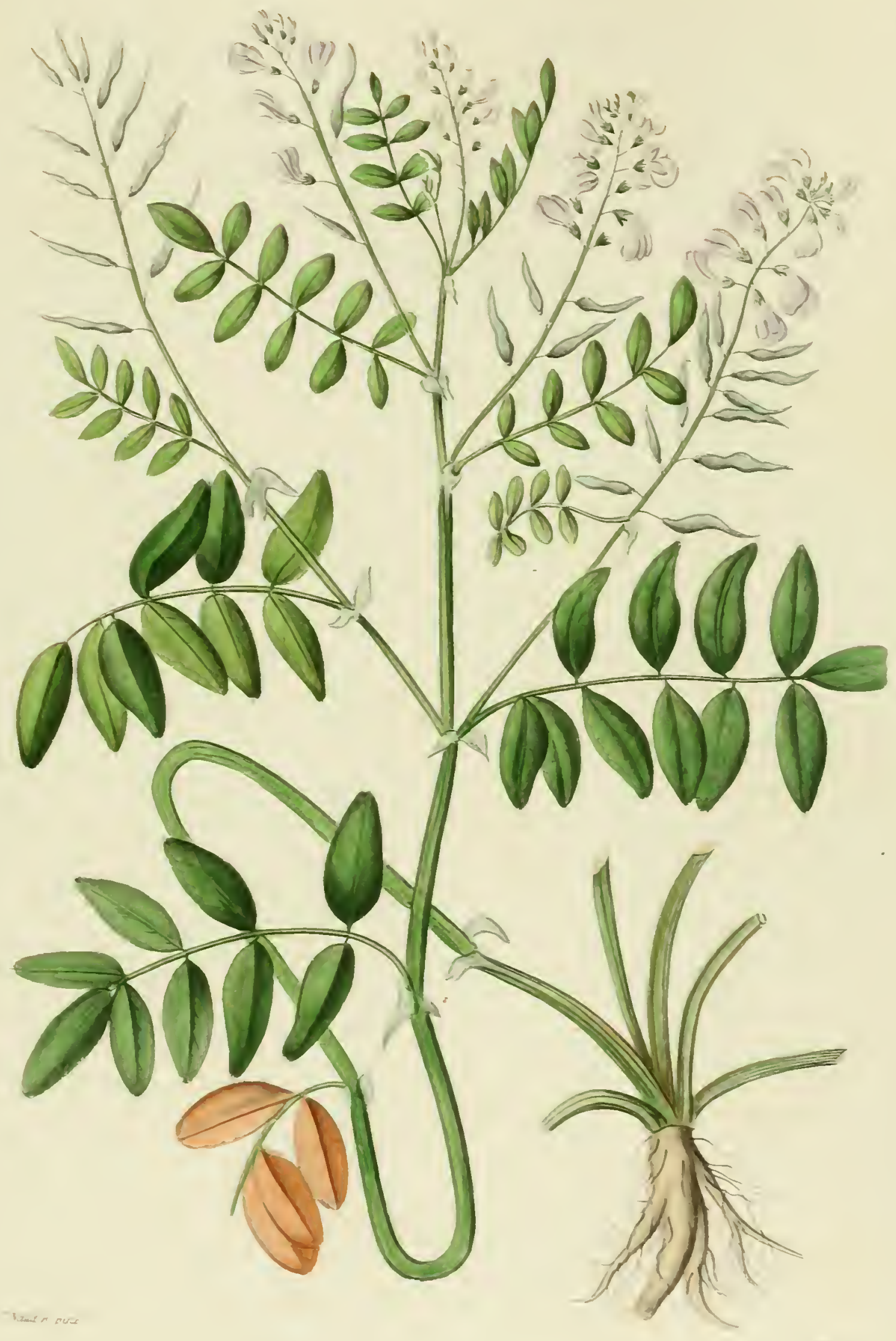





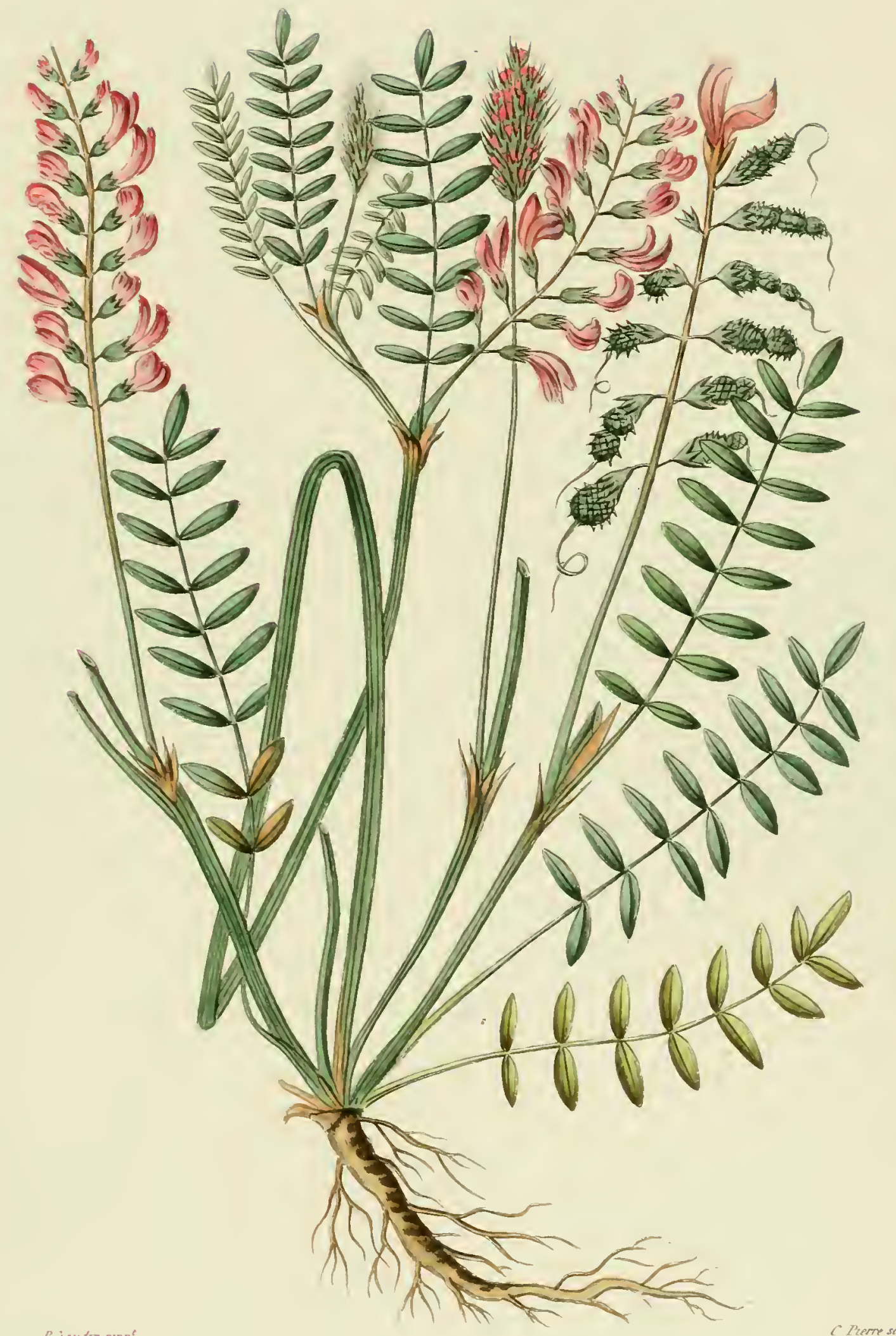





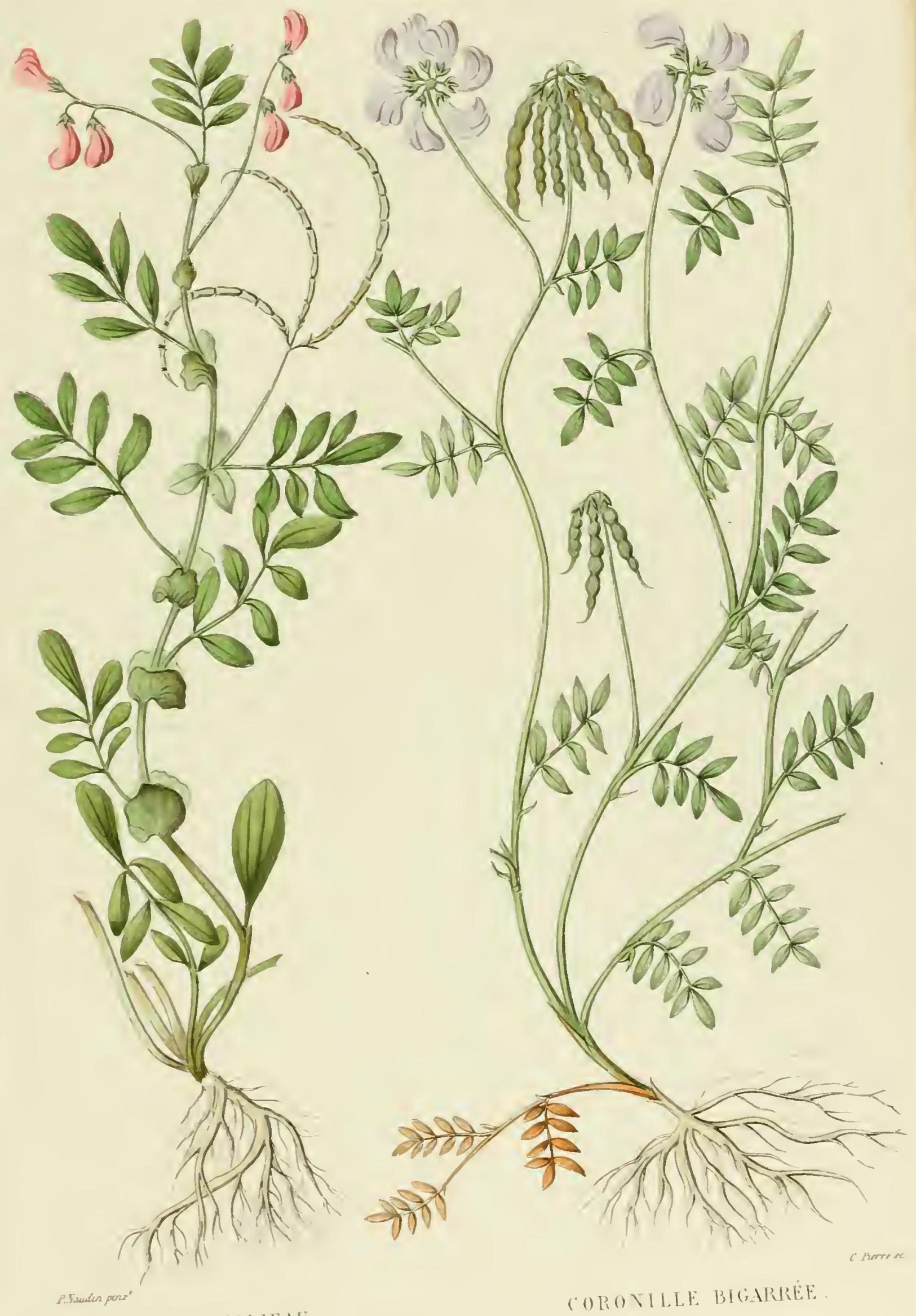




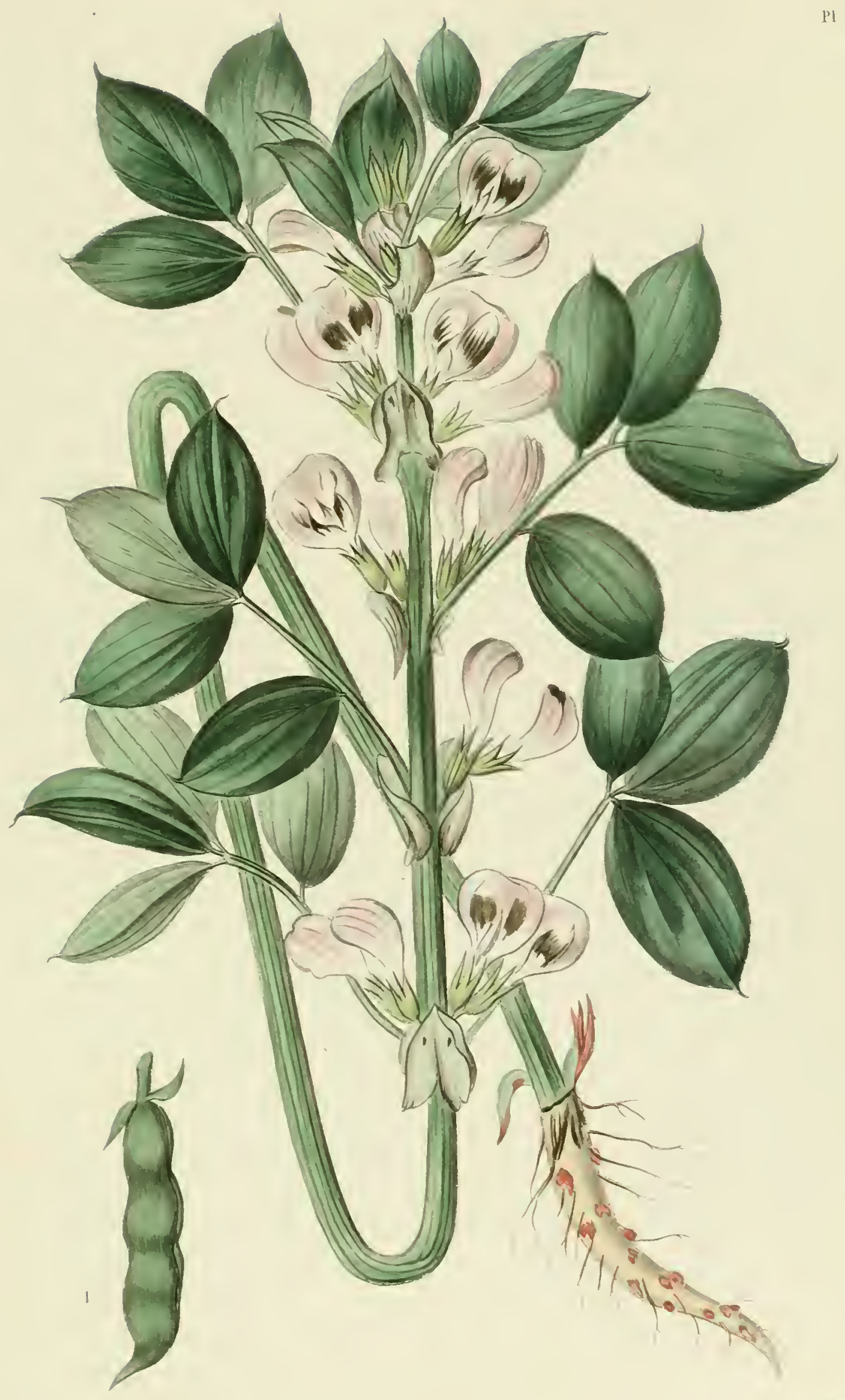

FEYF IUES MARUS. 



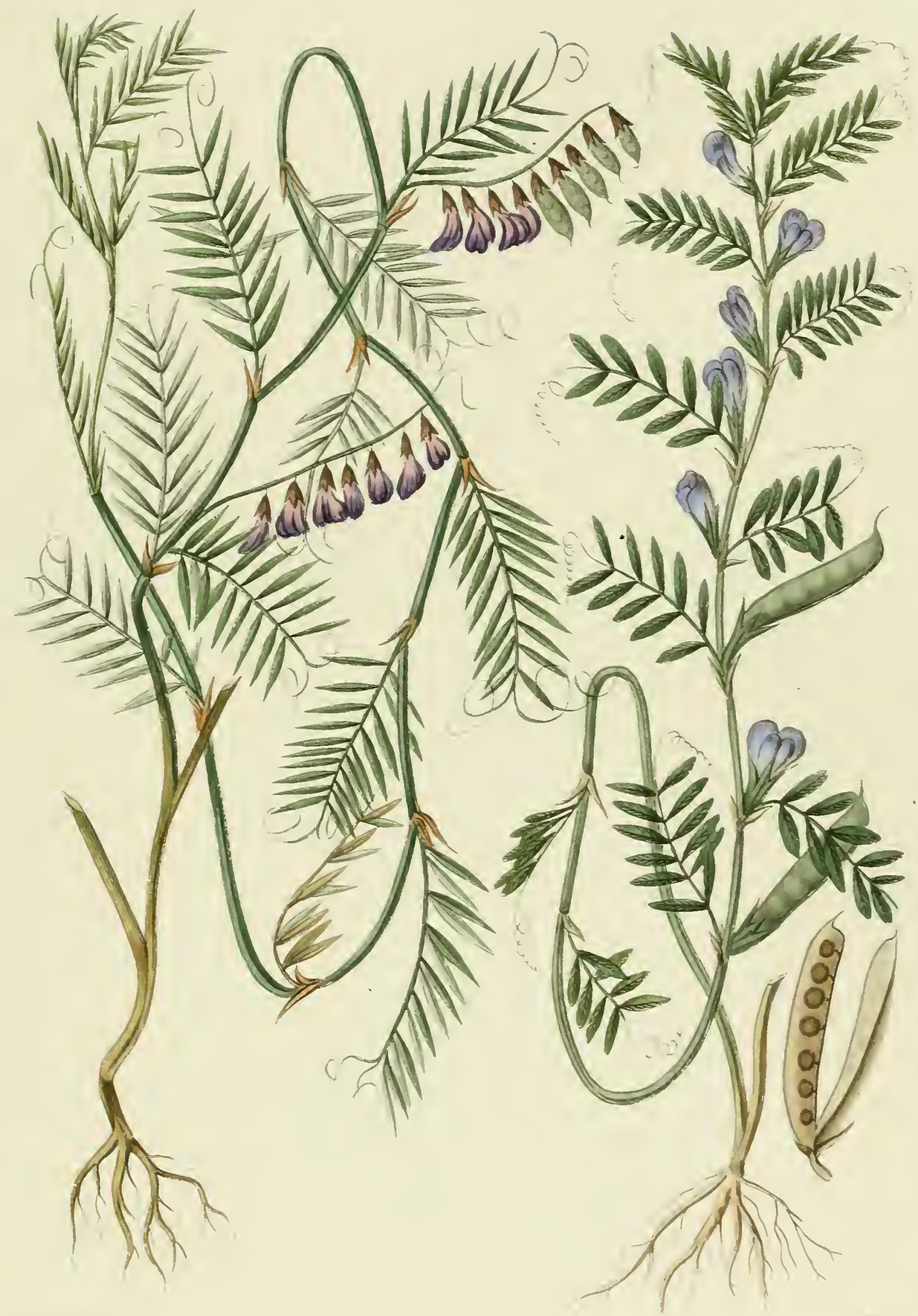




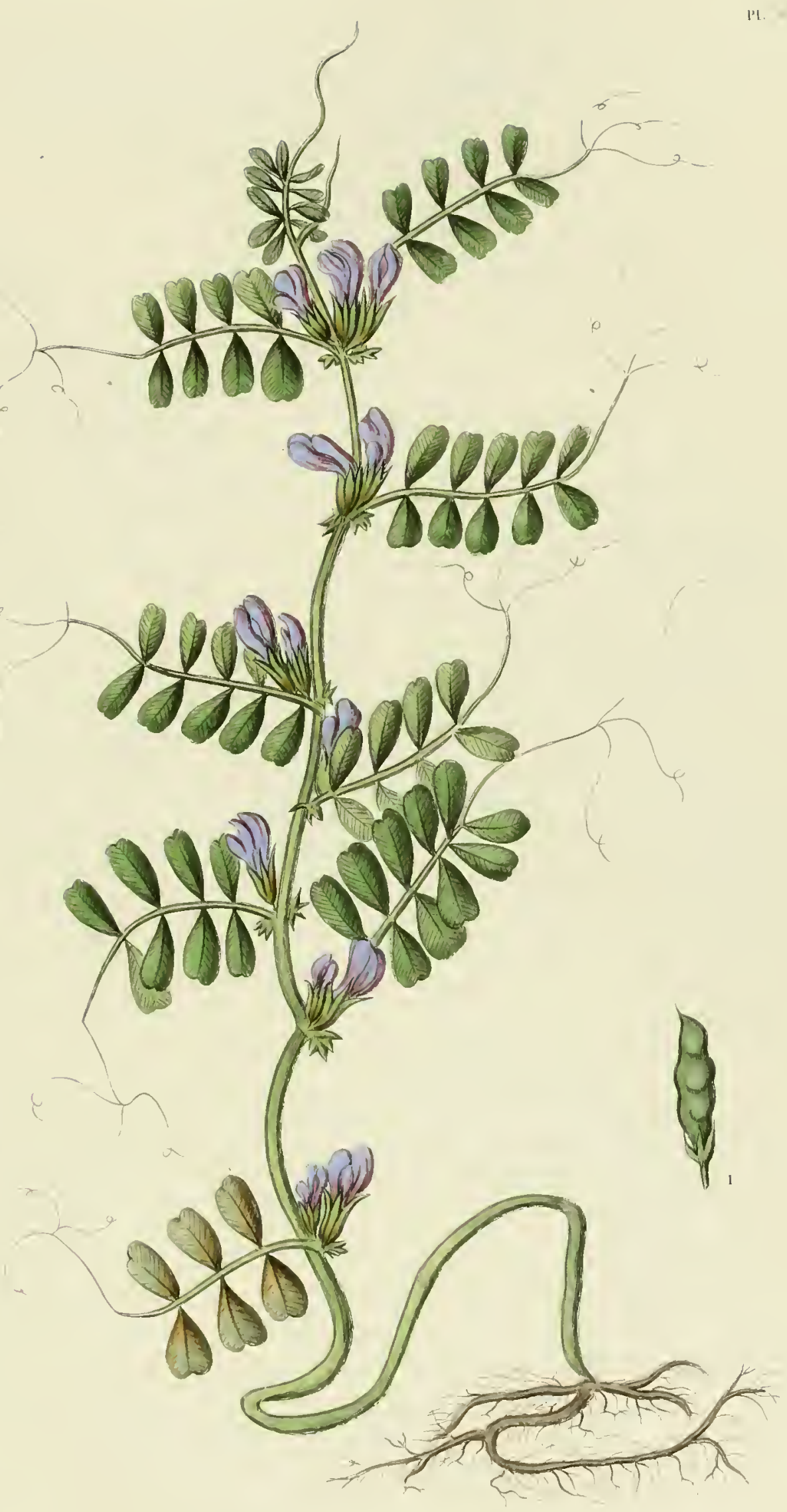





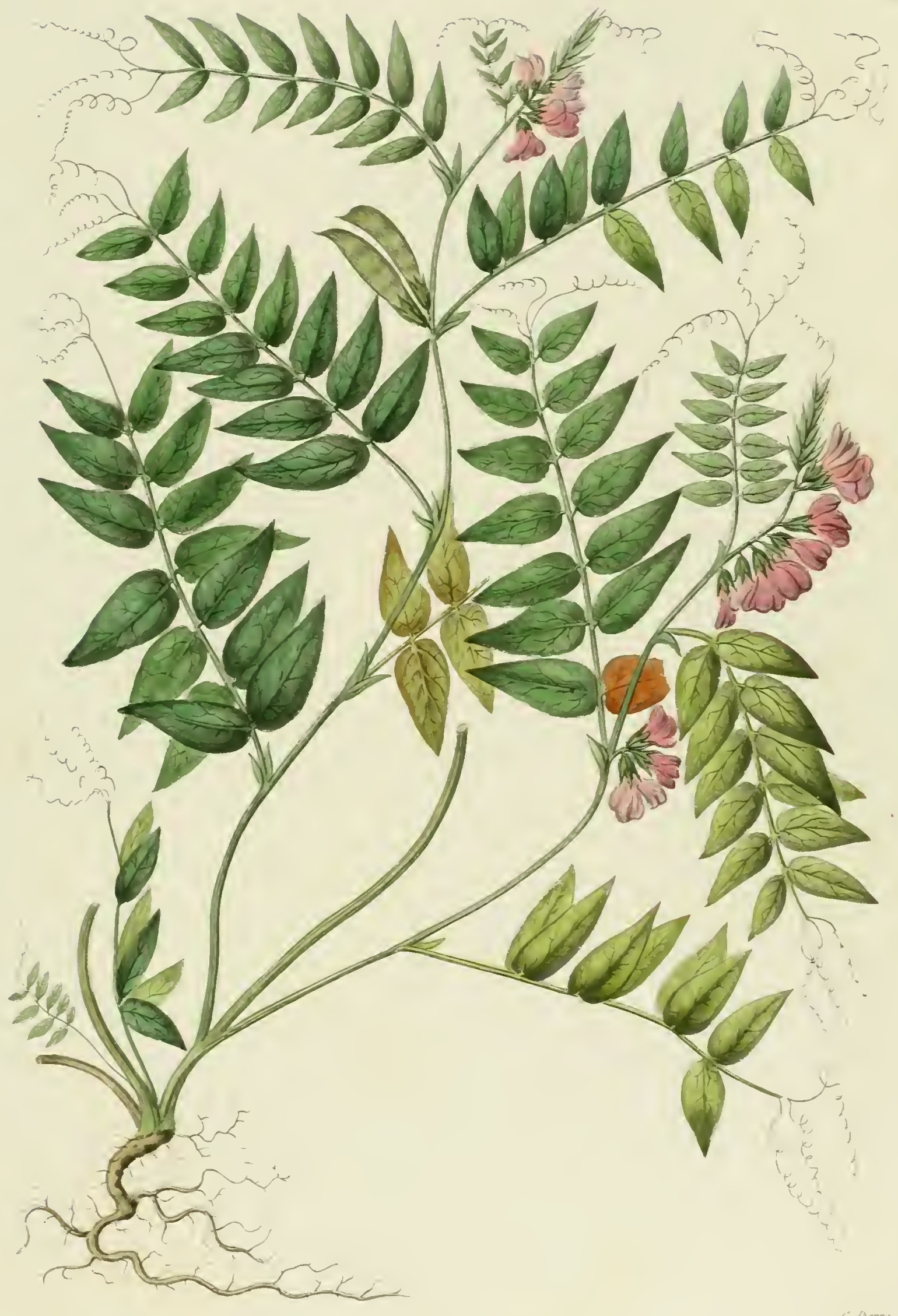

TFACE DES HAIES 

"Wu

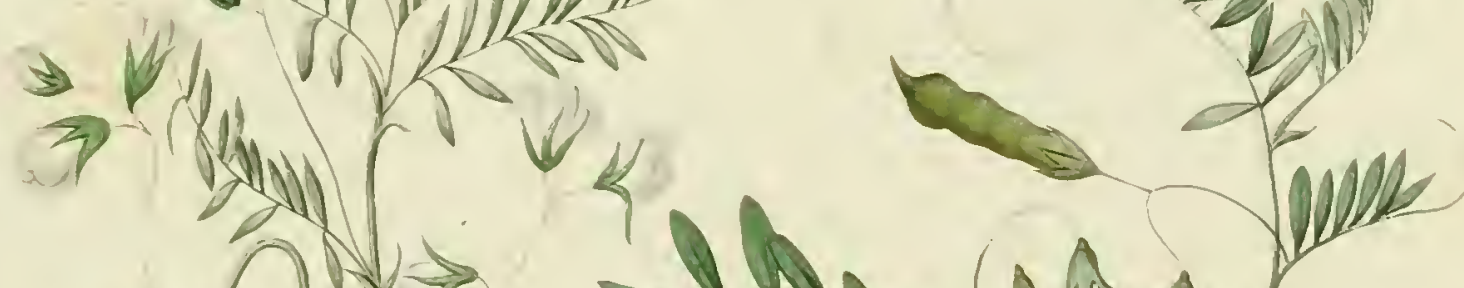

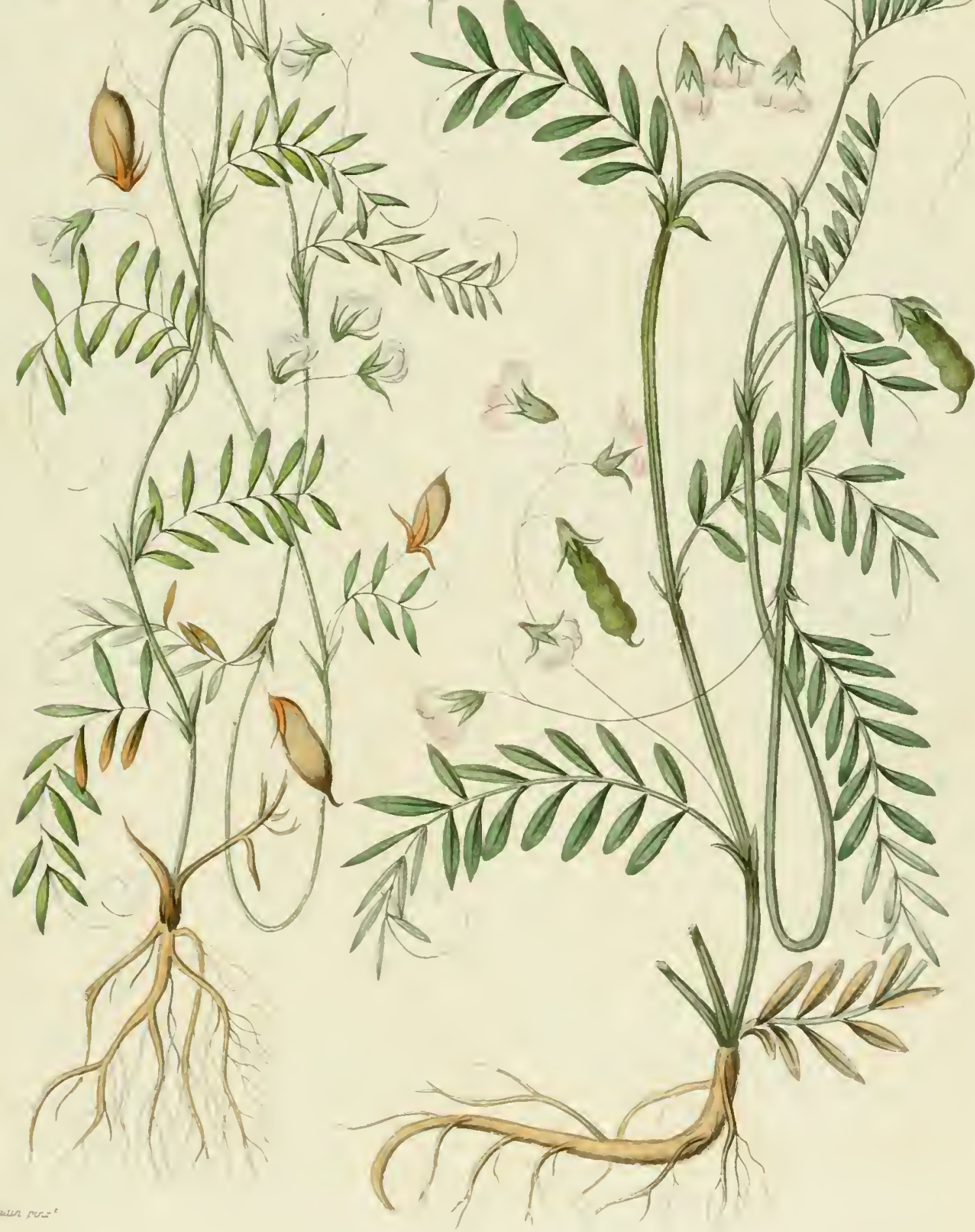





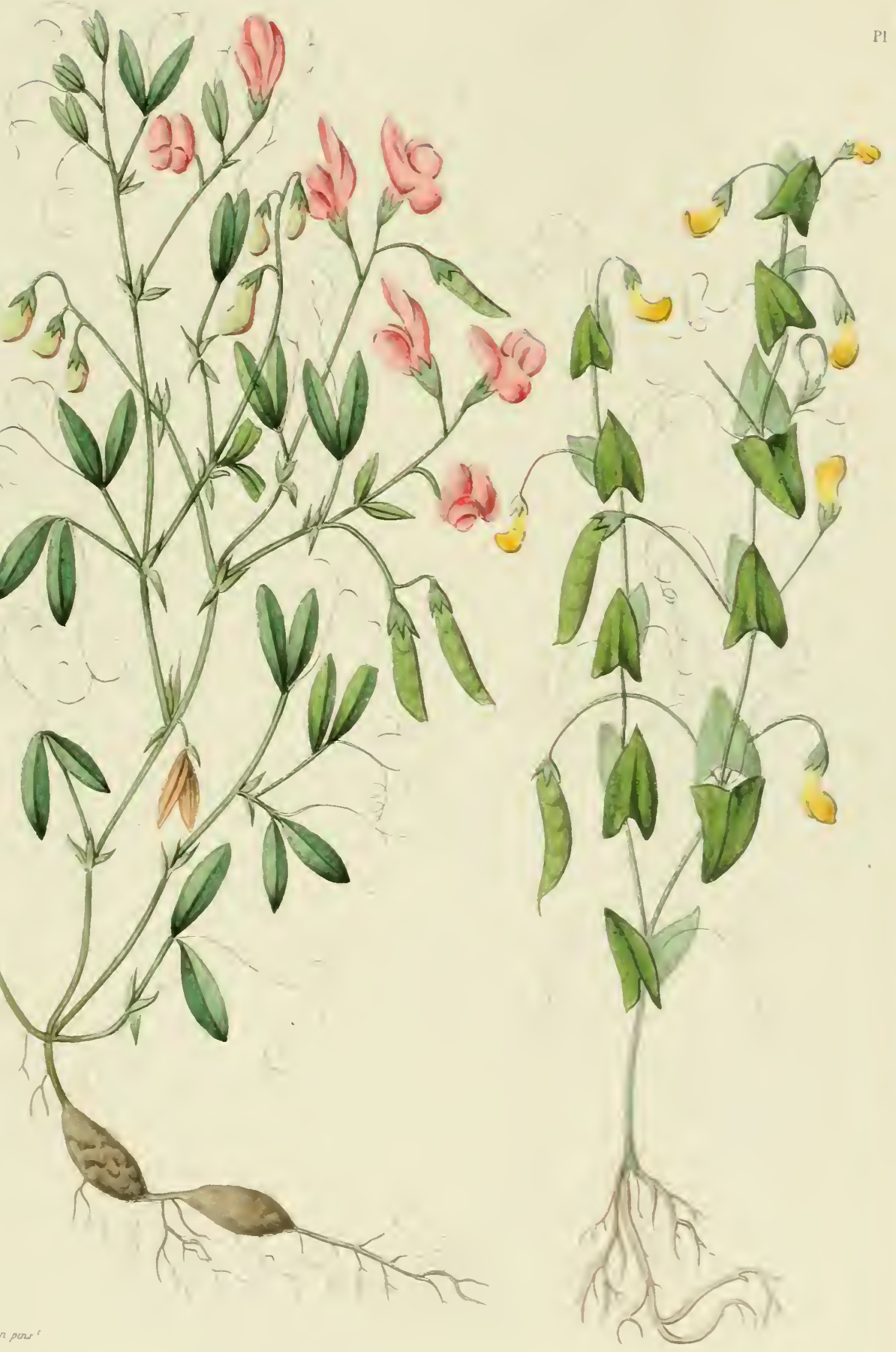





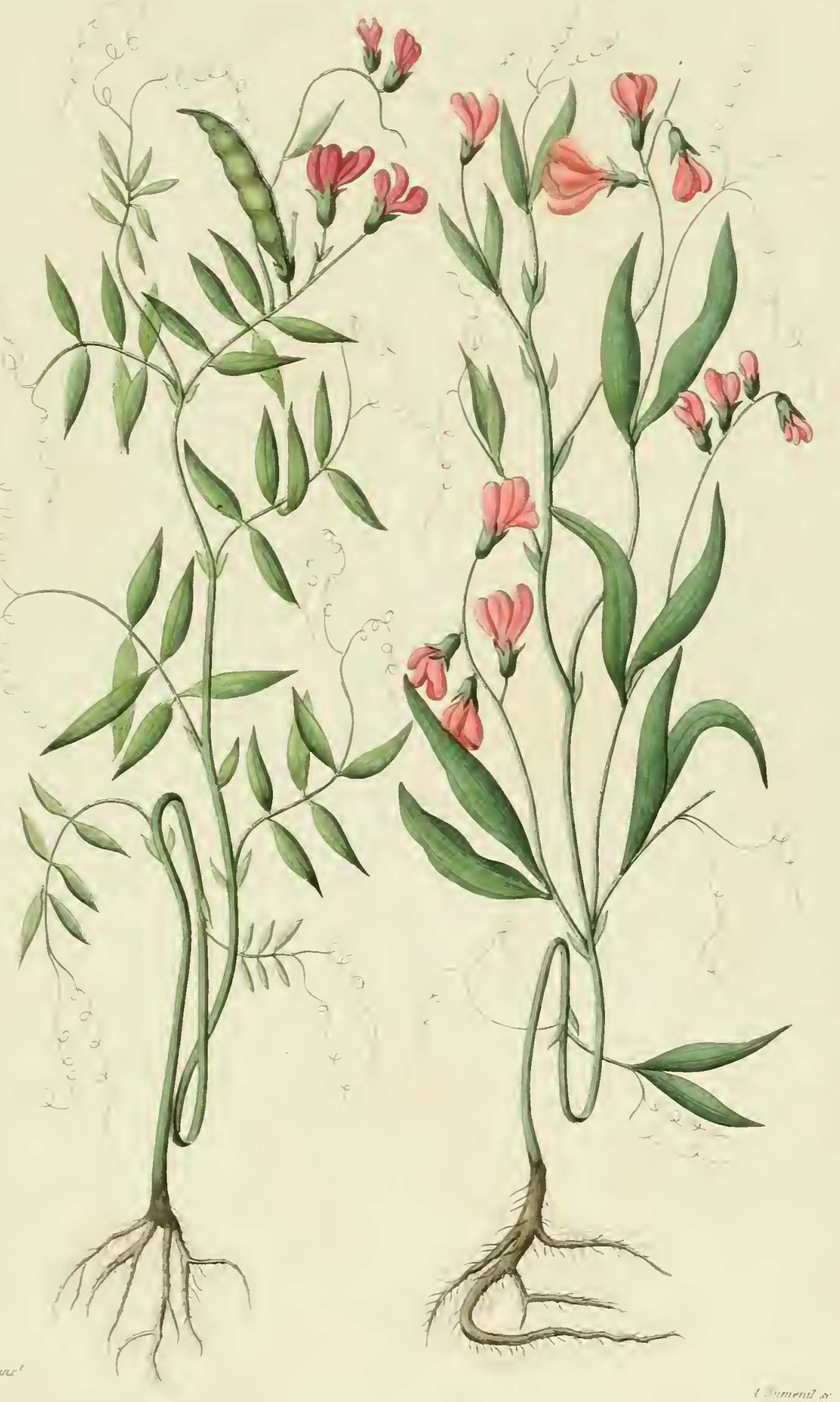

(HES CF, ULTIFE 



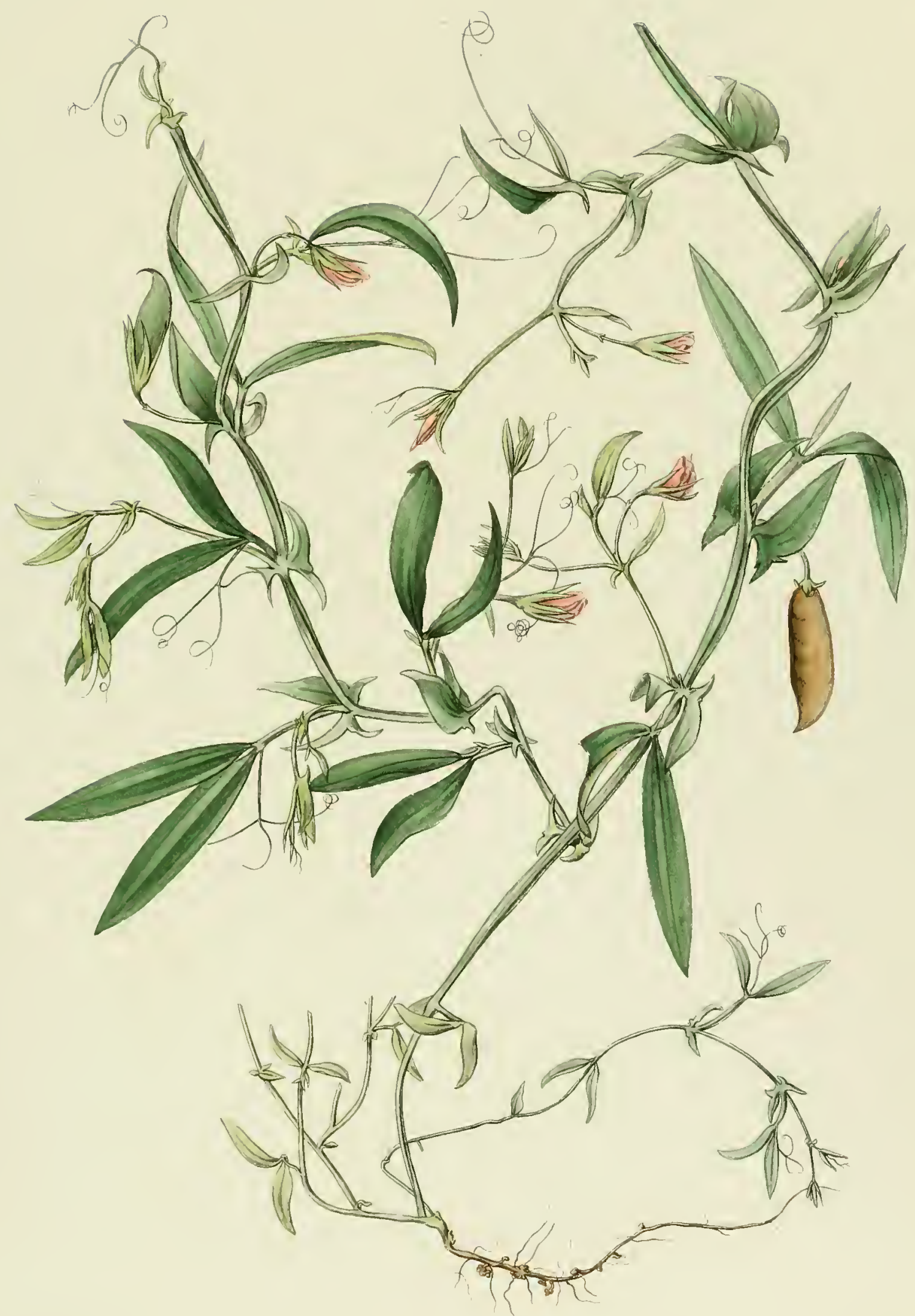





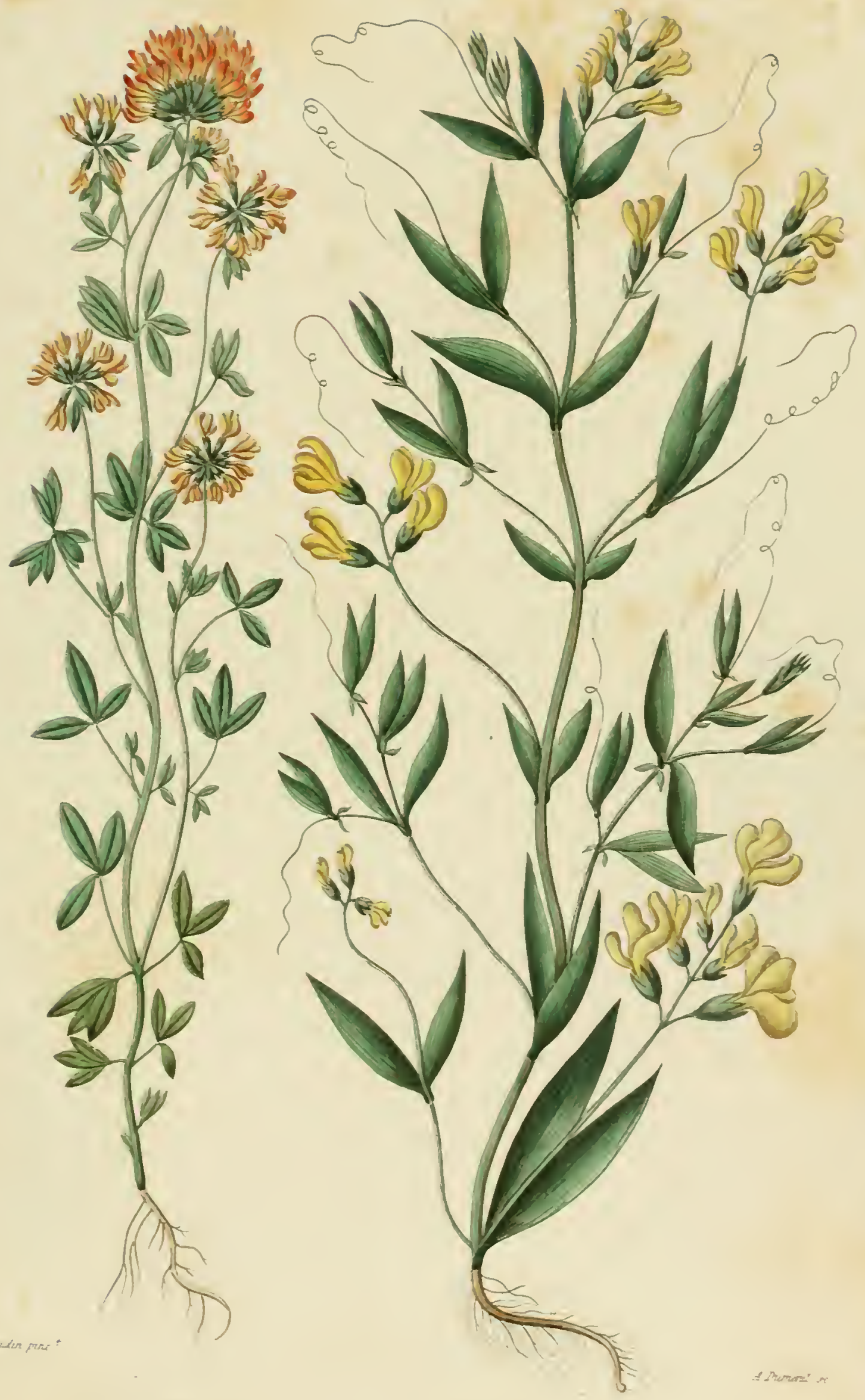





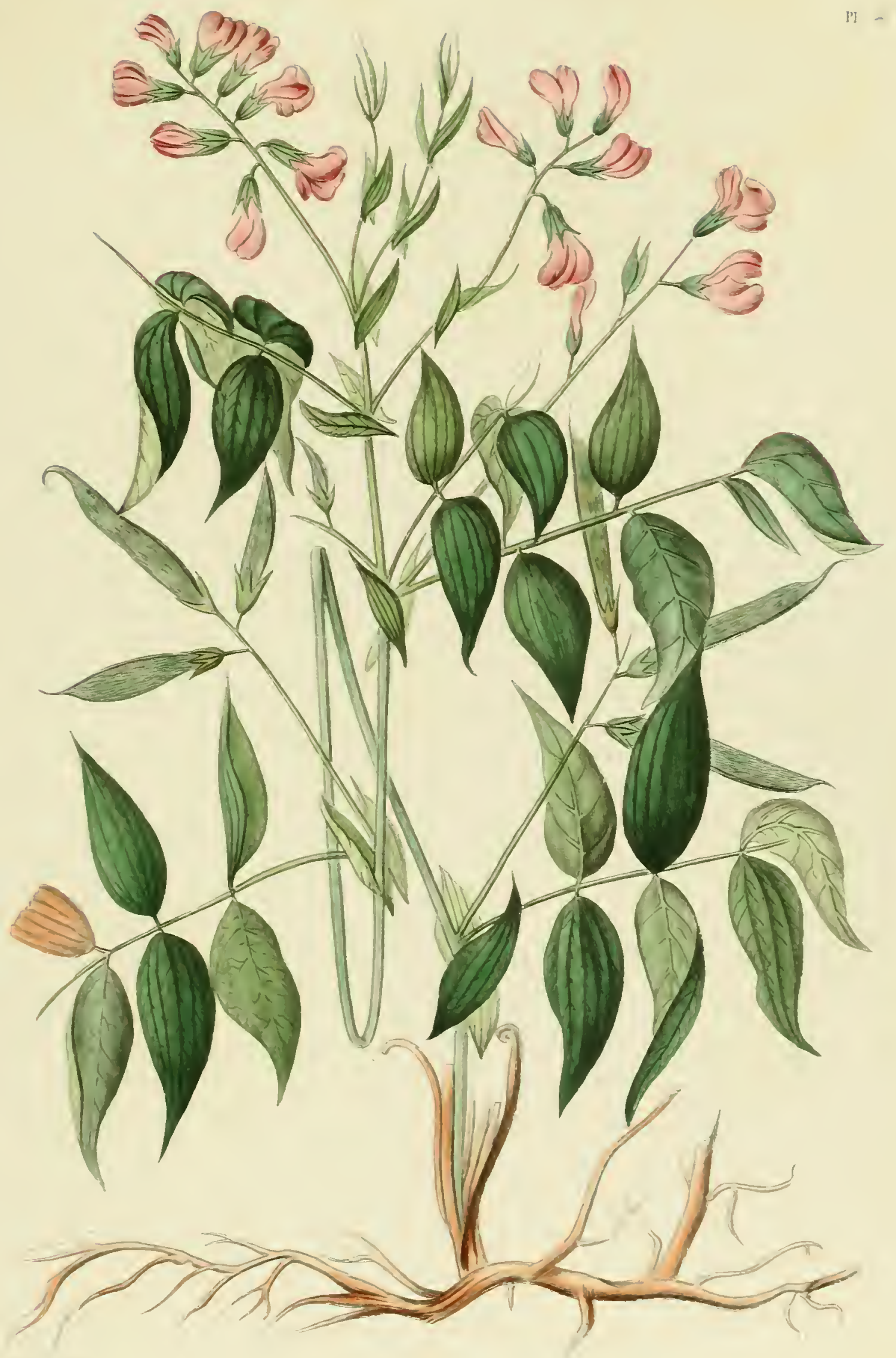

OROBF PRINTIINIER 



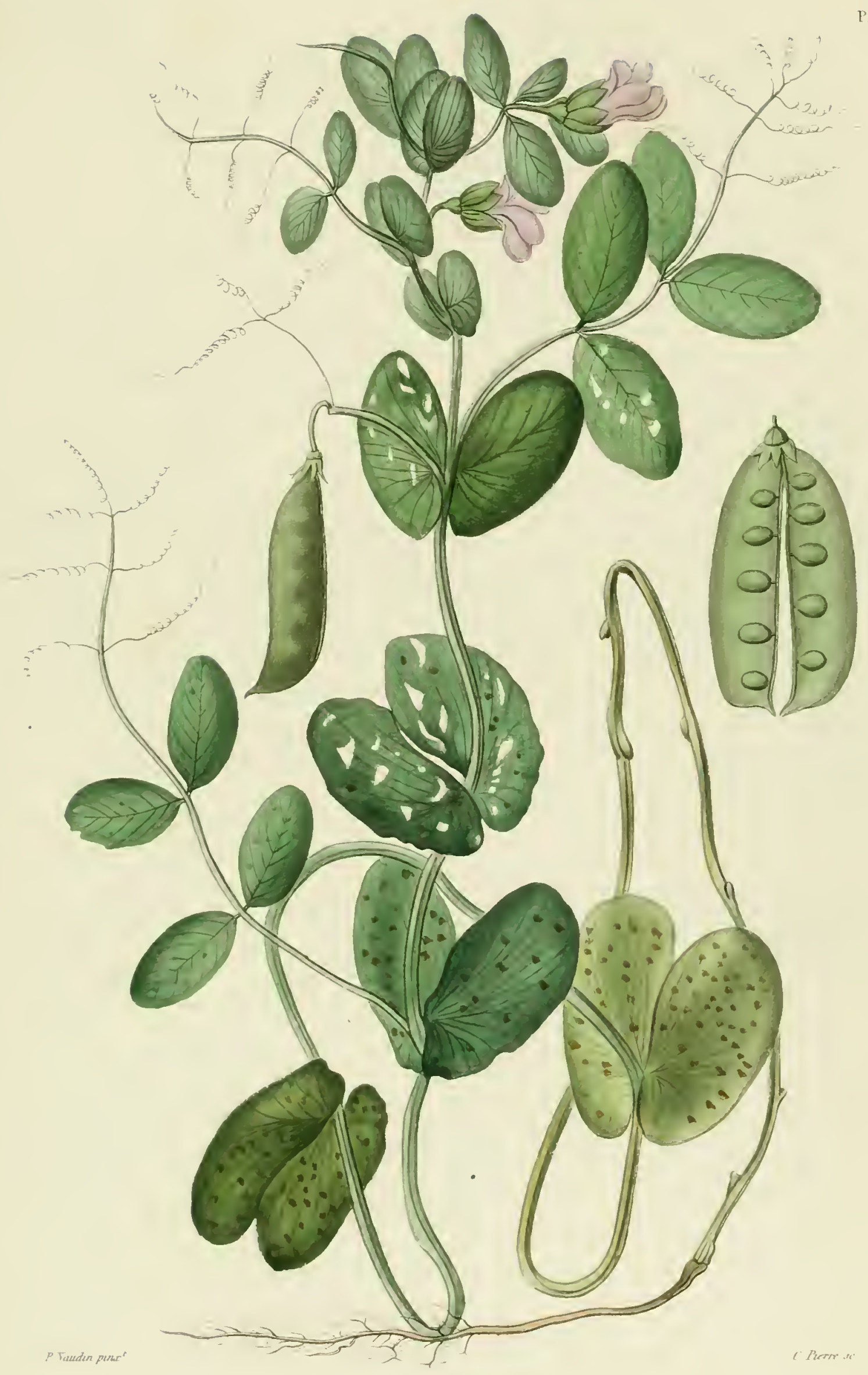

POIS DES (OHAYPS. 



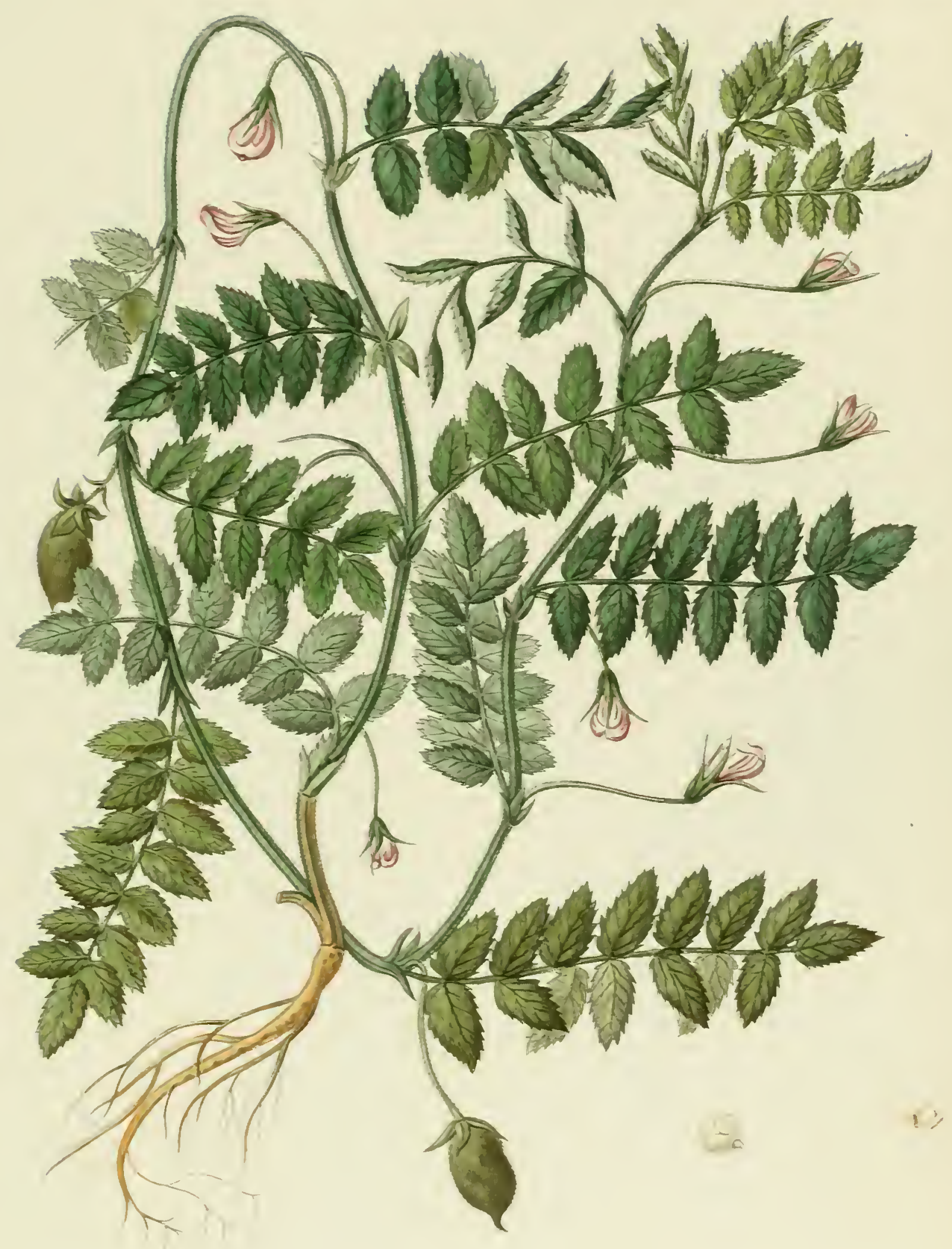





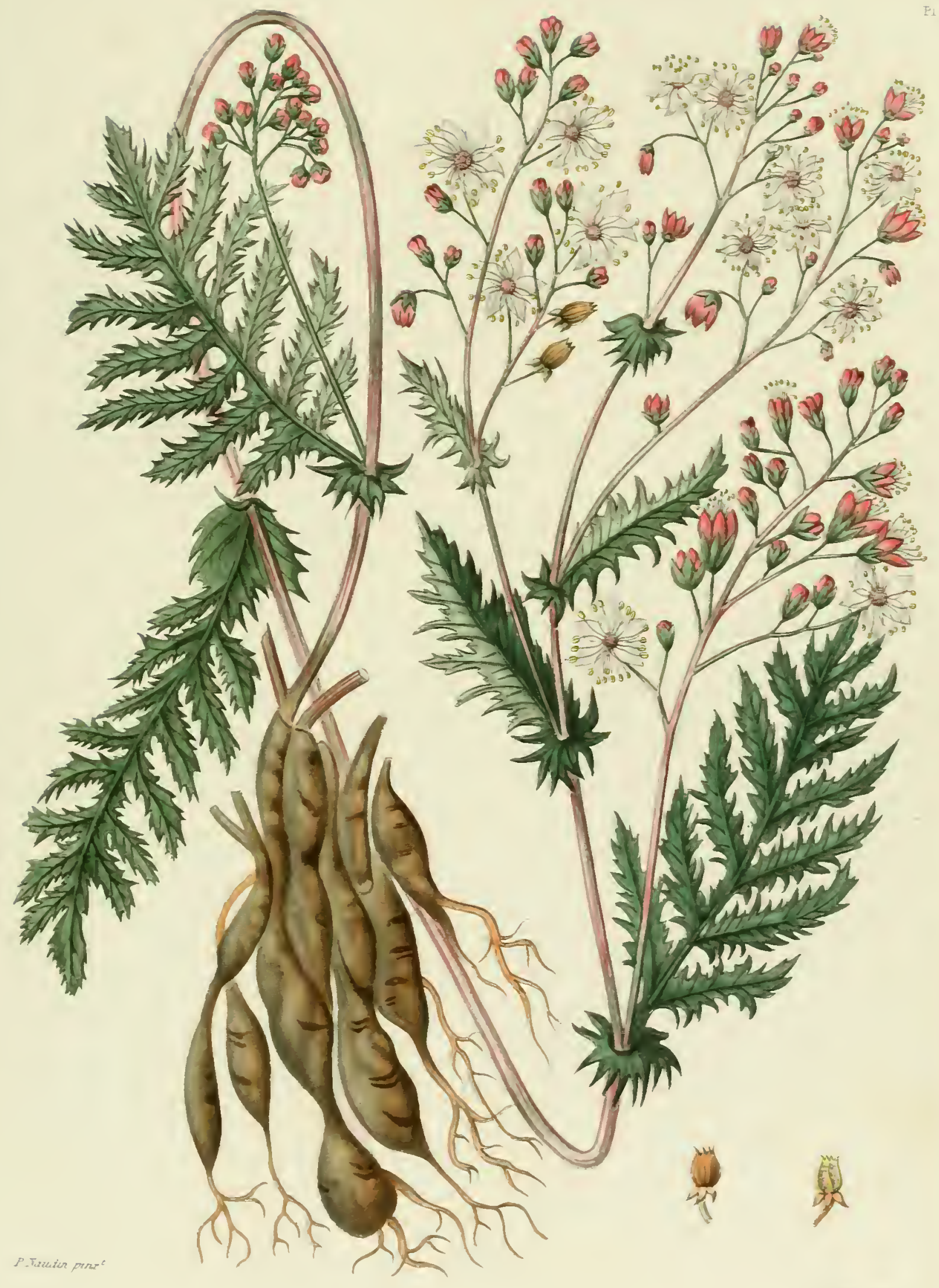

FI I. I PE I D [ I. E 



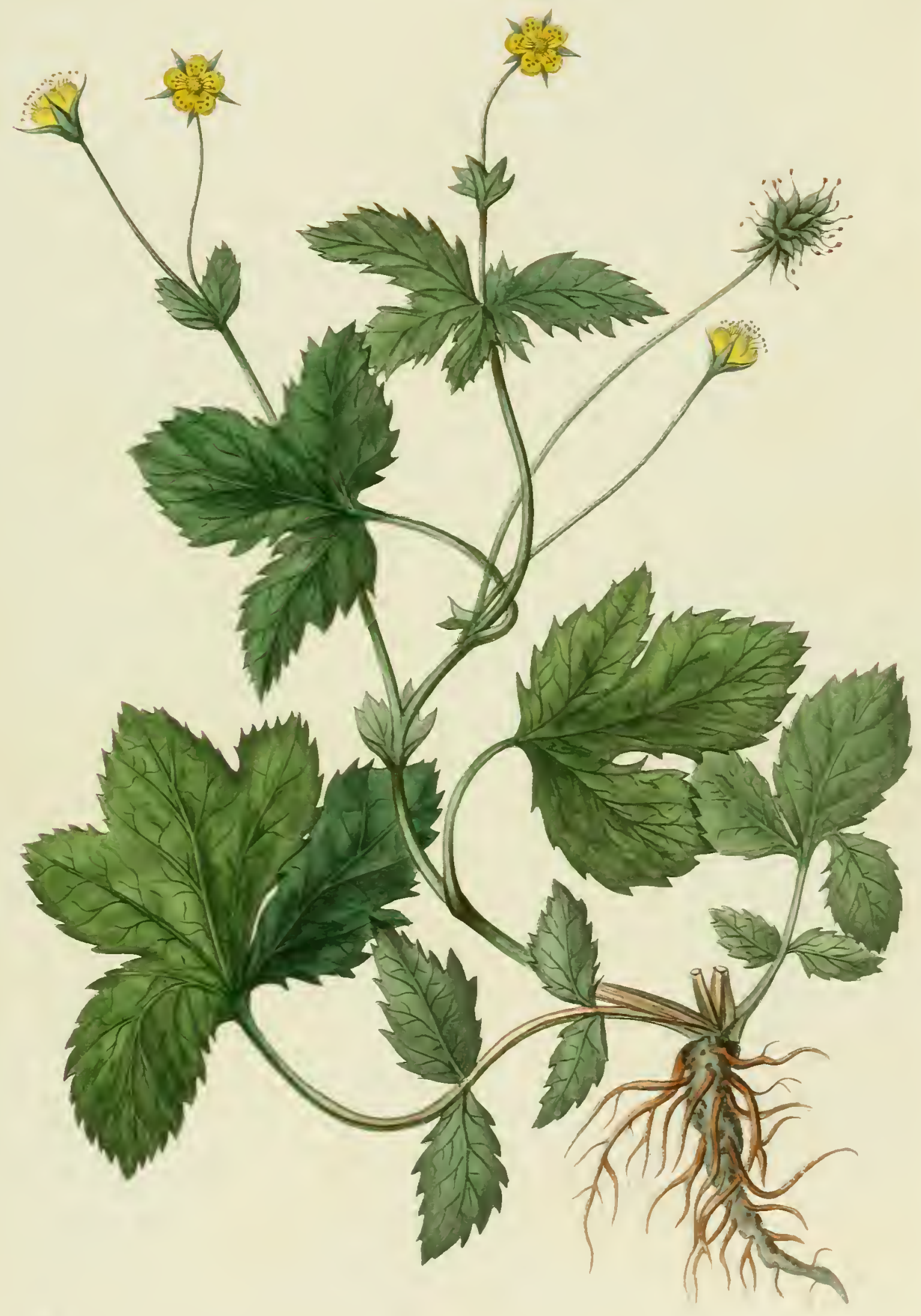





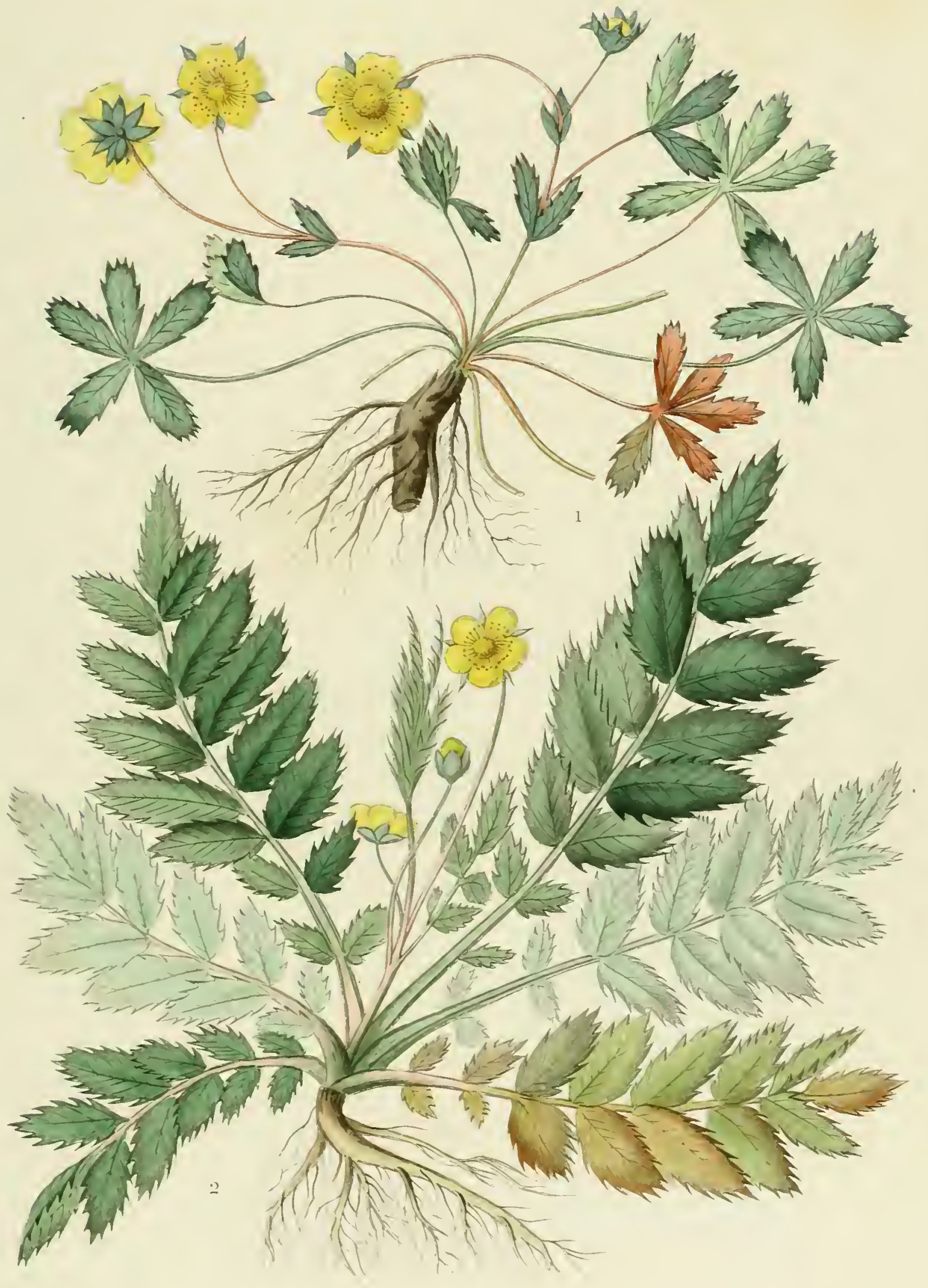

1 I'OTEXTILLE, 2. ANSERISE ARGENTINE 



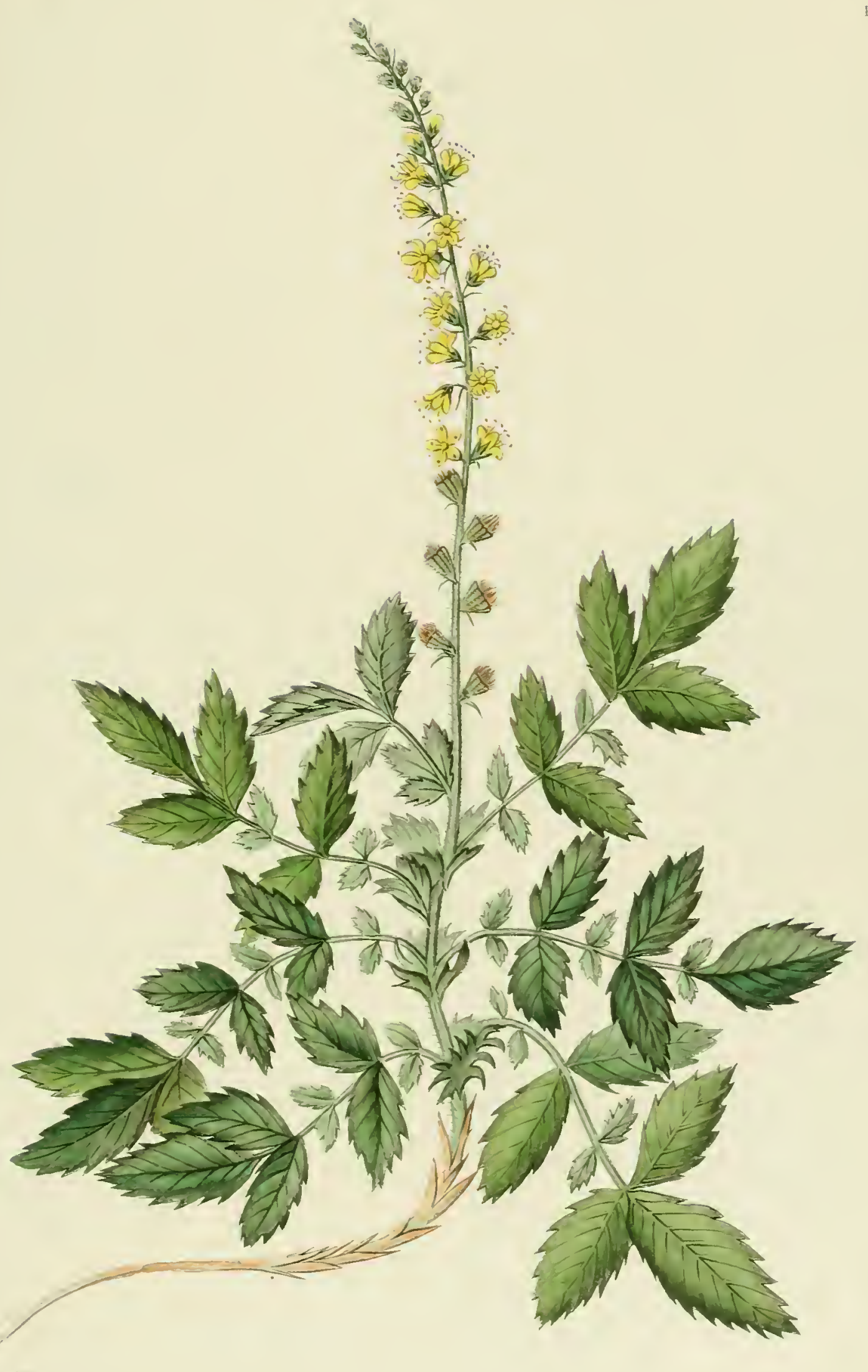





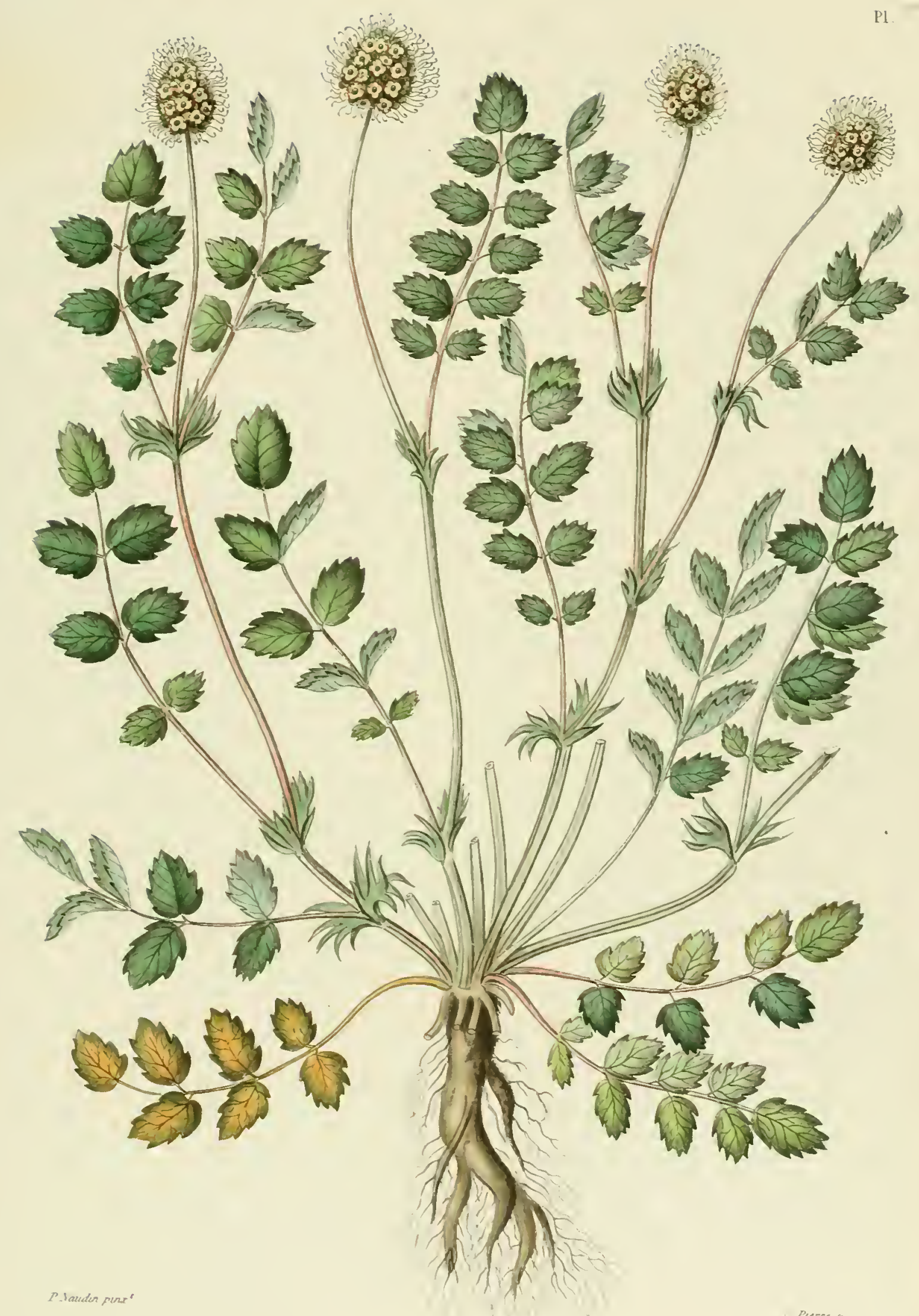




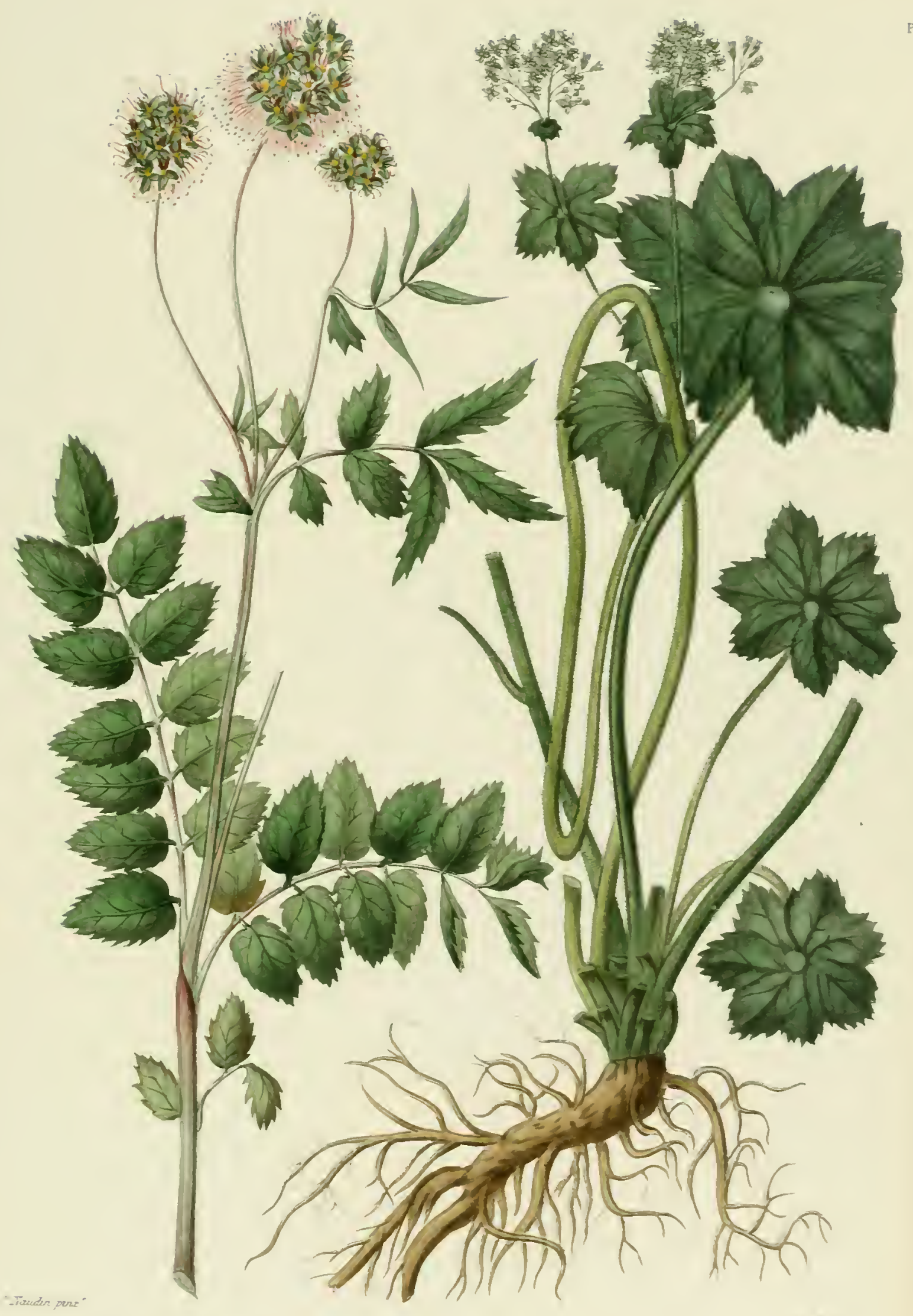

¿AVGTSORBE, OFEICIMILF. 



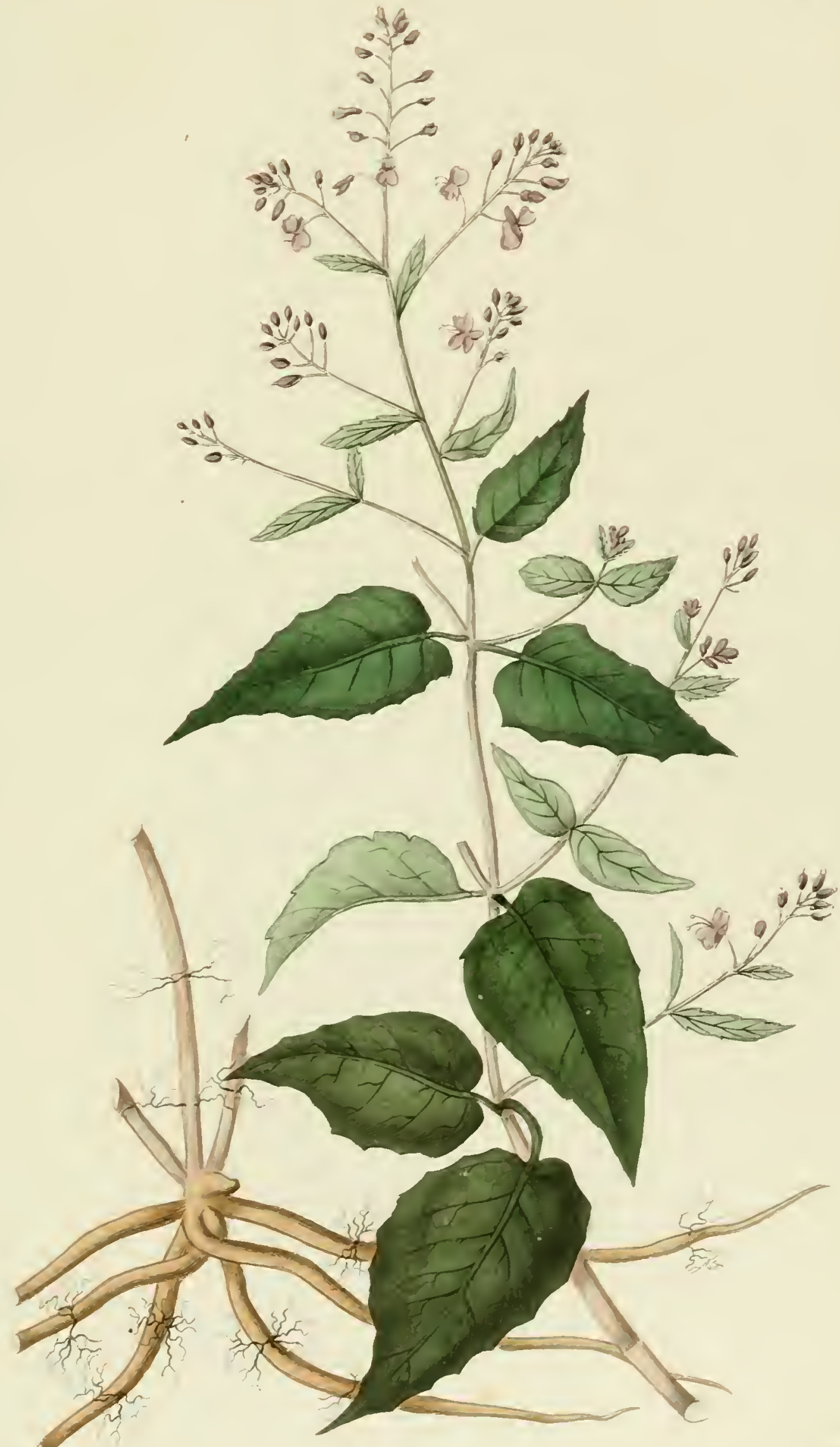





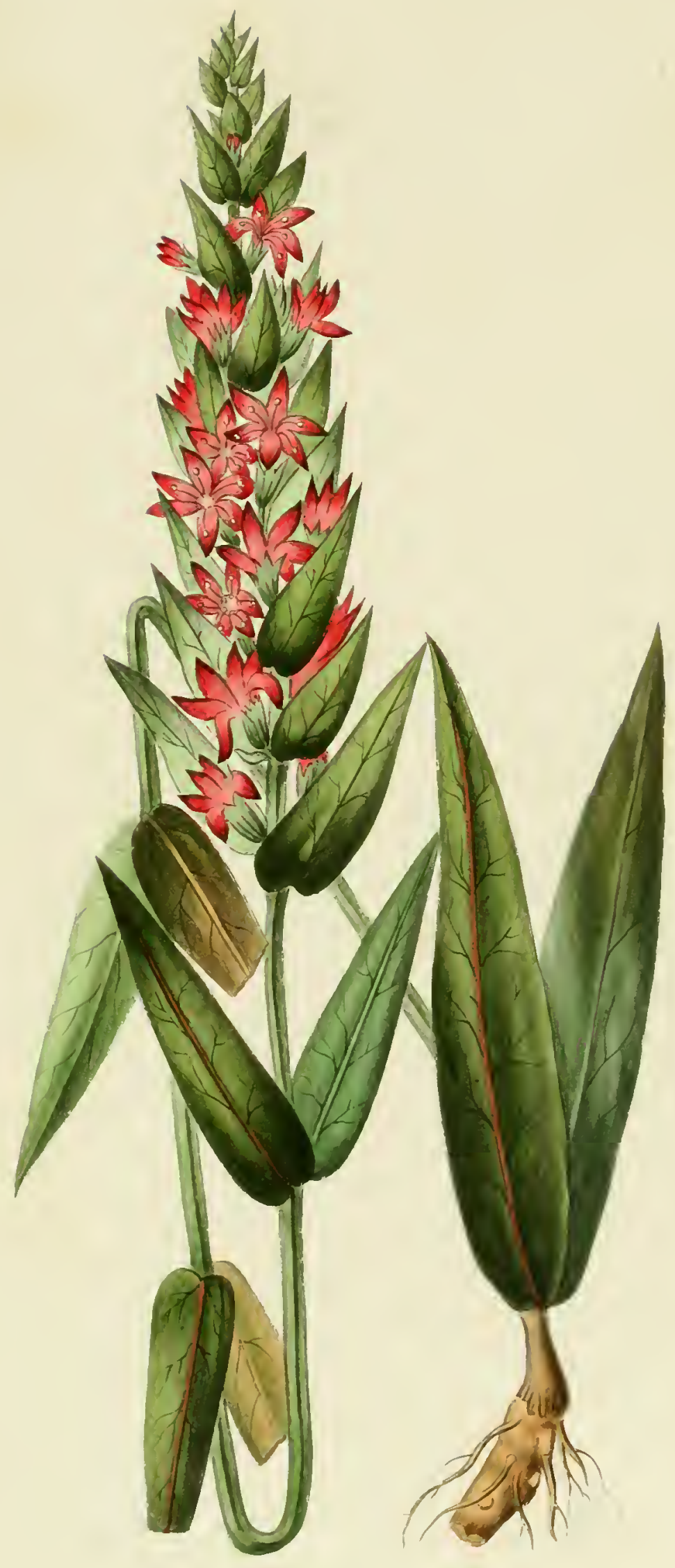





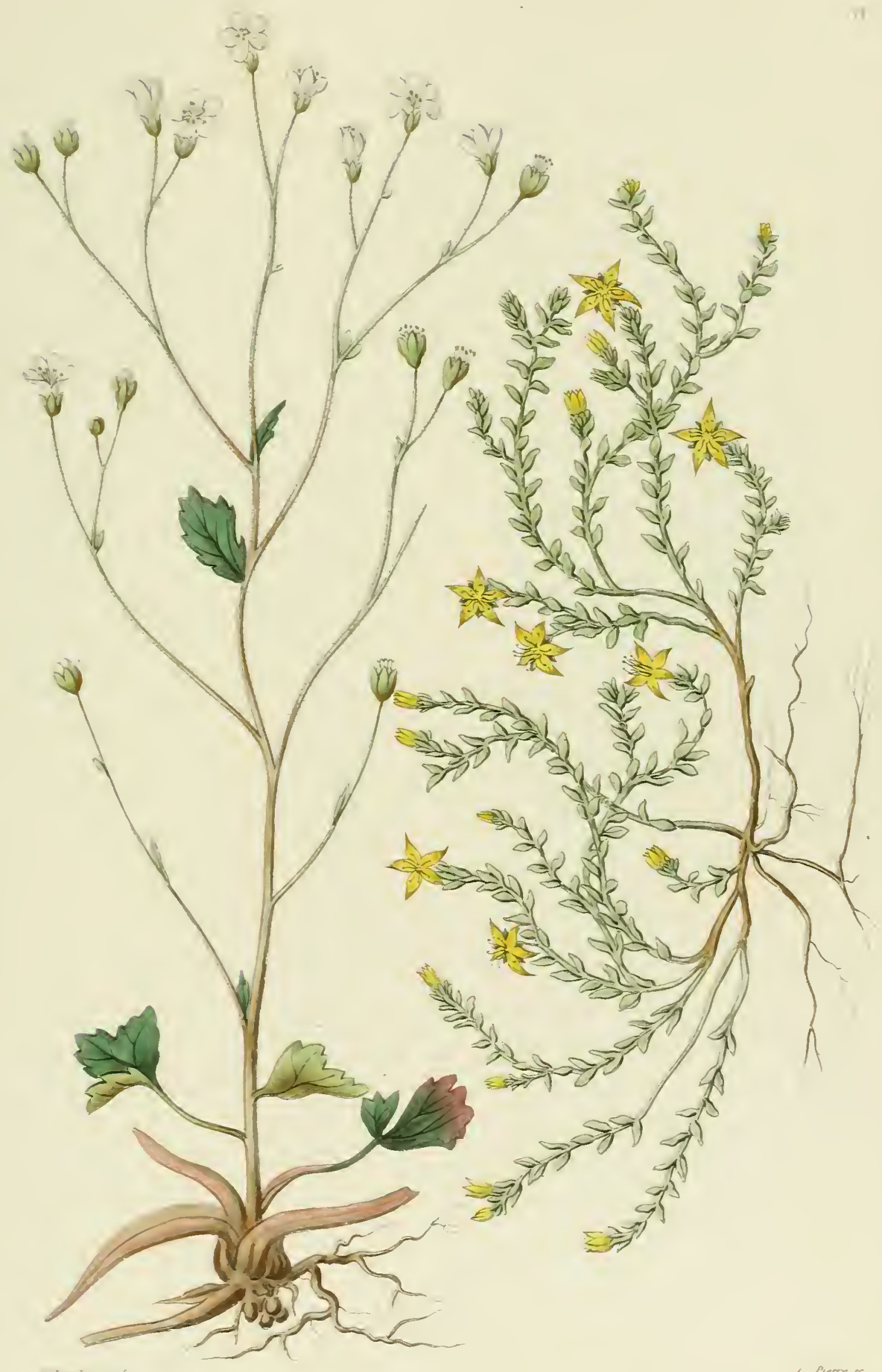





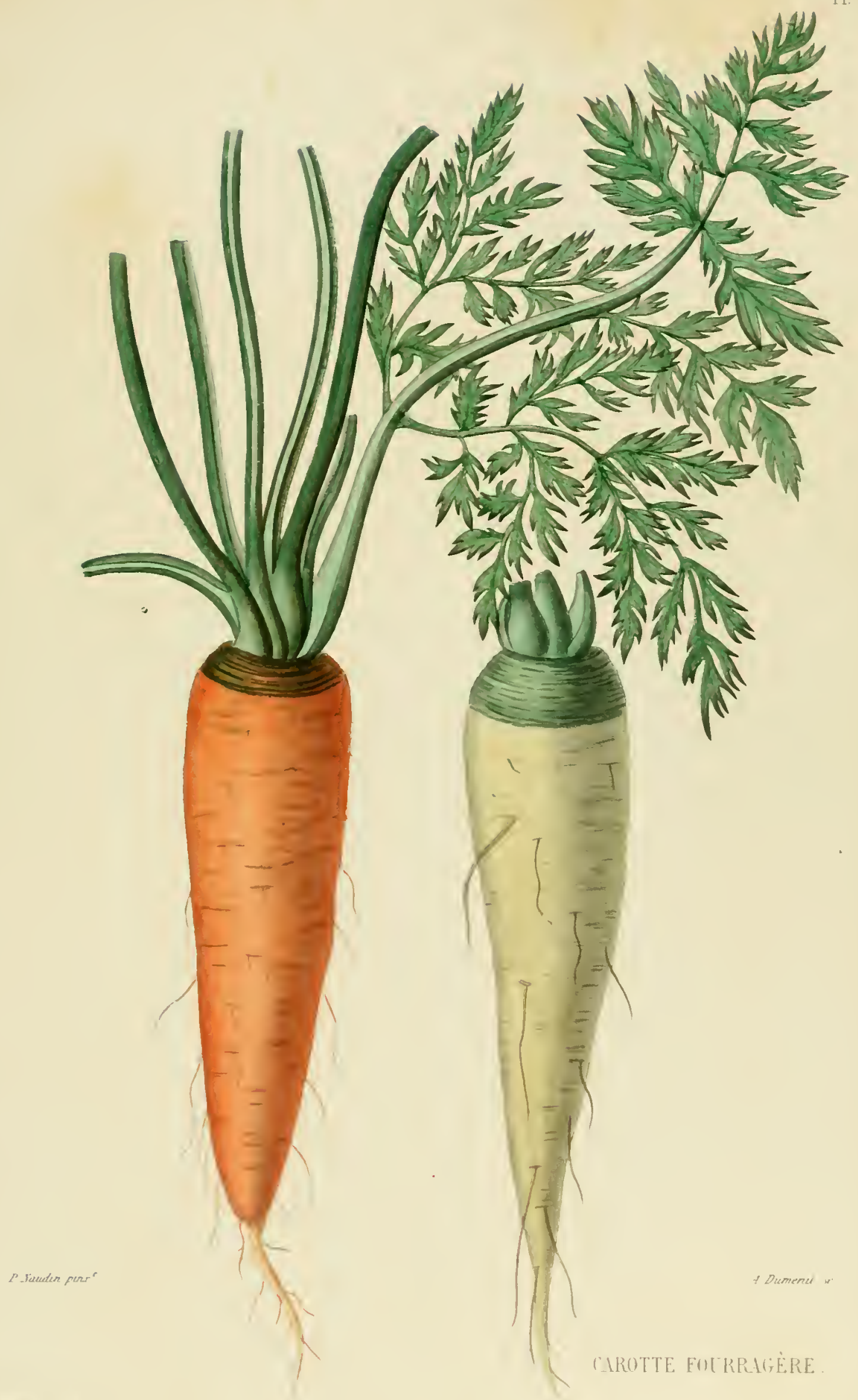




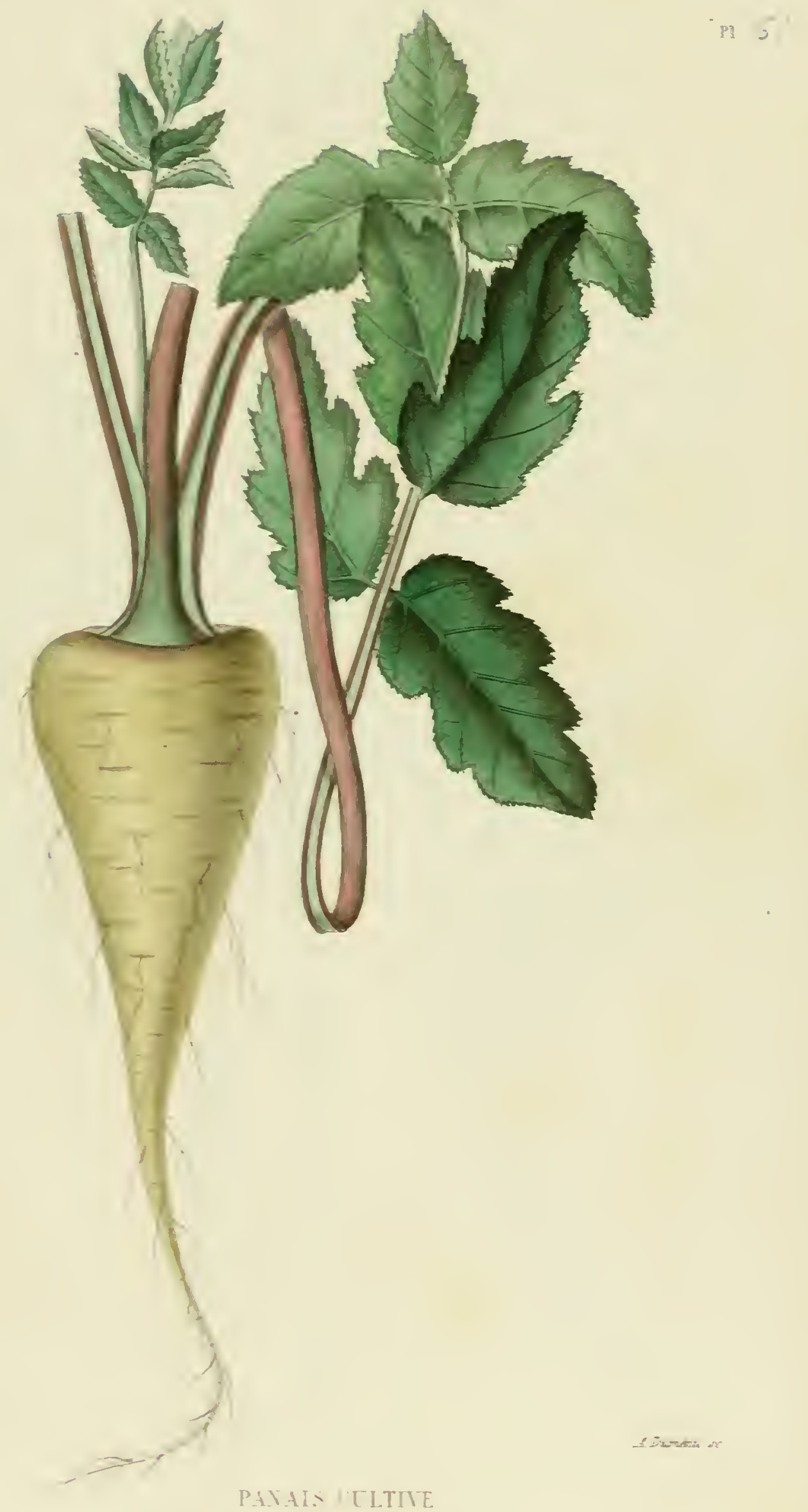

PAIAIS ILTIEE 



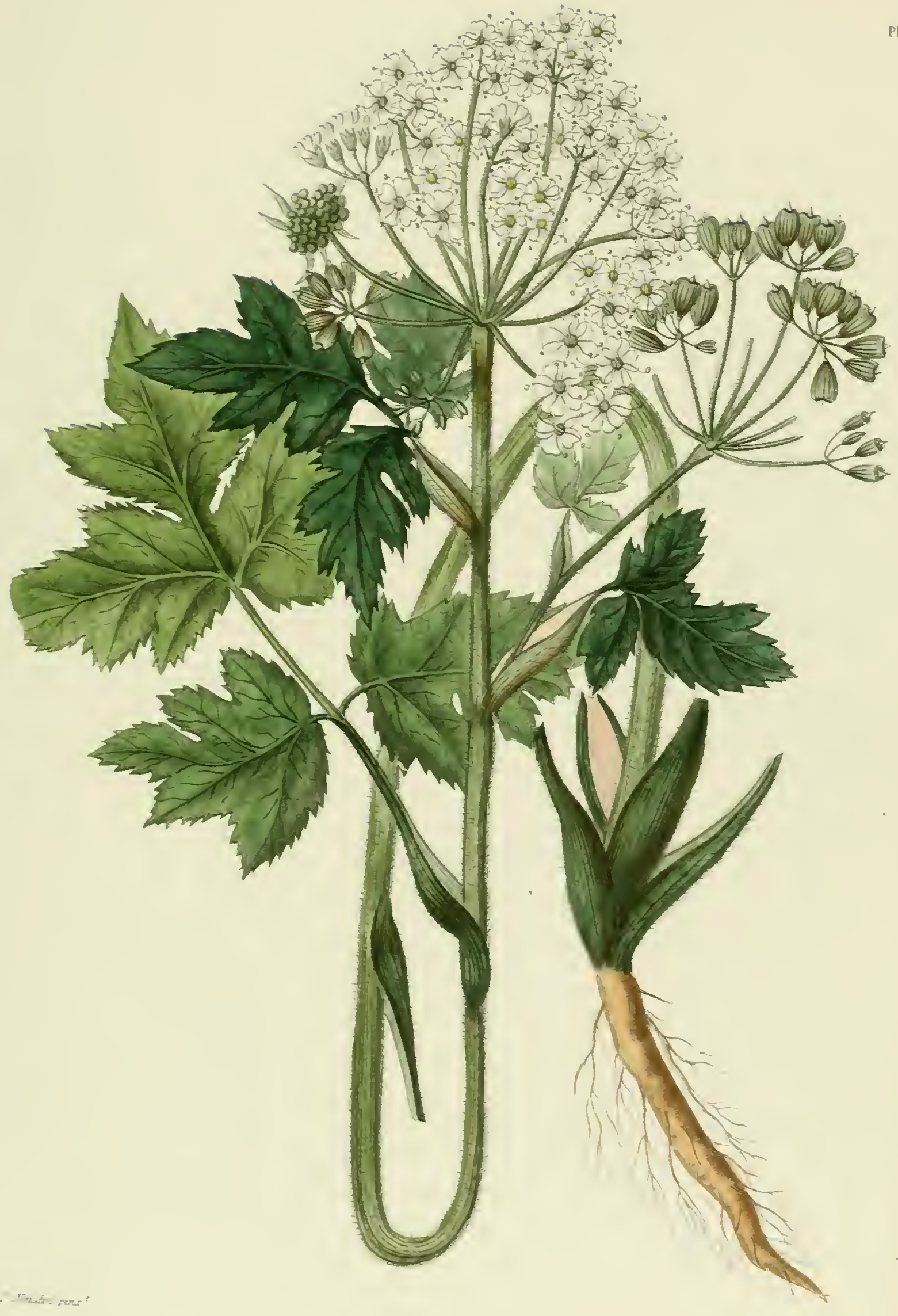

B F. RIF 



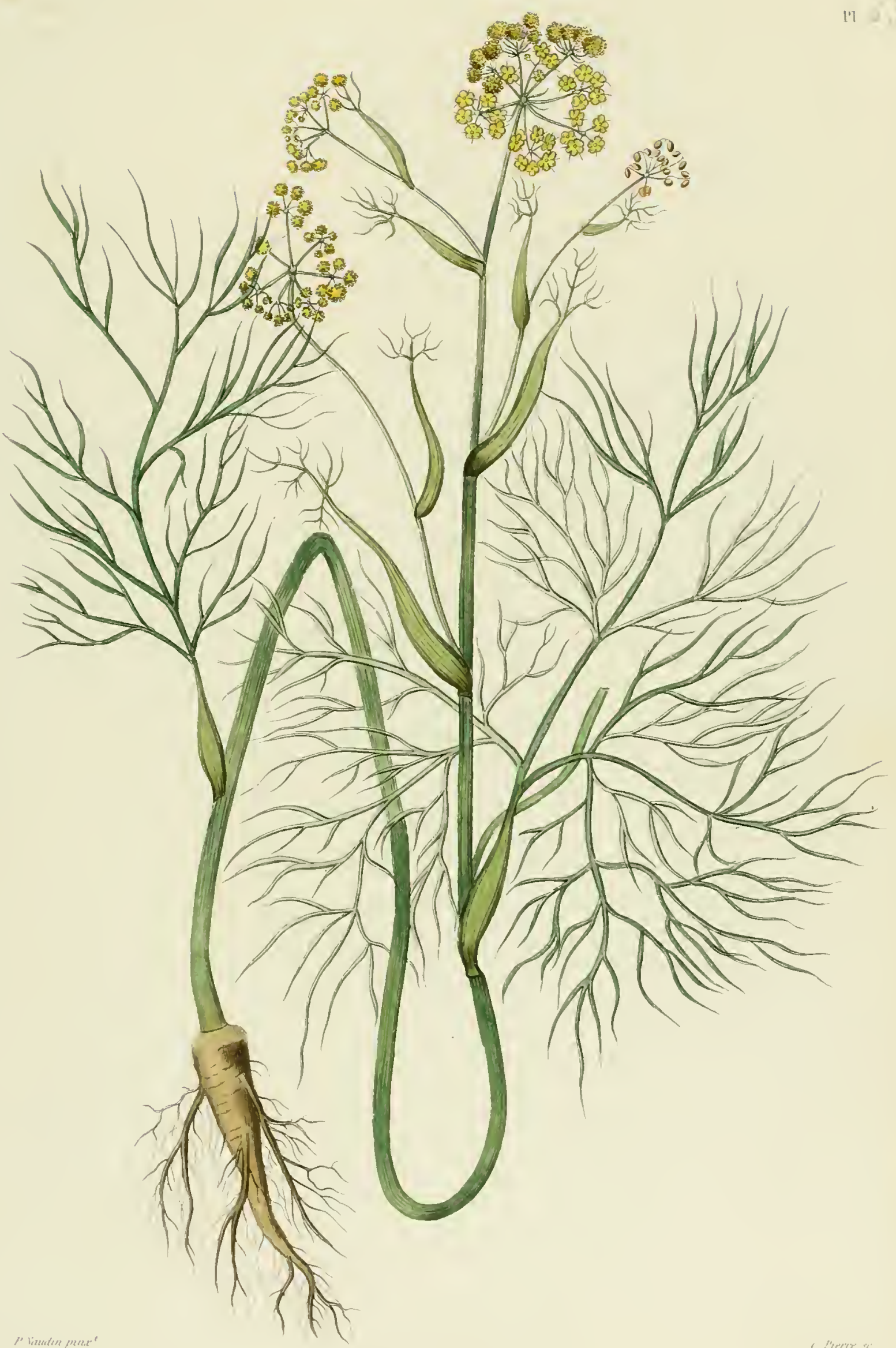





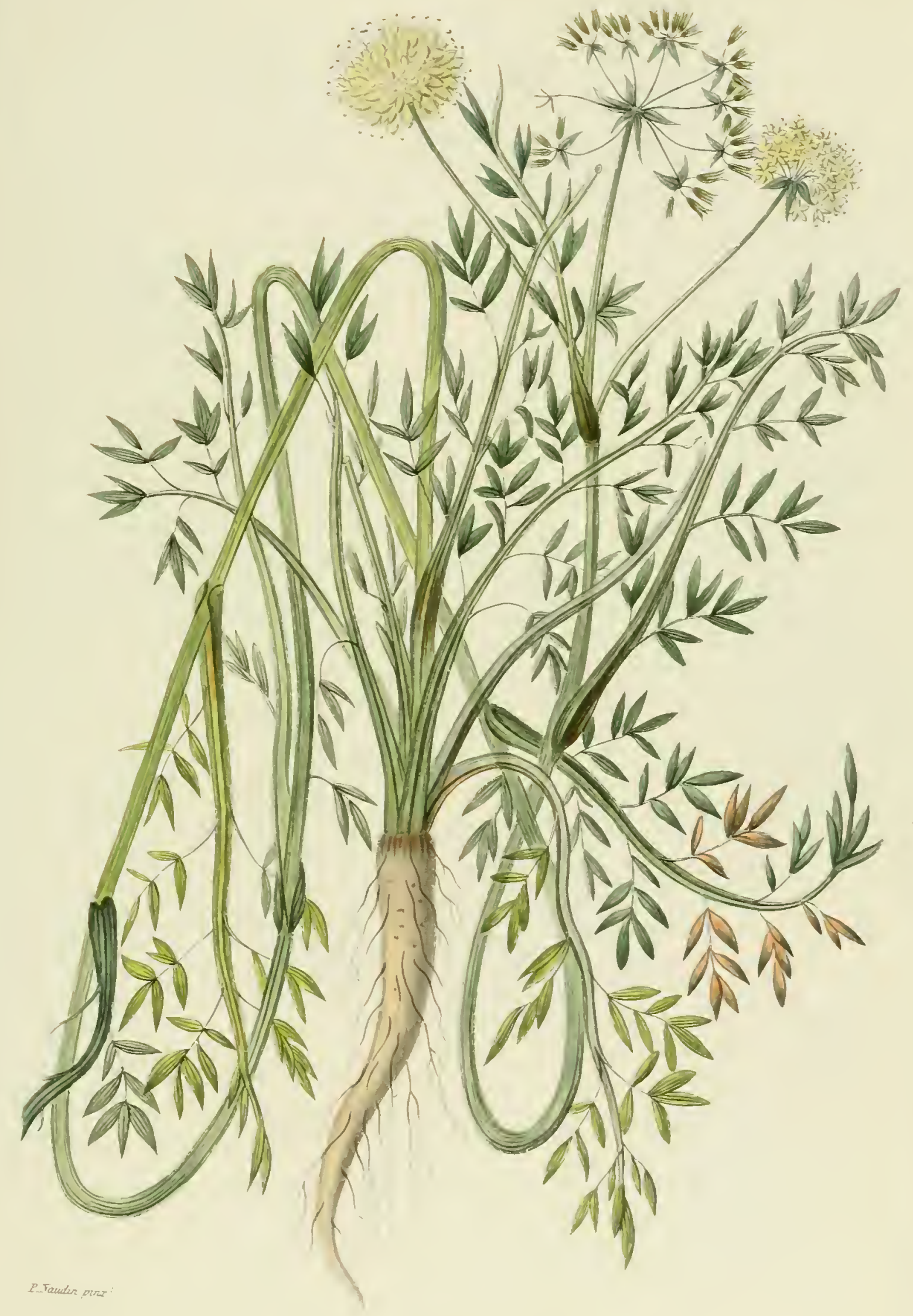





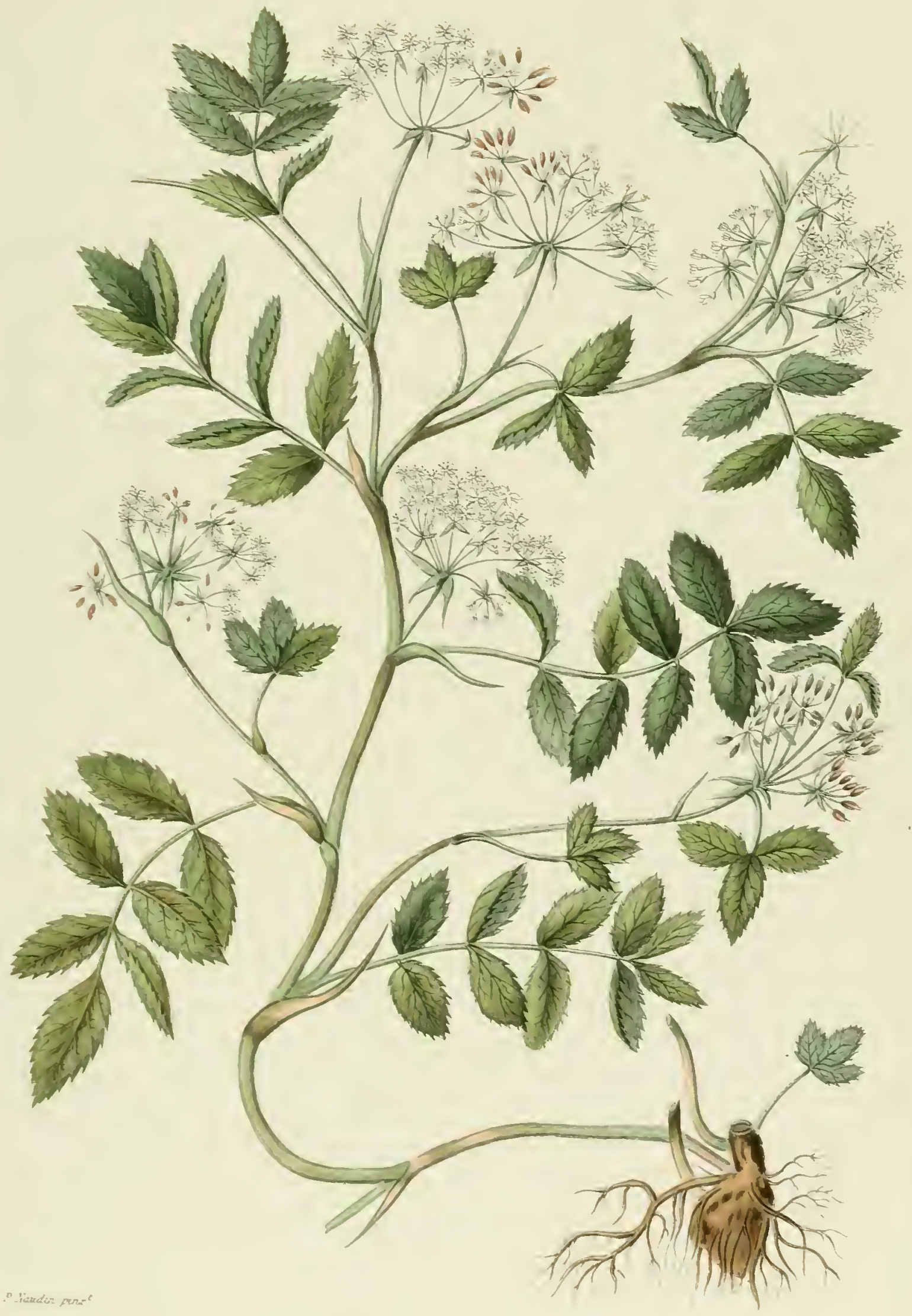

BERLE A LARGES FEULLES 



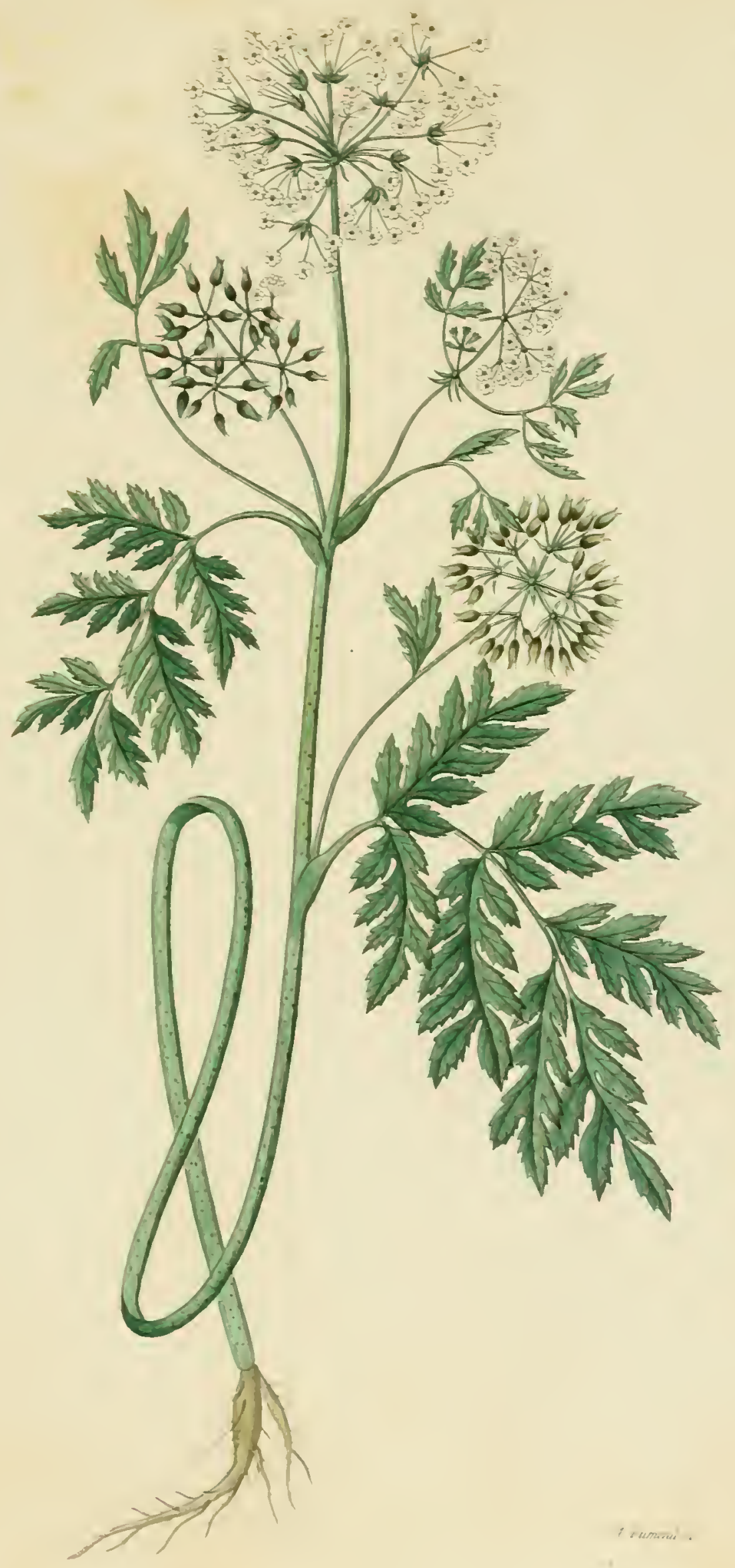





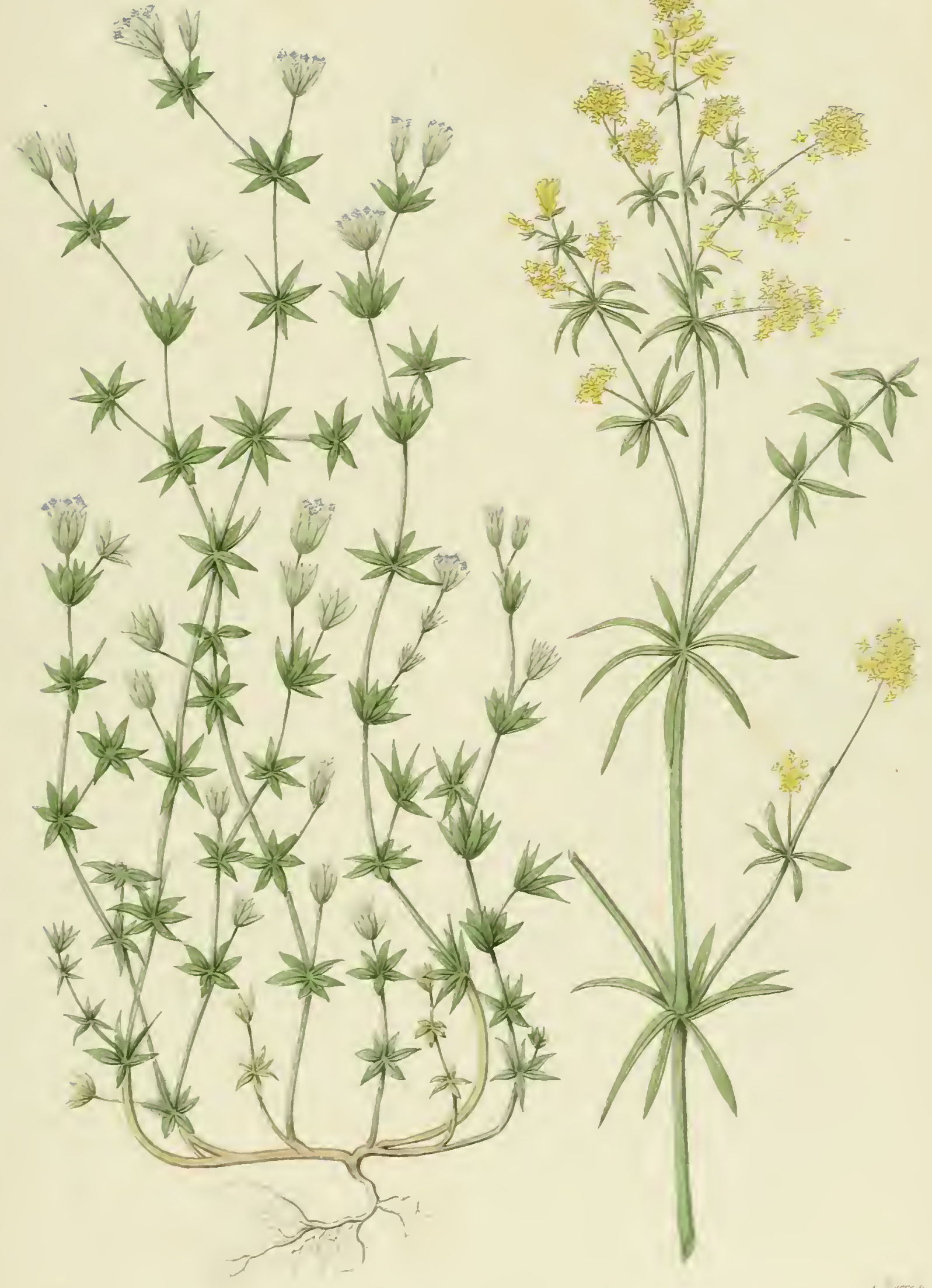





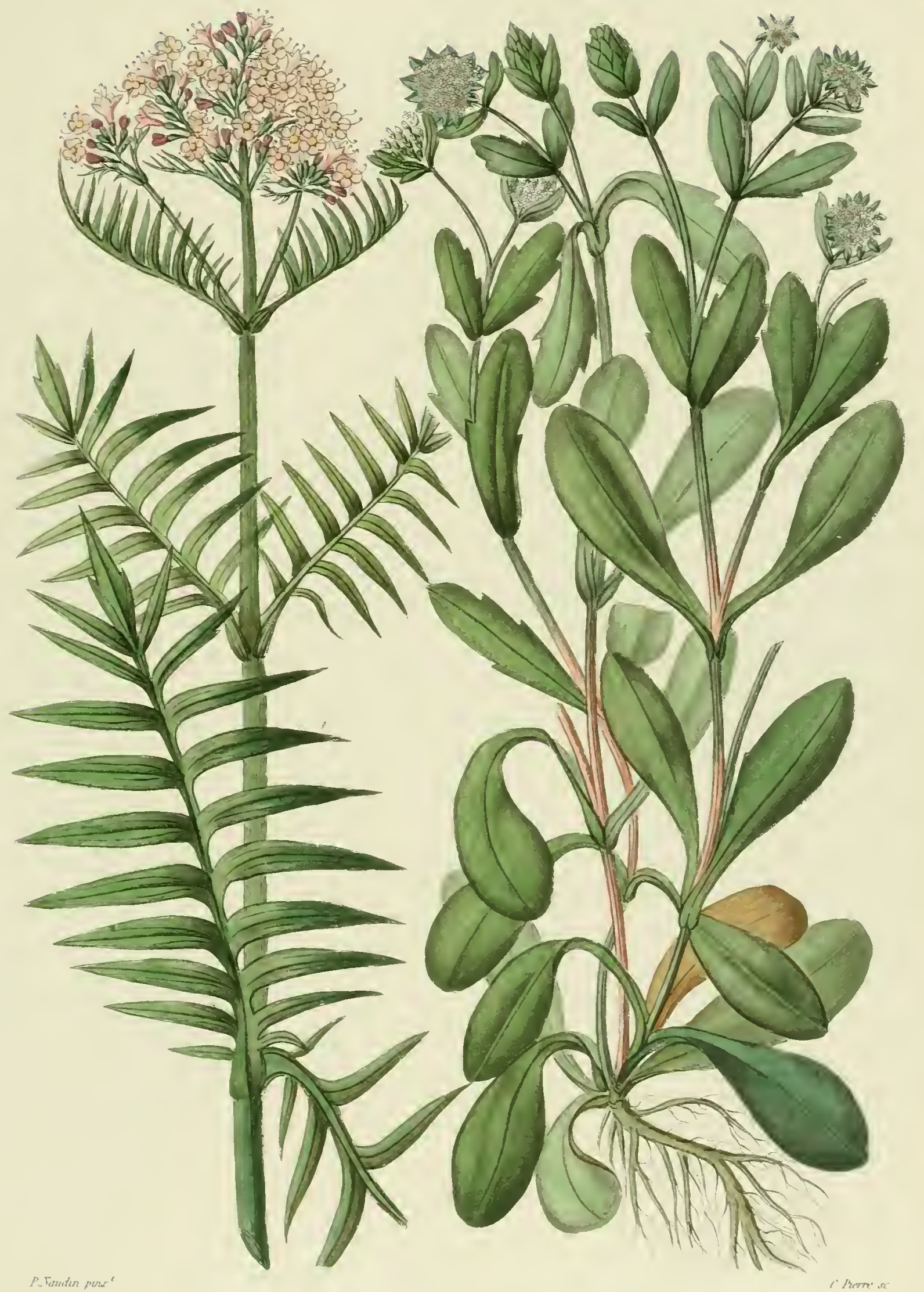





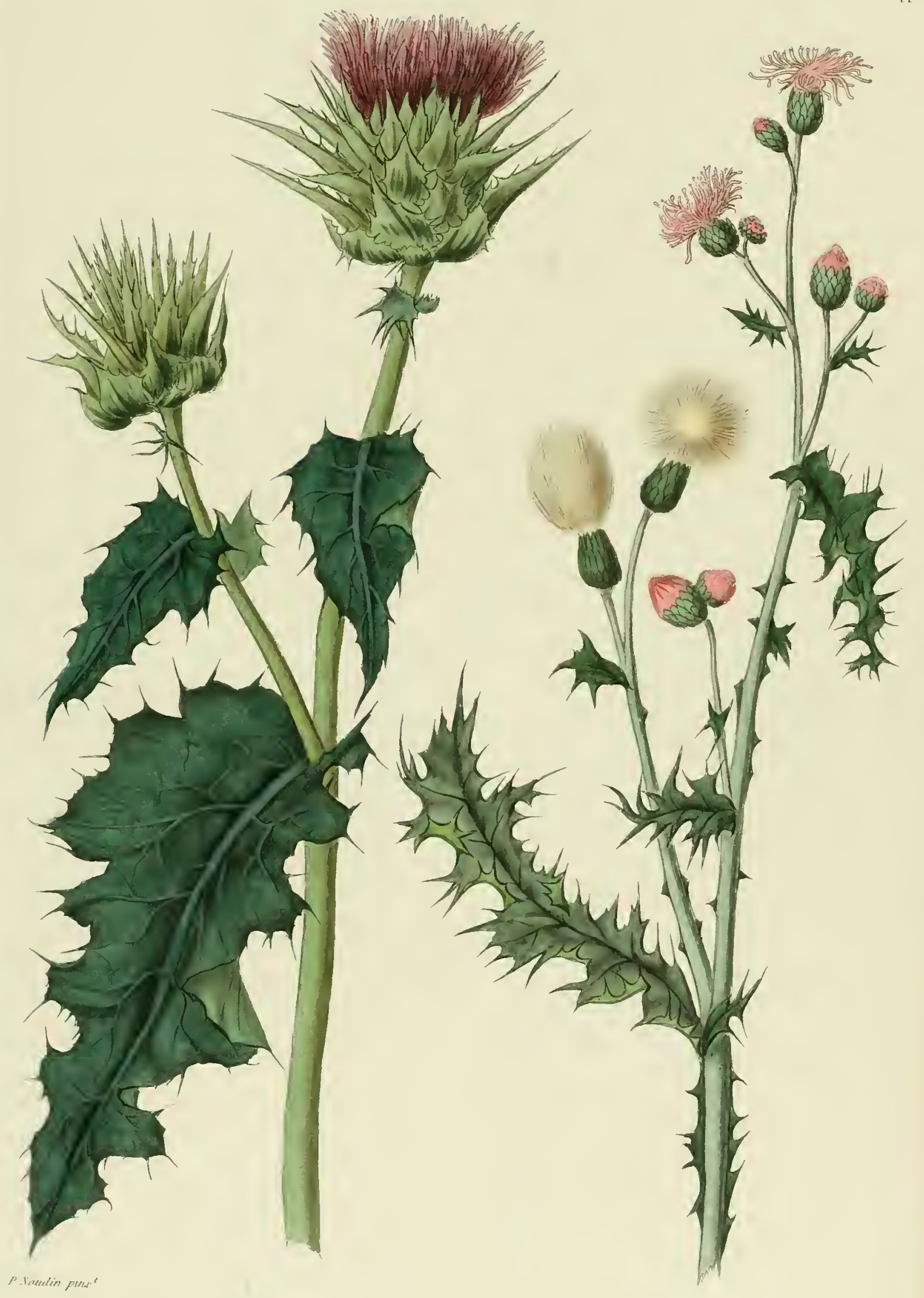





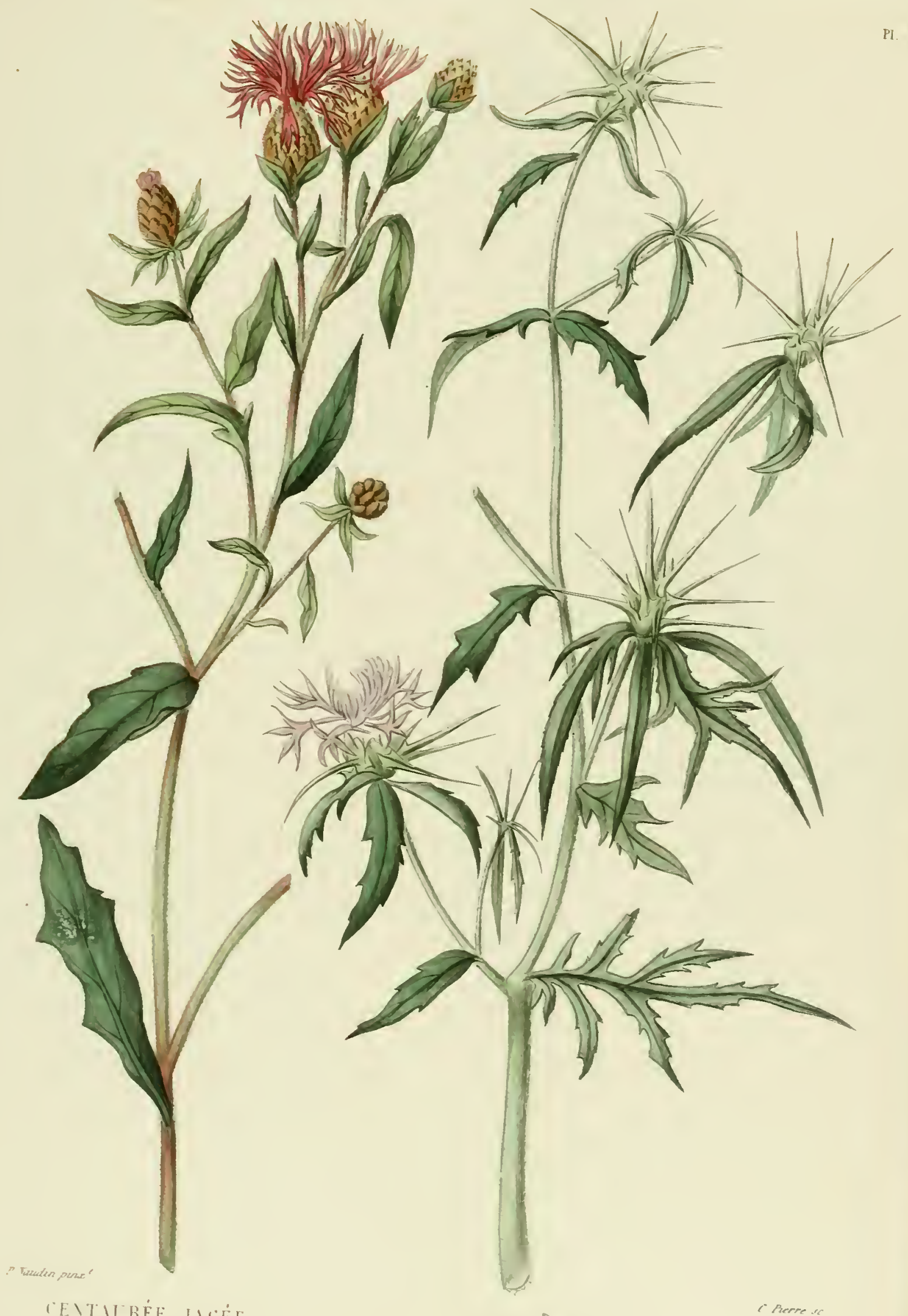

CE\TILREE JACÉE. 



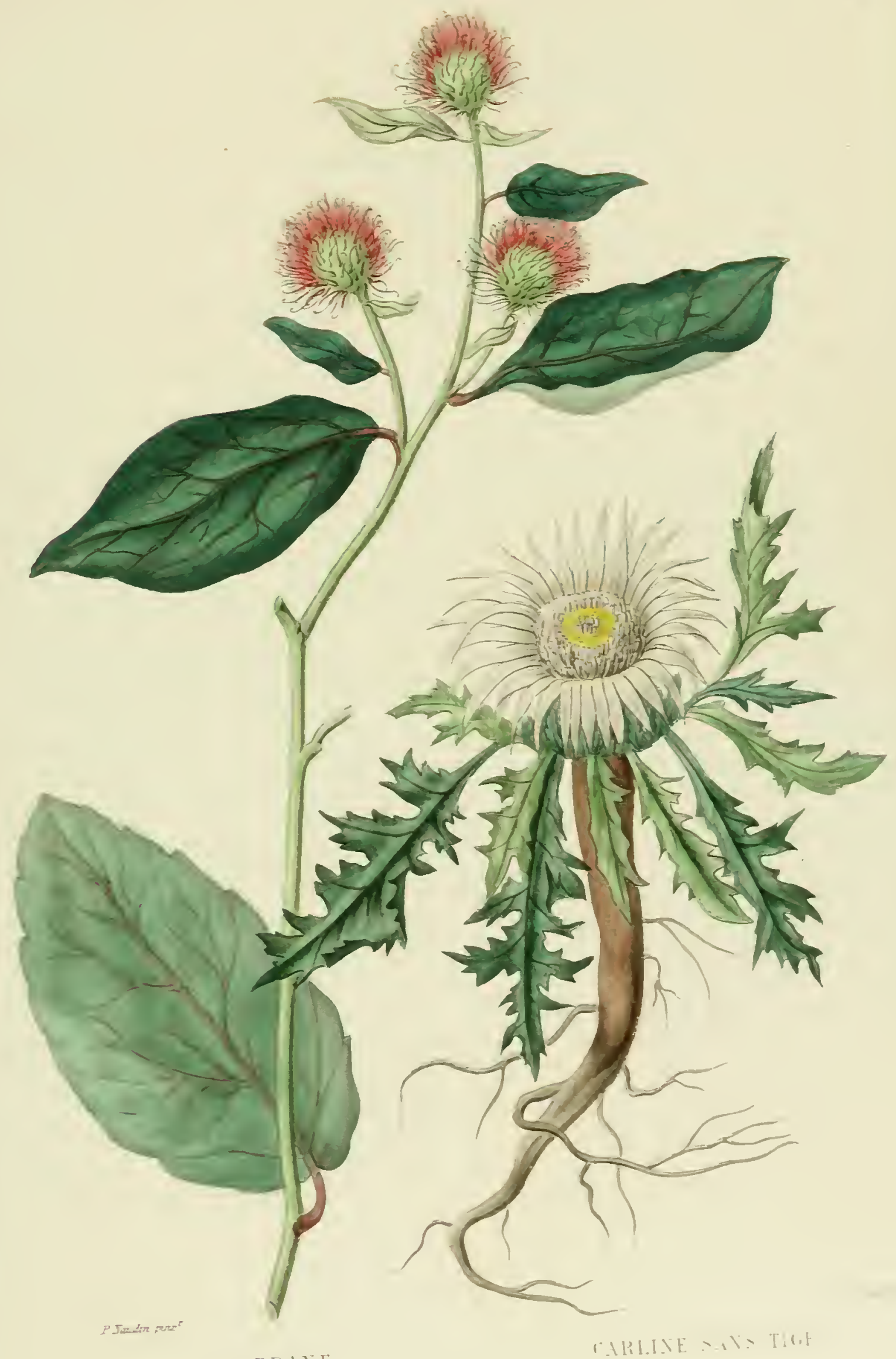





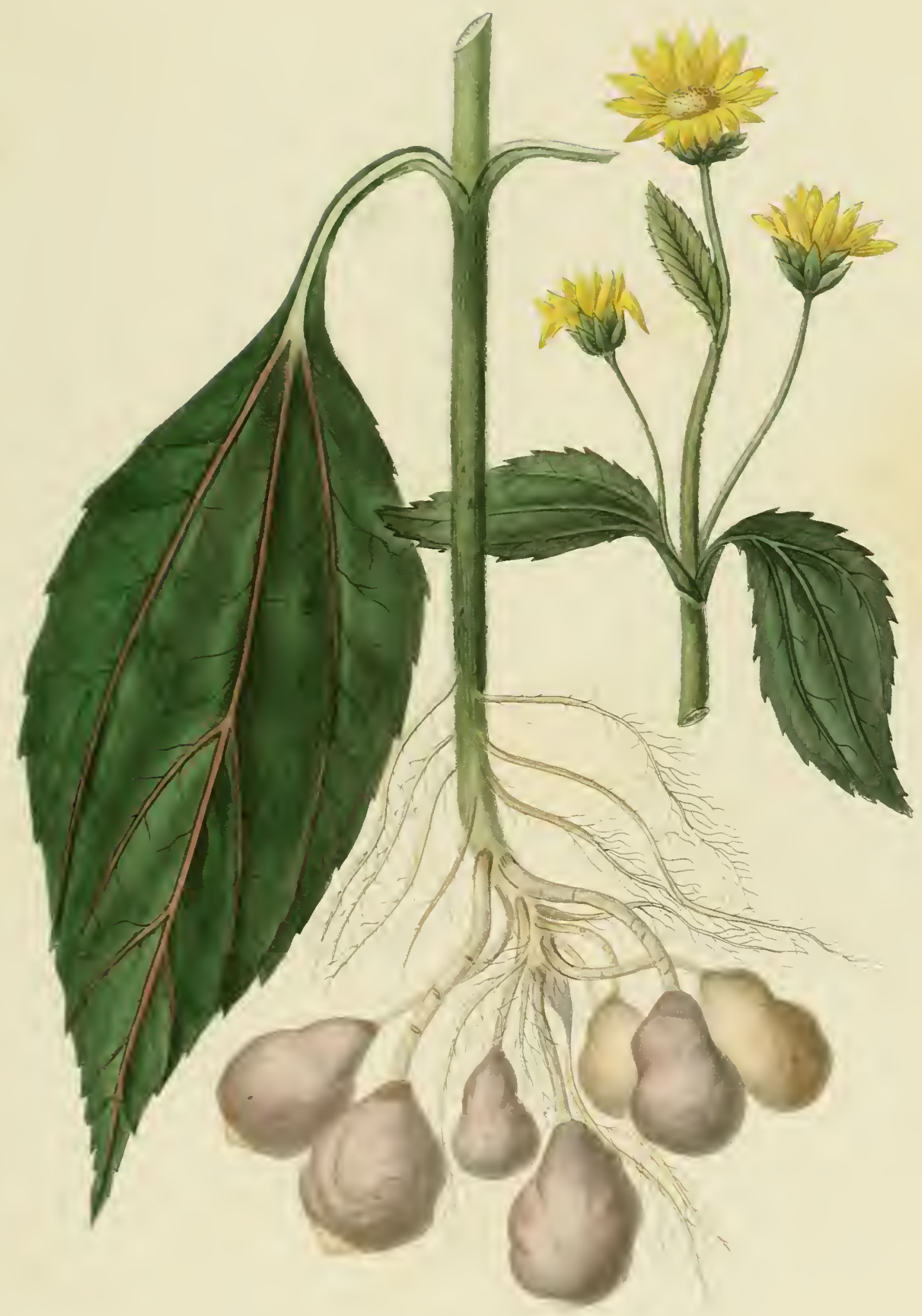

TOPIIIVBOLR 



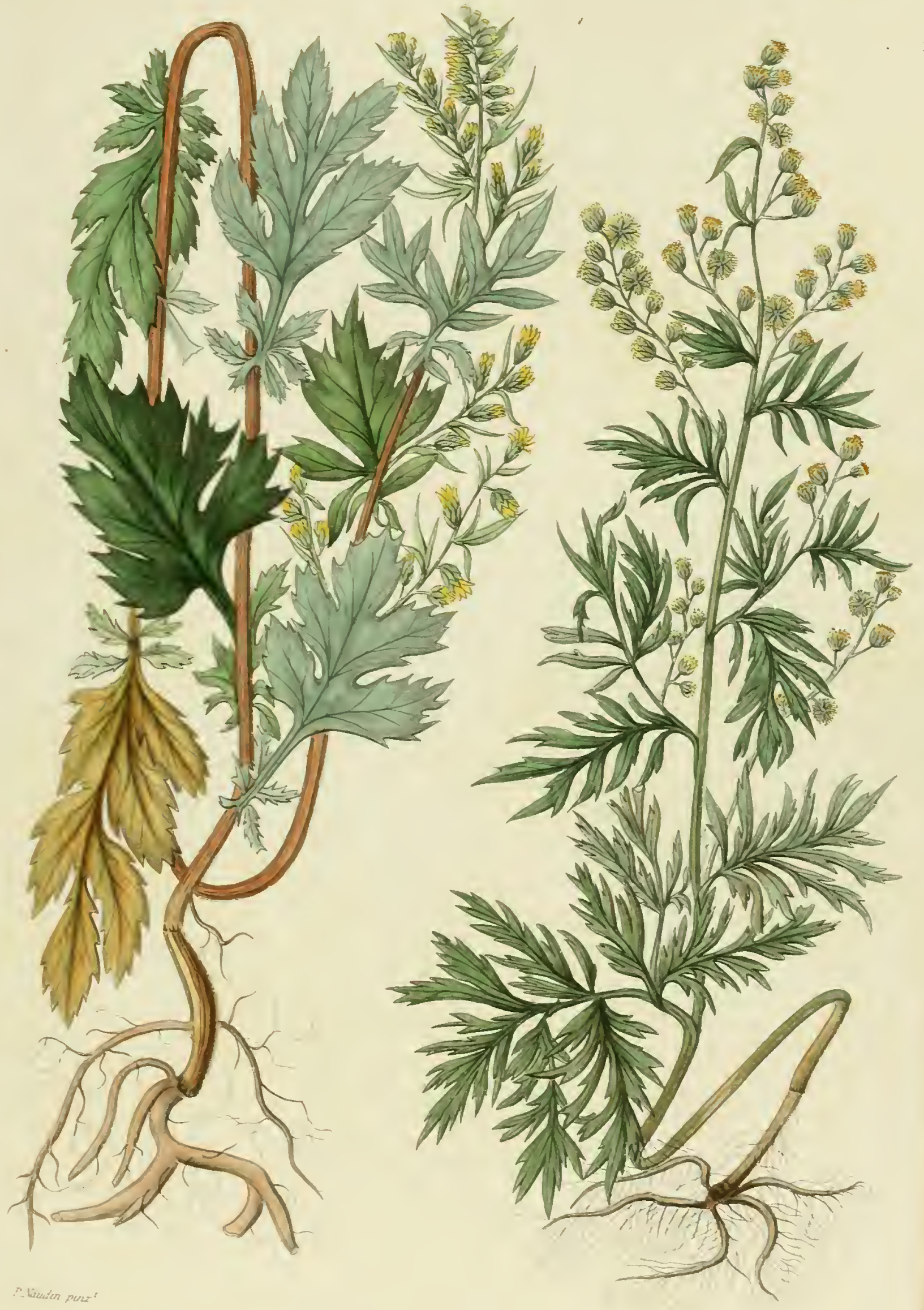





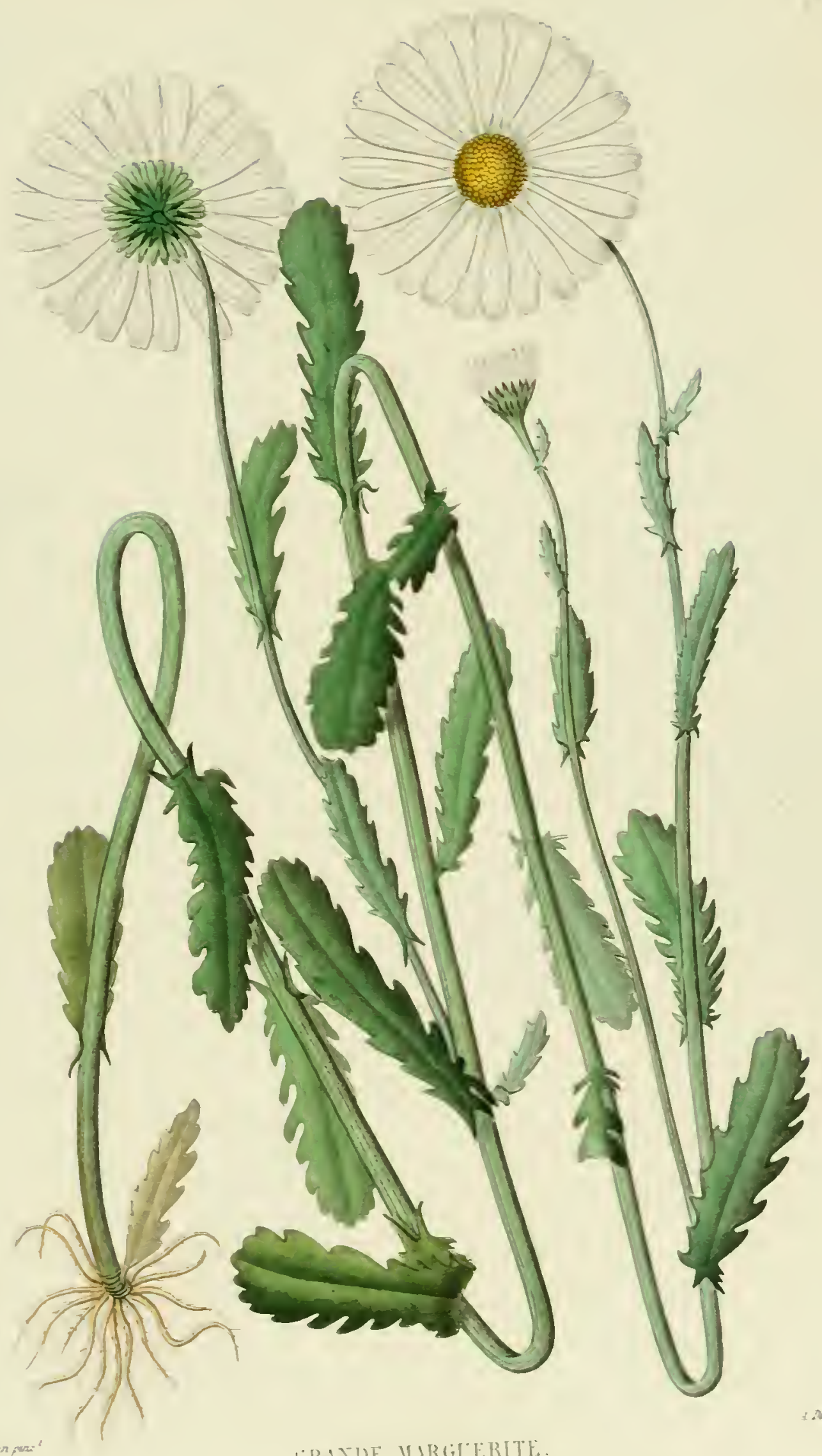

IRIXI)F, IIRGI'ERITE. 



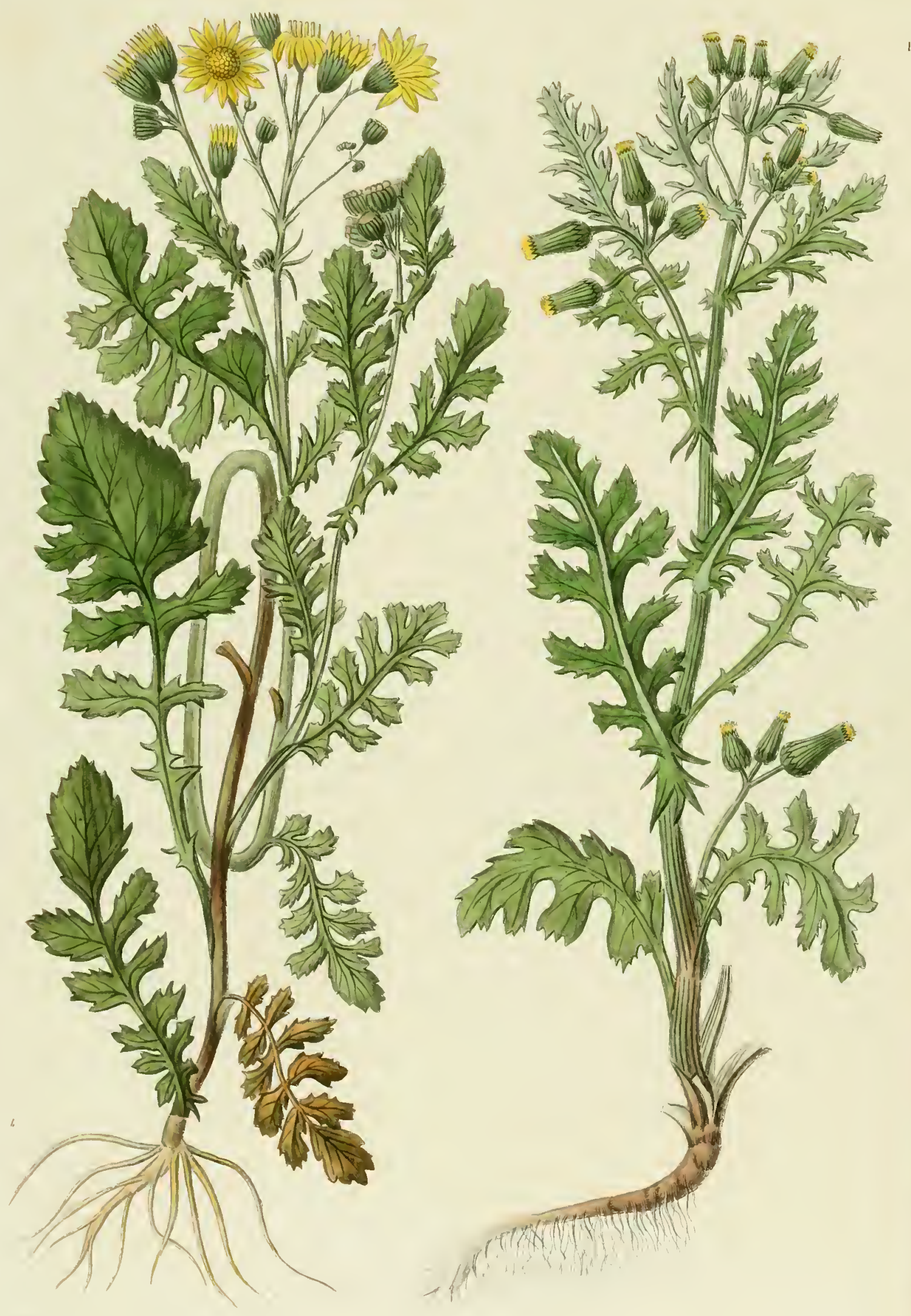





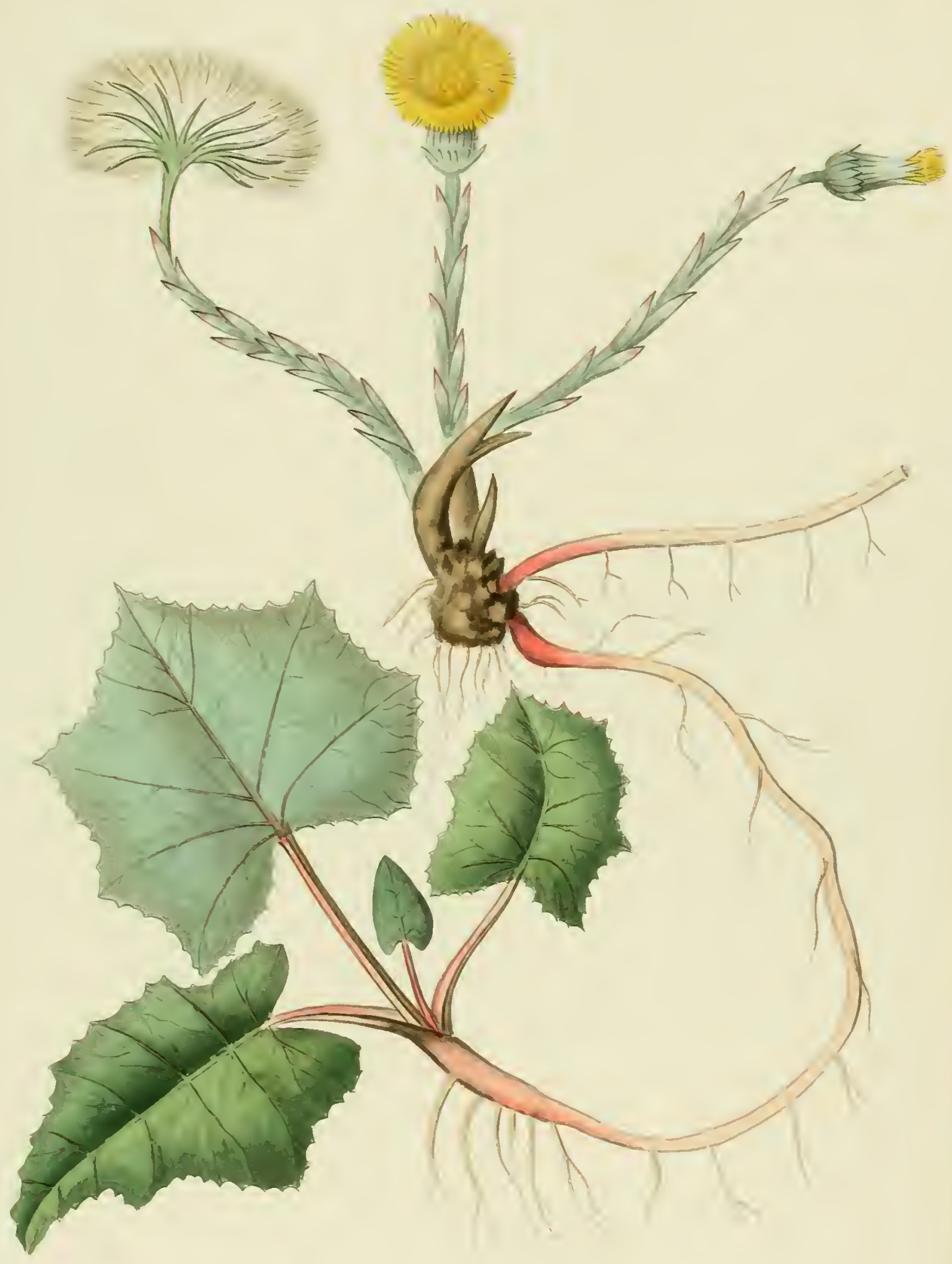

Prouder pore

TLSSILAE 



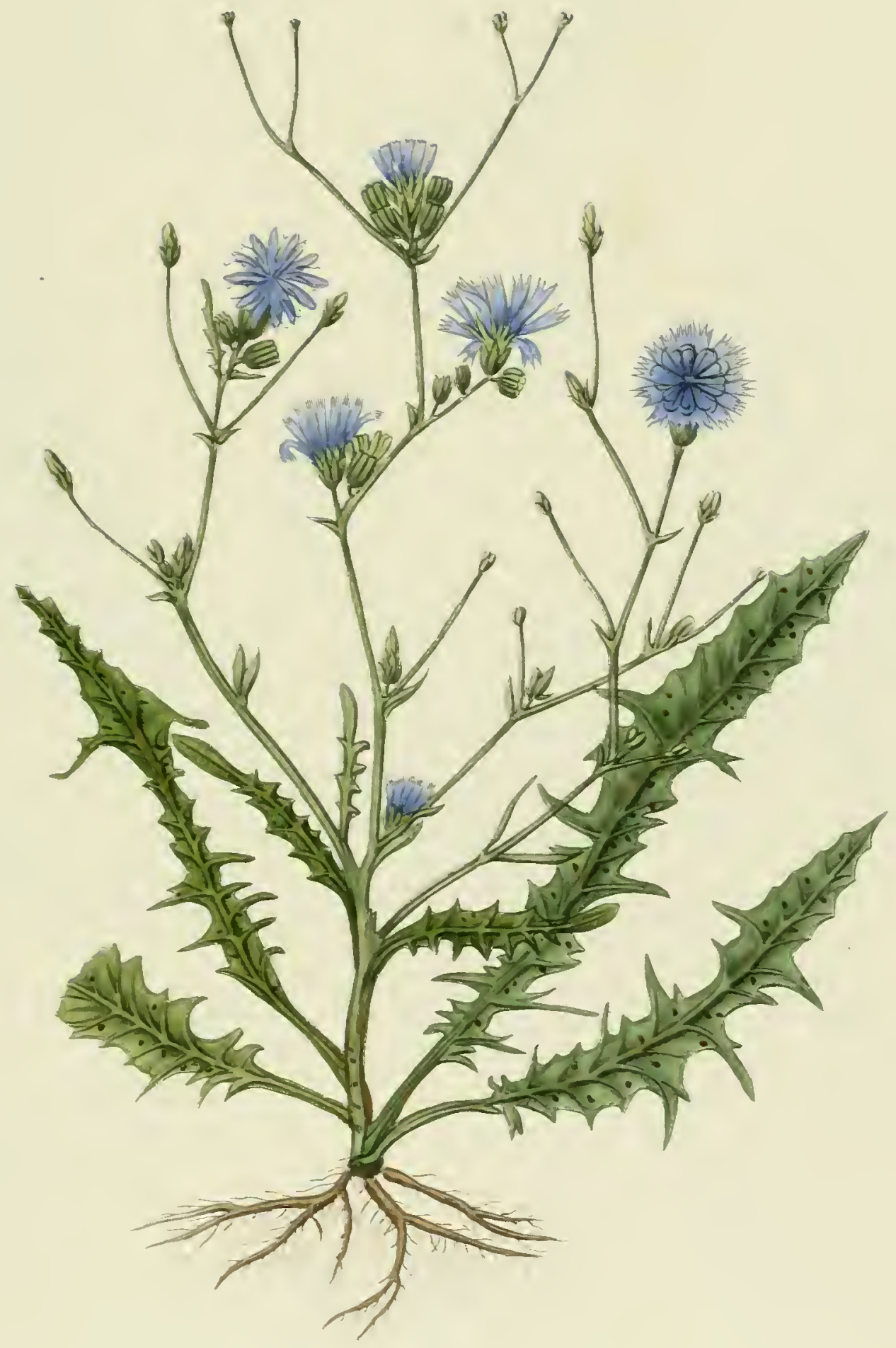





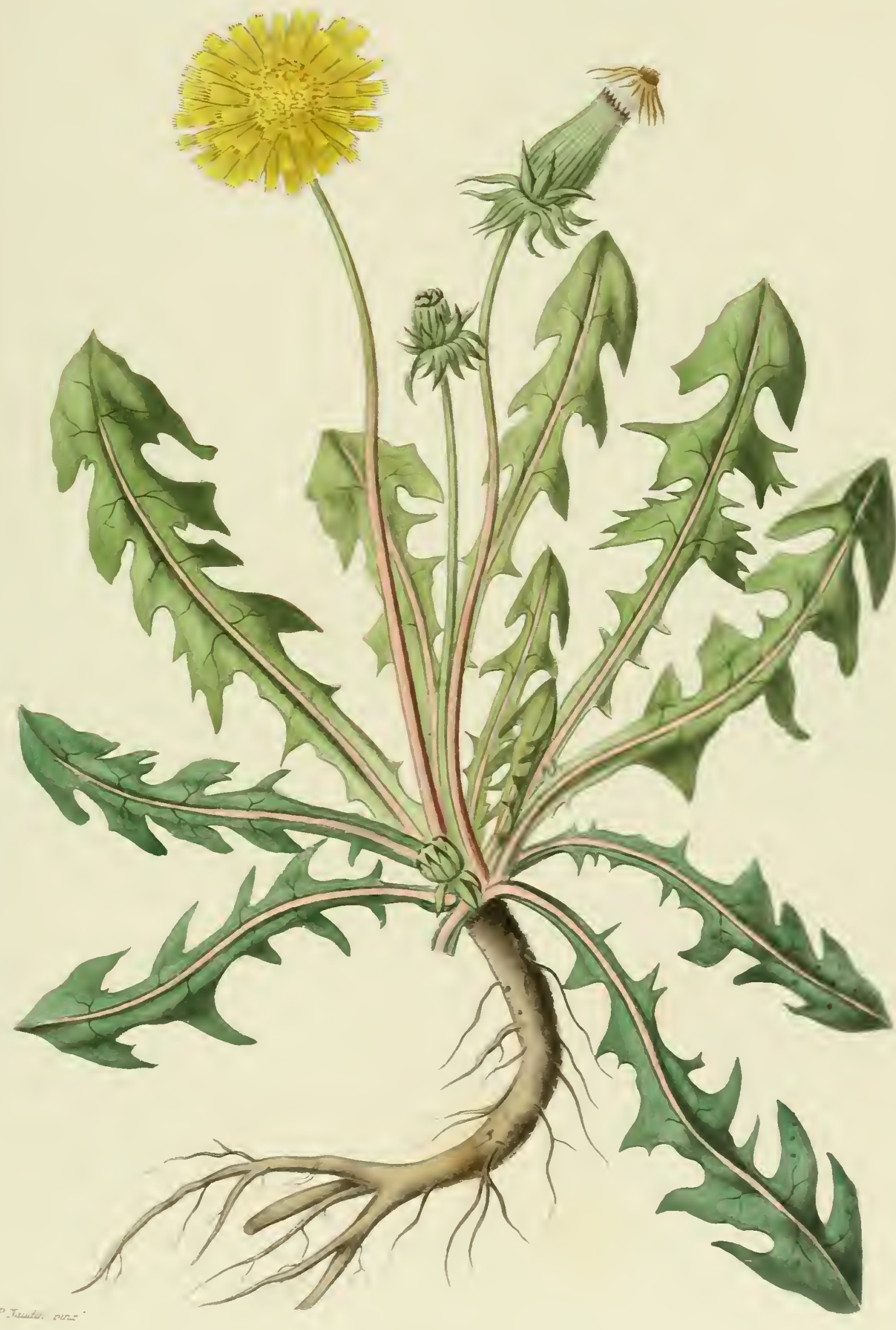





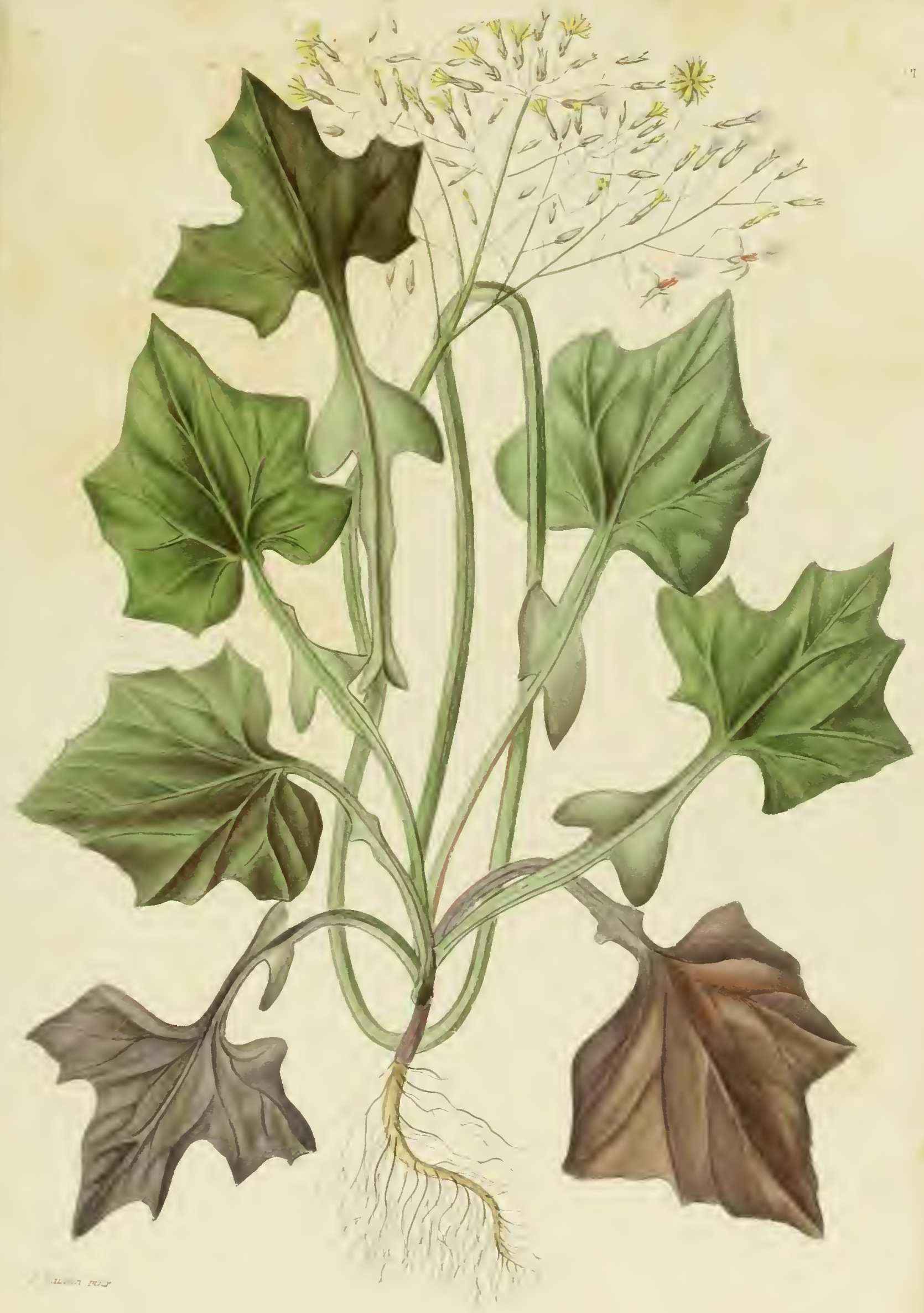





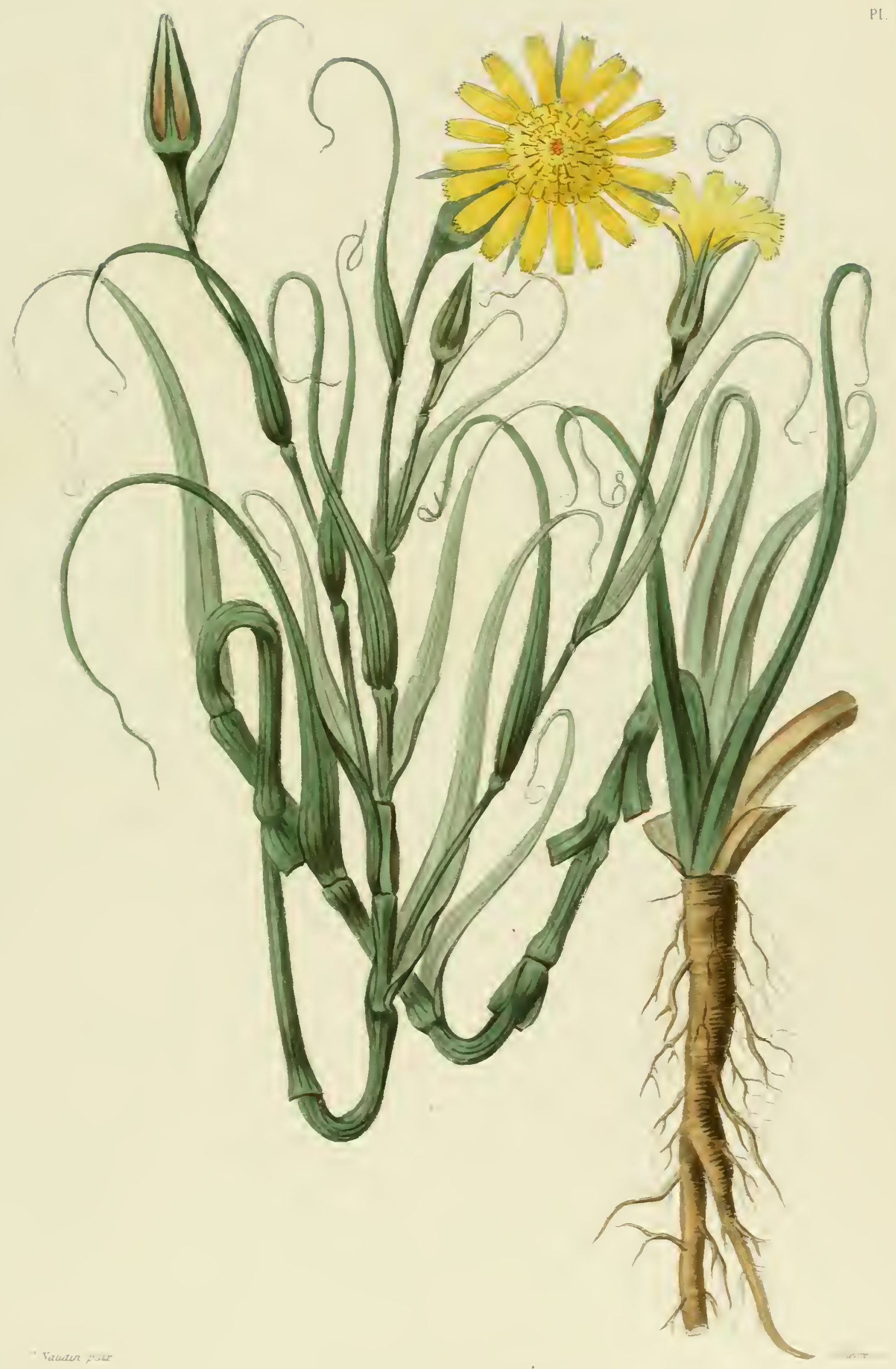





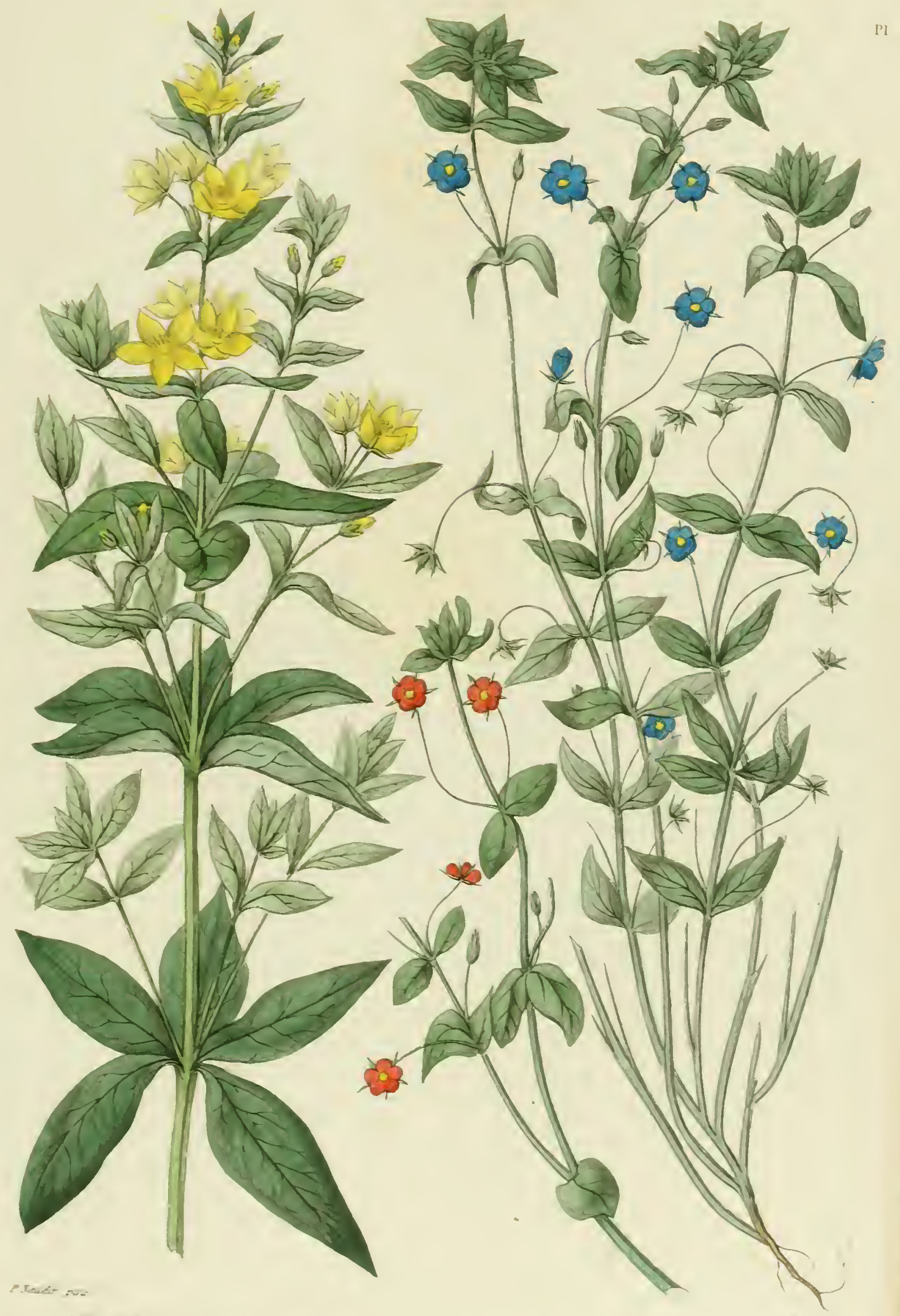

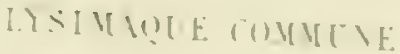





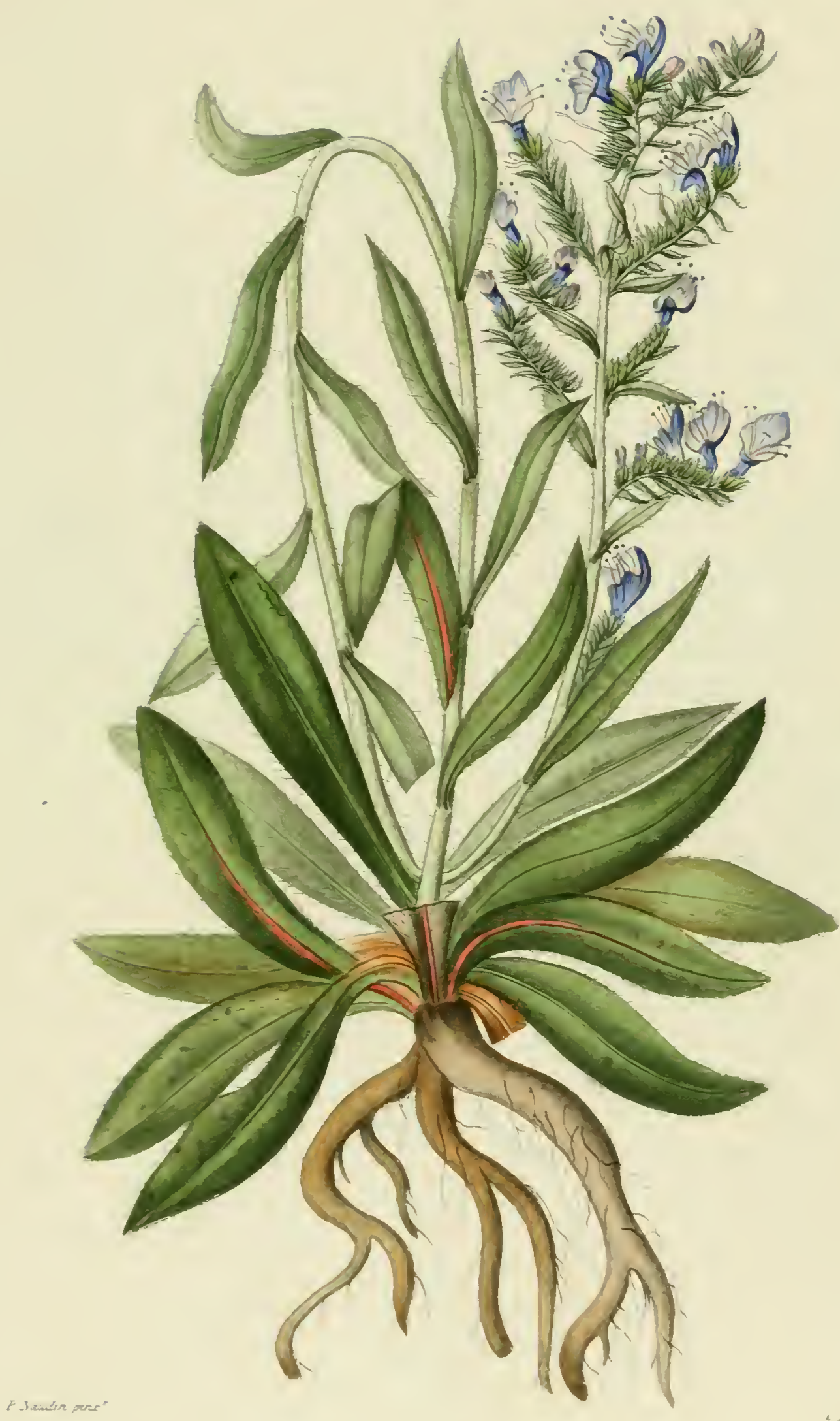

VIPERINE 



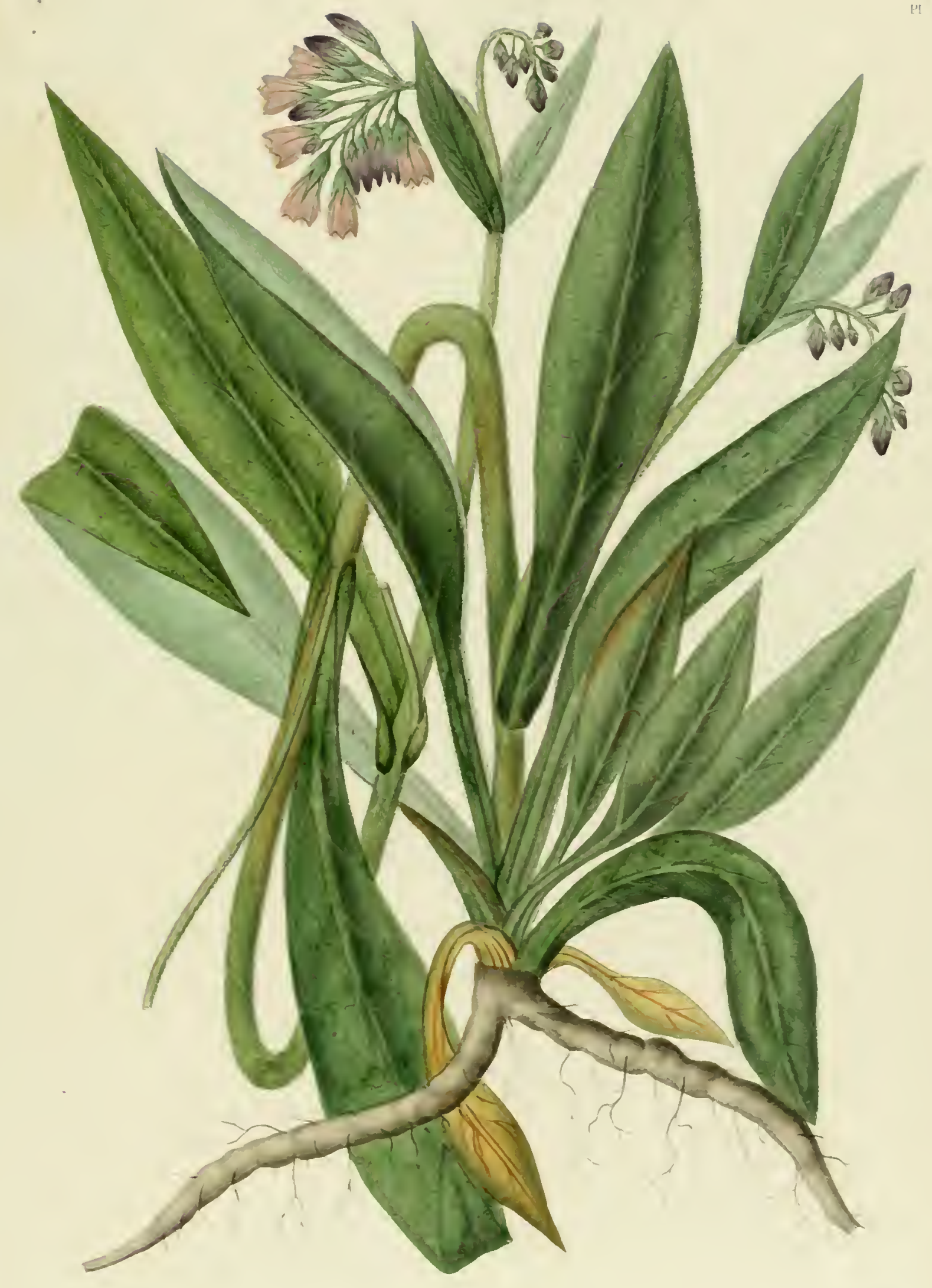





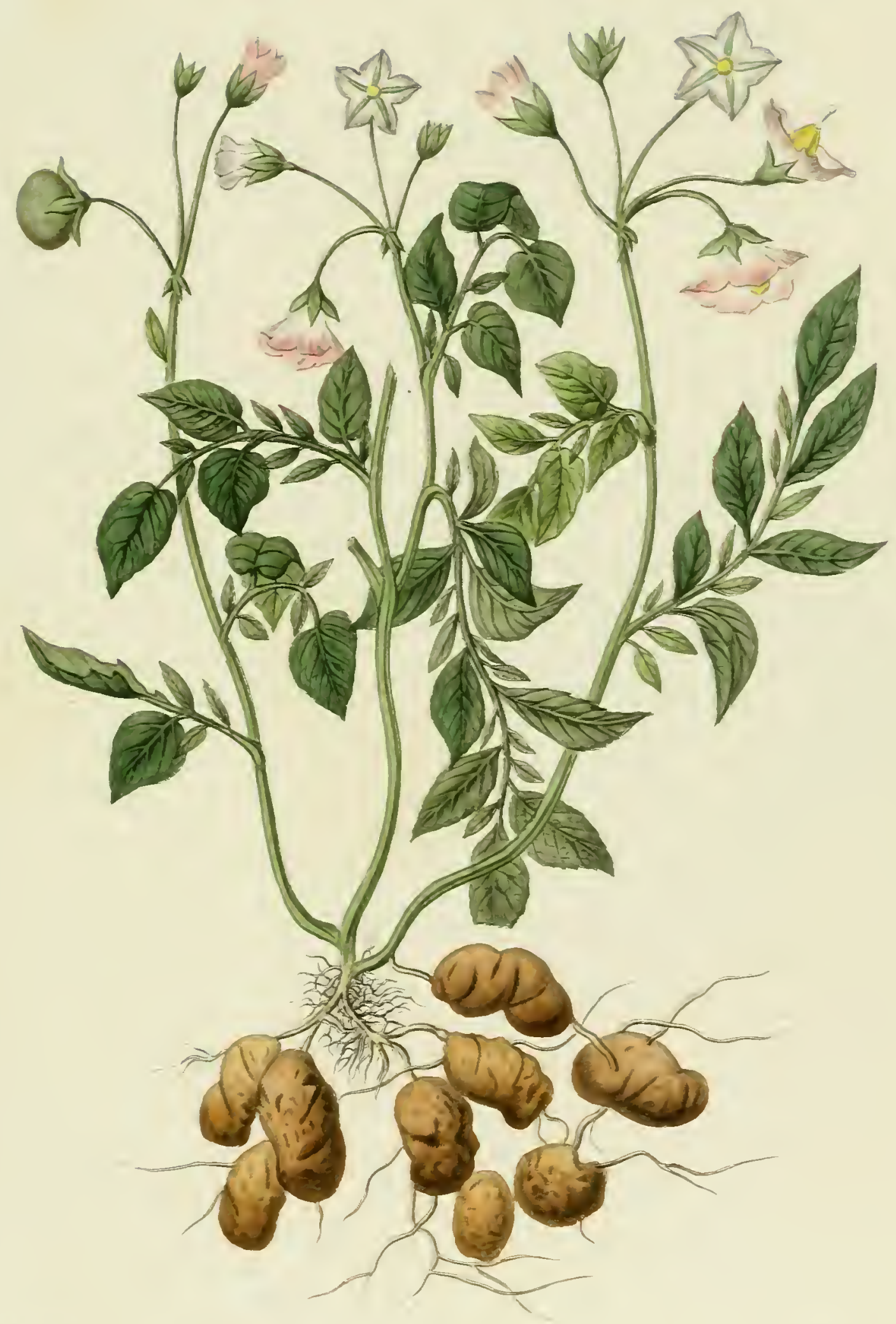




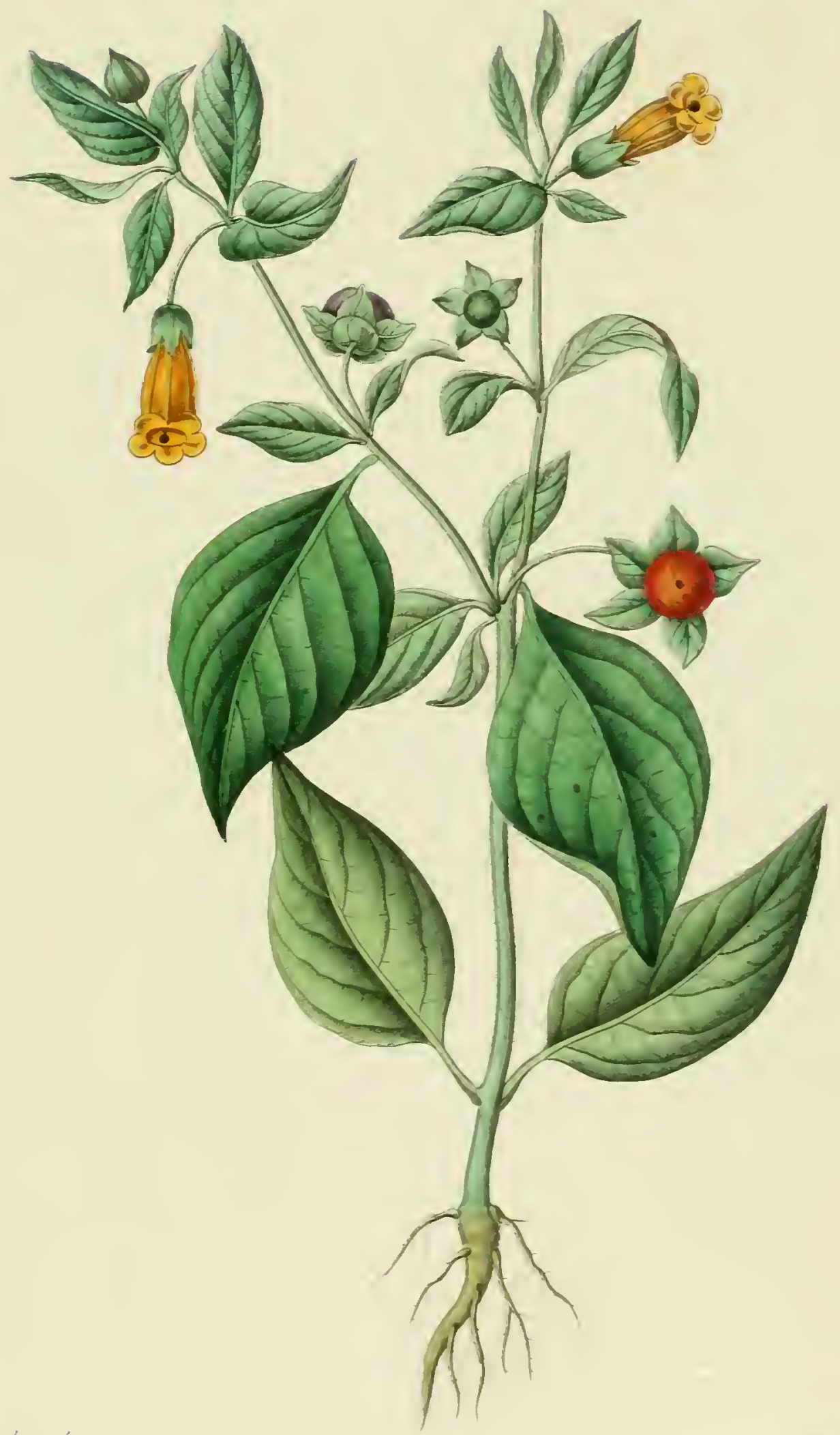



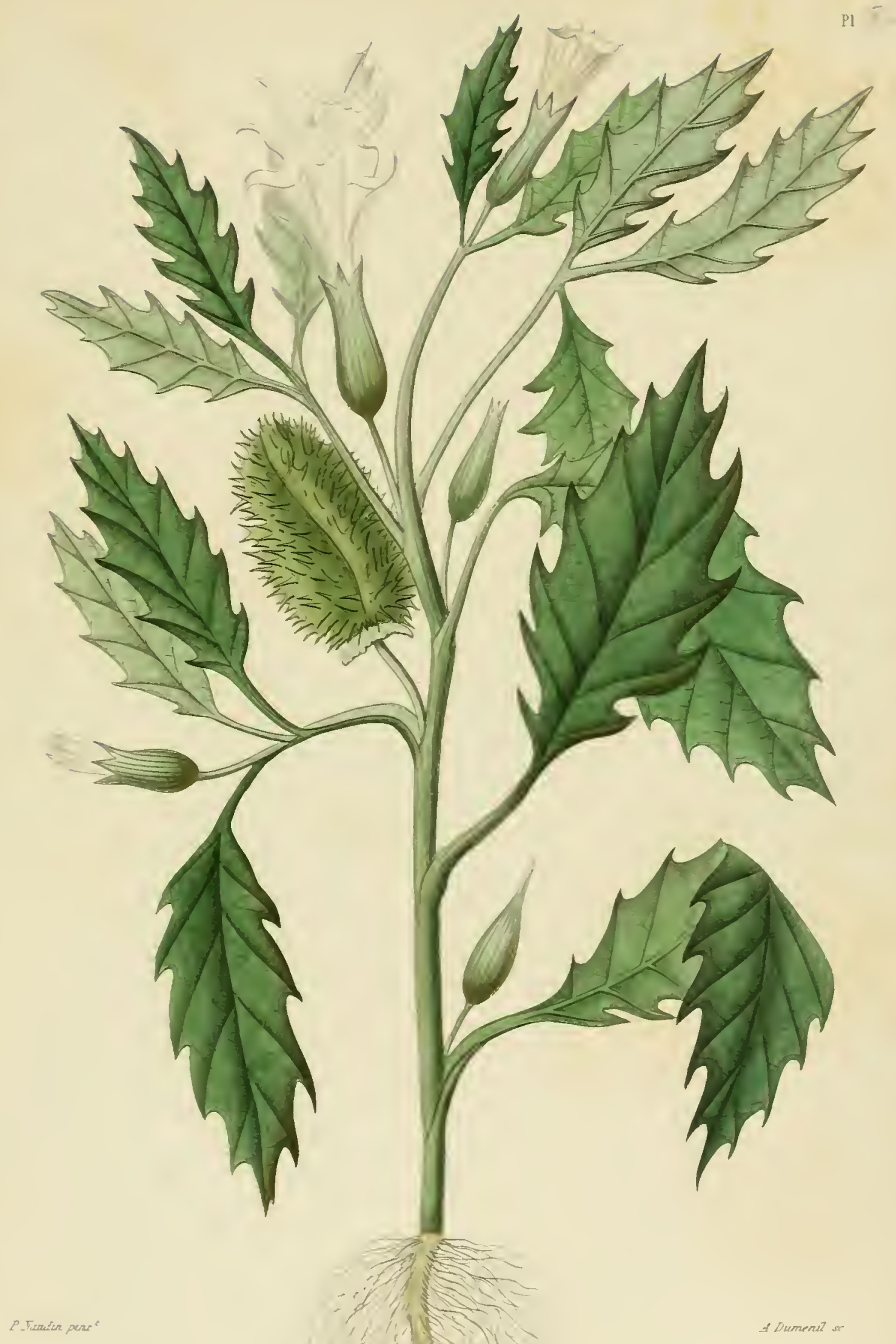

PUUME EPIXET:E 



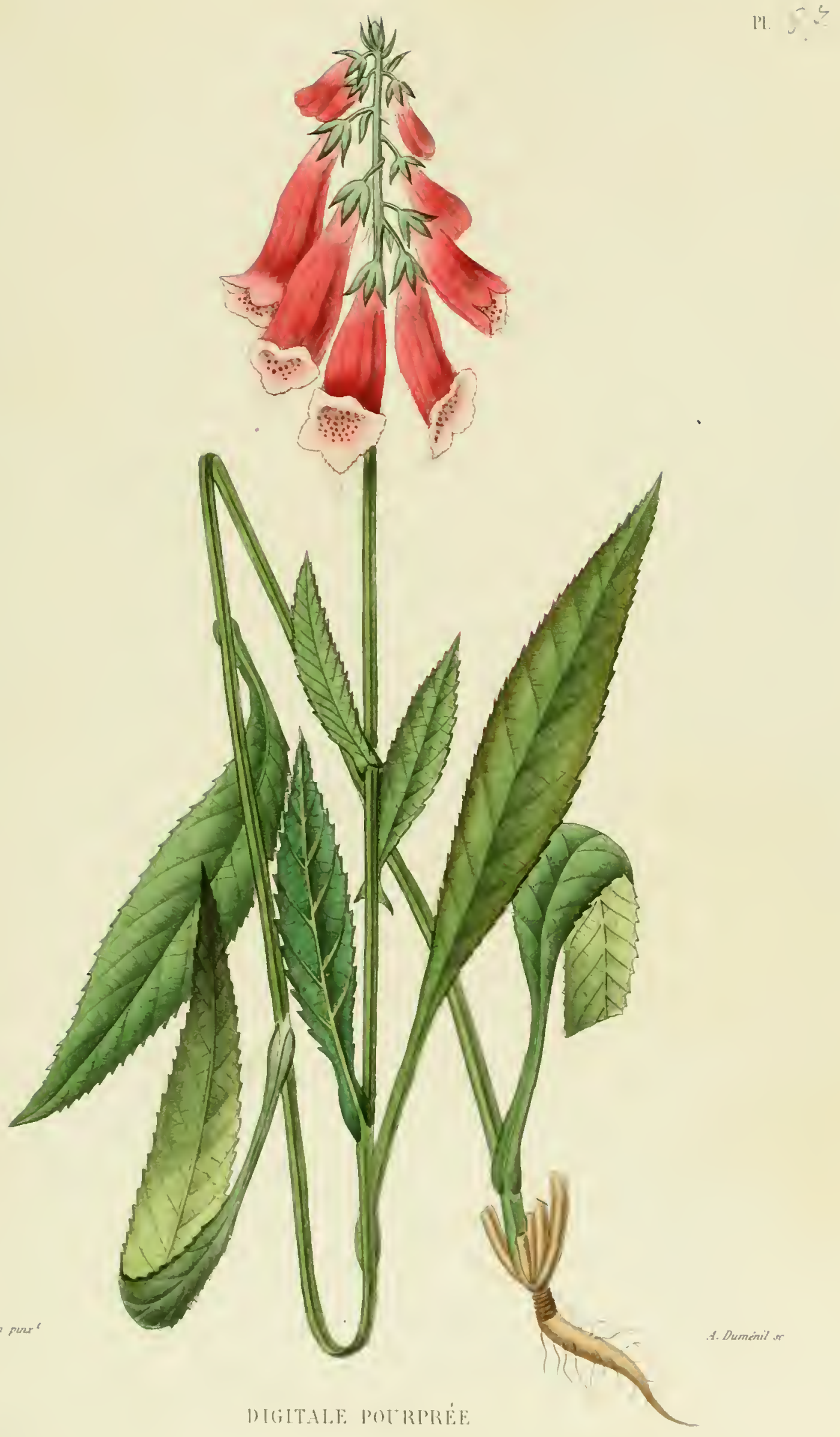





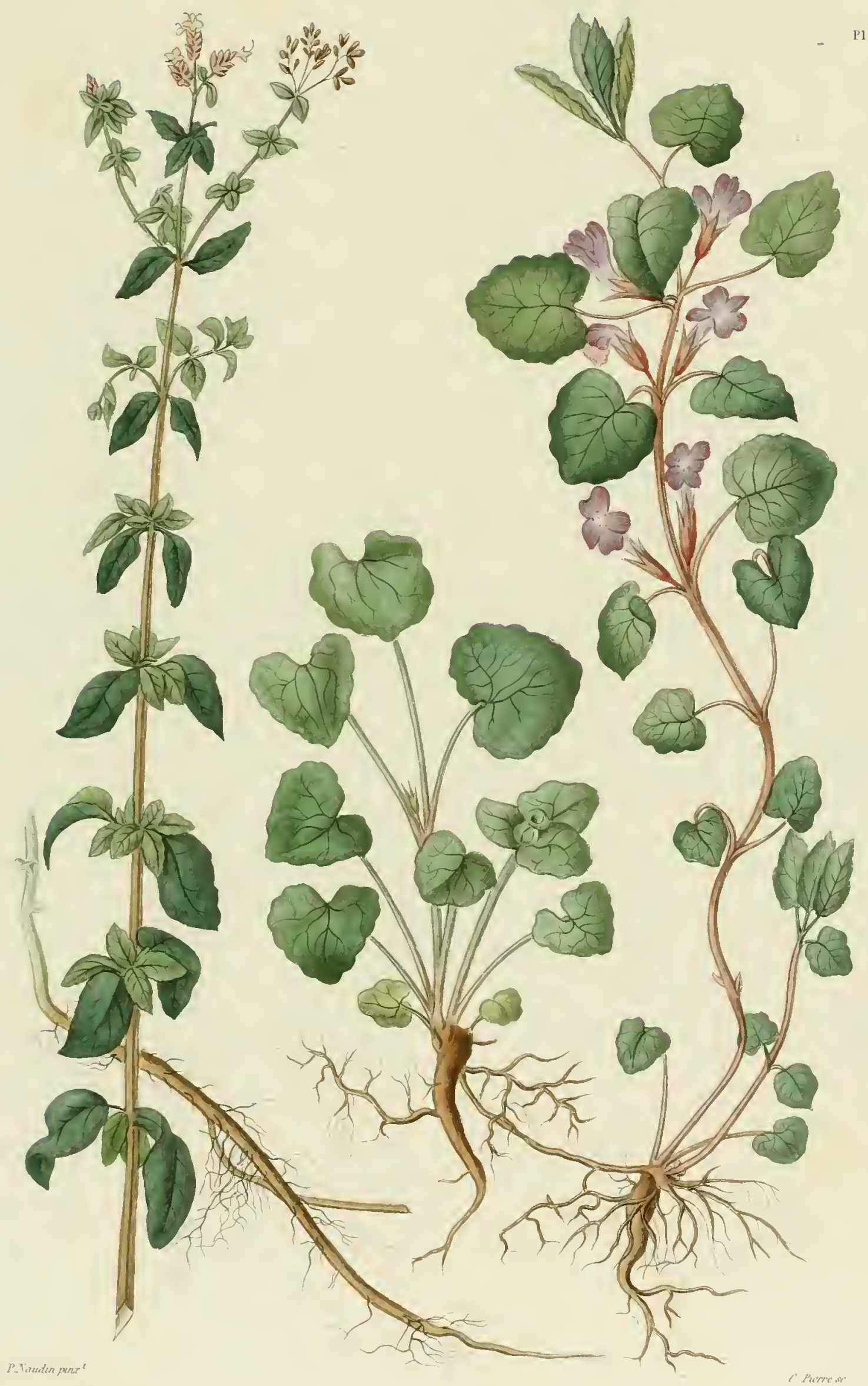





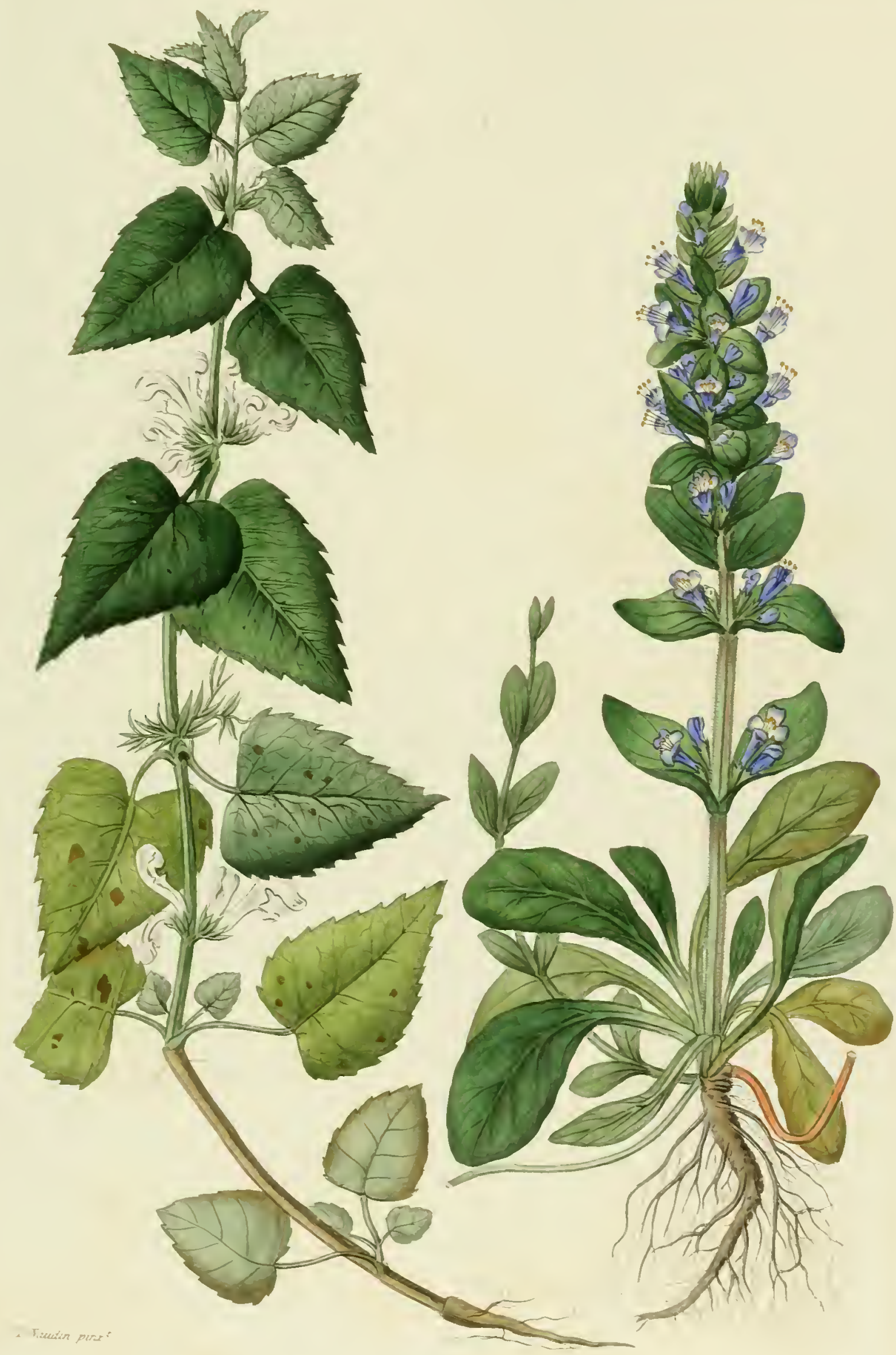





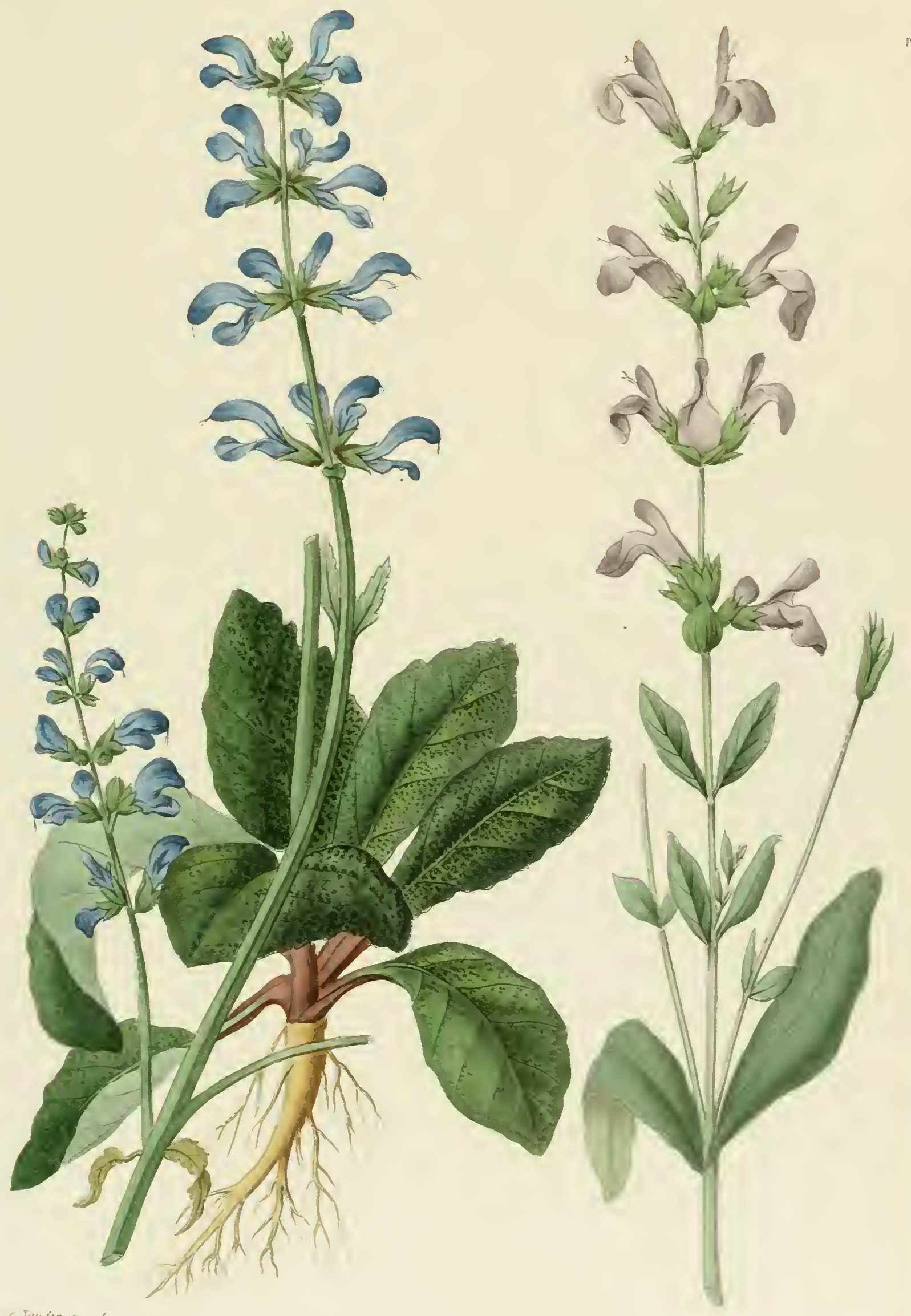





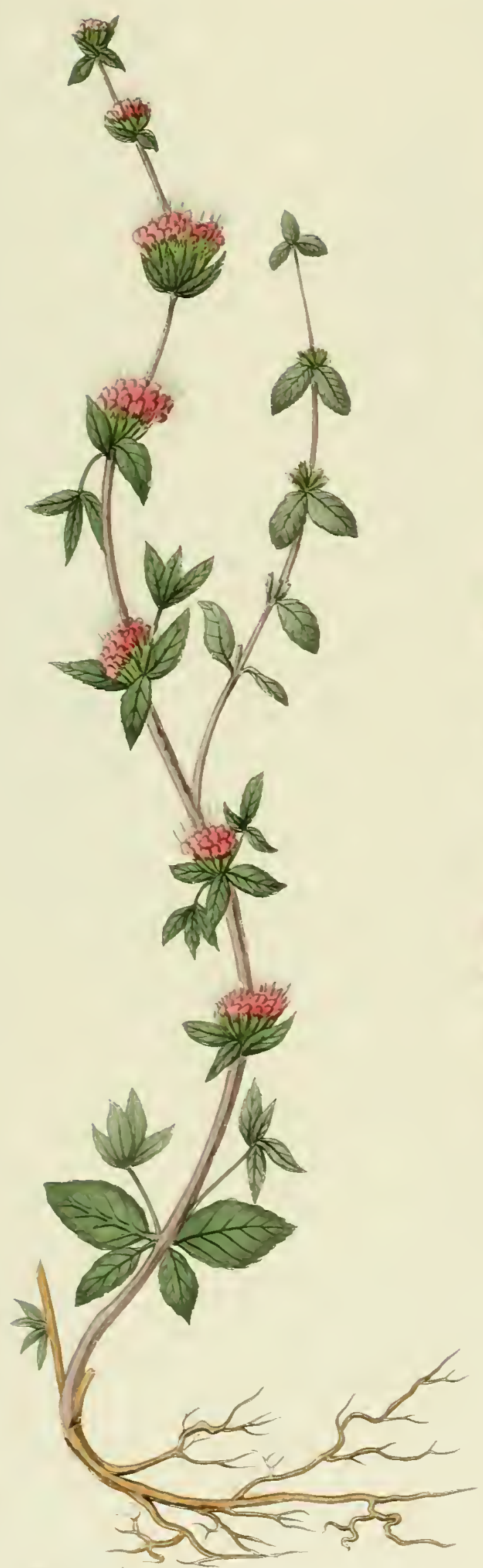

ILENTHE POTLIOT

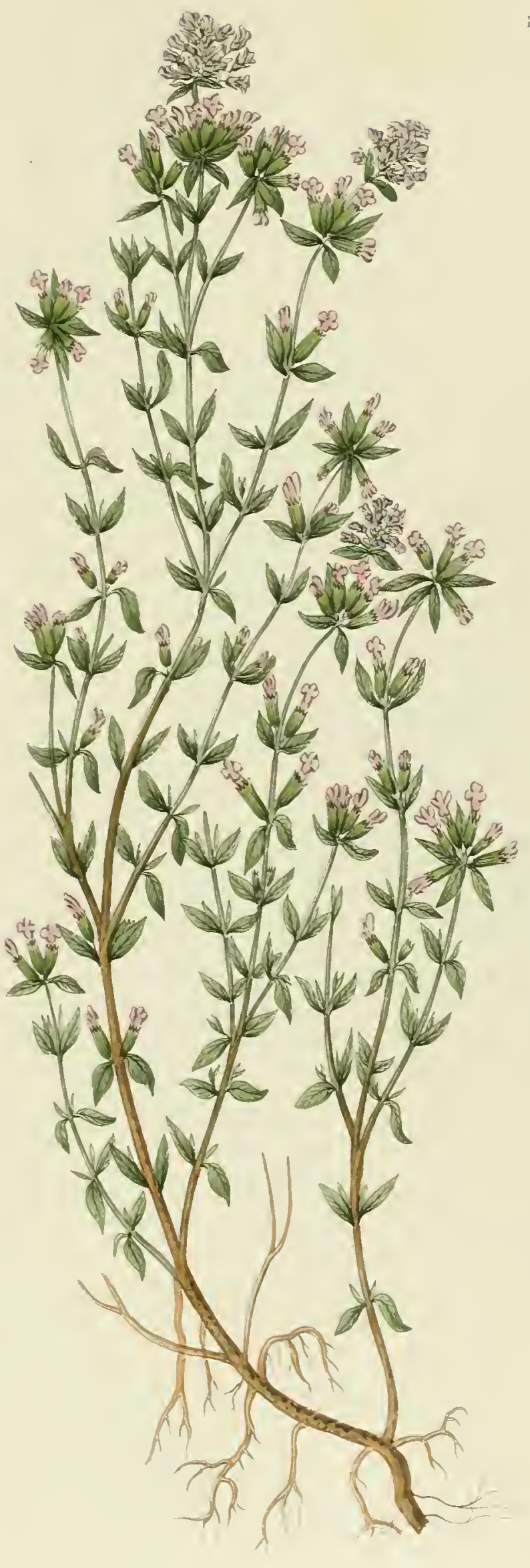

THIY SERPOLLET 


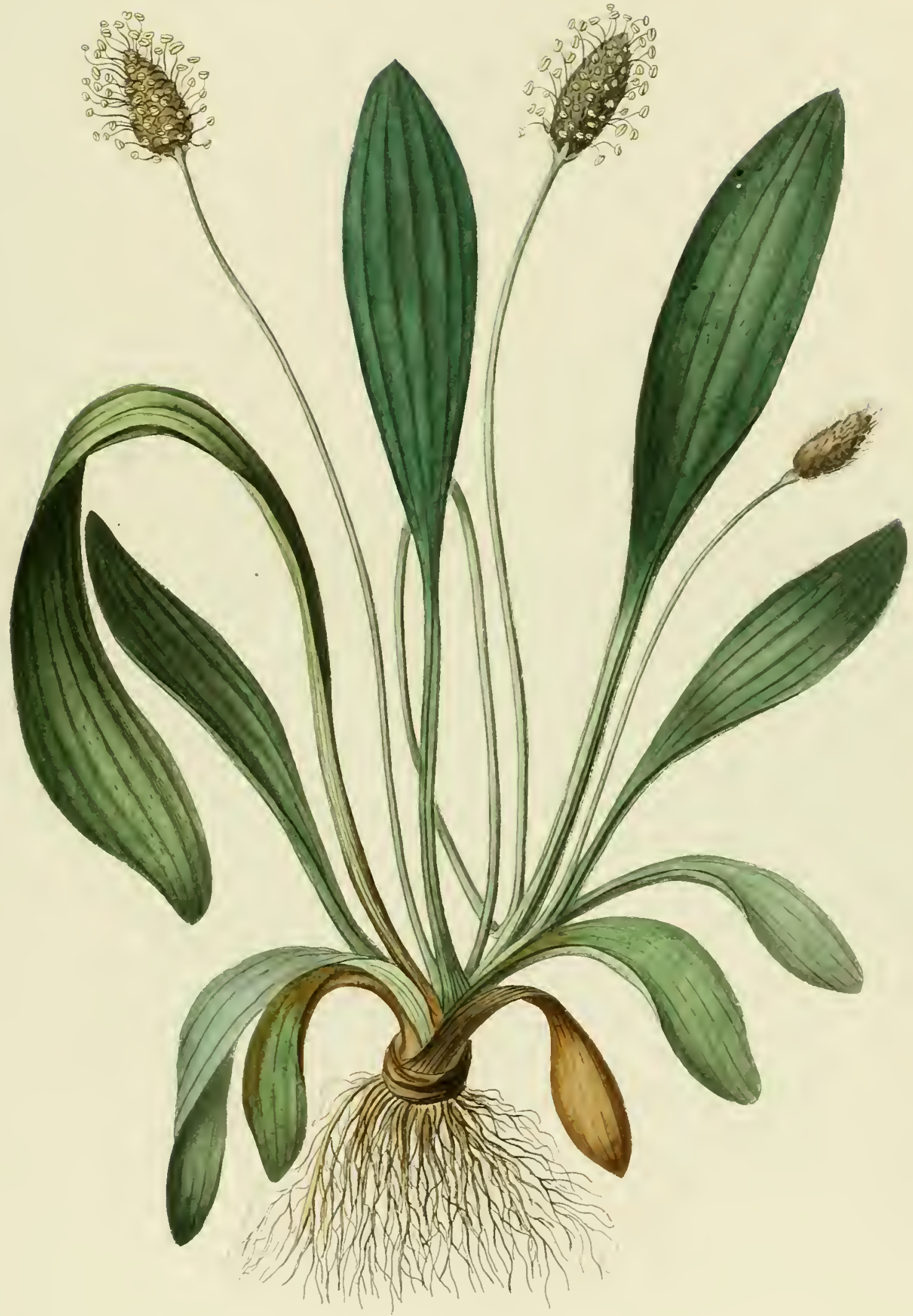





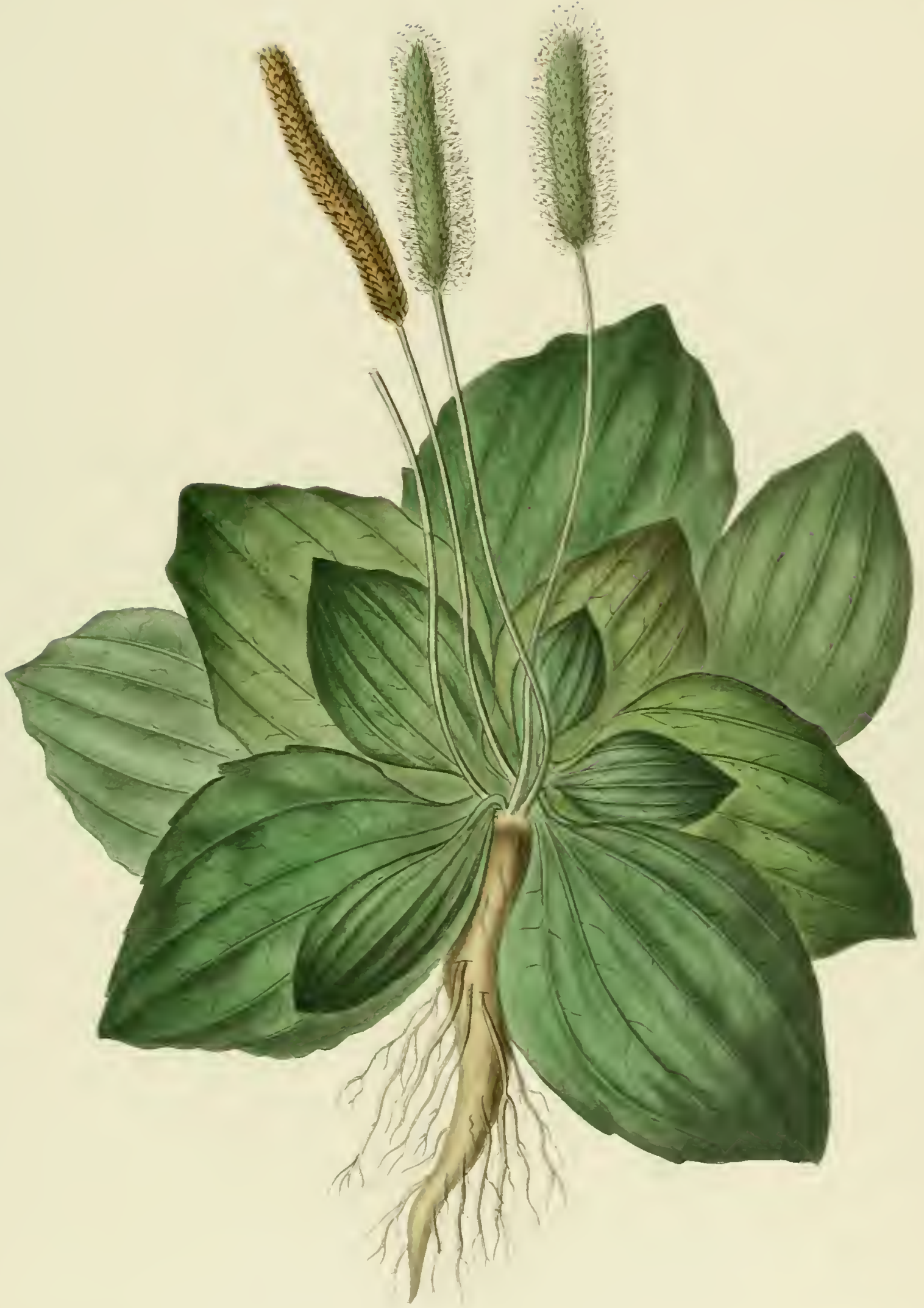





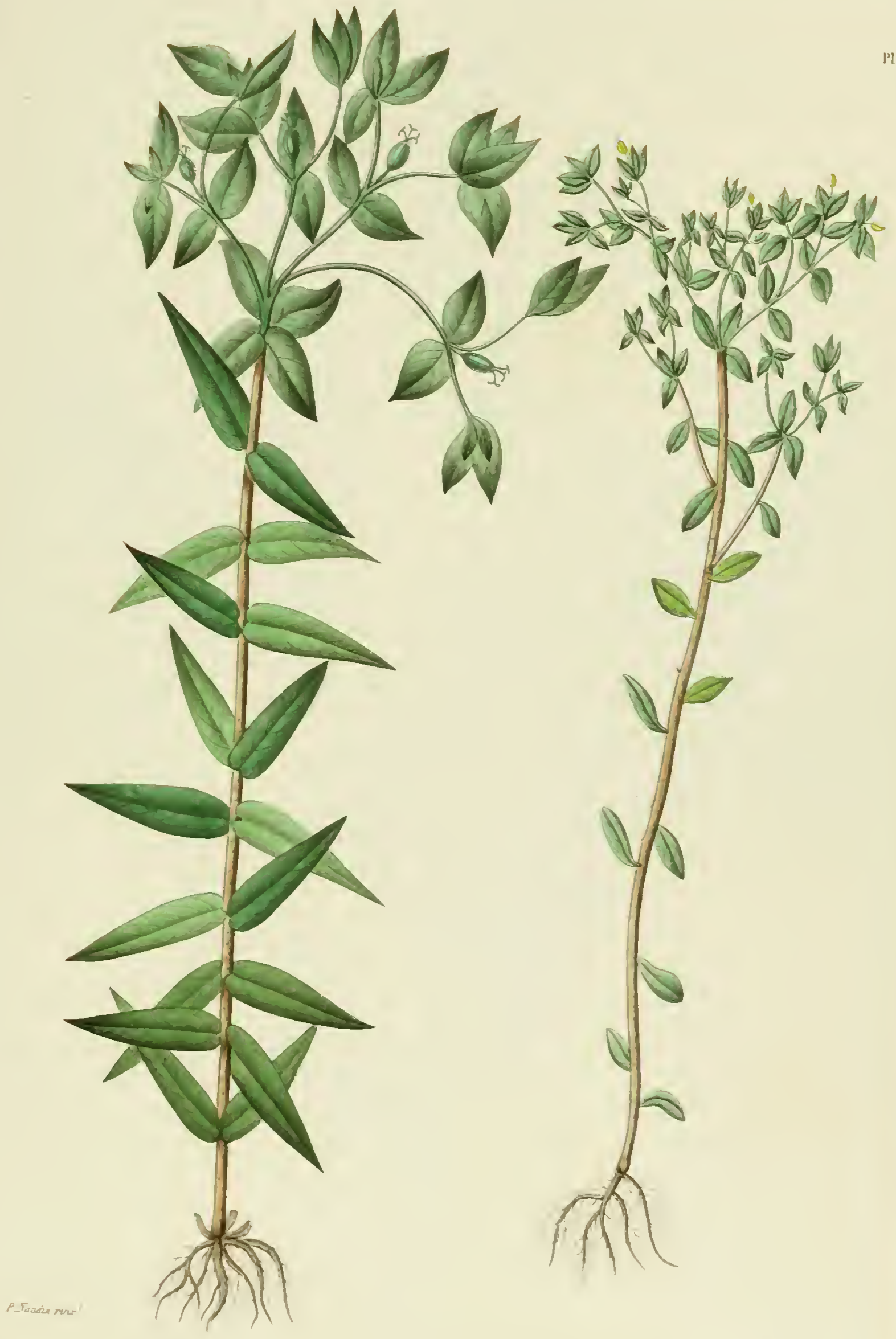

"II $O 4$ 



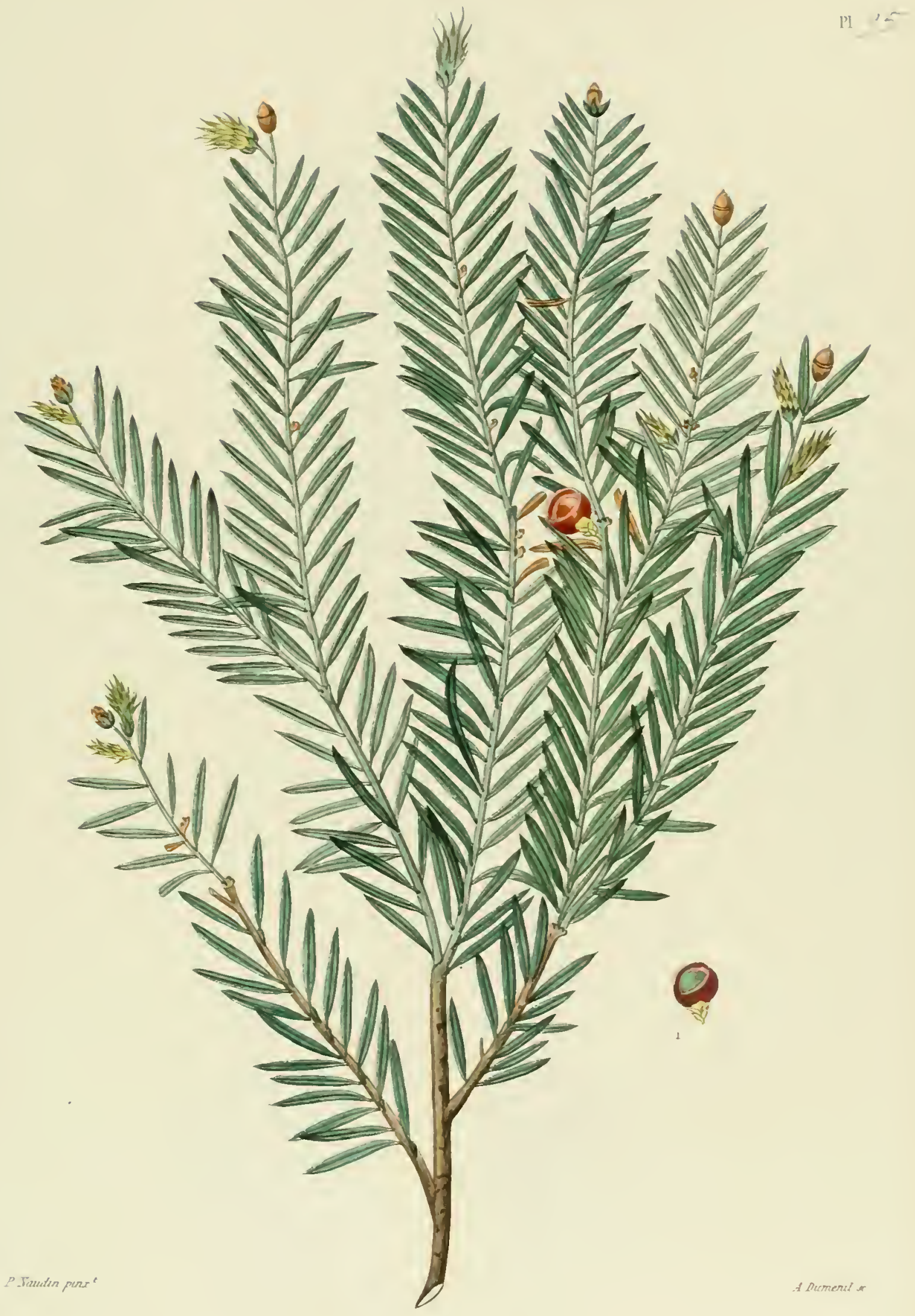




$$
\text { - }
$$


Pl ?

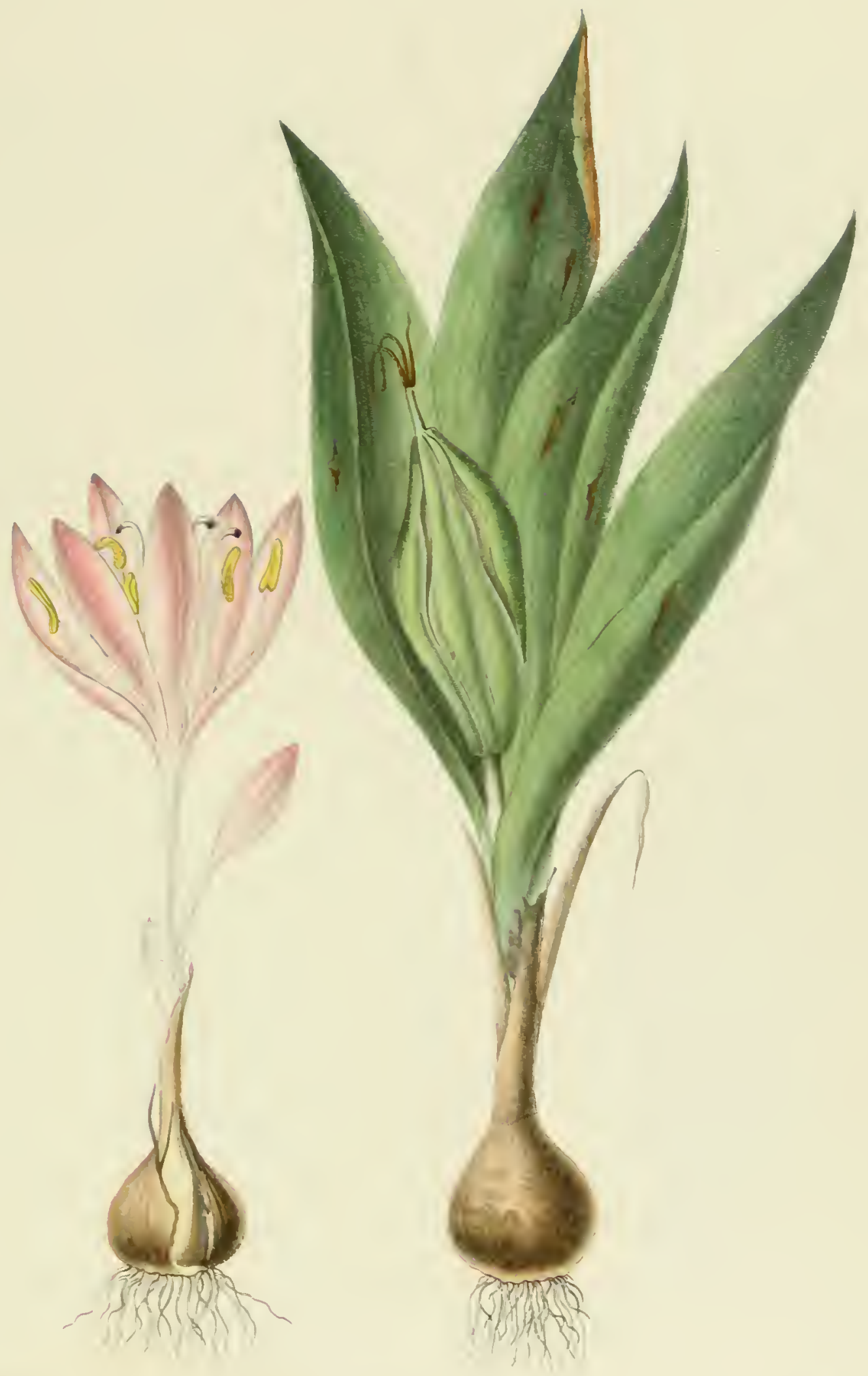




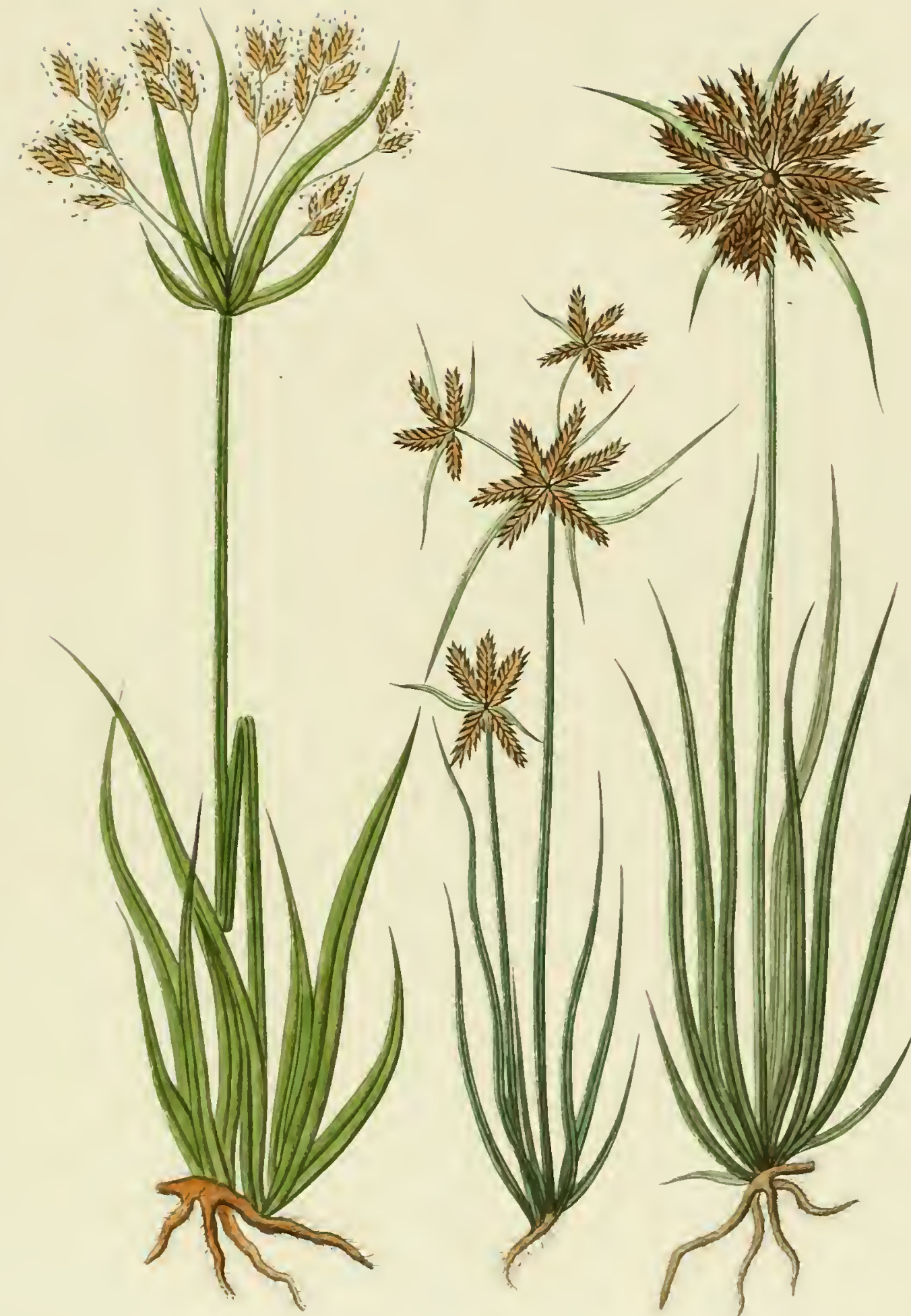



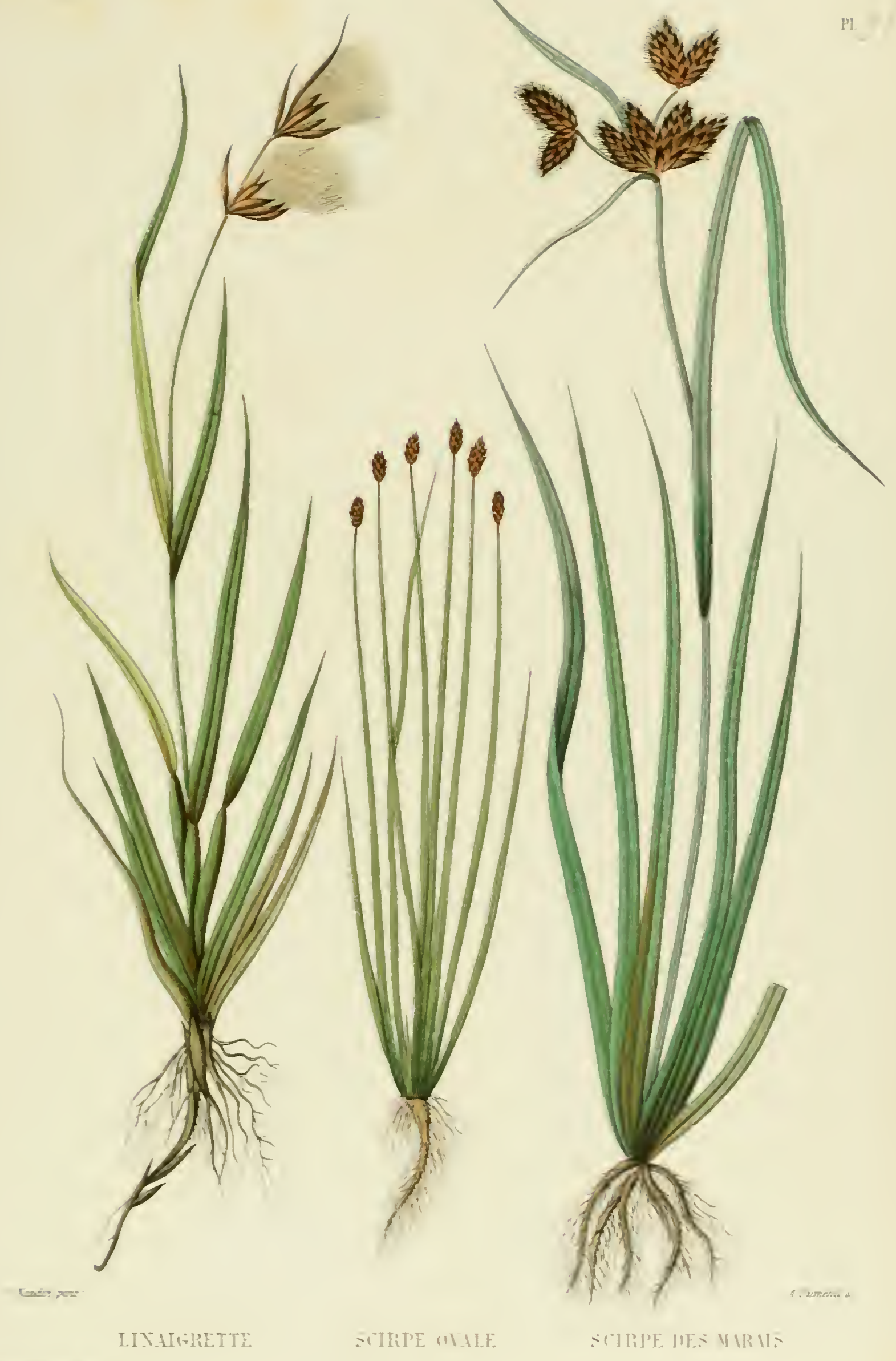





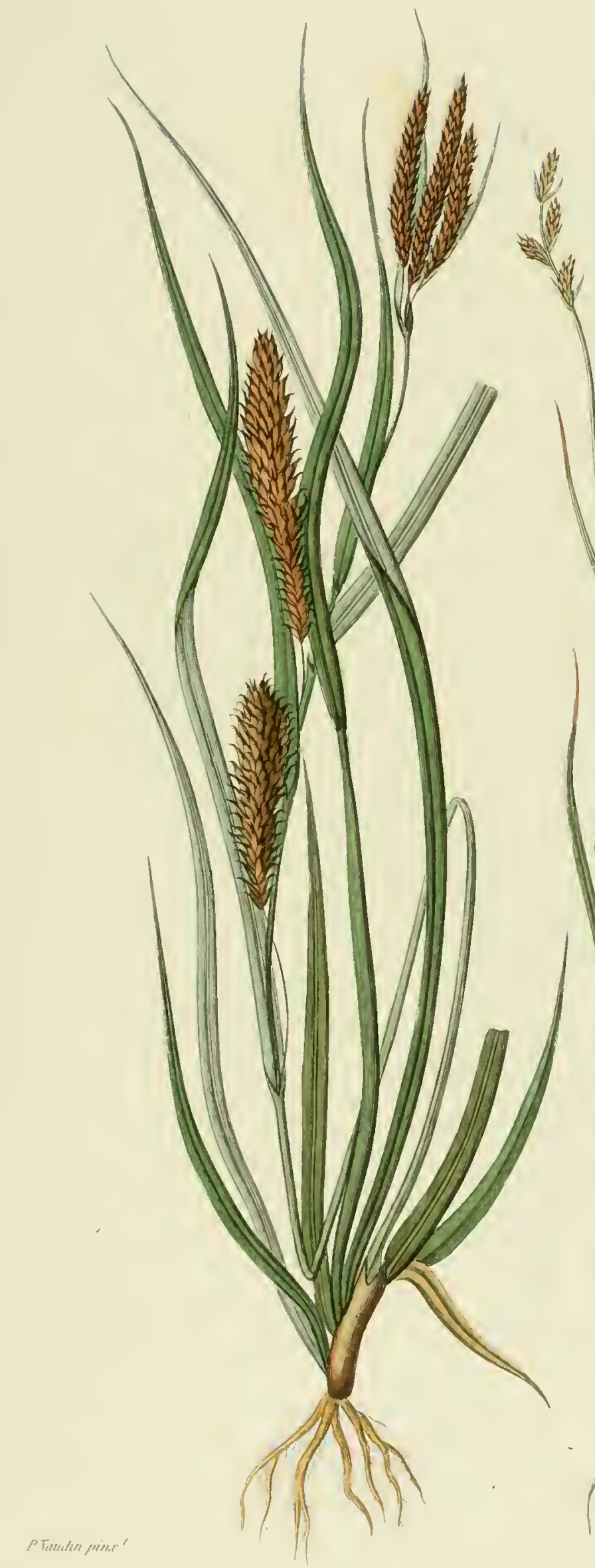

11. ?Y

L t 1 



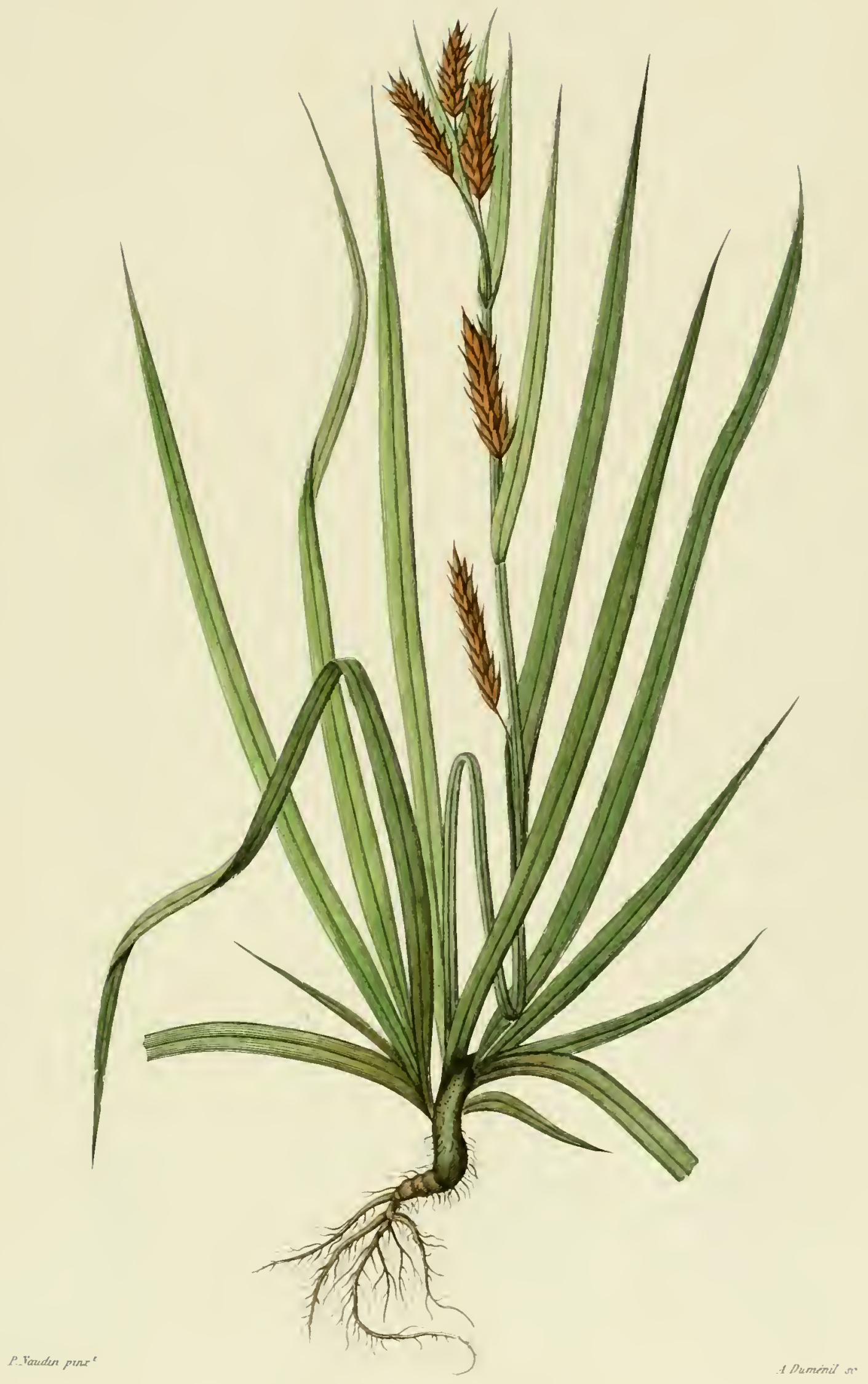

PI. $/ \infty$ 


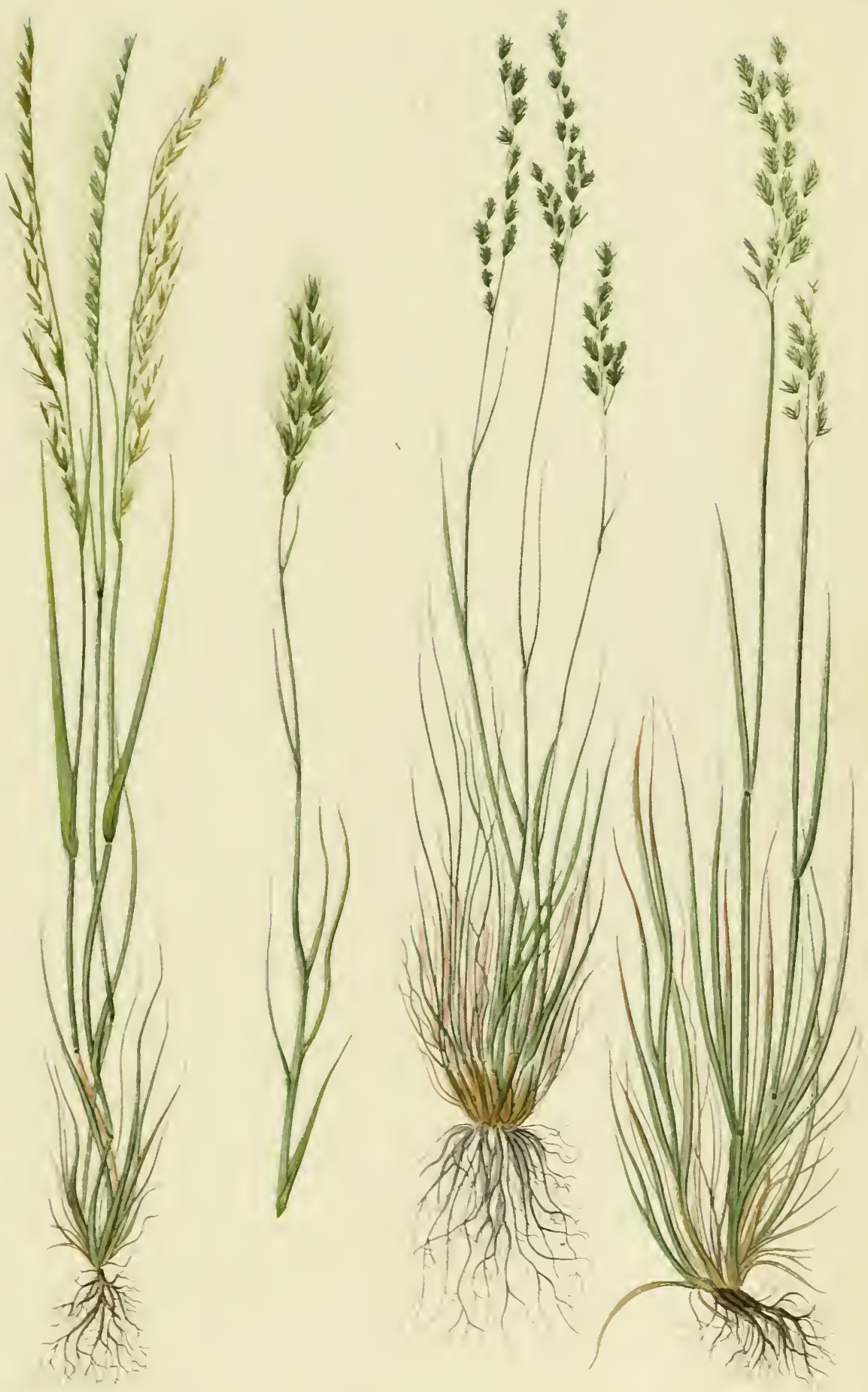



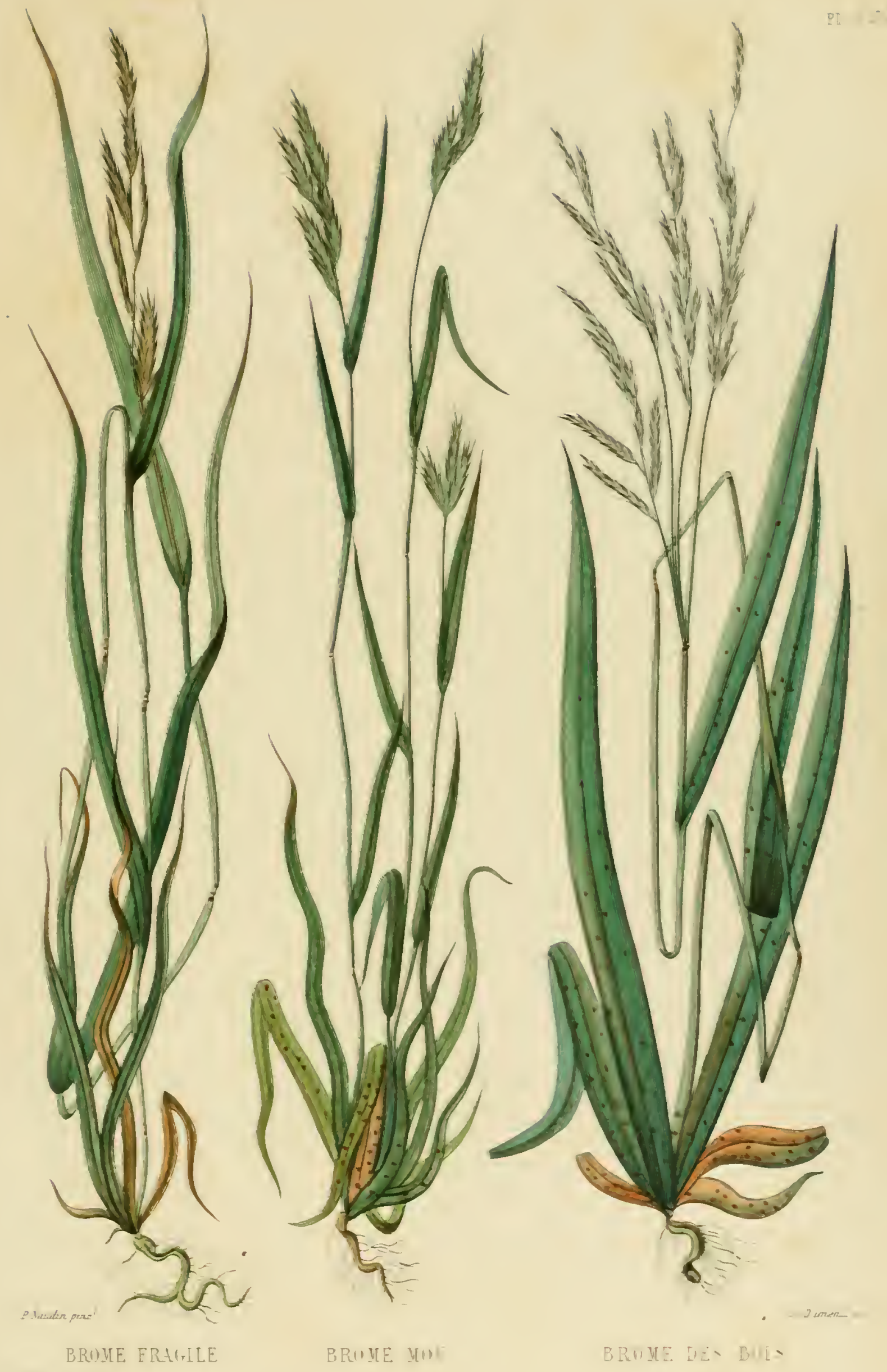





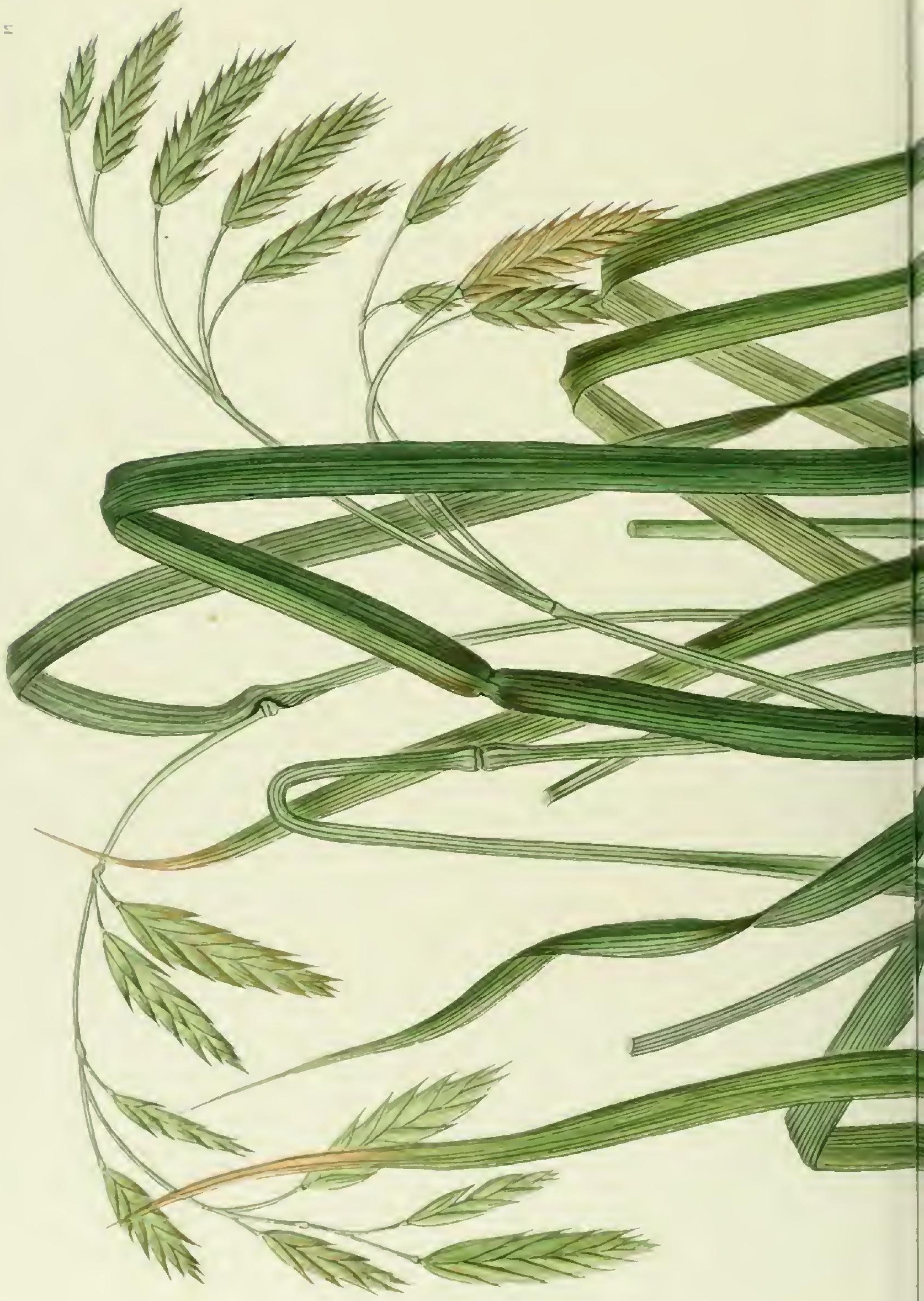





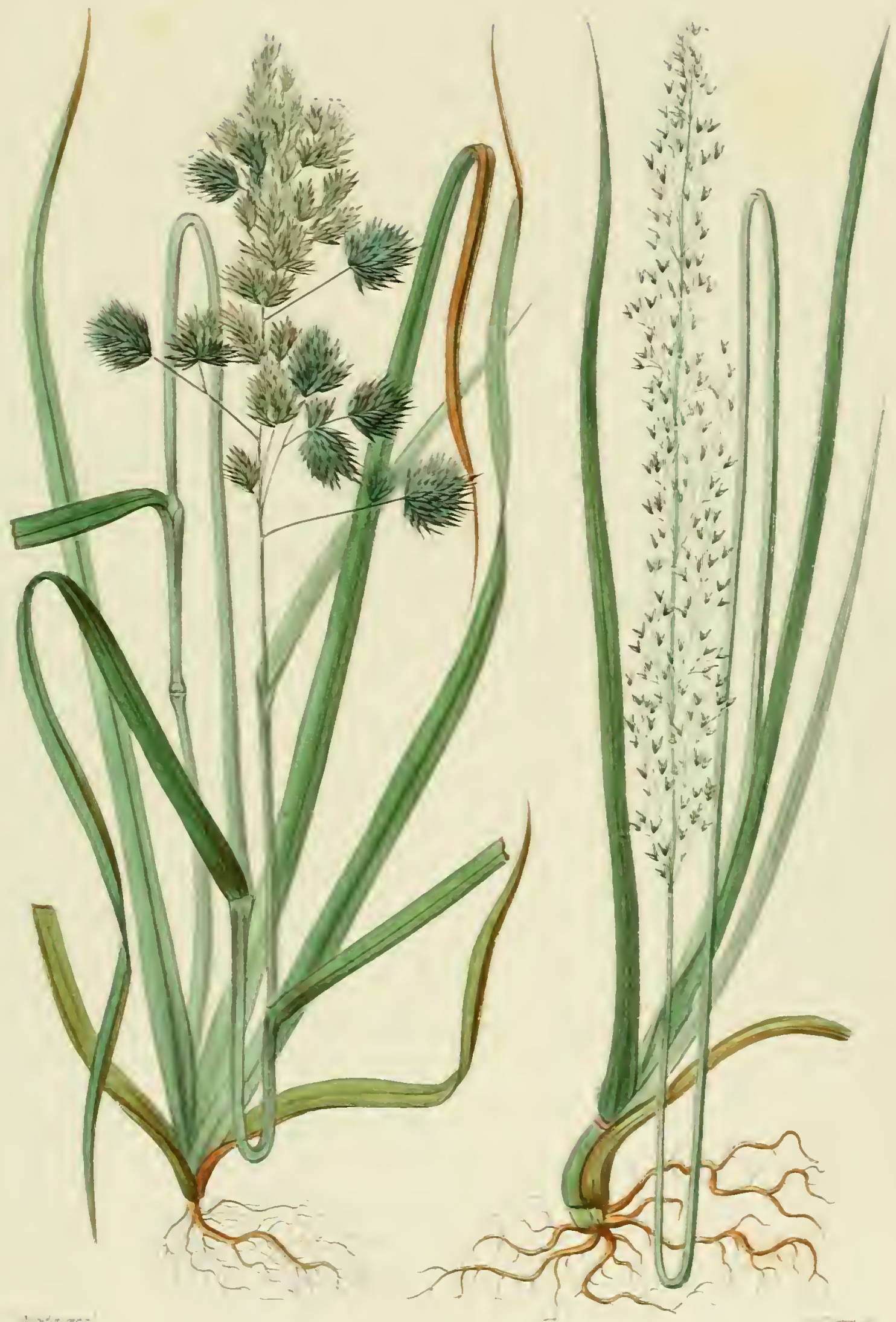

DA, TYLE PELUTMIIE. 


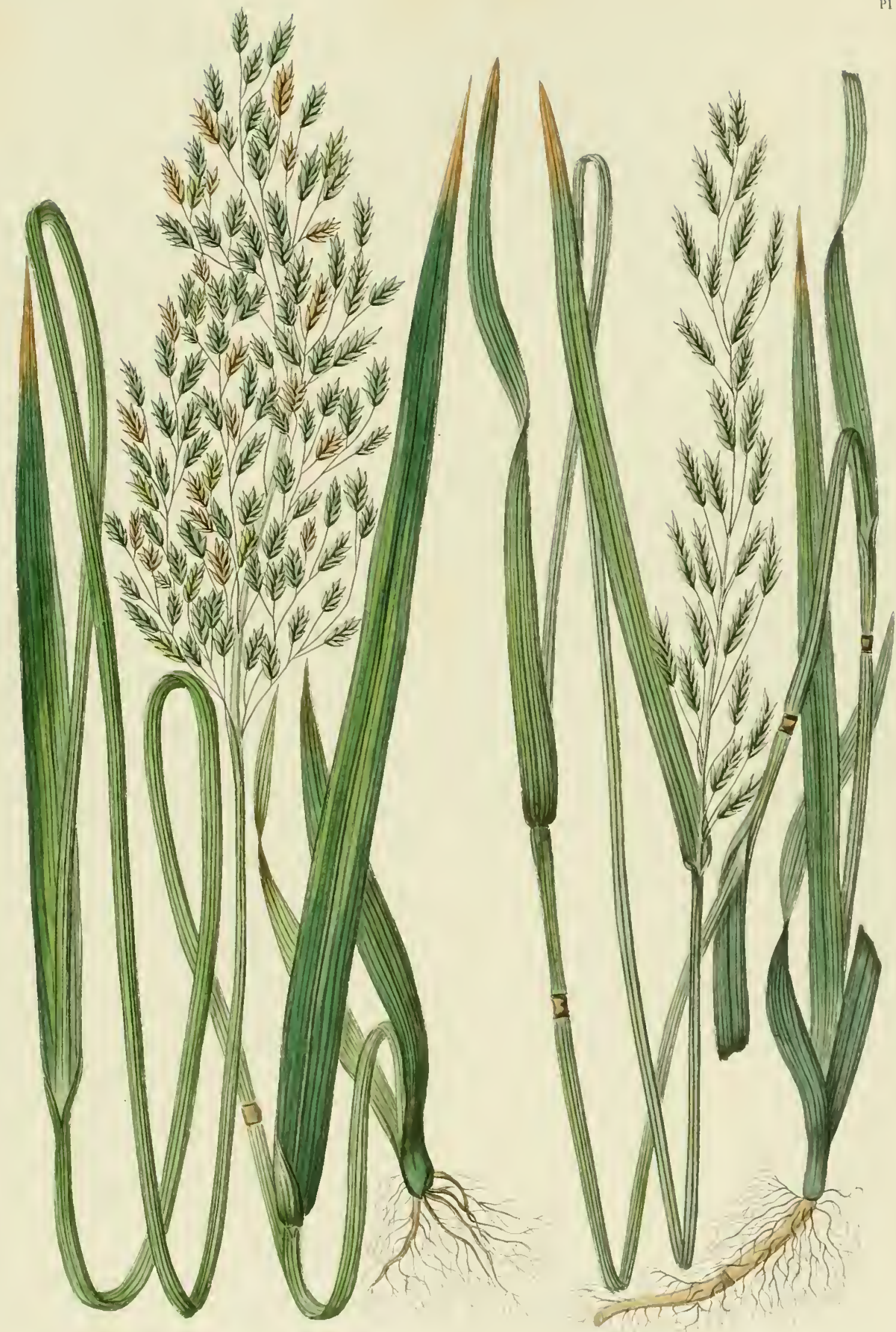

(SLCERIE AOI ATHOLE. 



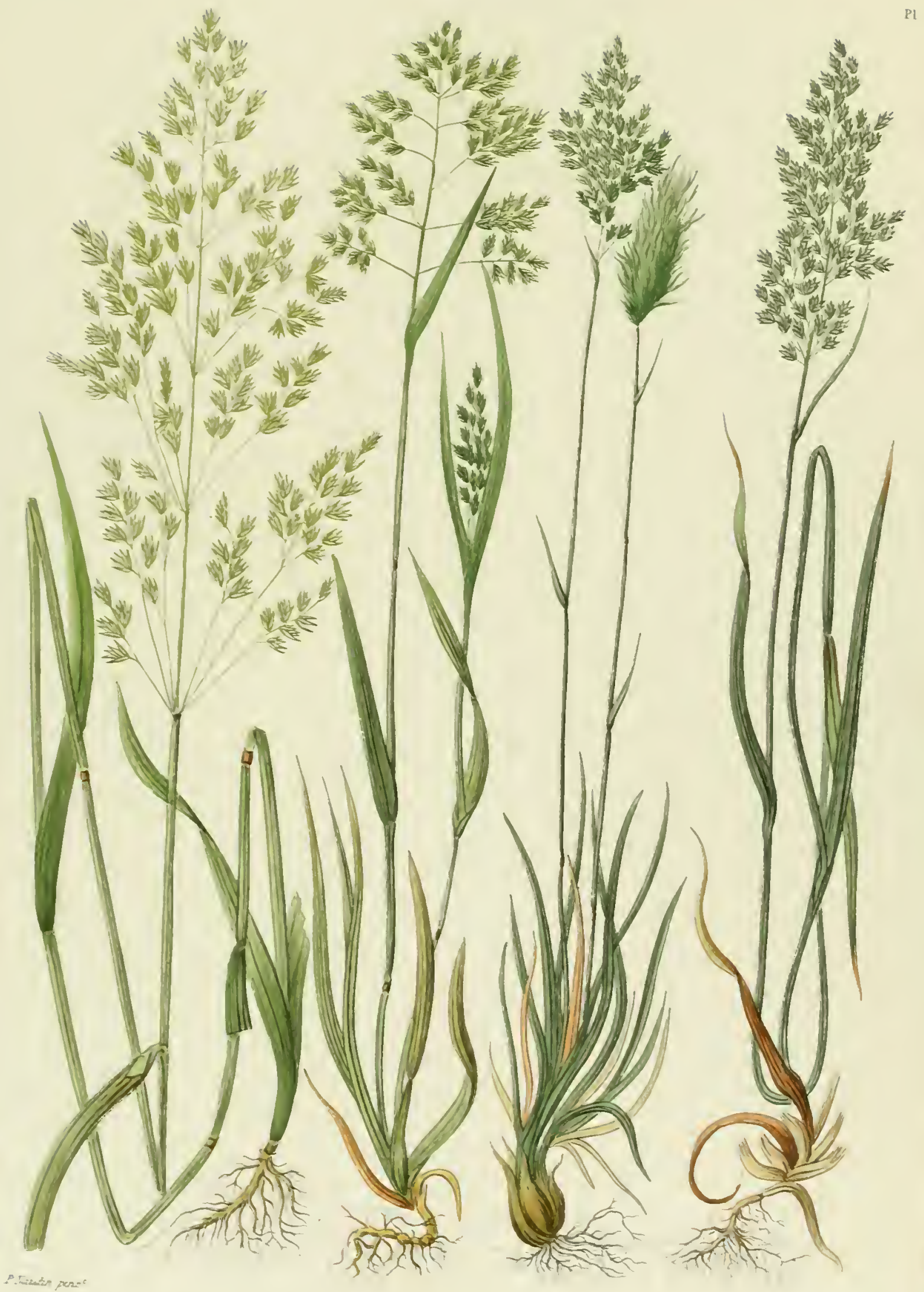

PATI RIS (') YIII 



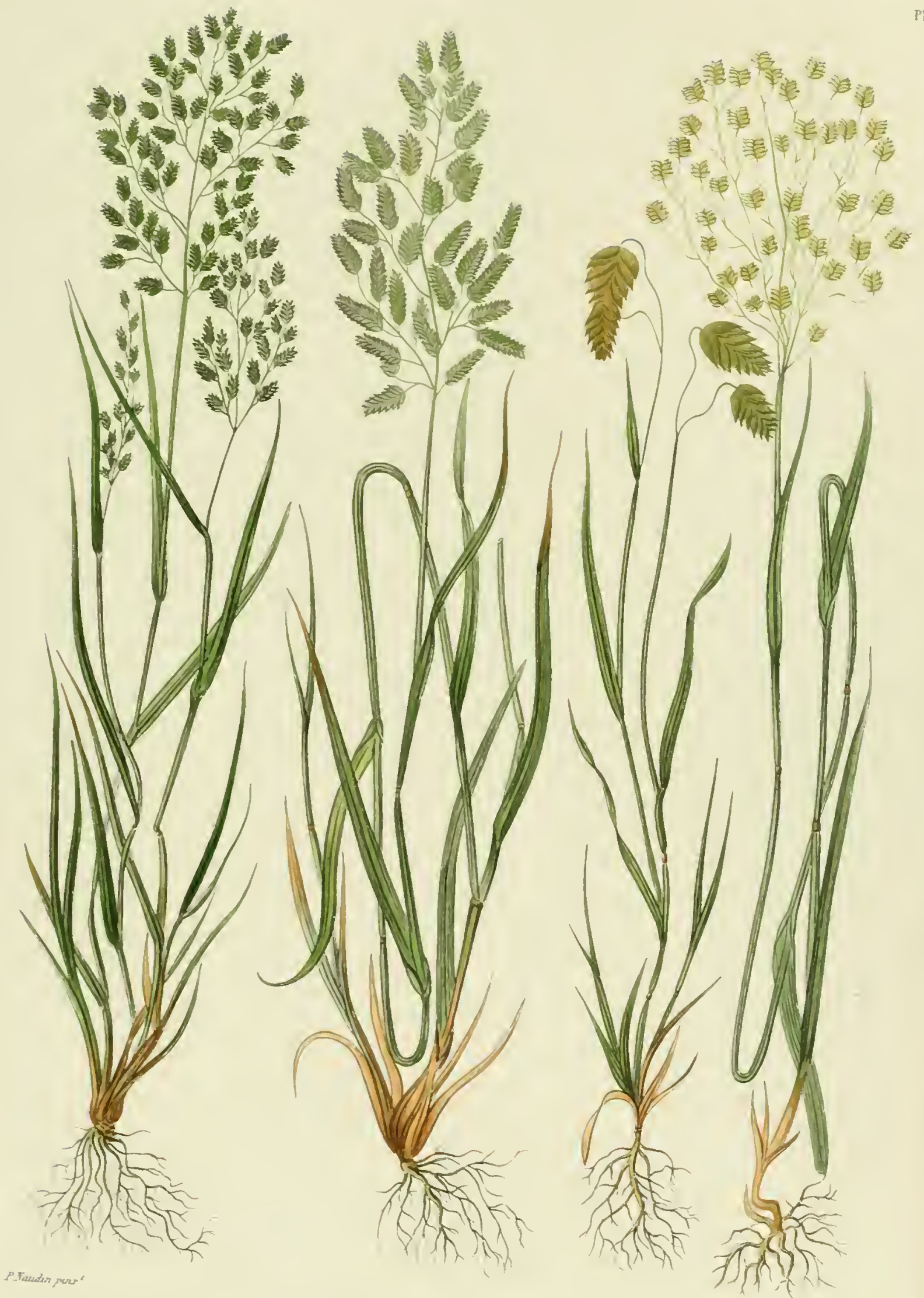

PITIRIT ERAGROSTI: 


$$
\text { , }
$$




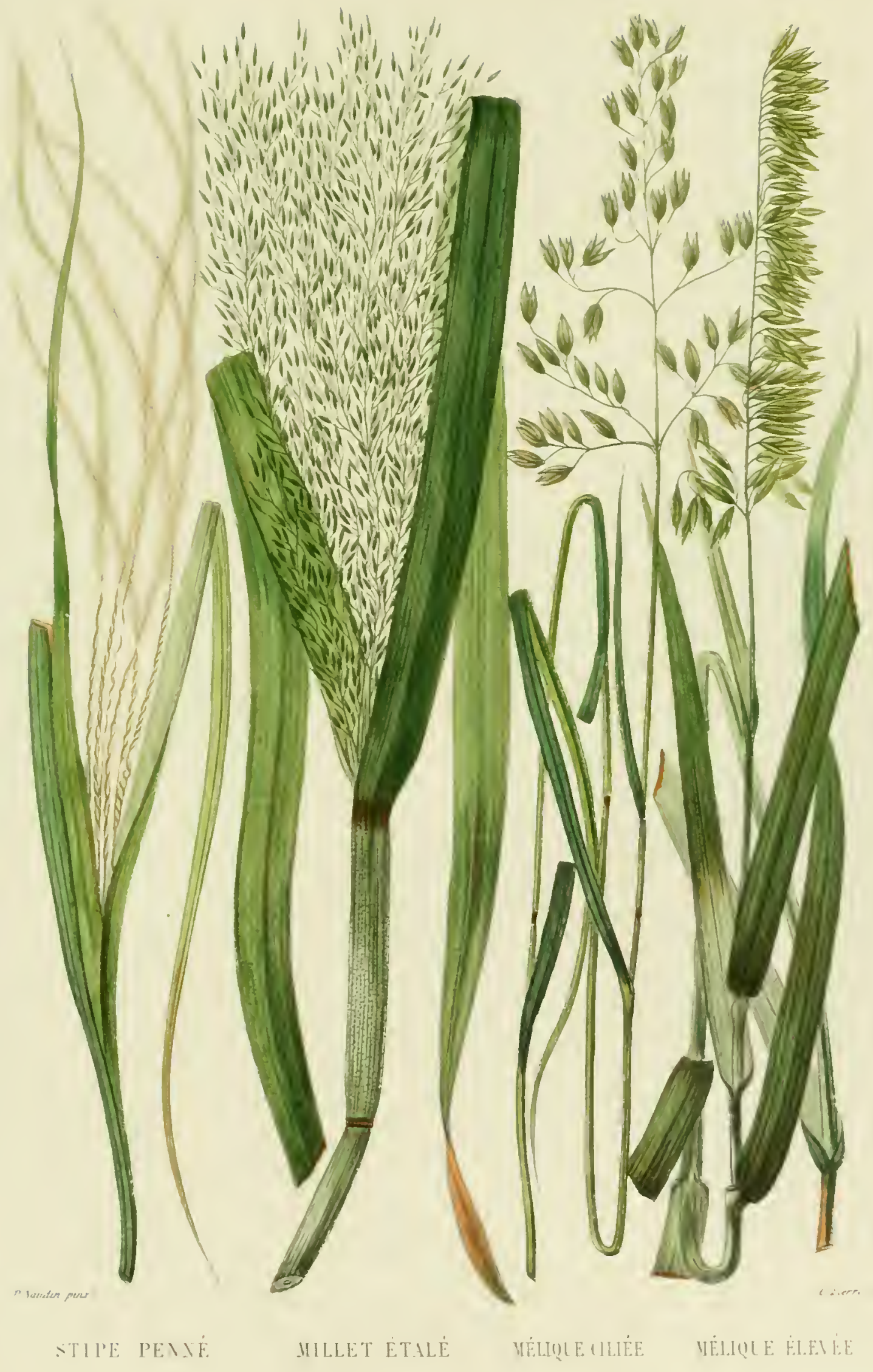





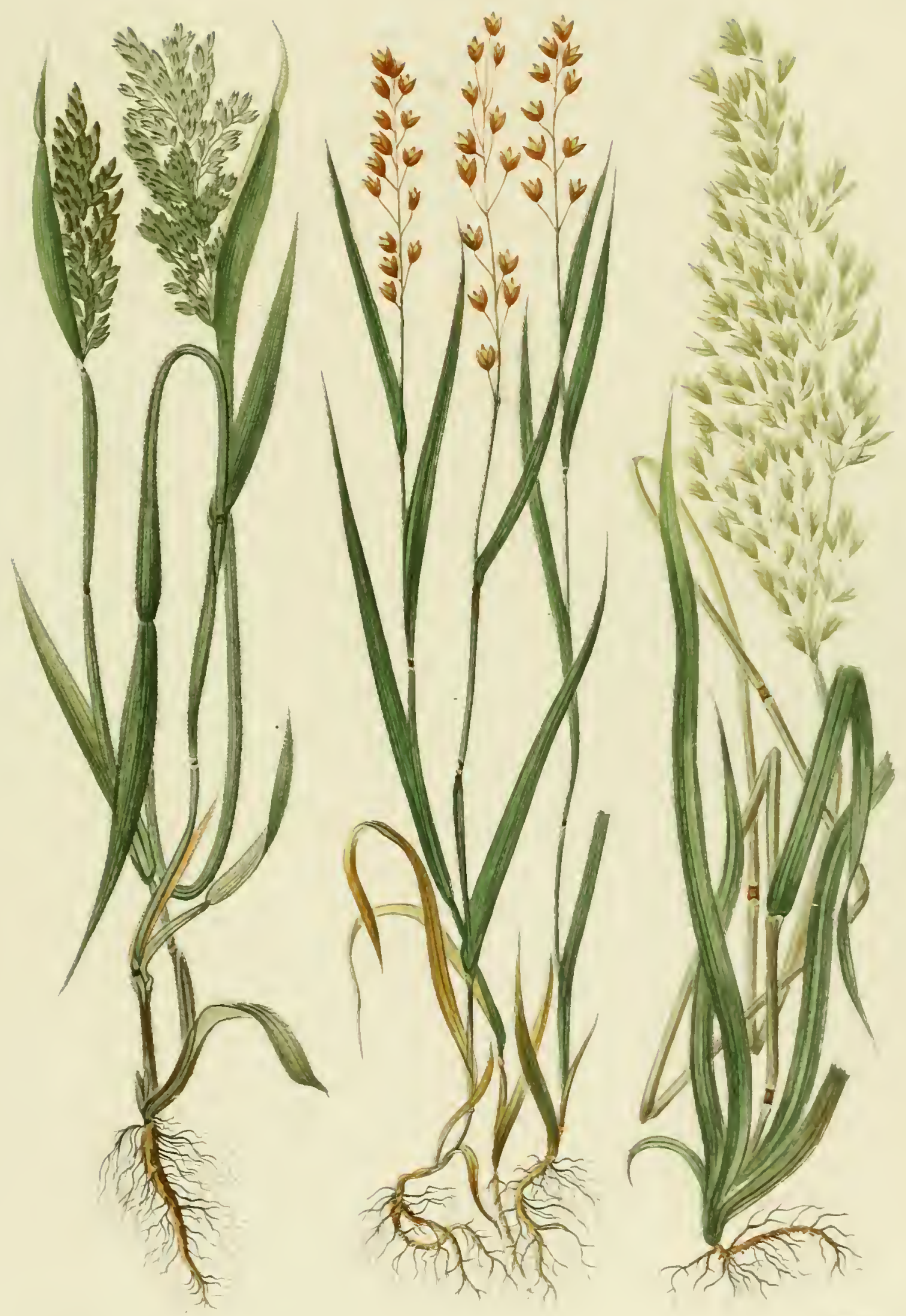





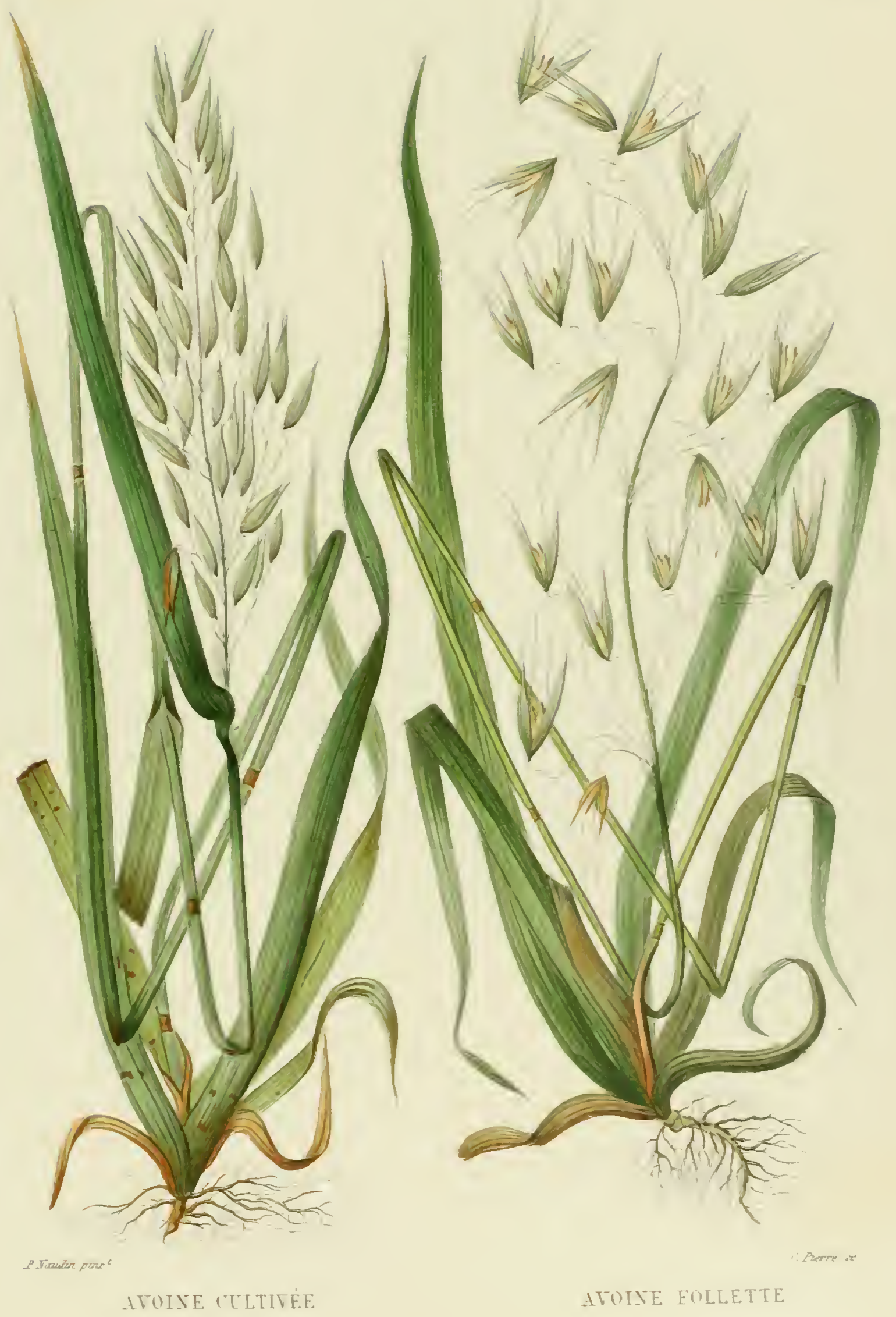





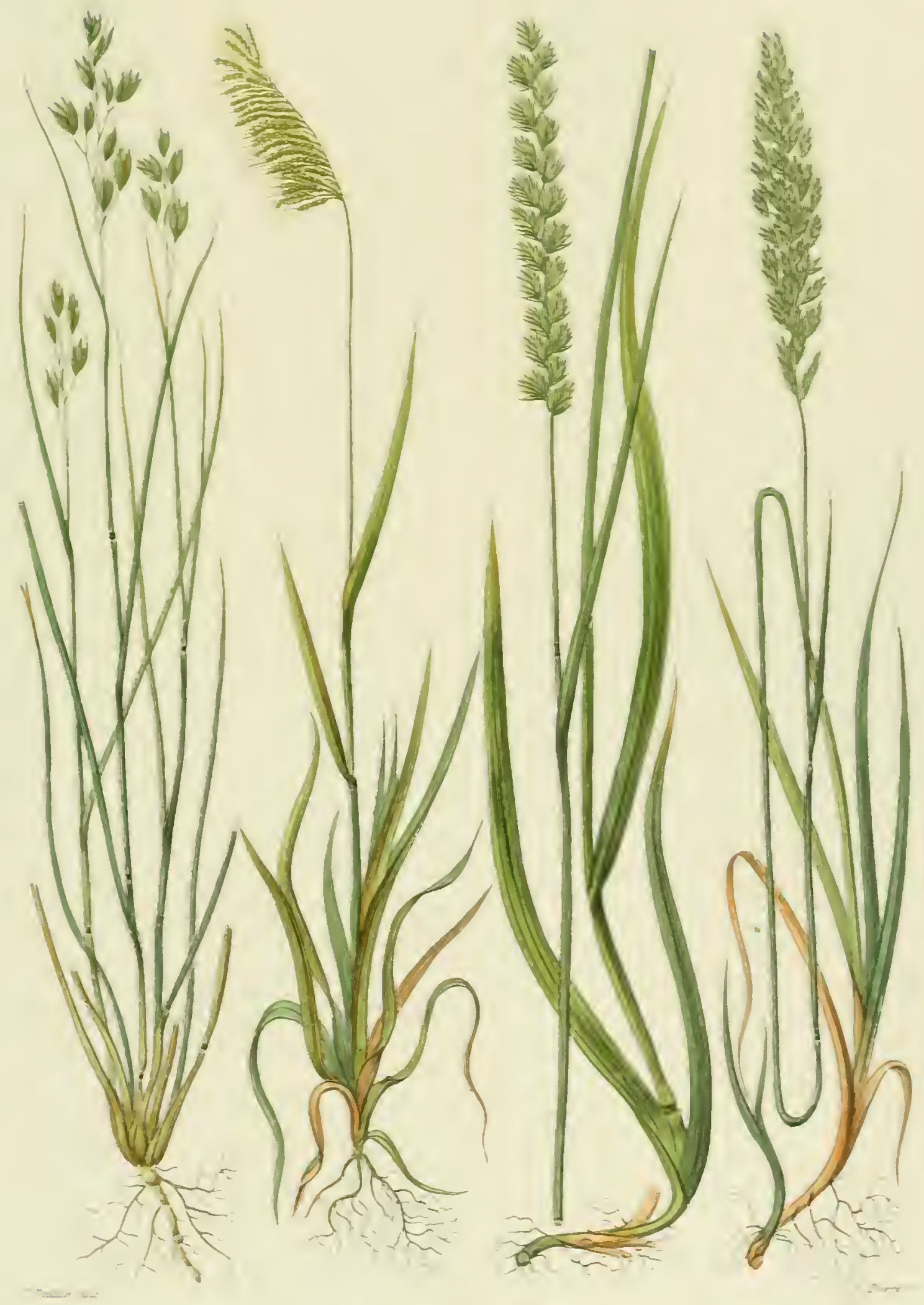

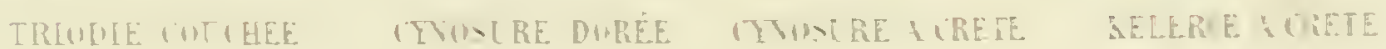




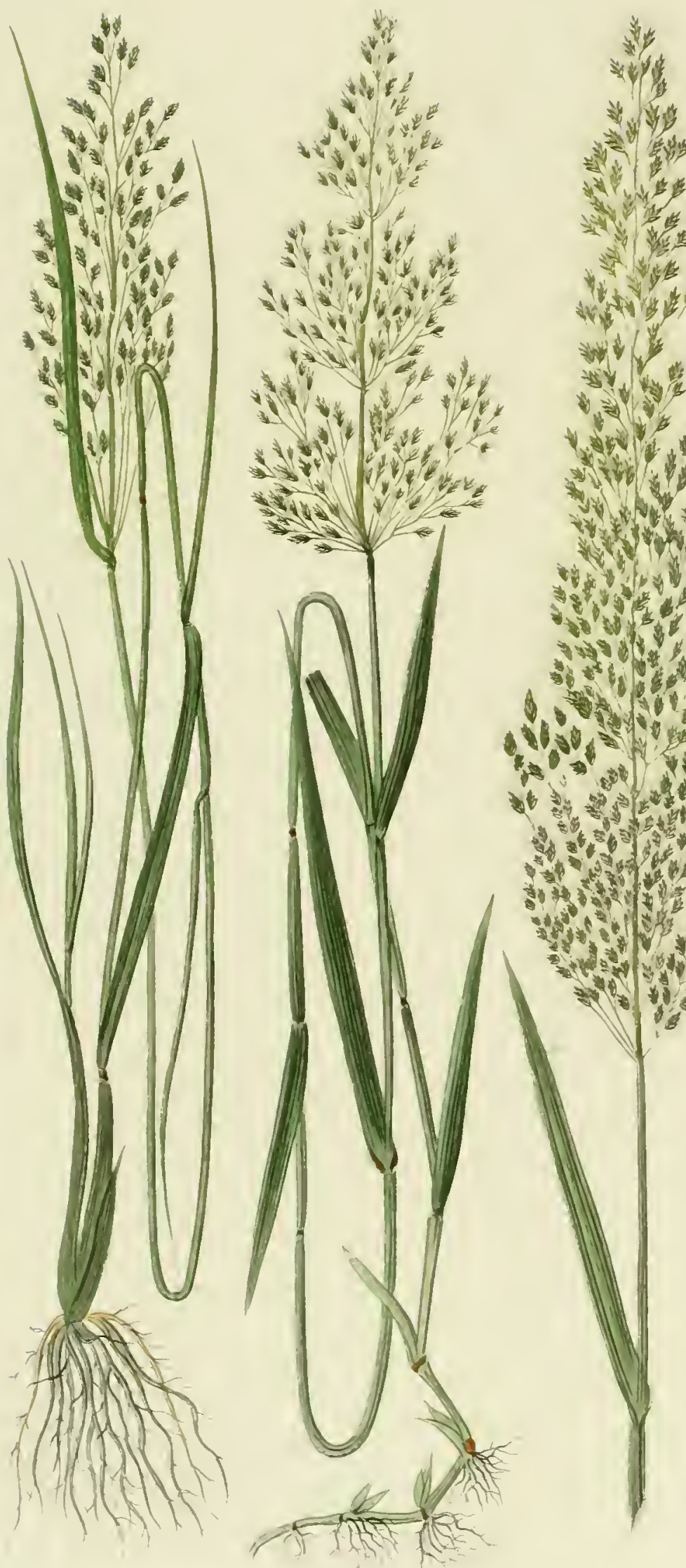

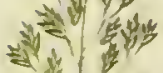

4iv w

补,

* t

tive

诂y

$\forall=1$

Nove

*itiv

*1 ve

Ny

+

3 (1)

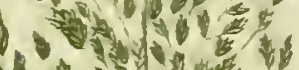

$101, y$

- 1

40 b

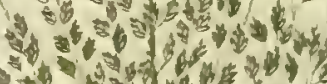

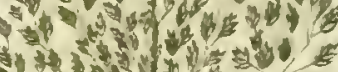
$-1+1$ ?

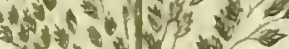

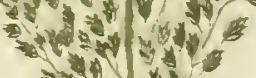

*1.
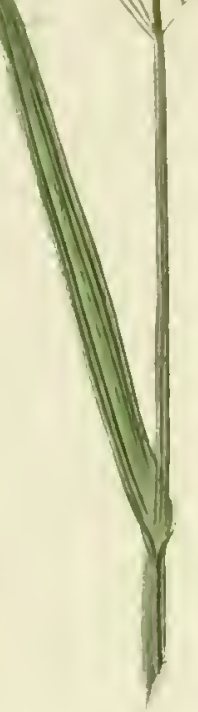

an

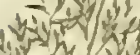
- 1 , $\checkmark y$ $x-1=1$ (5) 그 स $y_{1} y<$ सै तो है A 14 \&
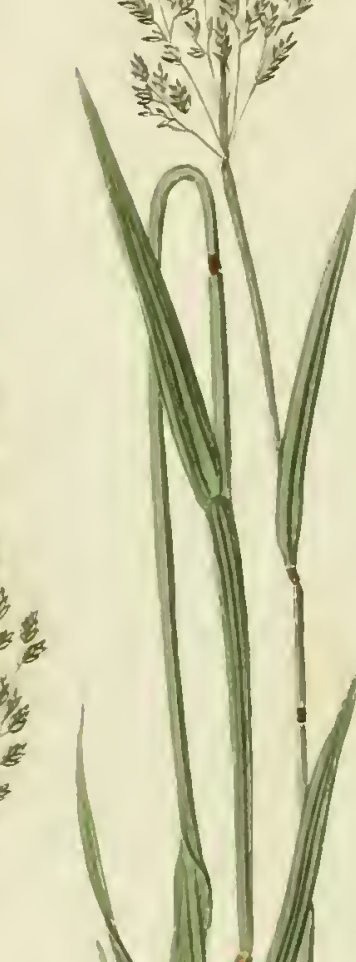


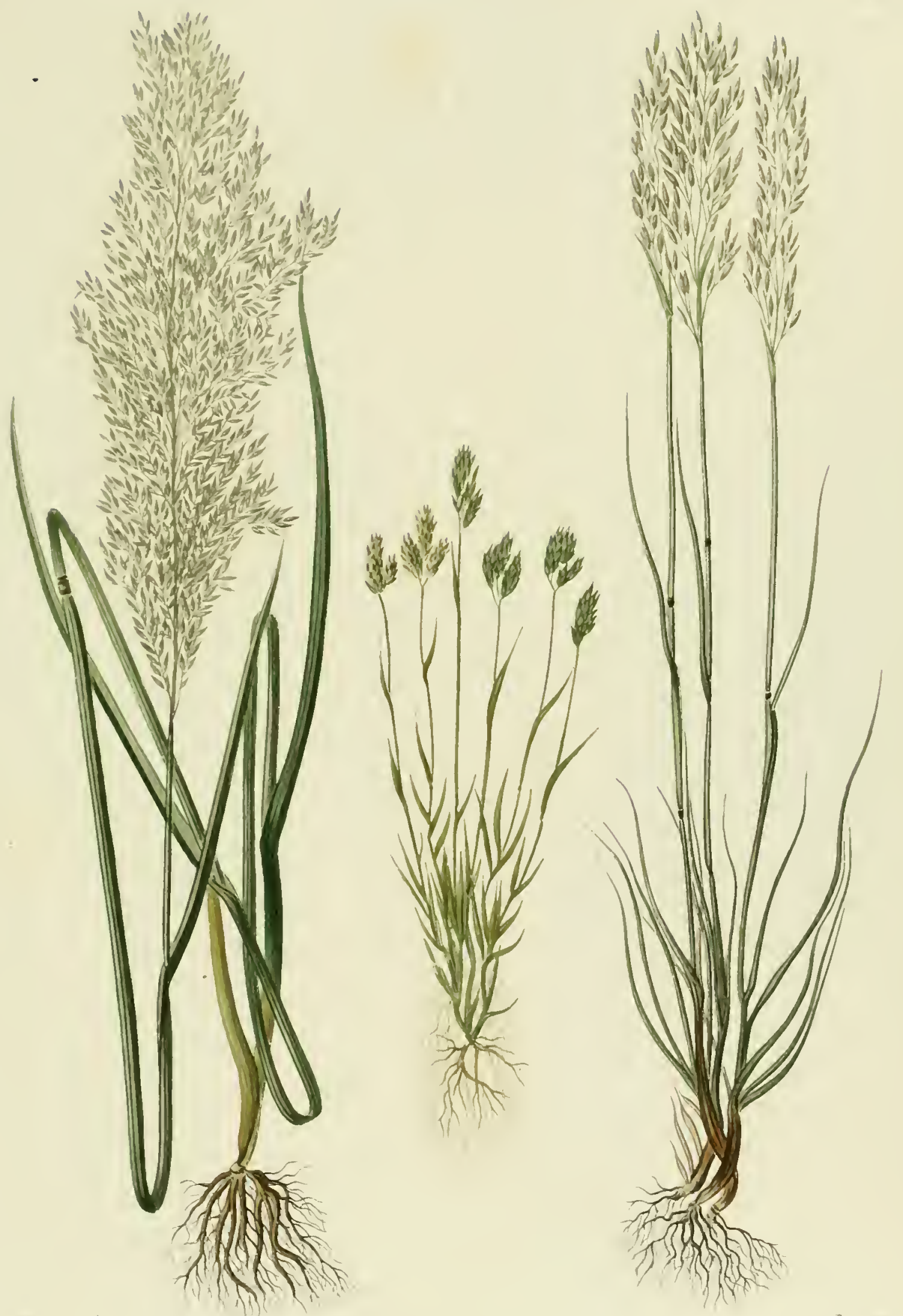

CANCHE GIZONINTE.

(INCIE PRECOCE

CNYCHE FLEXUFLSE 



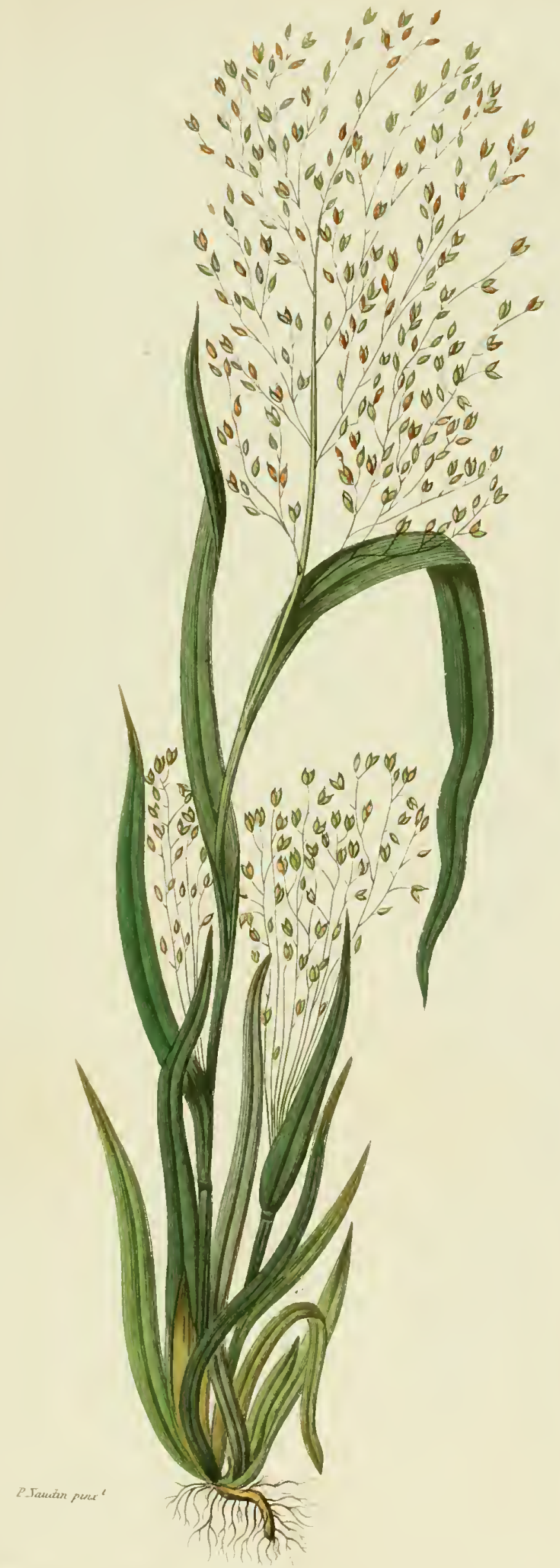

I'INIC INPIILIIRE

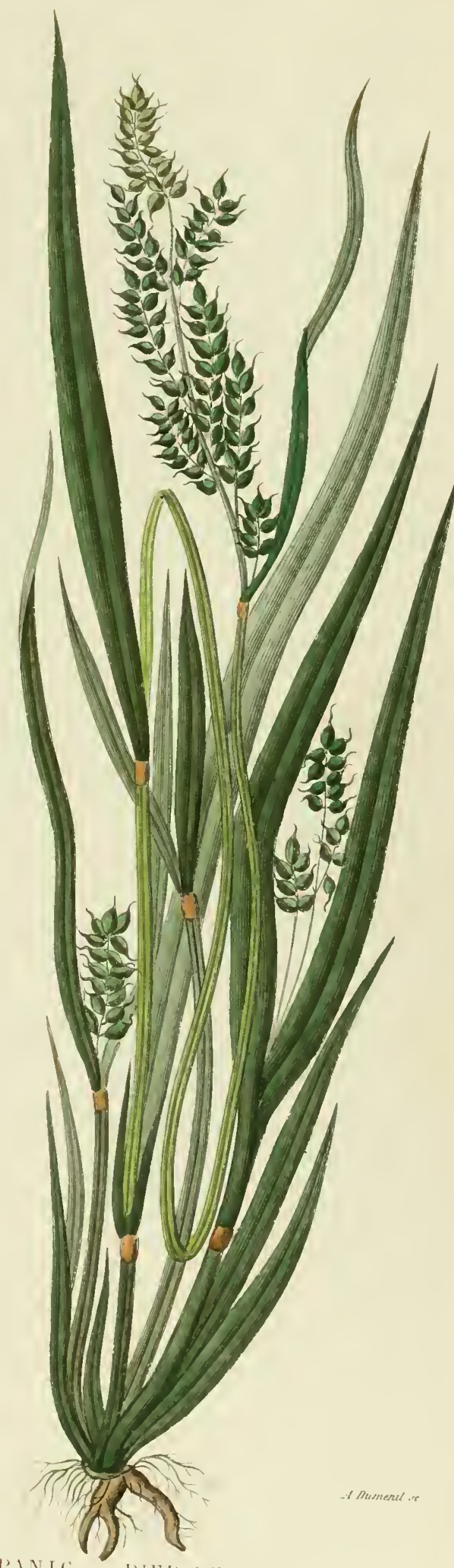




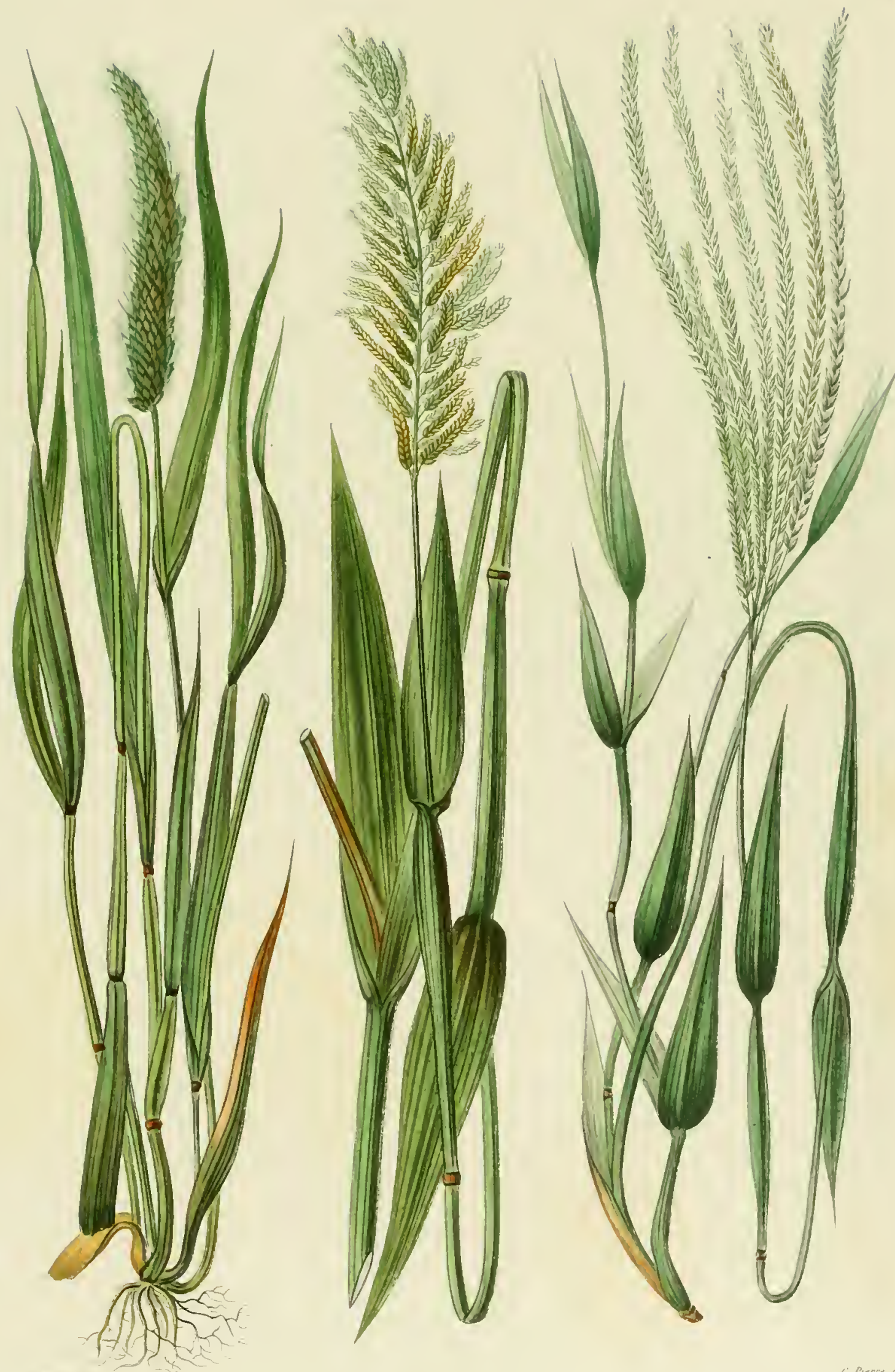



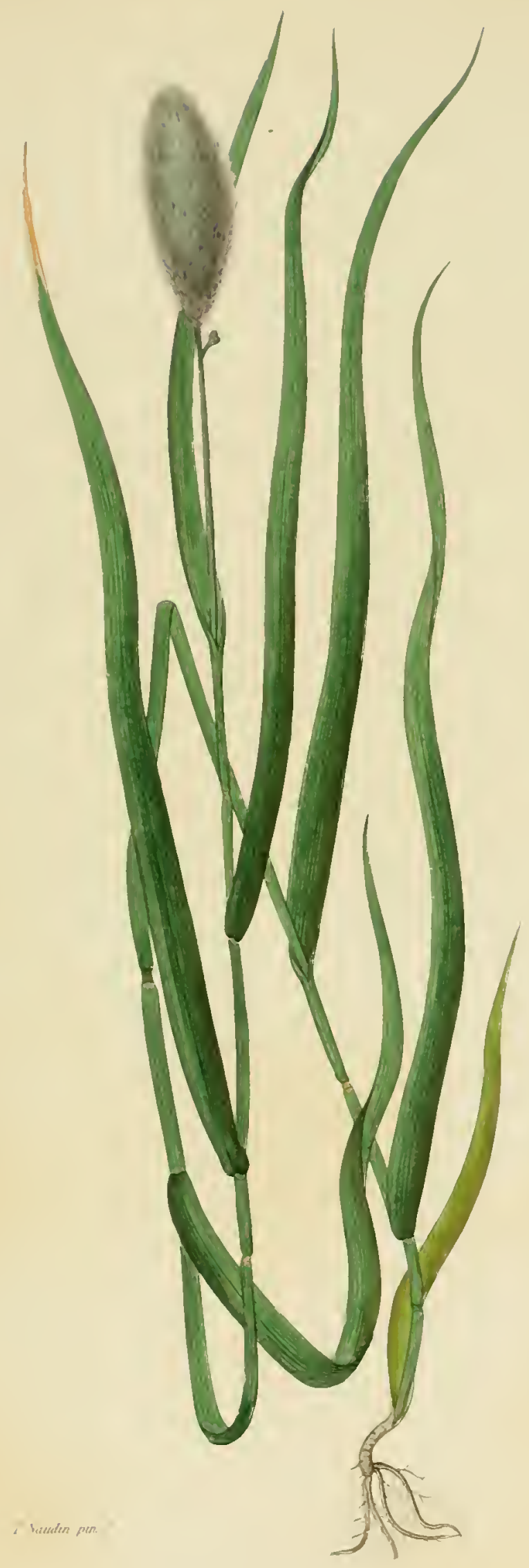

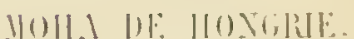

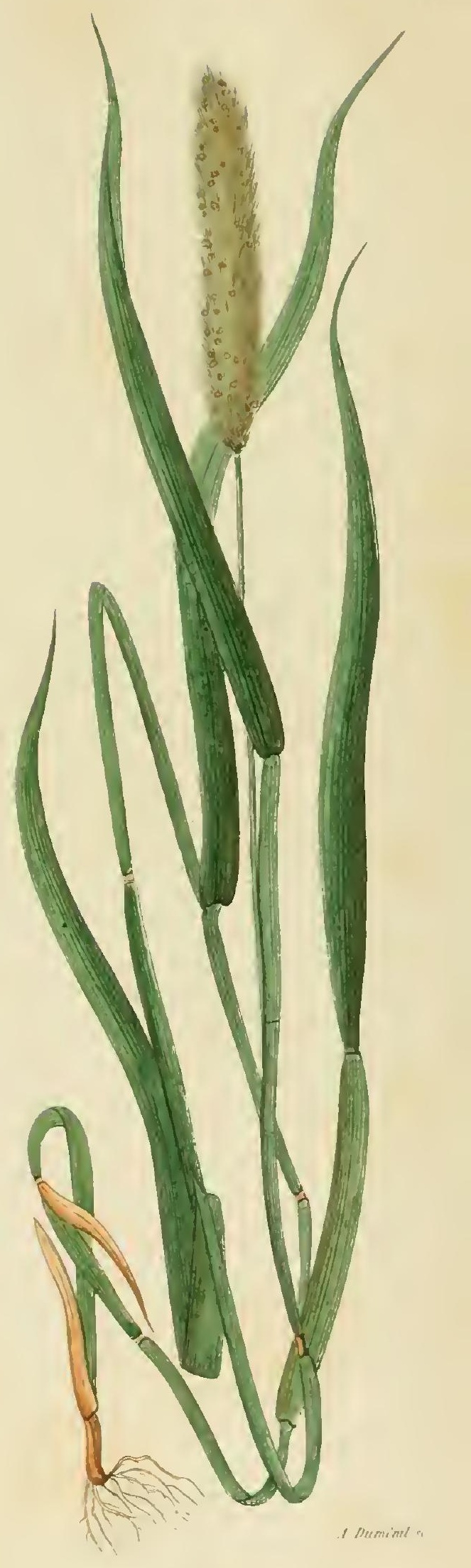

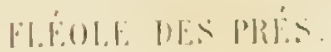





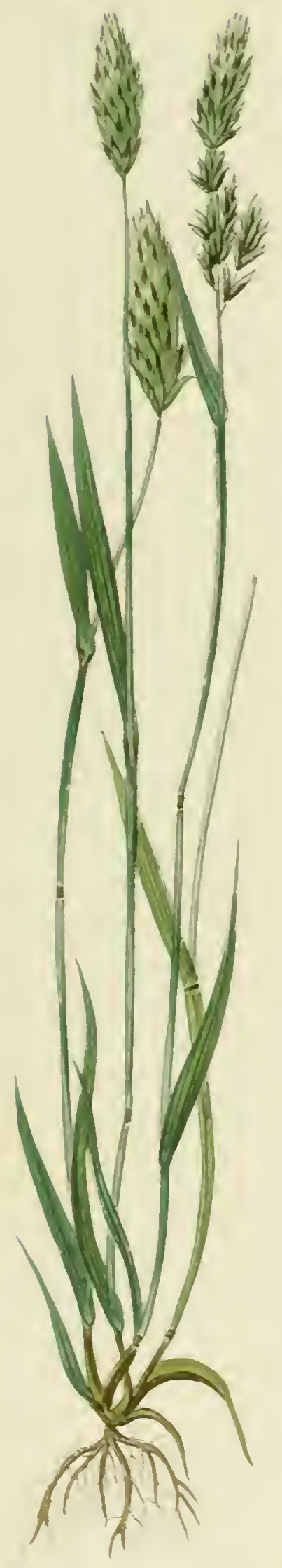

ELII IE OI) UR I TE

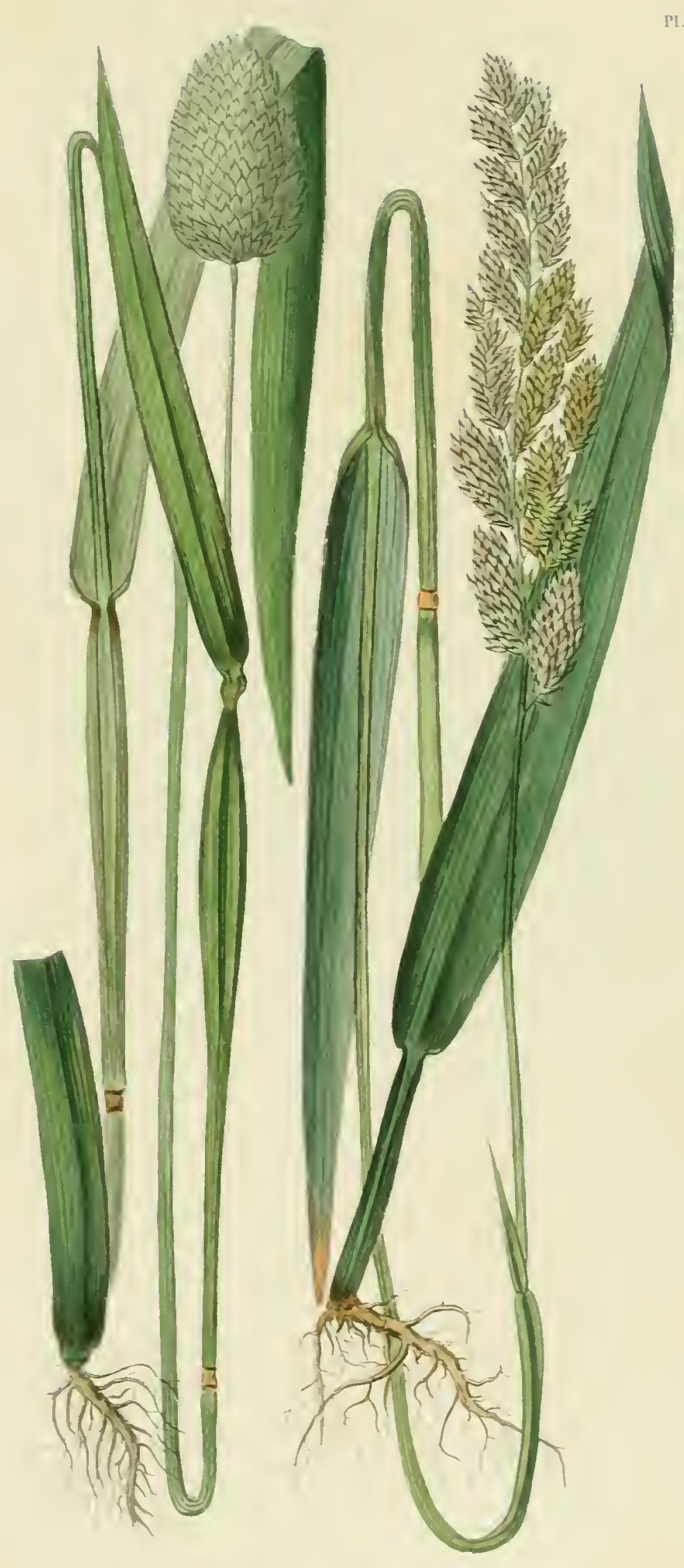

- Perrs

ILPSTE DES (IIARIES.

ILPLTE RO:E II. 


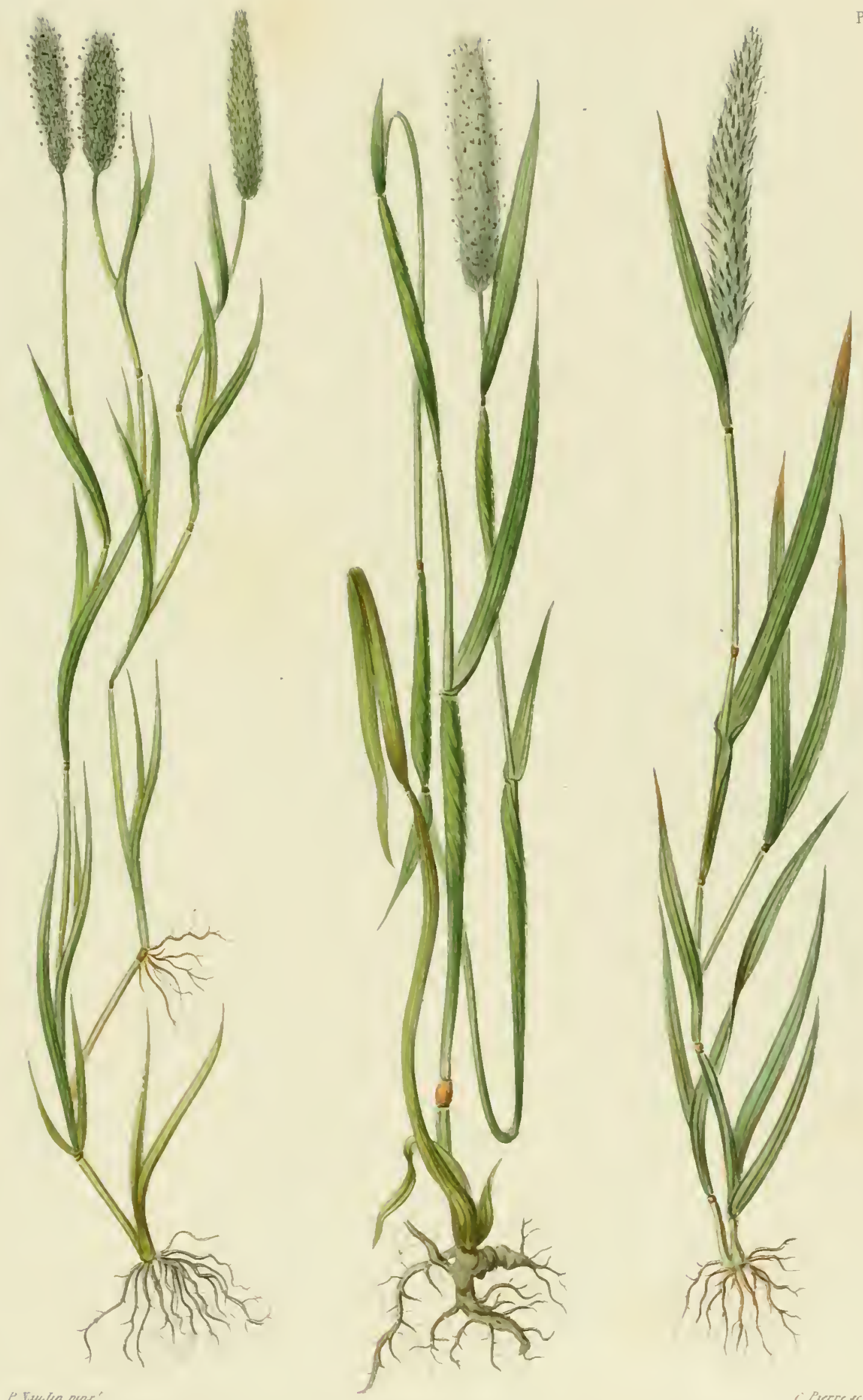

ILLPIS (FESOCILI.E 


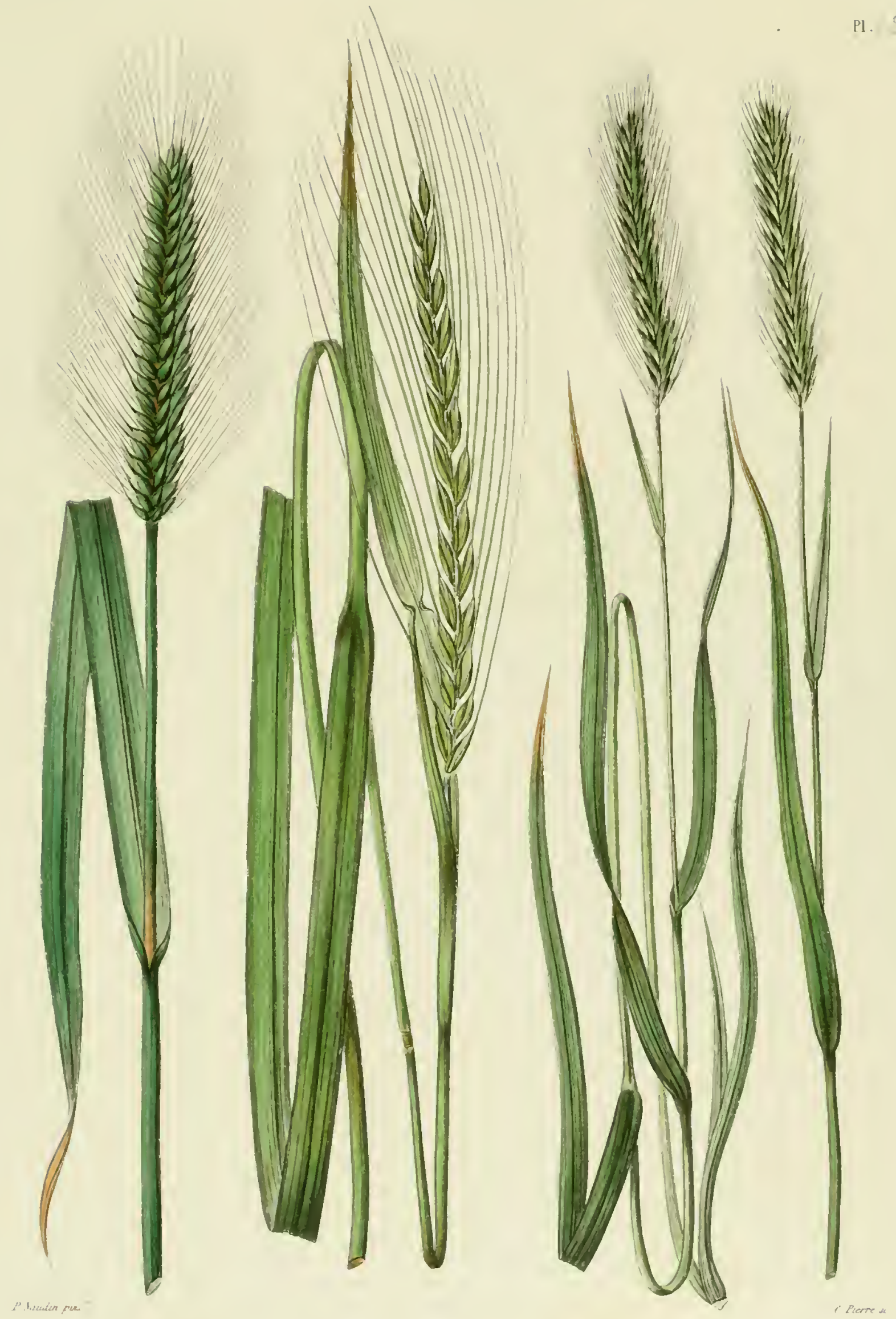

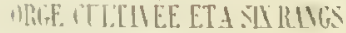

ORGE. ADELX RAVGS

ORGE. QLECE DE SOLRIS 



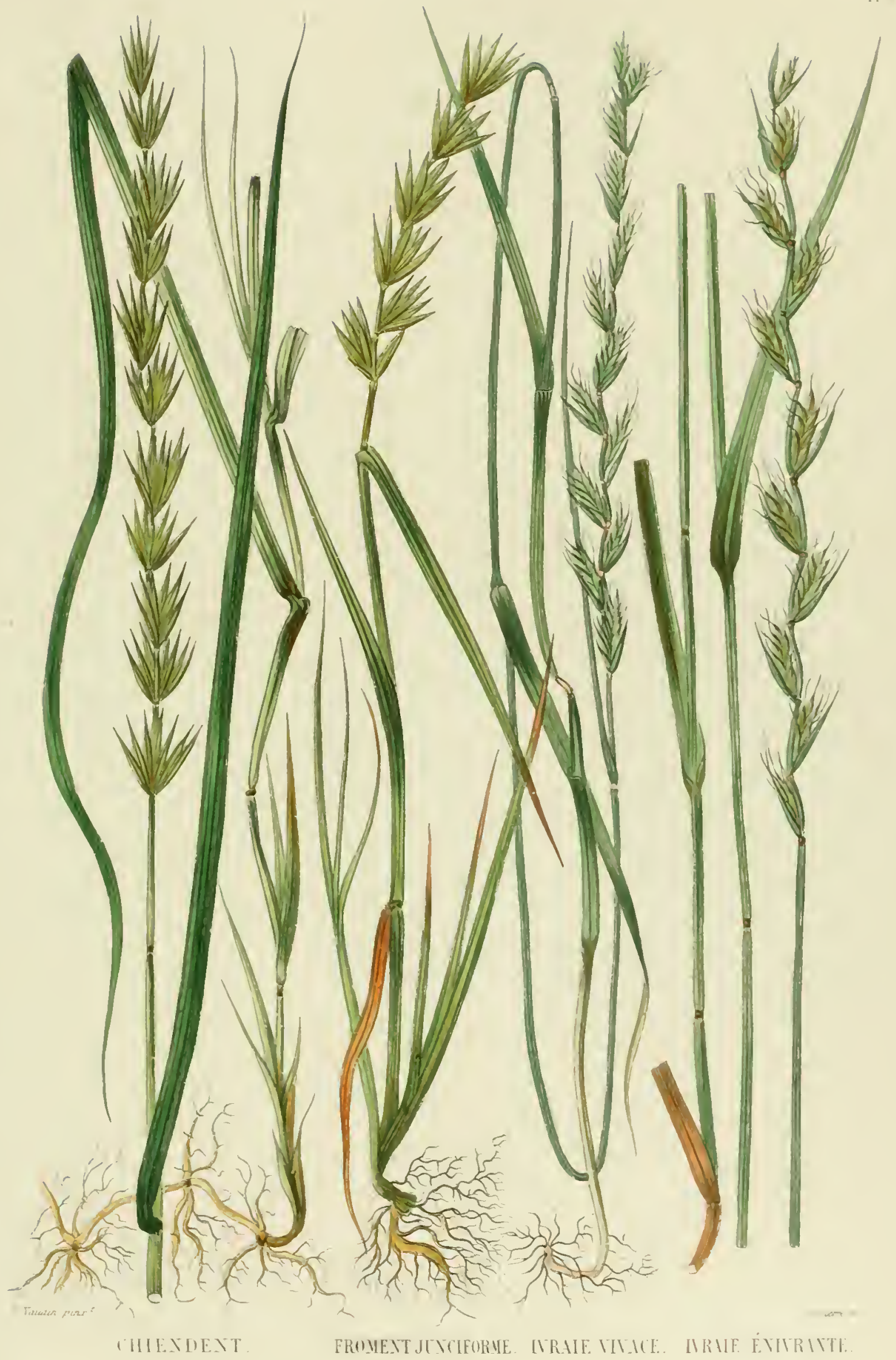





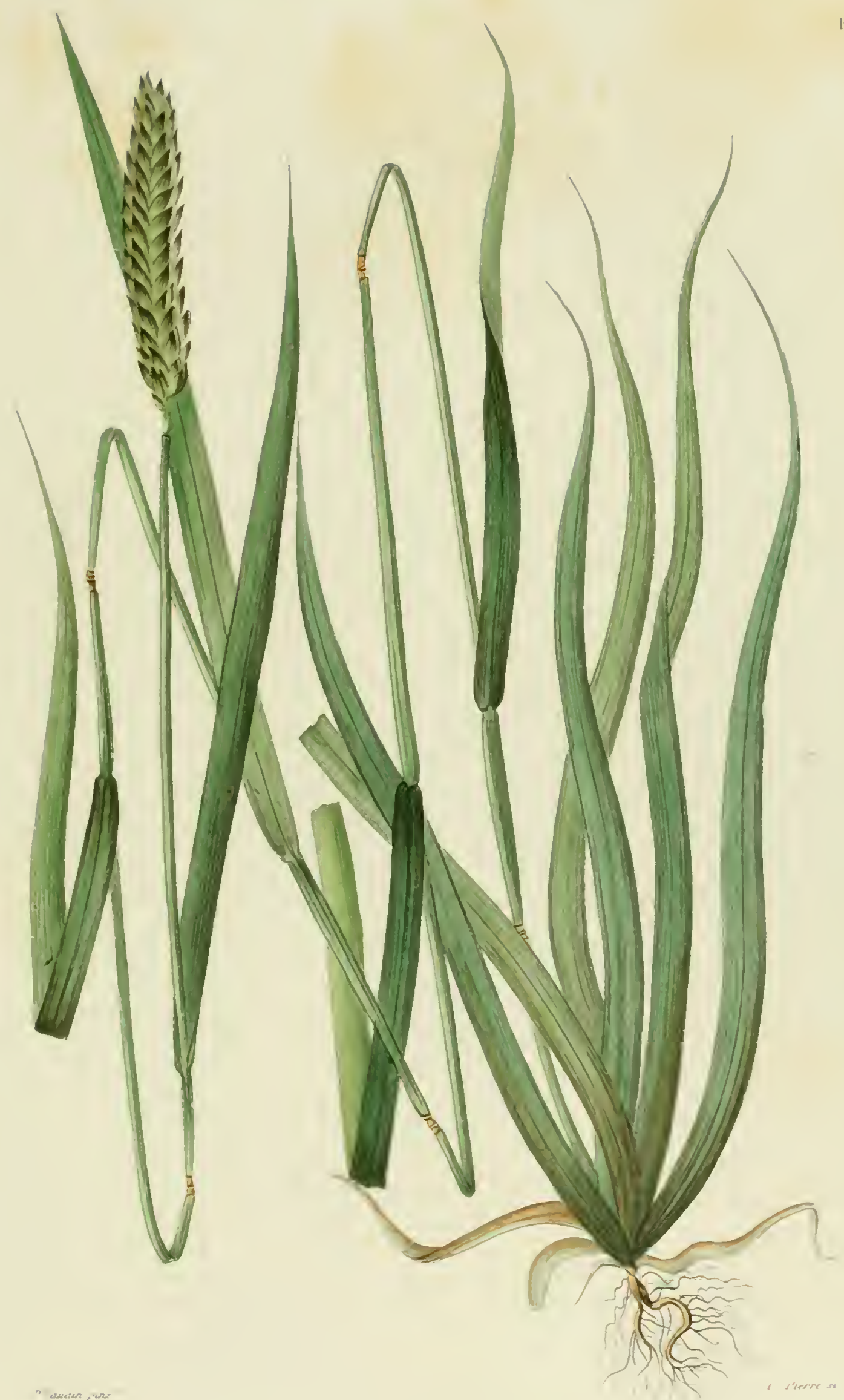

BI. I O I T NE 



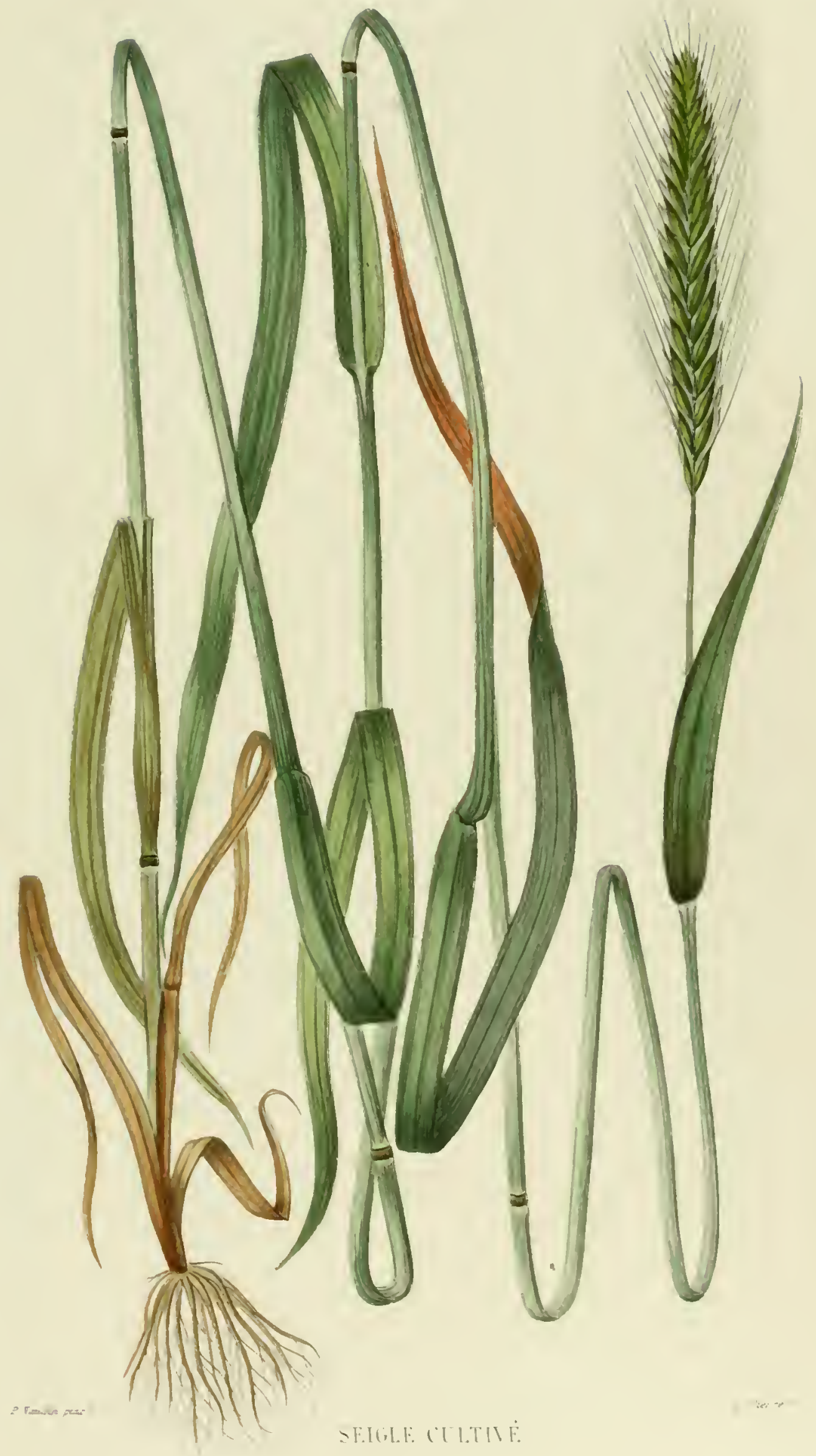





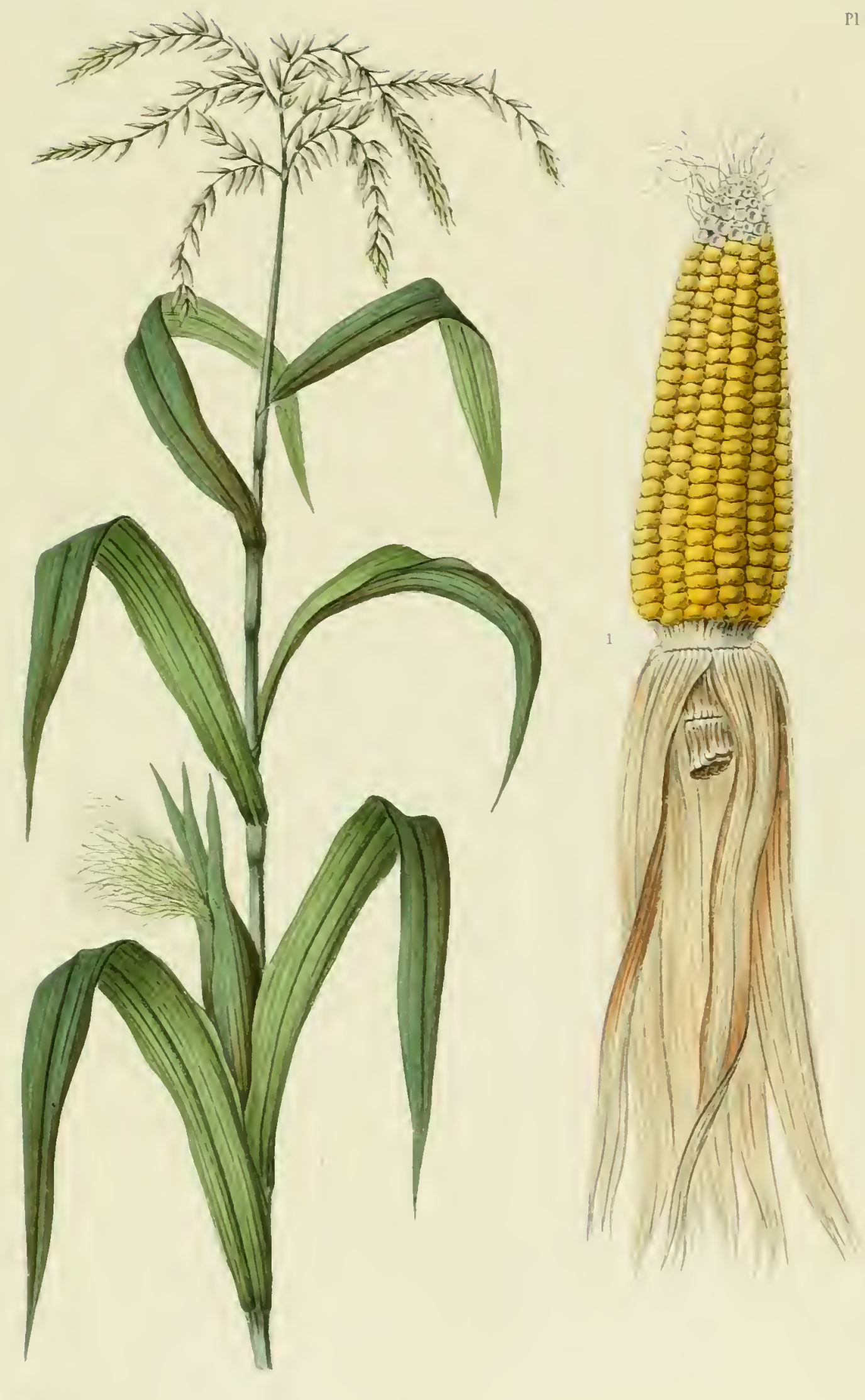

$\mathrm{Pl}=-2$ 



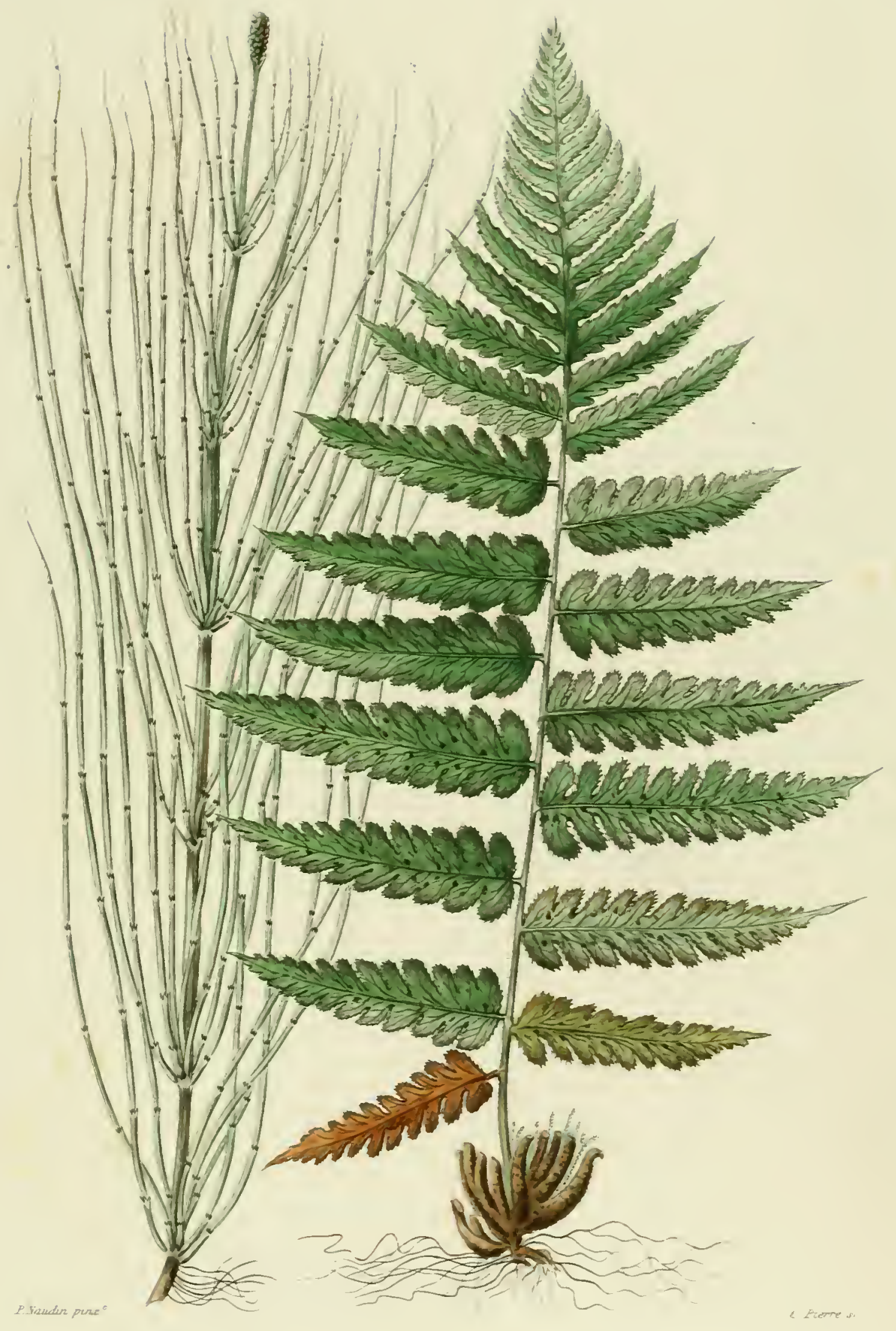

PREI.E

FOLGERE VILE 




\section{1.}

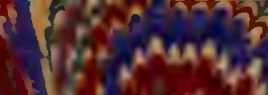

C

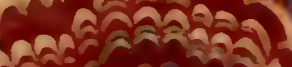

(m)

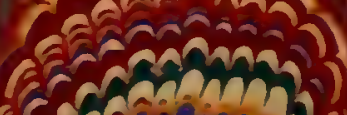

crañana

Iif

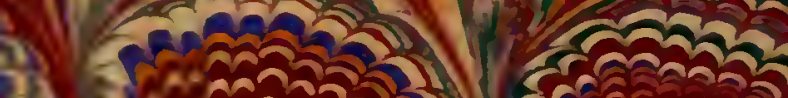

coinasing

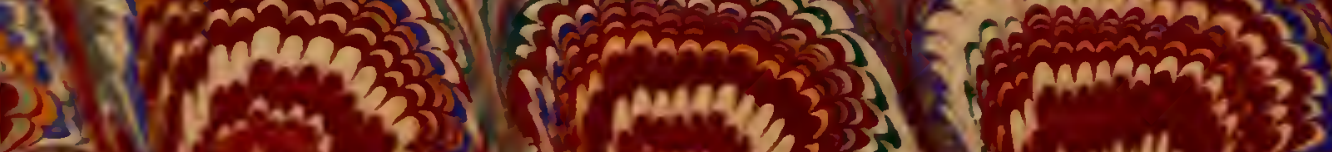

急

QRिA

-

(inf

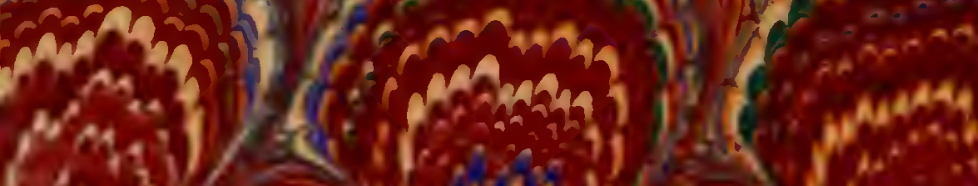

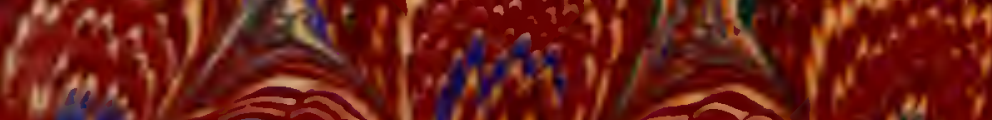

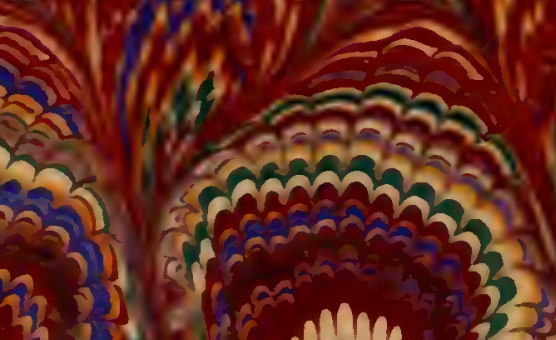

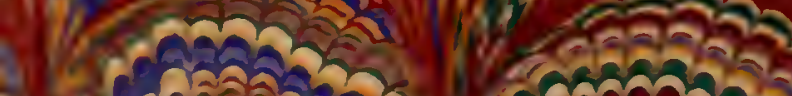

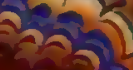

14.

3.

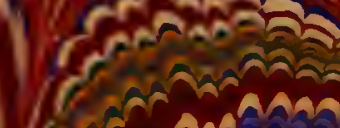

तै whans?

3 Non?

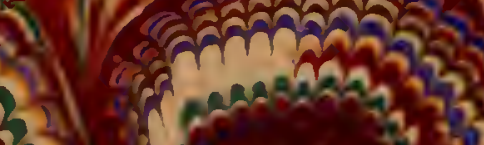
intonen

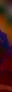


\%

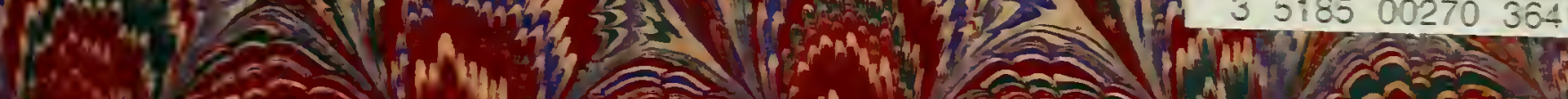

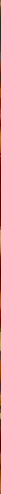

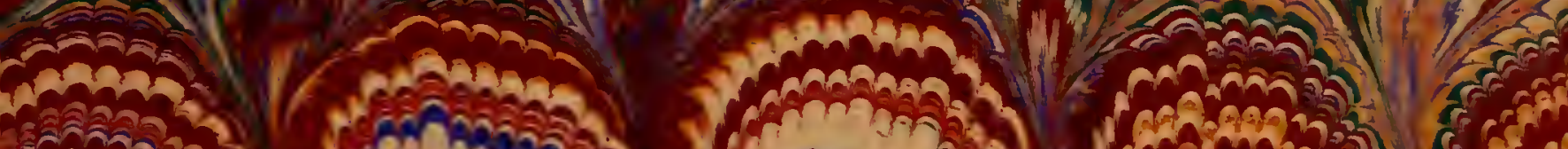
(Fens?

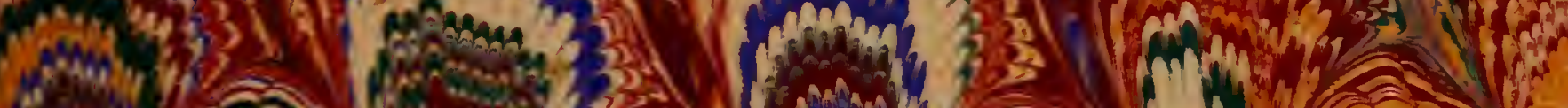
Piling

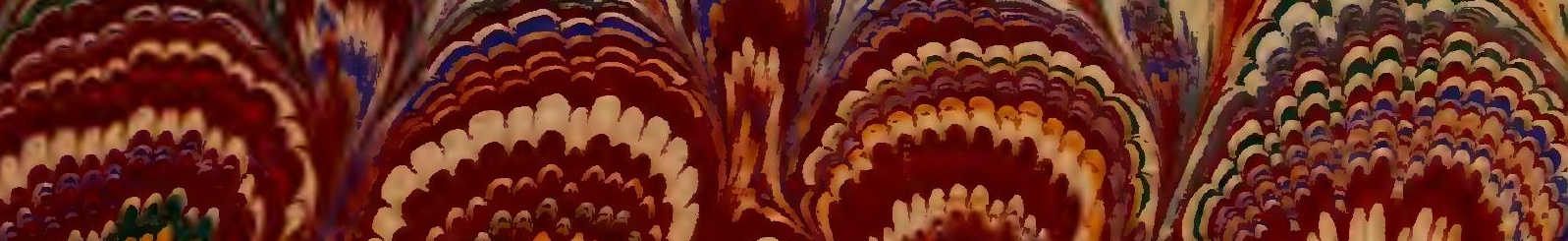

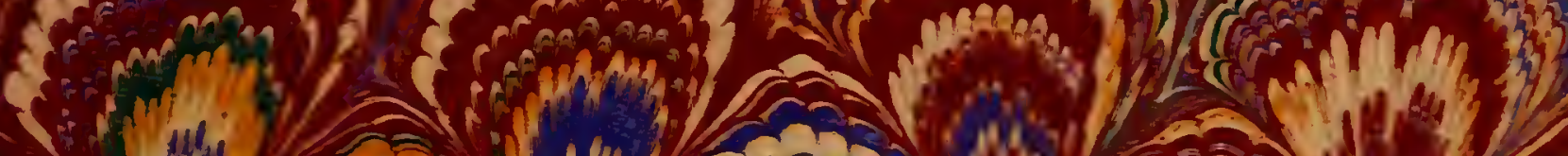
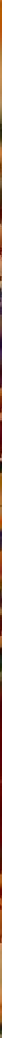

to
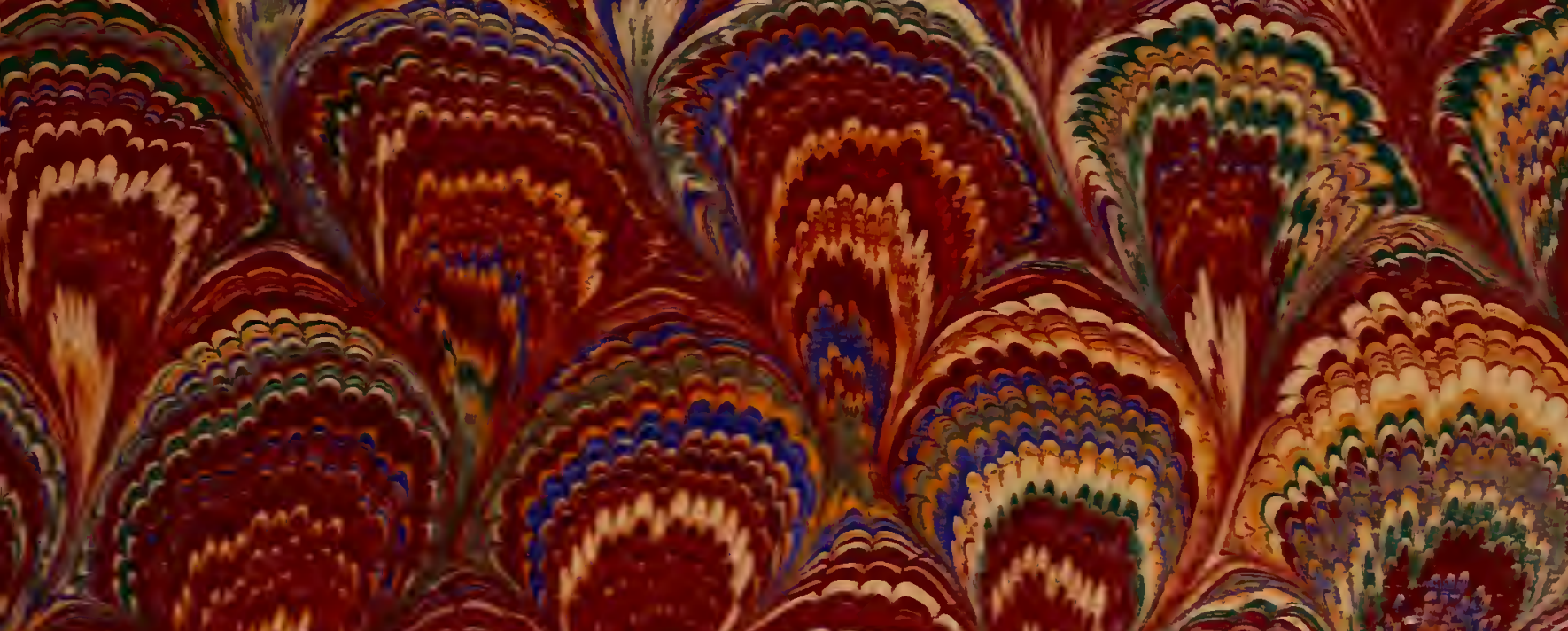

(f?
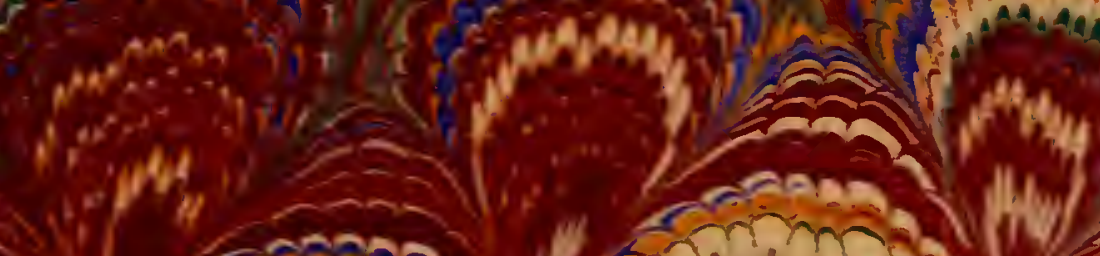

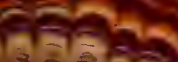
000 m

\% 207

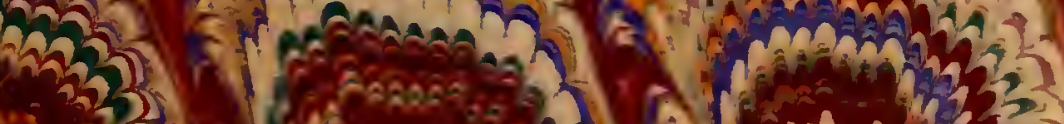
mul $=1$ .

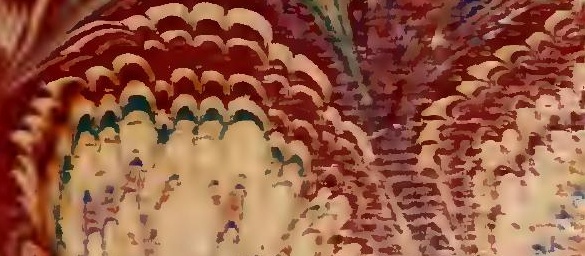

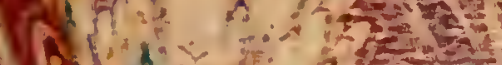

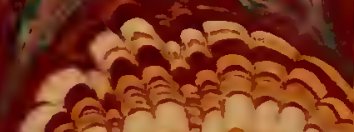
Âे

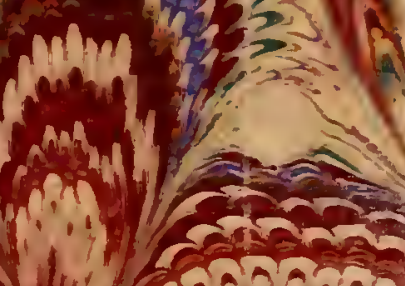
1ilin Noving 
